\title{
Exploration of Injection Strategy and Fuel Property Effects on Advanced Combustion
}

Ross H. Ryskamp

West Virginia University

Follow this and additional works at: https://researchrepository.wvu.edu/etd

\section{Recommended Citation}

Ryskamp, Ross H., "Exploration of Injection Strategy and Fuel Property Effects on Advanced Combustion" (2011). Graduate Theses, Dissertations, and Problem Reports. 4780.

https://researchrepository.wvu.edu/etd/4780

This Thesis is protected by copyright and/or related rights. It has been brought to you by the The Research Repository @ WVU with permission from the rights-holder(s). You are free to use this Thesis in any way that is permitted by the copyright and related rights legislation that applies to your use. For other uses you must obtain permission from the rights-holder(s) directly, unless additional rights are indicated by a Creative Commons license in the record and/ or on the work itself. This Thesis has been accepted for inclusion in WVU Graduate Theses, Dissertations, and Problem Reports collection by an authorized administrator of The Research Repository @ WVU. For more information, please contact researchrepository@mail.wvu.edu. 
Exploration of Injection Strategy and Fuel Property Effects on Advanced Combustion

\author{
Ross H. Ryskamp
}

Thesis submitted to the

College of Engineering and Mineral Resources

at West Virginia University

in partial fulfillment of the requirements

for the degree of

\author{
Master of Science \\ in \\ Mechanical Engineering \\ Dr. Benjamin Shade, Chair \\ Dr. John Nuszkowski \\ Dr. Hailin Li
}

Department of Mechanical and Aerospace Engineering

Morgantown, West Virginia

2010

Keywords: Advanced Combustion, Emissions, Fuel Injection, Diesel 


\title{
Exploration of Injection Strategy and Fuel Property Effects on Advanced Combustion
}

\section{Ross H. Ryskamp}

\begin{abstract}
Over the past two decades increasingly strict emissions regulations have been implemented for on-road diesel engines. Additionally, reduced fuel consumption has recently become a priority for government regulatory agencies promising more stringent regulations on the horizon. This desire for less polluting, more efficient vehicles has fueled advanced engine research and development. Advanced combustion regimes such as homogeneous charge compression ignition (HCCI), premixed charge compression ignition (PCCI), and low temperature combustion (LTC) are topics at the forefront of this research. Each of these advanced combustion regimes essentially follow the same principle in which a homogeneous or near-homogeneous air and fuel mixture combusted at low temperatures can provide reductions in oxides of nitrogen $\left(\mathrm{NO}_{\mathrm{X}}\right)$, soot and fuel consumption while increasing brake-thermal efficiency.

Research performed at the Center for Alternative Fuels, Engines, and Emissions (CAFEE) at West Virginia University focused on achieving advanced combustion utilizing a European 1.9 Liter General Motors light-duty diesel engine. The engine was retrofit with a fully programmable electronic control unit (ECU) allowing for flexible control of fuel injection parameters, exhaust gas recirculation (EGR), boost pressure, and other independent control variables. Four different fuels with varying fuel properties, including but not limited to cetane number, aromatic content, 90 percent distillation temperature, and specific gravity, were tested during this research. Advanced injection strategies performed on each fuel were used to determine the effects of the fuel injection parameters, EGR, boost pressure, and fuel properties on advanced combustion.

Implementation of a single injection strategy with increased EGR levels and an advanced start of injection (SOI) timing resulted in significantly reduced $\mathrm{NO}_{\mathrm{x}}$ and soot emissions. Undesirable fuel consumption, extremely high carbon monoxide (CO) and hydrocarbon (HC) emissions, and in-cylinder pressure rise rates accompanying this strategy led to the development of a split injection strategy. Injection of 50 percent of the fuel at an early SOI timing, and the rest near top dead center reduced $\mathrm{HC}$ and $\mathrm{CO}$ emissions, improved fuel consumption from baseline tests, and retained $\mathrm{NO}_{\mathrm{x}}$ and soot emissions reductions. This split injection strategy also resulted in much safer in-cylinder pressure rise rates. Through testing of the different fuels it became apparent that cetane number was the dominant fuel property affecting gaseous emissions, soot, and in-cylinder pressure rise rates. Lower gaseous emissions were measured during the operation of high cetane number fuels. Fuels with lower cetane number resulted in less soot formation and lower in-cylinder pressure rise rates.
\end{abstract}




\section{Table of Contents}

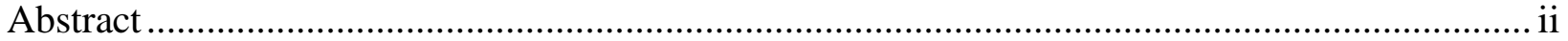

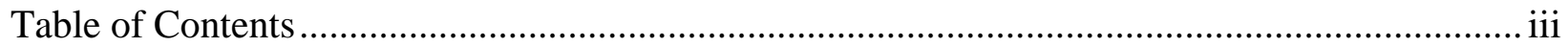

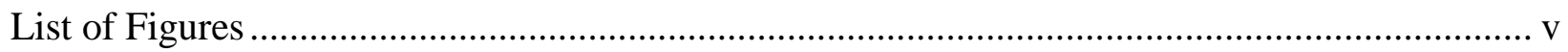

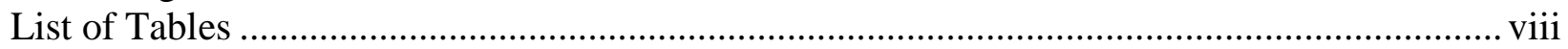

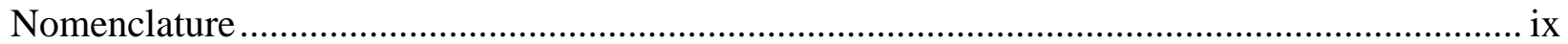

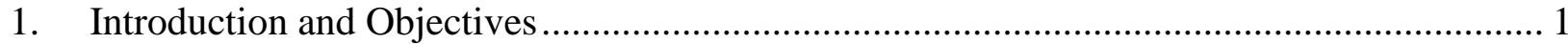

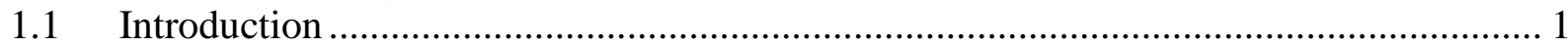

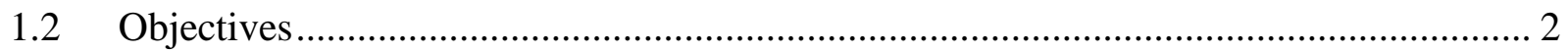

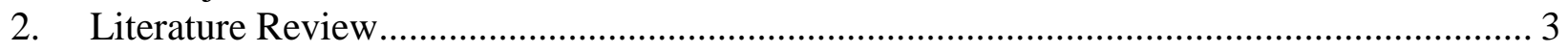

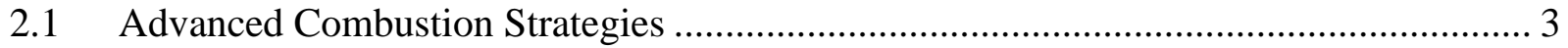

2.1.1 Low Temperature Combustion ........................................................................ 3

2.1.2 Premixed Charge Compression Ignition ......................................................... 4

2.1.3 Homogeneous Charge Compression Ignition ............................................... 4

2.2 Initiating and Controlling Advanced Combustion Strategies .................................... 5

2.2.1 Fuel Injection and Air Handling System Control ............................................ 5

2.2.2 Engine Hardware Modifications ...................................................................... 13

2.3 Effect of Fuel Properties on Advanced Combustion Strategies ................................. 17

2.3.1 Cetane Number ...................................................................................... 18

2.3.2 Aromatic Content......................................................................................... 21

2.3.3 90 Percent Distillation Temperature ........................................................... 21

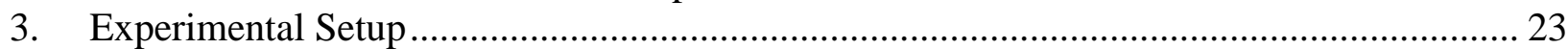

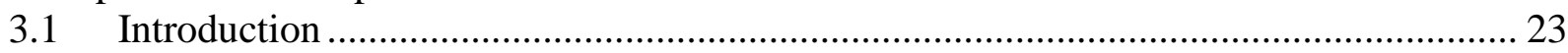

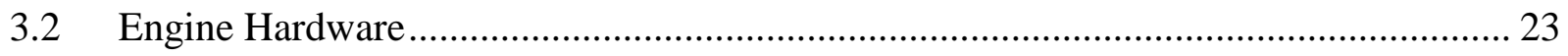

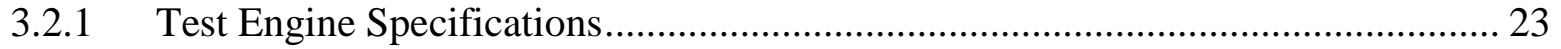

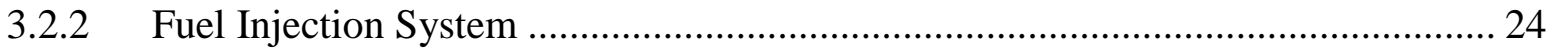

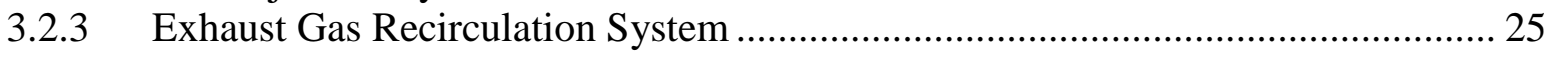

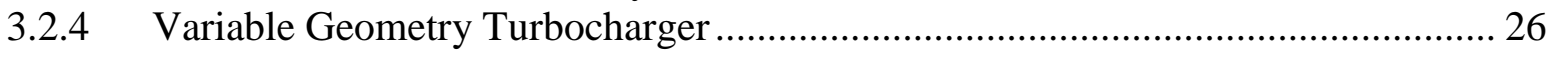

3.2.5 Intake Air Heating System ........................................................................ 27

3.2.6 Engine Performance Measurement Sensors.................................................... 28

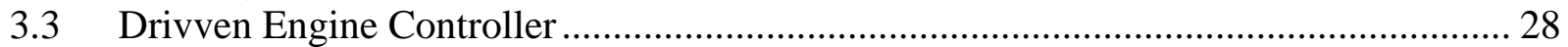

3.3.1 Drivven Engine Controller Hardware ............................................................. 28

3.3.2 Drivven Engine Controller Software ...................................................... 31

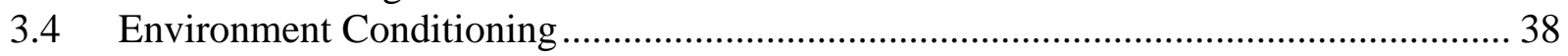

3.4.1 Engine Intake Air Temperature and Humidity ............................................ 39

3.4.2 Engine Cooling System............................................................................... 39

3.4.3 Fuel Conditioning System......................................................................... 40

3.5 Performance and Environmental Conditions Measurement...................................... 40

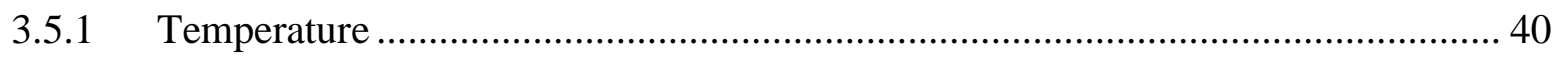

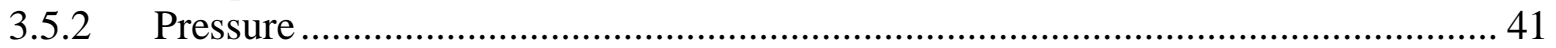

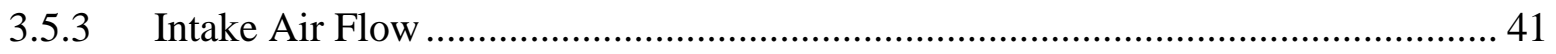

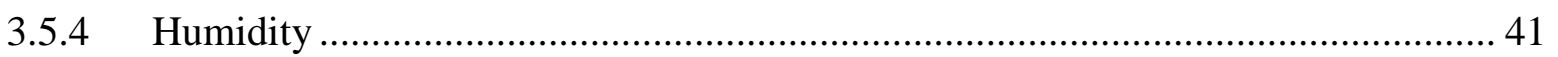

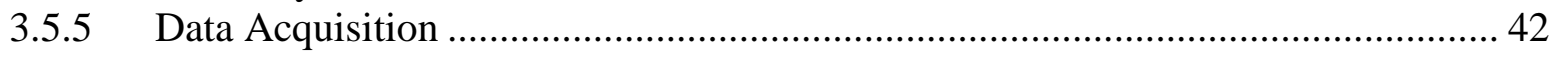

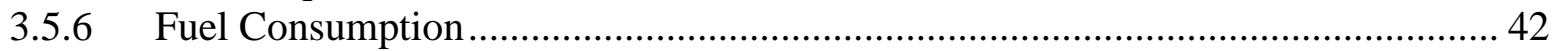

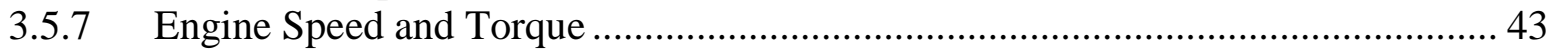




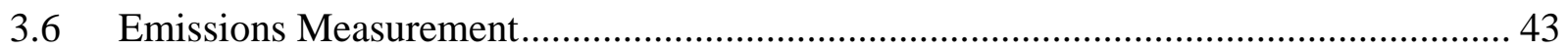

3.6.1 Constant Volume Sampling System …………….............................................. 44

3.6.2 Gaseous Emissions Measurement..................................................................... 45

3.6.3 Particulate Matter and Soot Emissions Measurement ........................................... 48

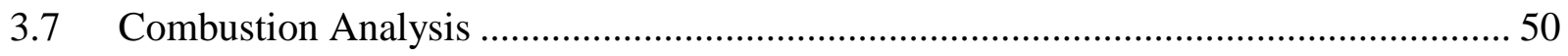

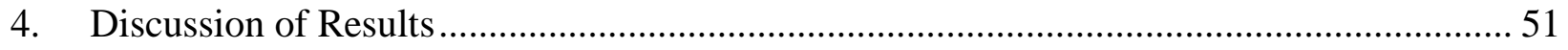

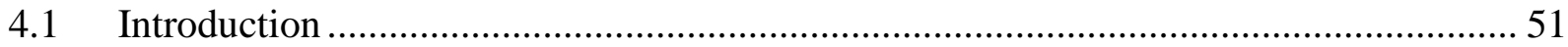

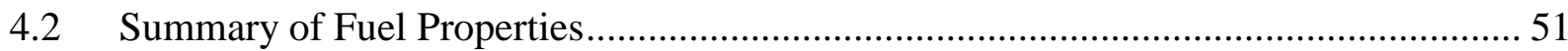

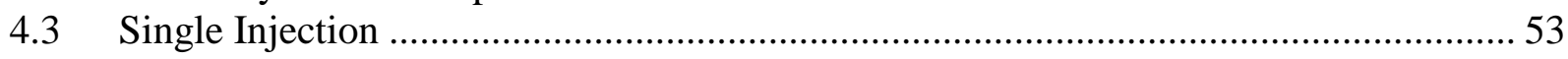

4.3.1 Initial Exploration of Single Injection Events ..................................................... 53

4.3.2 Shakedown Fuel and FACE 1 Fuel Single Injection Comparison........................... 59

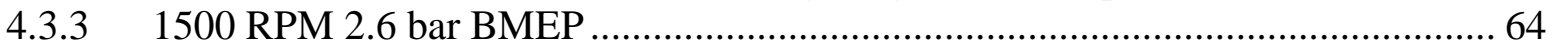

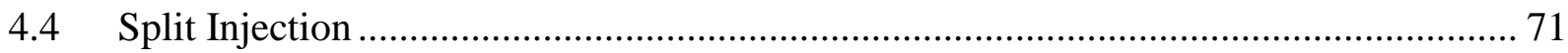

4.4.1 Base Configuration Comparison...................................................................... 71

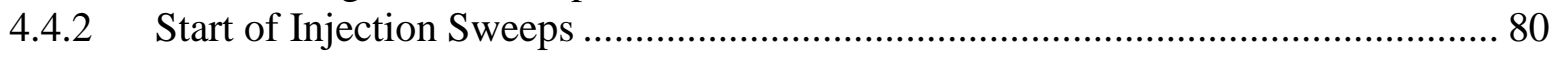

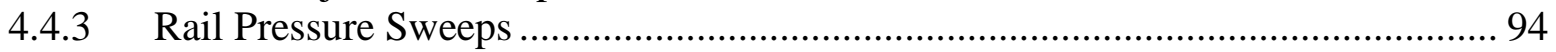

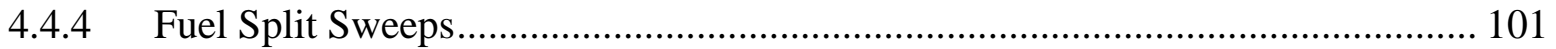

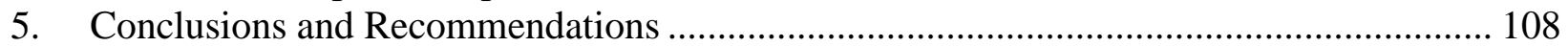

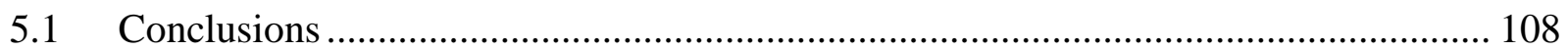

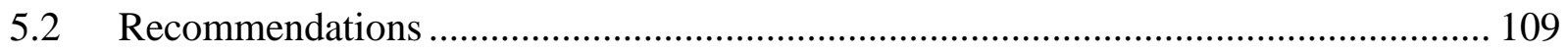

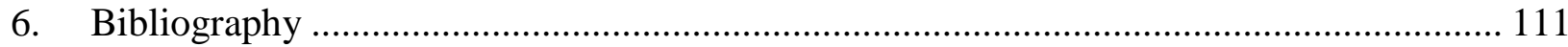

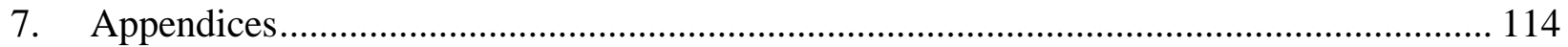




\section{List of Figures}

Figure 1: Temperature and Equivalence Ratio Regions for Advanced Combustion Strategies [4] 3 Figure 2: Brake Specific Emissions, Fuel Consumption and Smoke vs. Injection Timing [8] ...... 6

Figure 3: UNIBUS and Comparison Injection Strategies [10] …………………….................... 7

Figure 4: BMEP, NOx and Smoke Emissions, and Rate of Effective Injection Quantity for

UNIBUS and Comparison Injection Strategies [10] ......................................................... 8

Figure 5: $\mathrm{NO}_{\mathrm{x}}$ and PM Emissions a Function of Lambda for Varying Rail Pressure [12]............ 9

Figure 6: $\mathrm{NO}_{\mathrm{x}}$ Emissions plotted against Fuel Consumption at Varying Injection Timings for

Cooled and Un-Cooled EGR [6] ................................................................................... 10

Figure 7: Ignition Delay for Additional Intake Valve Opening with Varying EGR Fraction [8] 11

Figure 8: Maximum Pressure Rise Rate for Additional Intake Valve Opening with Varying EGR

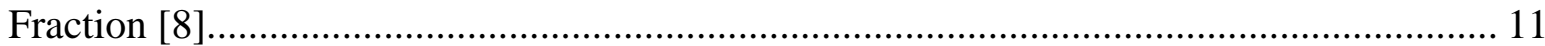

Figure 9: Cylinder Pressure Curves as a Function of Crank Angle for varying Intake Air

Temperatures [13] ............................................................................................... 12

Figure 10: Cylinder Pressure as a function of Crank Angle for varying Compression Ratio [6]. 14

Figure 11: Various Piston Bowl Configurations and their Effects on Soot, Fuel Consumption,

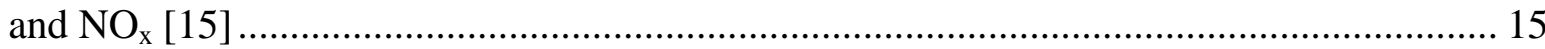

Figure 12: HC emissions as a function of Start of Injection Pulse for varying Injection Angle [17]

Figure 13: Ignition Delay and Combustion noise as a function of SOI Timing for the FACE

Matrix [21] ..................................................................................................... 19

Figure 14: Emissions and Fuel Consumption at varying SOI for the FACE Matrix [21] ............ 20

Figure 15: Distillation Percentage as a Function of Temperature for the FACE Matrix [21] ..... 22

Figure 16: Bosch Common Rail Fuel Injection System Diagram [26]........................................ 25

Figure 17: EGR System with Retrofit Heavy Duty EGR Cooler .................................................. 26

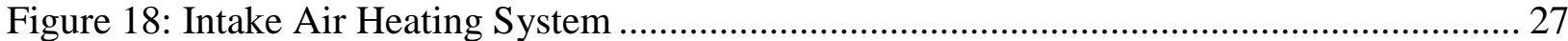

Figure 19: Drivven Common Rail Diesel Injector Driver Module Kit [27] ................................ 30

Figure 20: Breakout Box, Wiring Harness, NI CRIO Expansion Chassis and Drivven Modules 31

Figure 21: National Instruments LabVIEW Real Time Virtual Interface for the GM 1.9 Liter

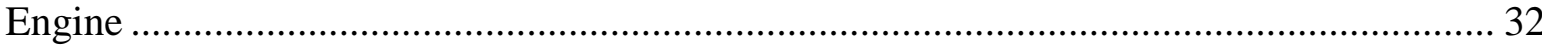

Figure 22: Drivven CalVIEW Main Operating Screen............................................................. 33

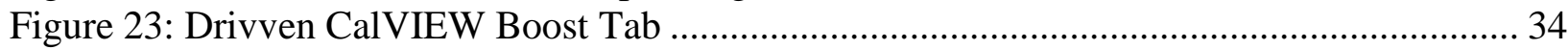

Figure 24: Drivven CalVIEW EGR Tab............................................................................ 35

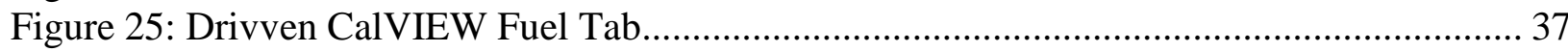

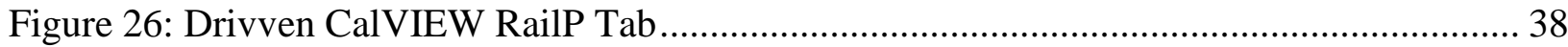

Figure 27: HC and CO Emissions as a Function of SOI Timing during Single Injection Operation

for Two Different IMT..................................................................................................... 54

Figure 28: HC and CO Emissions as a Function of EGR Fraction during Single Injection

Operation for Two Different IMT............................................................................... 54

Figure 29: $\mathrm{NO}_{\mathrm{x}}$ Emissions during Single Injection Operation.................................................... 55

Figure 30: Maximum In-Cylinder Temperature during Single Injection Operation ..................... 56

Figure 31: PM emissions during Single Injection Operation....................................................... 57

Figure 32: Fuel Consumption during Single Injection Operation ................................................ 58

Figure 33: Heat Release Rate during Single Injection Operation................................................. 58

Figure 34: Pressure Rise Rate during Single Injection Operation ............................................... 59 
Figure 35: Intake Oxygen versus EGR Fraction for Shakedown Fuel and FACE 1 60

Figure 36: $\mathrm{NO}_{\mathrm{x}}$ Emissions and Maximum In-Cylinder Temperature for Shakedown Fuel and

FACE 1 61

Figure 37: HC Emissions and CO emissions for Shakedown Fuel and FACE 1 .................... 62

Figure 38: Heat Release Rate for Shakedown Fuel (SD) and FACE 1 ...................................6 62

Figure 39: Fuel Consumption and Pressure Rise Rate for Shakedown Fuel and FACE 1 .......... 63

Figure 40: $\mathrm{NO}_{\mathrm{x}}$ Emissions for $5^{\circ}$ BTDC Single Injection ................................................ 65

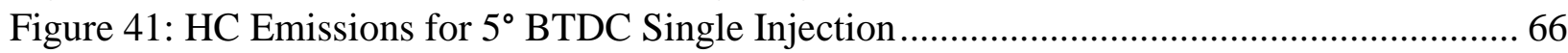

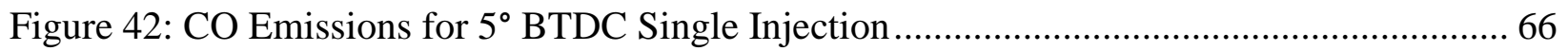

Figure 43: Coolant and Intake Manifold Temperature for $5^{\circ}$ BTDC Single Injection ............... 67

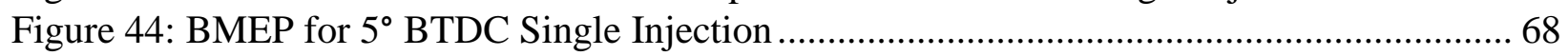

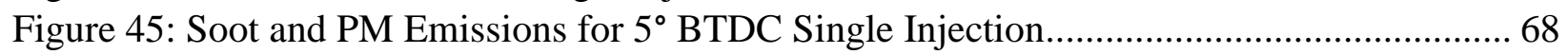

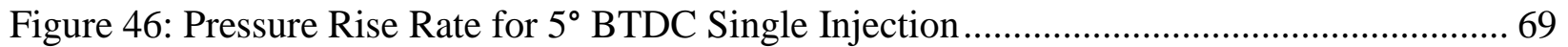

Figure 47: Maximum In-Cylinder Temperature for $5^{\circ}$ BTDC Single Injection ........................ 70

Figure 48: Heat Release Rate for $5^{\circ}$ BTDC Single Injection................................................. 70

Figure 49: Intake Oxygen versus EGR Fraction for the Base Configuration ............................ 72

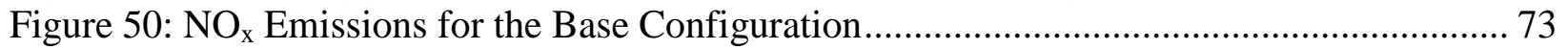

Figure 51: HC Emissions for the Base Configuration ......................................................... 74

Figure 52: CO Emissions for the Base Configuration ..................................................... 74

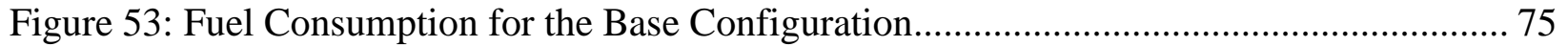

Figure 54: $\mathrm{CO}_{2}$ Emissions for the Base Configuration ..................................................... 76

Figure 55: Gravimetric Based PM Emissions for the Base Configuration ............................... 77

Figure 56: Gravimetric Based PM Emissions as a Function of $\mathrm{CO}$ emissions for the Base

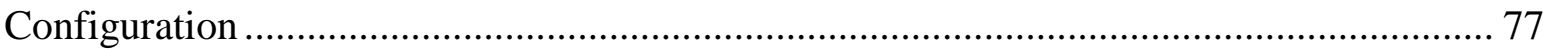

Figure 57: Pressure Rise Rate for the Base Configuration ................................................ 78

Figure 58: Maximum In-Cylinder Temperature for the Base Condition.................................. 79

Figure 59: CA10-50 for the Base Condition........................................................................ 79

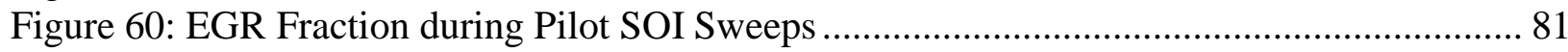

Figure 61: HC and CO Emissions during Pilot SOI Sweeps ........................................... 82

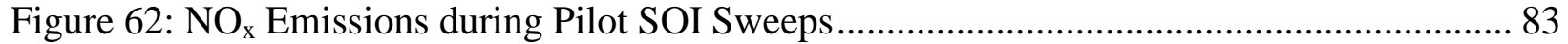

Figure 63: PM \& Soot Emissions during Pilot SOI Sweeps................................................. 84

Figure 64: BSFC during Pilot SOI Sweeps .................................................................... 85

Figure 65: CO2 Emissions during Pilot SOI Sweeps ........................................................... 85

Figure 66: Maximum Pressure Rise Rate during Pilot SOI Sweeps ....................................... 86

Figure 67: Maximum In-Cylinder Temperature during Pilot SOI sweeps ............................... 87

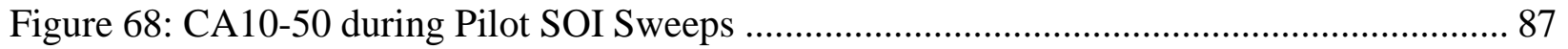

Figure 69: Heat Release Rate for FACE 1 during Pilot SOI sweeps ....................................... 88

Figure 70: Heat Release Rate for FACE 6 during Pilot SOI sweeps ....................................... 88

Figure 71: Intake and Exhaust $\mathrm{O}_{2}$ Concentrations and $\mathrm{CO}$ emissions during Main SOI Sweeps 89

Figure 72: $\mathrm{HC}$ and $\mathrm{NO}_{\mathrm{x}}$ Emissions during Main SOI Sweeps............................................. 90

Figure 73: Maximum In-Cylinder Temperature during Main SOI Sweeps.............................. 91

Figure 74: Soot and PM Emissions during Main SOI Sweeps .......................................... 92

Figure 75: Max Pressure Rise Rate and CA10-50 during Main SOI Sweeps ........................... 93

Figure 76: Heat Release Rate during Main SOI Sweeps ................................................. 93

Figure 77: Fuel Consumption during Main SOI Sweeps ..................................................... 94

Figure 78: EGR Fraction during Rail Pressure Sweeps .................................................... 95 
Figure 79: $\mathrm{NO}_{\mathrm{x}}$ Emissions during Rail Pressure Sweeps.................................................... 96

Figure 80: $\mathrm{NO}_{\mathrm{x}}$ Emission as a Function of EGR fraction during Rail Pressure Sweeps ............. 96

Figure 81: HC emissions during Rail Pressure Sweeps ..................................................... 97

Figure 82: CO emissions during Rail Pressure Sweeps ....................................................... 98

Figure 83: Gravimetric Based PM during Rail Pressure Sweeps ........................................... 99

Figure 84: Fuel Consumption during Rail Pressure Sweeps ................................................. 100

Figure 85: $\mathrm{CO}_{2}$ Emissions during Rail Pressure Sweeps ................................................... 100

Figure 86: EGR Fraction during Fuel Split Sweeps ....................................................... 102

Figure 87: $\mathrm{NO}_{\mathrm{x}}$ Emissions during Fuel Split Sweeps ......................................................... 103

Figure 88: CO Emissions during Fuel Split Sweeps....................................................... 104

Figure 89: HC Emissions during Fuel Split Sweeps.......................................................... 104

Figure 90: Gravimetric PM Emissions during Fuel Split Sweeps ......................................... 105

Figure 91: Soot Emissions during Fuel Split Sweeps ....................................................... 106

Figure 92: Max Pressure Rise Rate during Fuel Split Sweeps ............................................. 107

Figure 93: CP CHEM 2007 ULSD Certification Fuel Certificate of Analysis......................... 115

Figure 94: Guttman ULSD Certificate of Analysis 12/30/06 ............................................ 116

Figure 95: Guttman ULSD Certificate of Analysis 8/8/07 ................................................ 117 


\section{List of Tables}

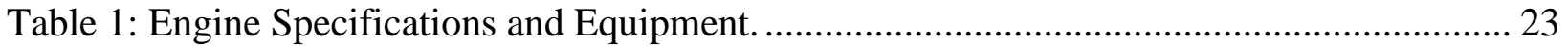

Table 2: Emissions Measurement Devices ........................................................................... 44

Table 3: Fuel Properties ................................................................................................... 52

Table 4: Injection Configuration for Each Fuel Tested ....................................................... 101

Table 5: ASTM Method of Fuel Property Measurement ...................................................... 118 


\section{Nomenclature}

1-D

2-D

AD

ATDC

BSFC

BMEP

$\mathrm{BSNO}_{\mathrm{x}}$

BTDC

BTE

C

CA

CA10-50

CAFEE

CFR

CI

CLD

$\mathrm{CO}$

$\mathrm{CO}_{2}$

CVS

DAQ

deg

DI

ECU

EERL

EGR

FACE

FID

FPGA

$\mathrm{g}$

GM

$\mathrm{HC}$

$\mathrm{HCCI}$

HECC

HEPA

$\mathrm{hr}$

IMP

IMT

INOx

ISFC

ISoot

K

$\mathrm{kg}$

$\mathrm{kW}$
Number One Diesel Fuel

Number Two Diesel Fuel

Analog and Digital

After Top Dead Center

Brake Specific Fuel Consumption

Brake Mean Effective Pressure

Brake Specific Oxides of Nitrogen

Before Top Dead Center

Brake Thermal Efficiency

Celsius

Crank Angle

Duration in Degrees of 10 Percent to 50 percent Mass Fraction Burned

Center for Alternative Fuels, Engine, and Emissions

Code of Federal Regulations

Compression Ignition

Chemiluminescence Detector

Carbon Monoxide

Carbon Dioxide

Constant Volume Sampling

Data Acquisition

Degree

Diesel Injection

Engine Control Unit

Engine and Emissions Research Laboratory

Exhaust Gas Recirculation

Fuels for Advanced Combustion Engines

Flame Ionization Detector

Field Programmable Gate Array

Gram

General Motors

Hydrocarbon

Homogeneous Charge Compression Ignition

High Efficiency Clean Combustion

High Efficiency Particulate Air

Hour

Intake Manifold Pressure

Intake Manifold Temperature

Indicated Oxides of Nitrogen

Indicated Fuel Consumption

Indicated Soot

Kelvin

Kilogram

Kilowatt 


$\begin{array}{ll}\text { L } & \text { Liter } \\ \text { LFE } & \text { Laminar Flow Element } \\ \text { LTC } & \text { Low Temperature Combustion } \\ \mathrm{MAF} & \text { Mass Air Flow } \\ \mathrm{mm} & \text { Millimeters } \\ \mathrm{NDIR} & \text { Non-Dispersive Infrared } \\ \mathrm{NI} & \text { National Instruments } \\ \mathrm{NIST} & \text { National Institute of Standards and Technology } \\ \mathrm{NO} & \text { Nitric Oxide } \\ \mathrm{NO}_{2} & \text { Nitrogen Dioxide } \\ \mathrm{NO}_{x} & \text { Oxides of Nitrogen } \\ \mathrm{O}_{2} & \text { Oxygen } \\ \mathrm{O}_{3} & \text { Ozone } \\ \mathrm{OEM}_{\mathrm{PCC}} & \text { Original Equipment Manufacturer } \\ \mathrm{PCC} & \text { Pre-Mixed Charge Compression Ignition } \\ \mathrm{PFI} & \text { Port Fuel Injection } \\ \mathrm{PID} & \text { Proportional Integral Derivative } \\ \mathrm{PM} & \text { Particulate Matter } \\ \mathrm{PRR} & \text { Pressure Rise Rate } \\ \text { Qf } & \text { Input Injection Quantity } \\ \text { Qfe } & \text { Injection Quantity Calculated by Carbon Method } \\ \mathrm{QHV}_{\mathrm{HV}} & \text { Net Heat of Combustion } \\ \mathrm{RT} & \text { Real Time } \\ \mathrm{RTD} & \text { Resistance Temperature Detector } \\ \text { SCFM } & \text { Standard Cubic Feet per Minute } \\ \text { SD } & \text { Shakedown Fuel } \\ \text { SOF } & \text { Soluble Organic Fraction } \\ \text { SHS } & \text { Sample Handling System } \\ \text { SOI } & \text { Start of Injection } \\ \text { SSV } & \text { Sub-Sonic Venturi } \\ \text { T90 } & \text { Temperature at which 90 Percent Distillation has occurred } \\ \text { TDC } & \text { Top Dead Center } \\ \text { UNIBUS } & \text { Uniform Bulky Combustion System } \\ \text { VB } & \text { Visual Basic } \\ \text { VGT } & \text { Variable Geometry Turbocharger } \\ \text { WVU } & \text { West Virginia University } \\ \text { ZrO } & \text { Zirconium Oxide } \\ & \end{array}$




\section{Introduction and Objectives}

\subsection{Introduction}

Advances in engine technology have been driven by many factors since the inception of the internal combustion engine. In recent decades, several key legislations have required engine manufacturers to decrease engine emissions in an effort to increase air quality. Concurrent to these legislations, tariffs such as the Energy Tax Act of 1978 established a "gas guzzler tax" for passenger cars failing to meet a minimum fuel economy rating [1]. While this act only applies to passenger vehicles, its tariffs as well as consumer demand for more fuel efficient vehicles have fueled research and development of more efficient engines. Federal regulations beginning in 2014 are now targeting even greater fuel efficiencies for heavy duty and light duty vehicles as outlined by President Barack Obama on May 21, 2010 [2] and further specified by EPA on October 25, 2010 [3].

Conventionally, a tradeoff has occurred between complying with emissions regulations and improving engine efficiencies. Exhaust after treatment systems and other methods of reducing troublesome emissions generally negatively affect engine performance and fuel economy. Advanced combustion strategies seek the opposite; retaining acceptable thermal and combustion efficiency while decreasing certain environmentally harmful emissions. Besides the advantage of retaining efficiencies and reducing specific emissions, advanced combustion strategies do not share the same cost, volume, and mass associated with after treatment systems such as diesel particulate filters and selective catalytic reduction systems found on many model year 2010 compression ignition engines.

Achieving and sustaining advanced combustion has proved difficult for many organizations. Operation of an engine under an advanced combustion regime is normally performed at low loads and low engine speeds. This is in part due to the erratic nature of the combustion sought as well as the presence of extreme cylinder pressures related to higher loads. Elevated hydrocarbon and carbon monoxide emissions also prove to be a disadvantage of many advanced combustion methods. Despite these drawbacks, the allure of low $\mathrm{NO}_{\mathrm{x}}$ and soot emissions, as well as increased efficiency continues to fuel research for various organizations including WVU. 


\subsection{Objectives}

Determination of the influences of injection strategies with different fuels on advanced combustion is the primary focus of this experiment. To accomplish this objective, measurements of an engine's emissions, efficiencies, and combustion characteristics must be quantified and compared for several different fuels with varying properties. Emissions species under scrutiny include $\mathrm{HC}, \mathrm{NO}_{\mathrm{x}}, \mathrm{CO}, \mathrm{CO}_{2}$, soot and PM. Fuel consumption, pressure rise rate, in-cylinder temperature, combustion duration, and heat release rate are also examined.

In order to achieve a global knowledge of injection strategy effects on advanced combustion it is essential that multiple injection parameters and engine system configurations be explored. Injection parameters include number of injection events, SOI timing, injection pressure, and percent fuel split for multiple injection events. In addition to injection strategies, engine technologies such as EGR and VGT need be explored.

The feasibility of performing these injection strategies with contrasting fuels can be determined through emissions, performance and combustion data analysis. A particular injection strategy coupled with a specific engine configuration may provide low emissions and comparably high efficiencies for a particular fuel, while proving the opposite for a fuel with drastically different properties. Under particular strategies cylinder misfire and unstable combustion arise as limiting factors, thus injection strategies and engine configurations may also need to be tailored to a specific fuel's properties.

Through the topics mentioned above, secondary objectives supporting the primary focus can be defined.

- Characterization of emissions, performance, and combustion characteristics of various injection strategies.

- Definition of trends related to specific fuel properties for a given injection strategy.

- Observation of the limits SOI timing, EGR levels, and rail pressure for fuels with varying properties. 


\section{Literature Review}

\subsection{Advanced Combustion Strategies}

Several methods of advanced combustion exist, but strategically they are all very similar. In essence a homogeneous air and fuel mixture with combustion occurring at a low temperature has the capability to retain efficiencies, while reducing oxides of nitrogen and soot emissions. The strategies discussed in this document include low temperature combustion (LTC), premixed charge compression ignition (PCCI), and homogenous charge compression ignition (HCCI). The local temperature and equivalence ratio regions in which these advanced combustion strategies exist are displayed in Figure 1. Conventional diesel combustion occupies the largest region in the figure with operating points located in heavy soot and NO formation regions, while LTC, PCCI and HCCI have limited operating points in these regions.

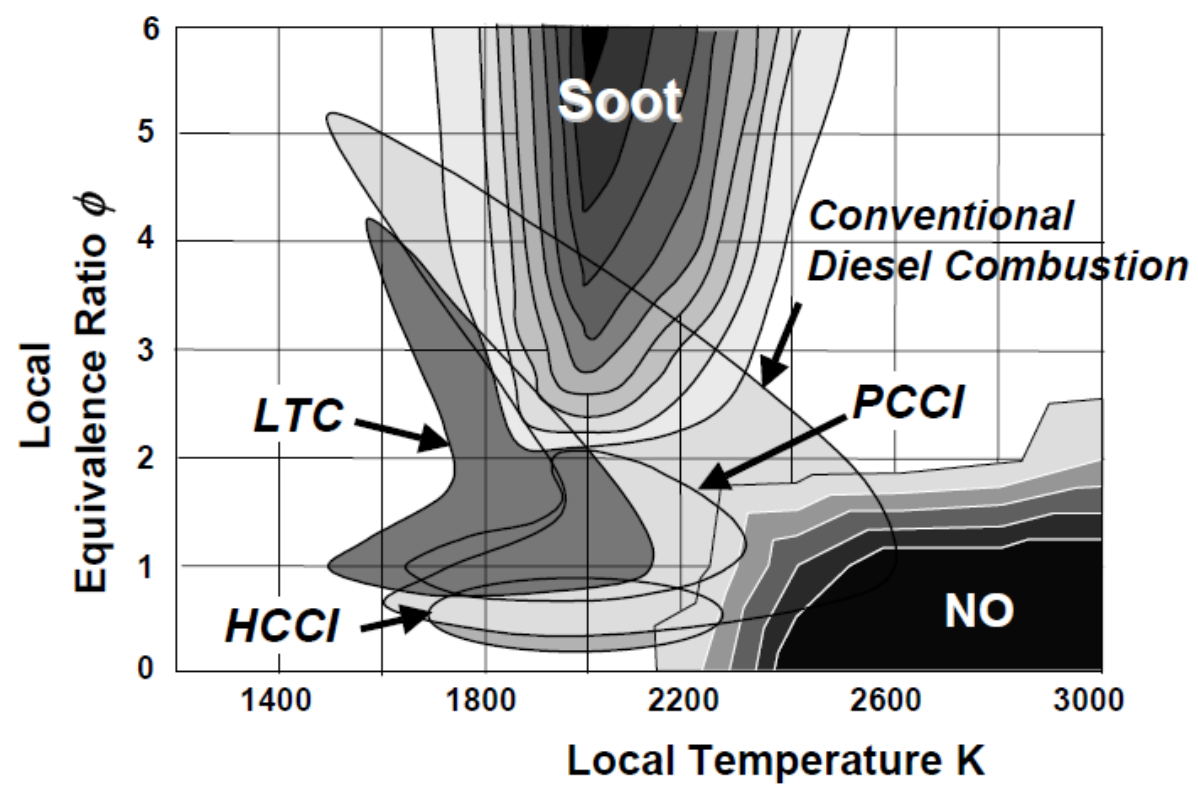

Figure 1: Temperature and Equivalence Ratio Regions for Advanced Combustion Strategies [4]

\subsubsection{Low Temperature Combustion}

Formally introduced in the year 2000 under the name "low temperature oxidation" by Toyota Motor Corporation at the Ninth Aachen Colloquium, LTC seeks a simultaneous reduction of $\mathrm{NO}_{\mathrm{x}}$ and soot formation through decreased combustion temperatures at 
stoichiometric and locally rich air to fuel ratios [5]. Visually the concept can be observed in Figure 1 where the outlined LTC region exists at local combustion temperatures less than $2200 \mathrm{~K}$ and local equivalence ratios range from nearly stoichiometric to four. While the LTC regions shape mimics that of the conventional diesel combustion region, its decreased area prevents it from entering heavy soot and $\mathrm{NO}_{\mathrm{x}}$ production zones. An apparent drawback regarding the decreased operating range is it generally does not allow for the achievement of LTC at high loads (high combustion temperature) especially at increased local equivalence ratios [4].

\subsubsection{Premixed Charge Compression Ignition}

Reductions in $\mathrm{NO}_{\mathrm{x}}$ and soot emissions resulting from near homogeneous mixtures through the use of early injection timings and elevated EGR levels have been demonstrated by various organizations and engine manufacturers including Simescu et al. [6]. By injecting fuel into the cylinder early and using EGR to control combustion phasing, more time for mixing is achieved avoiding a stratified air and fuel charge synonymous with conventional diesel combustion. Figure 1 displays a narrower local equivalence operating range for PCCI when compared to LTC, but the presence of a larger combustion temperature range allows for more $\mathrm{NO}_{\mathrm{x}}$ production. This limited area of operation presents issues when attempting to achieve PCCI at high speed, heavy load operating conditions where heavy fueling is necessary and early injection timings may not be feasible.

\subsubsection{Homogeneous Charge Compression Ignition}

Examples of research on HCCI combustion has existed for decades. This research effort has grown considerably in recent years due to a desire for efficient, less polluting internal combustion engines. The strategy of HCCI incorporates both that of LTC and PCCI, in which a homogeneous, lean air and fuel mixture is combusted rapidly and uniformly without flame propagation at a low combustion temperature. Elimination of locally rich air and fuel mixtures decreases PM emissions, while low combustion temperatures reduce $\mathrm{NO}_{\mathrm{x}}$ formation. Efficiencies comparable to modern compression ignition engines are retained through the use of high compression ratios, absence of throttling losses, and the rapid combustion of the homogeneous air and fuel mixture without flame propagation [7]. HCCI has been demonstrated for low to medium load operation, but similar to other advanced combustion strategies heavy load operation is difficult to achieve. This is demonstrated in Figure 1 where the operating 
region for HCCI is the smallest for all of the combustion strategies presented. Additionally, $\mathrm{HCCI}$ combustion generally results in greater $\mathrm{HC}$ and $\mathrm{CO}$ emissions.

\subsection{Initiating and Controlling Advanced Combustion Strategies}

In order to initiate and control any advanced combustion strategy some modification to a conventional compression ignition engine must be performed. Hardware changes as well as modifications of engine control strategies can have a profound effect on engine operation. To adequately achieve some forms of advanced combustion it is likely that several modifications must be performed to work in conjunction with each other.

\subsubsection{Fuel Injection and Air Handling System Control}

\subsubsection{Start of Injection Timing}

Arguably the most common method of promoting better mixing of the air and fuel charge is through the advancement of the start of injection (SOI) timing. Injecting fuel into the cylinder earlier allows more time for the development of a well-mixed air and fuel mixture.

Conventionally, $\mathrm{NO}_{\mathrm{x}}$ emissions increase as SOI timing is advanced, but researchers such as Kawano et al. have demonstrated, as shown in Figure 2, that advanced SOI timing paired with increased injection pressure can result in reduced NOx emissions for SOI timings greater than $30^{\circ} \mathrm{BTDC}$ on a single cylinder HCCI research engine [8]. 


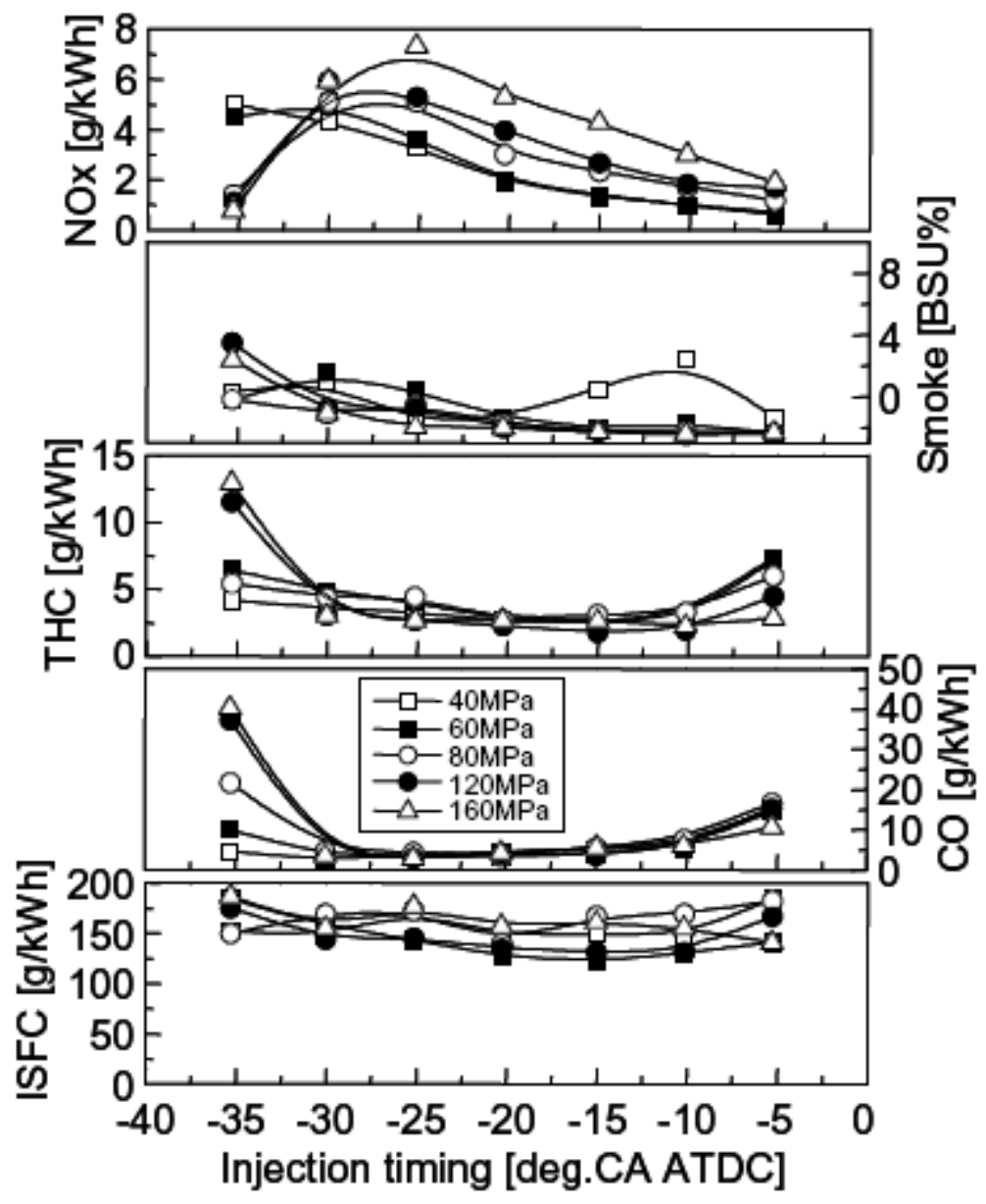

Figure 2: Brake Specific Emissions, Fuel Consumption and Smoke vs. Injection Timing [8]

Synonymous with the decrease in $\mathrm{NO}_{\mathrm{x}}$ emissions, an increase in $\mathrm{CO}$ and $\mathrm{HC}$ emissions occur in Figure 2 as $\mathrm{HCCI}$ combustion is targeted. An increase in $\mathrm{HC}$ and $\mathrm{CO}$ emissions as injection timing was advanced was also observed by Park et al. [9]. In both instances this increase can be attributed to conditions such as wall wetting or raw fuel seeping into piston ring lands and other crevices where combustion will not occur. Additionally, increased pressure and pressure rise rates are common when advancing SOI timing. Engine durability becomes a concern under these conditions deeming a reduction in engine load or addition of a diluent such as EGR.

\subsubsection{Fuel Split}

Modern CI engines equipped with electronically controlled direct fuel injection systems commonly use multiple injections (i.e. a pilot injection). Injection of a relatively small pilot quantity of fuel prior to the main injection event has the capability to reduce in-cylinder pressure 
rise rates (PRR) and aid in optimizing combustion phasing for the main injection event. Accompanying the reduction in PRR is a decrease in audible noise emitted from the engine (a common characteristic of older CI engines) and lower in-cylinder temperatures. The lower incylinder temperatures aid in reducing NOx emissions.

Hasegawa et al. of Toyota Motor Corporation explored the effects of a multiple injection strategy on an HCCI concept termed Uniform Bulky Combustion System (UNIBUS) [10]. In this study a four cylinder, dual overhead camshaft engine with four valves per cylinder, displacing three liters was utilized as the test platform. The engine was also equipped with a common rail fuel injection system, variable nozzle turbo with intercooler, exhaust gas recirculation and had a compression ratio of 18.4:1. Figure 3 presents the UNIBUS injection strategy (Double Injection) as well as a single injection strategy and the conventional diesel combustion strategy.

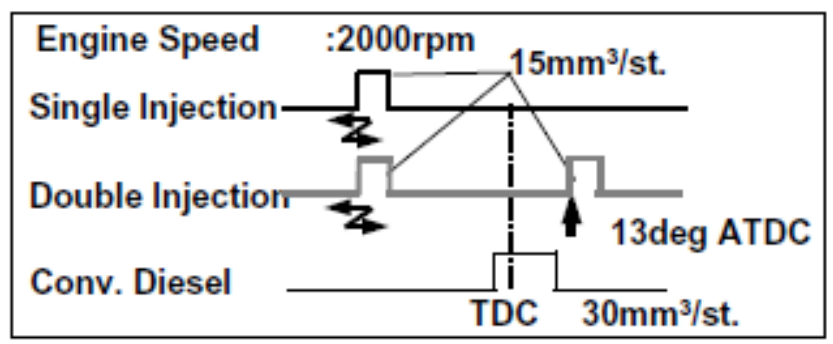

Figure 3: UNIBUS and Comparison Injection Strategies [10]

During the development of the UNIBUS strategy a number of tests were performed to quantify the effects of a double injection strategy with varying SOI timing versus a conventional diesel combustion strategy. In the case of the double injection tests, the main SOI was fixed at $13^{\circ}$ ATDC while the pilot SOI was varied and plotted in Figure 4. As displayed by Figure 3, the injection volume of fuel per stroke during the double injection strategy was held at $15 \mathrm{~mm}^{3}$ for both injection events. Focusing on the plot of BMEP, it is evident that the UNIBUS strategy, as well as the majority of double injection strategy tests, is capable of retaining a BMEP close to that of conventional combustion with the same fuel quantity injected. Therefore without a loss of performance additional plots in Figure 4 demonstrate significantly lower $\mathrm{NO}_{\mathrm{x}}$ and smoke emissions. Also plotted in Figure 4 is the rate of effective injection, which is the input injection quantity (Qf) divided by the injection quantity calculated by carbon number method (Qfe). This rate of effective injection shows that the UNIBUS strategy very close to its performance limit. 
Unfortunately $\mathrm{HC}$ and $\mathrm{CO}$ emissions are not presented for the UNIBUS strategy, therefore the effects of this early pilot injection cannot be completely understood.
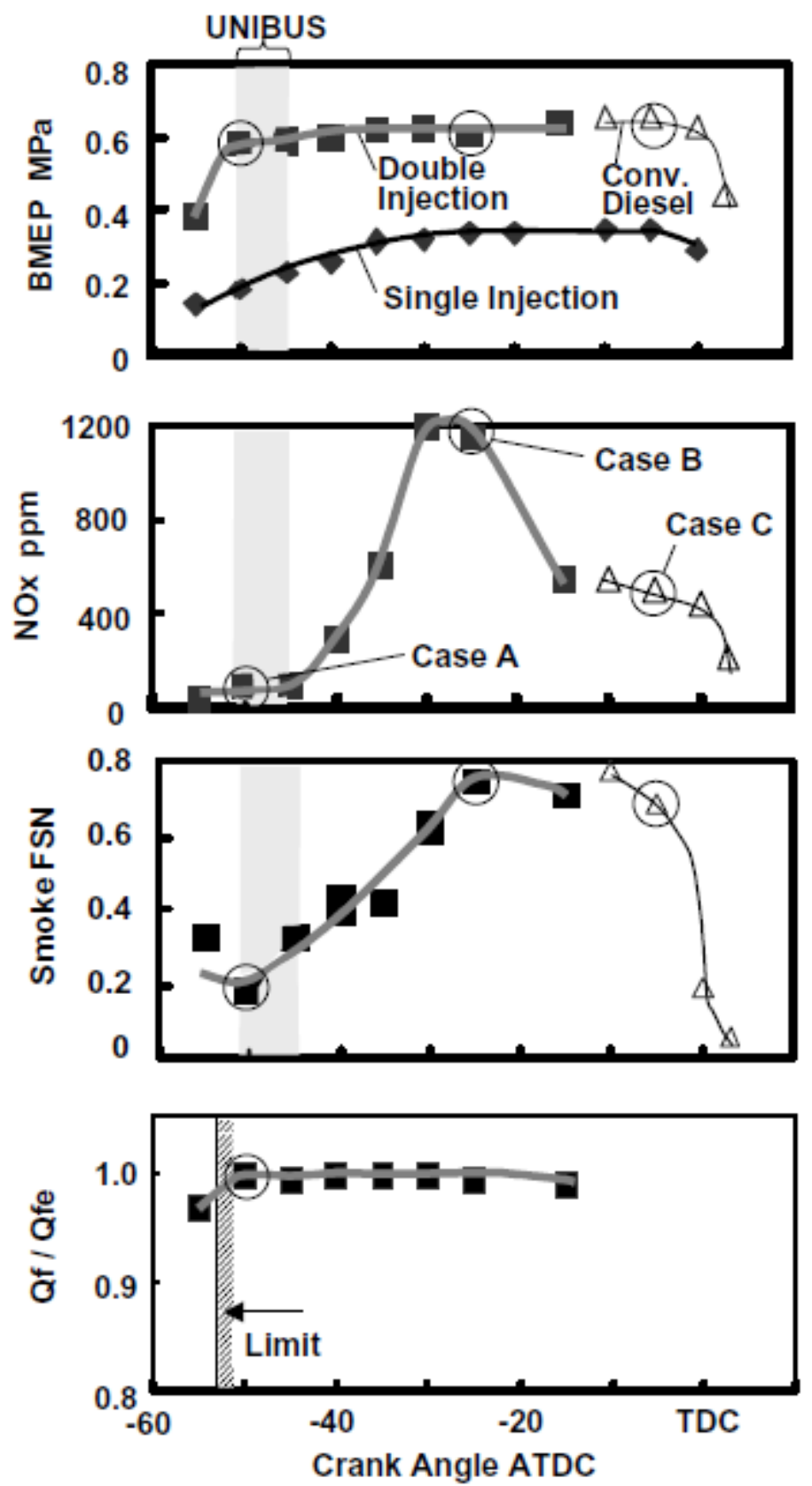

Figure 4: BMEP, NOx and Smoke Emissions, and Rate of Effective Injection Quantity for UNIBUS and Comparison Injection Strategies [10]

\subsubsection{Rail Pressure}

Modern compression ignition engines have increasingly begun to use a relatively new fuel injection technology labeled common rail injection. Common rail injection features an 
extremely high pressure fuel rail which feeds electronically controlled injectors. By increasing the fuel rail pressure, the fuel injection pressure is consequently also increased. Increased fuel injection pressure can have varying effects on combustion phasing as well as emissions formation. Ideally a greater fuel pressure will result in better fuel atomization, quicker delivery and ultimately a more homogeneous air and fuel mixture [11]. Figure 5 displays the effects of increased rail pressure on smoke and $\mathrm{NO}_{\mathrm{x}}$ emissions for varying values of lambda (attributed to changes in EGR fraction).

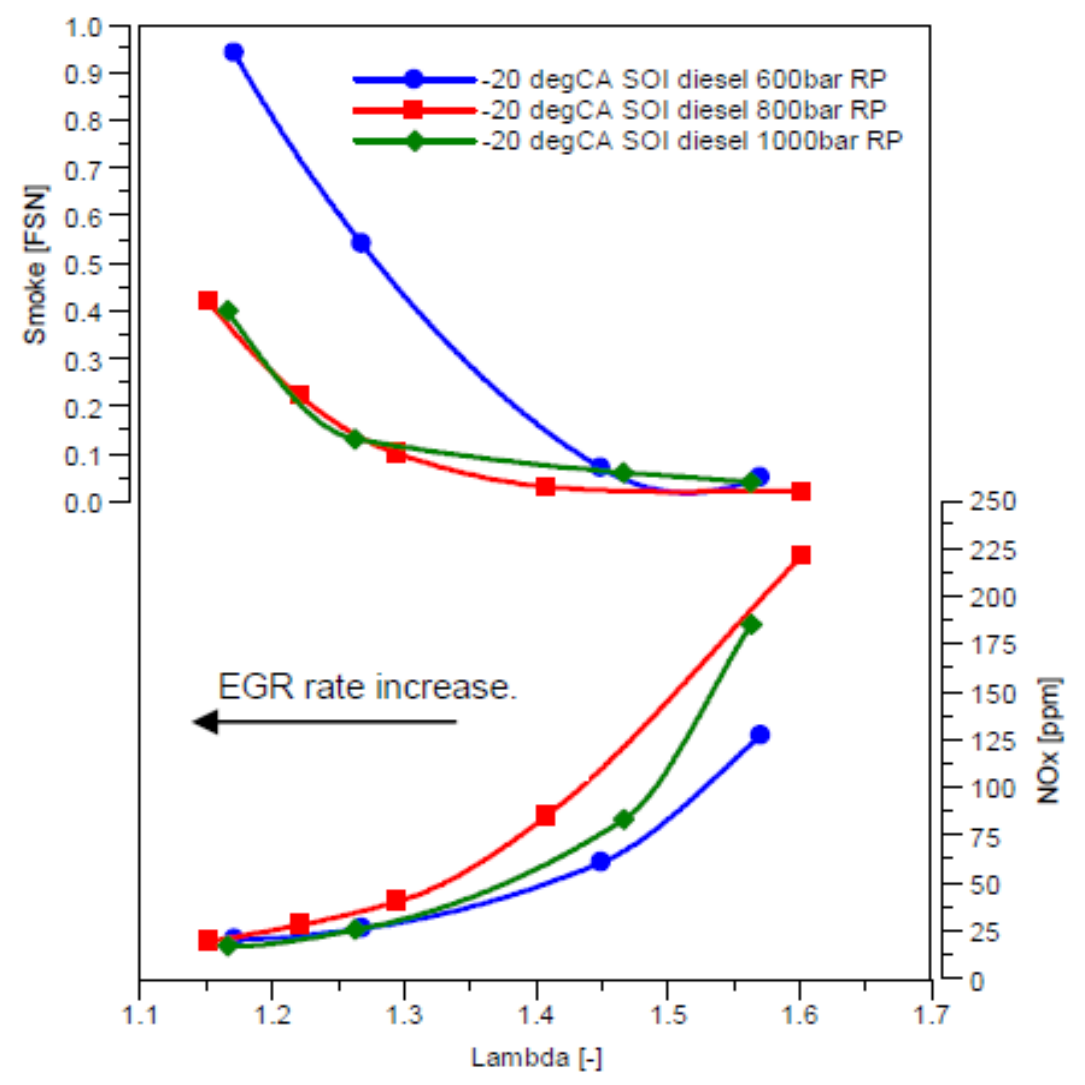

Figure 5: $\mathrm{NO}_{\mathrm{x}}$ and PM Emissions a Function of Lambda for Varying Rail Pressure [12]

Referring to Figure 5, an increase in rail pressure at near stoichiometric conditions results in over a 50 percent reduction in smoke most likely attributed to better fuel atomization and an overall more homogeneous air and fuel mixture. Increased rail pressure at a lean air to fuel ratio results in greater $\mathrm{NO}_{\mathrm{x}}$ emissions, possibly linked to elevated cylinder temperatures from the lack of EGR. It is interesting to note that Figure 2 provides similar results to Figure 5, except the $\mathrm{NO}_{\mathrm{x}}$ and smoke tradeoff as displayed is a function of injection timing rather than EGR rate. 


\subsubsection{Exhaust Gas Recirculation}

Reintroduction of exhaust gas affects combustion phasing and emissions formation by acting as a diluent in the cylinder. The presence of this diluent (EGR) reduces in-cylinder temperatures, pressures, and pressure rise rates. Through this reduction in temperature, decreased $\mathrm{NO}_{\mathrm{x}}$ emissions are normally observed, while increased $\mathrm{HC}, \mathrm{CO}$ and $\mathrm{PM}$ emissions are common as well as increased BSFC. The $\mathrm{NO}_{\mathrm{x}}$ and PM tradeoff created by EGR is exemplified in Figure 5. Development of cooled EGR has been shown to further reduce $\mathrm{NO}_{\mathrm{x}}$ emissions while helping to improve BSFC. The tradeoff between $\mathrm{NO}_{\mathrm{x}}$ emissions and BSFC for cooled and uncooled EGR at varying injection timings is displayed in Figure 6.

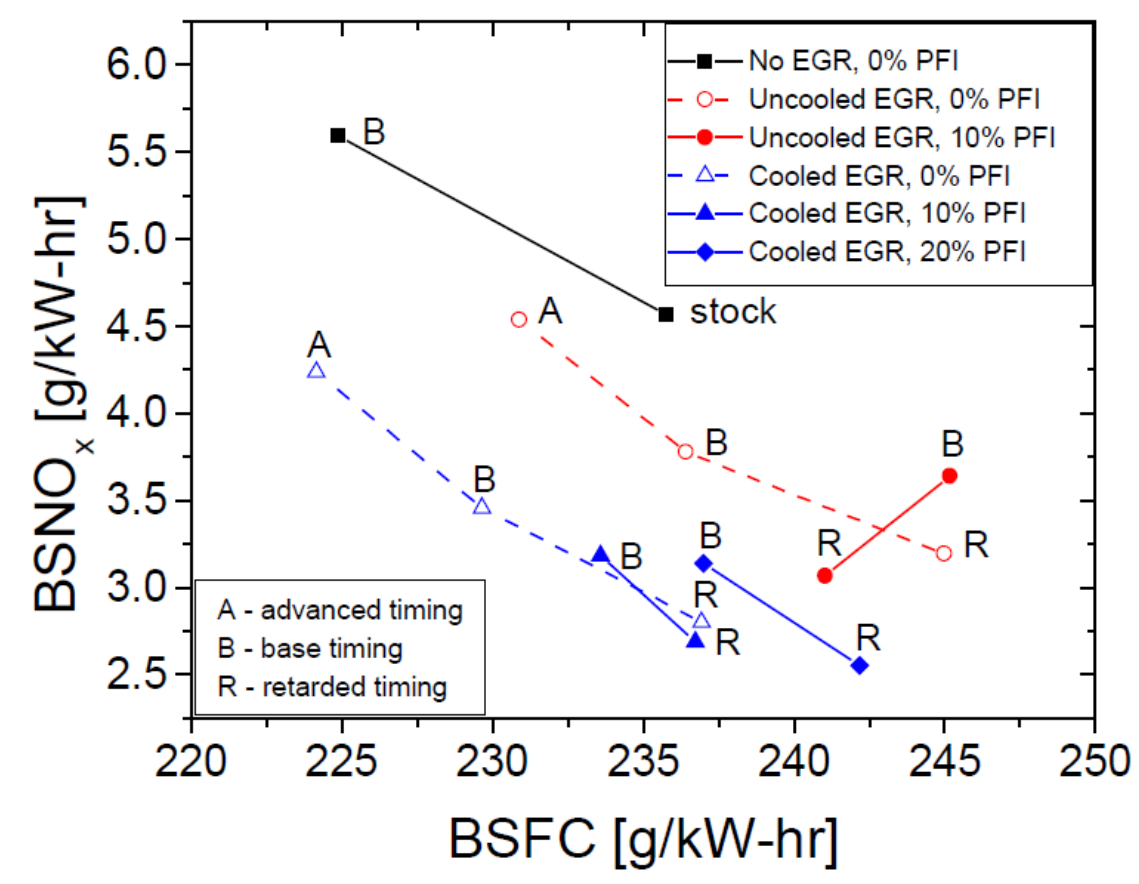

Figure 6: $\mathrm{NO}_{\mathrm{x}}$ Emissions plotted against Fuel Consumption at Varying Injection Timings for Cooled and Un-Cooled EGR [6] 


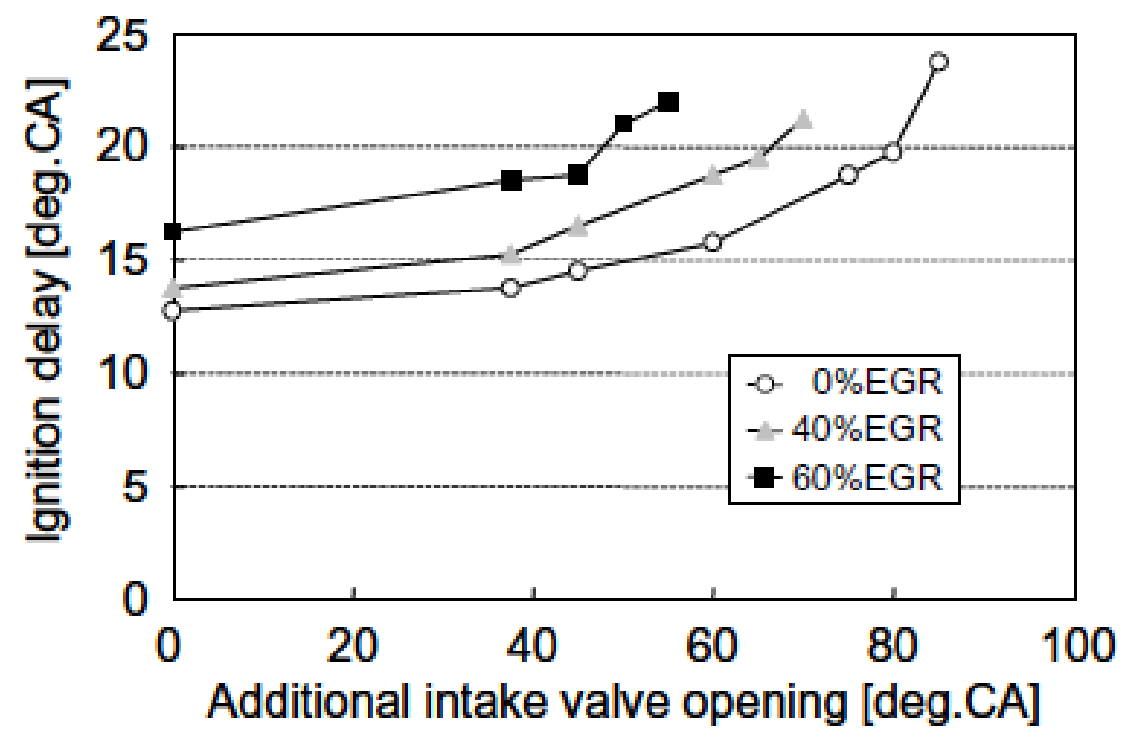

Figure 7: Ignition Delay for Additional Intake Valve Opening with Varying EGR Fraction [8]

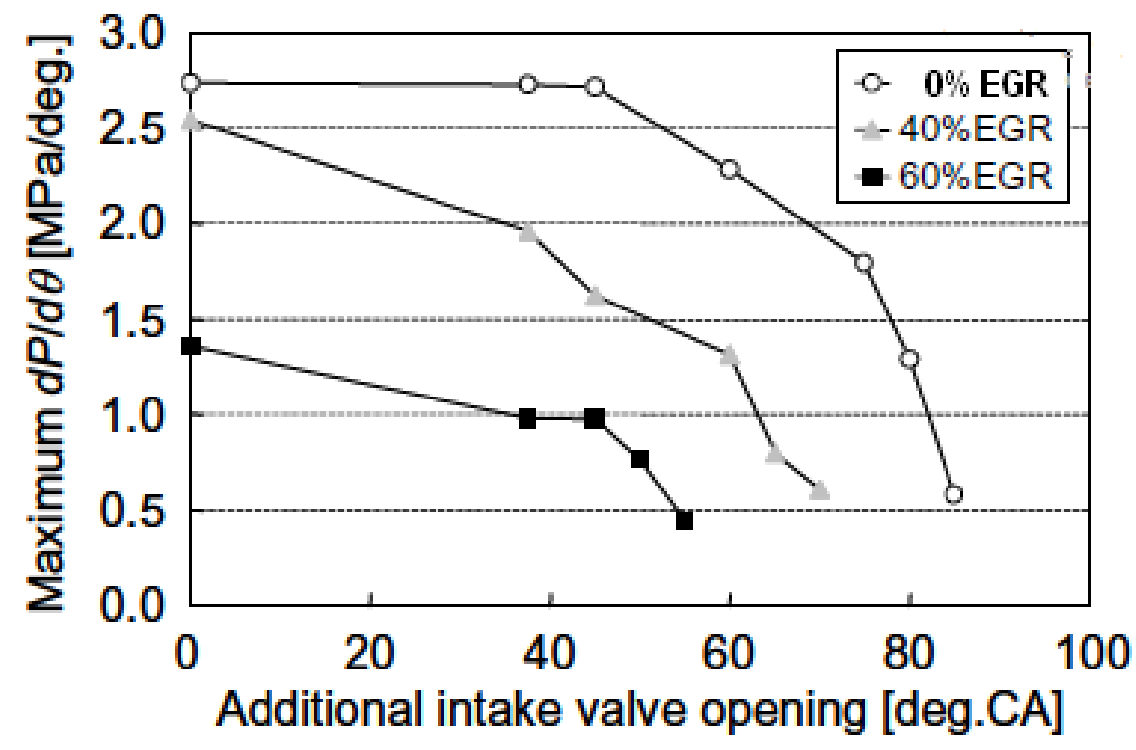

Figure 8: Maximum Pressure Rise Rate for Additional Intake Valve Opening with Varying EGR Fraction [8]

Besides lower combustion temperature and an accompanying decrease in $\mathrm{NO}_{\mathrm{x}}$ emissions the greatest benefit EGR offers advanced combustion strategies is the ability to control combustion phasing and limit dangerous pressure rise rates. Figure 7 demonstrates longer ignition delay for greater EGR fractions. This is especially helpful when attempting to control combustion phasing or eliminate engine knock after an early injection event. The increase of 
EGR fraction to 60 percent in Figure 8 results in approximately a 50 percent decrease in maximum cylinder pressure rise rate leading to greater engine durability under advanced combustion strategies.

\subsubsection{Intake Air Temperature}

Drastic changes in intake air temperature have a major effect on combustion and can subsequently be used to control combustion phasing. Elevating the intake air temperature will in turn bring the bulk mixture of air and fuel closer to the ignition temperature resulting in an earlier combustion event. In addition to combustion phasing, increased intake air temperatures generally promote better mixing and fuel atomization. Figure 9 shows cylinder pressure curves from an HCCI study on varying compression ratio, intake air temperature, and EGR [13].

Compression ratio was fixed at 14:1 and a higher cetane fuel was used (approximately 55) for the data presented. Notice for the greatest intake air temperature $\left(60{ }^{\circ} \mathrm{C}\right)$, combustion occurs earlier for similar EGR fractions. Also, Figure 9 shows the largest in-cylinder pressure and arguably the steepest pressure rise for a $60{ }^{\circ} \mathrm{C}$ intake air temperature test. This is beneficial during start up of a HCCI engine, as well as when using a lower cetane number fuel.

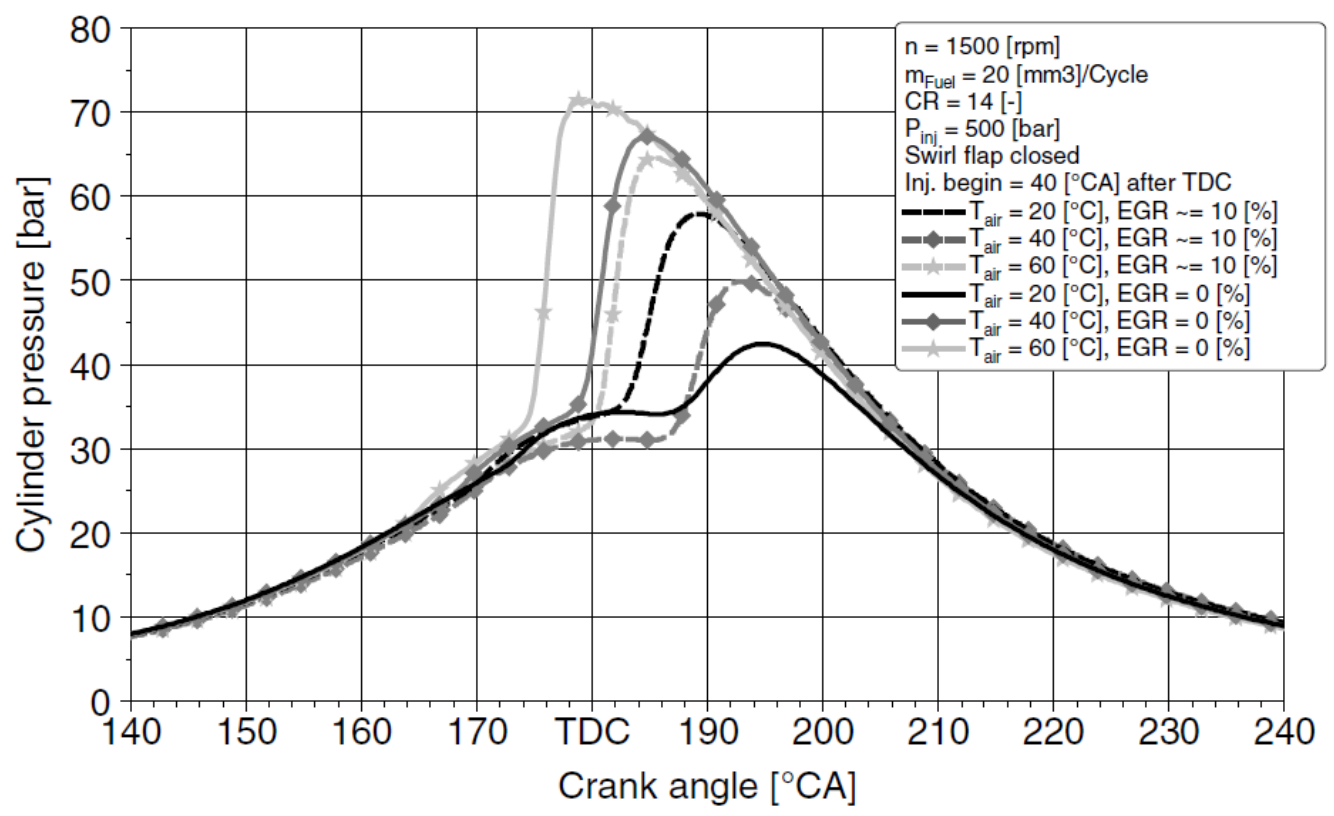

Figure 9: Cylinder Pressure Curves as a Function of Crank Angle for varying Intake Air Temperatures [13] 


\subsubsection{Intake Manifold Pressure}

Known also as boost pressure, intake manifold pressure is an essential part of modern compression ignition engines. The forceful introduction of air into the intake manifold affects emissions, fuel consumption, and combustion. The value of boost on advanced combustion strategies is much more significant when paired with other technologies such as variable valve timing. Nevin et al. of the University of Wisconsin-Madison performed research on a single cylinder version of a Caterpillar 3406E equipped with artificial boost and variable valve timing [14]. Their experiments displayed reduced PM emissions for late intake valve closing conditions with elevated boost pressure. A nearly linear decrease in exhaust temperature with the application of more boost pressure was also observed, but no real correlation to $\mathrm{NO}_{\mathrm{x}}$ emissions reduction could be made. A negative effect of the increased boost pressure and decreased exhaust temperature was greater $\mathrm{CO}$ and $\mathrm{HC}$ emissions due to less oxidation as well as increased BSFC.

\subsubsection{Engine Hardware Modifications}

\subsubsection{Compression Ratio}

An alteration of compression ratio may be necessary to transition a conventional compression ignition engine into an advanced combustion engine. This change may be performed statically or dynamically. A change in the dynamic compression ratio can be achieved through the application of variable valve actuation which is discussed in Section 2.2.2.3. A common method of changing the static compression ratio is through piston modification normally with removable piston crowns. Depending on the strategy employed to achieve an advanced combustion method, compression ratio may need to decrease to ensure safe operation of the engine or an increase may be necessary to ensure complete combustion without misfiring. Wagner et al. explored the effects of compression ratio on HCCI combustion [13]. The sweeps of compression ratio displayed in Figure 10 are for fuel with a cetane number of approximately 55. Notice as compression ratio is increased the cylinder pressure increases, and combustion occurs earlier deeming compression ratio as another factor in combustion phasing. The pressure trace with a compression ratio of 14:1 and an EGR fraction of 10 percent in Figure 10 shows weak and late combustion flagging this as a less than optimal condition. 


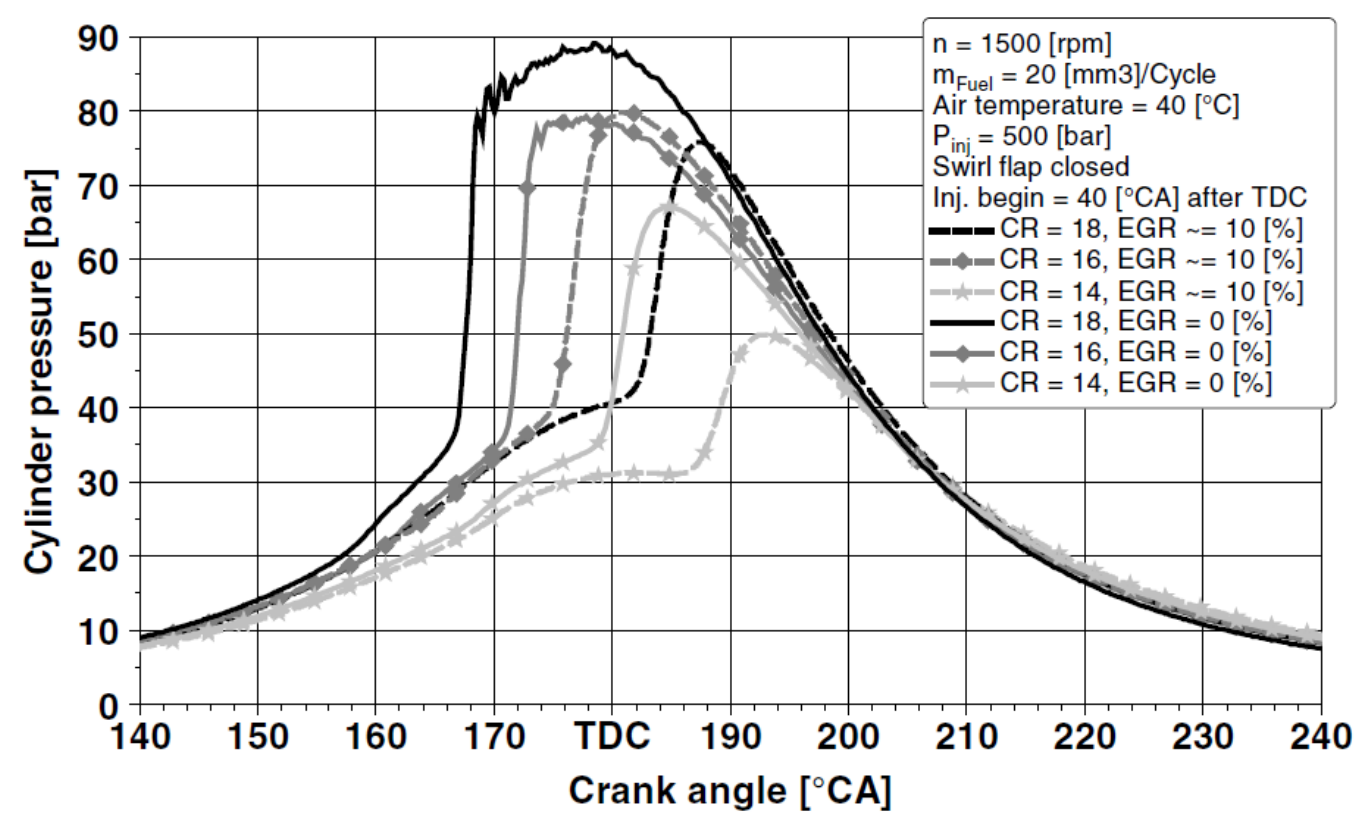

Figure 10: Cylinder Pressure as a function of Crank Angle for varying Compression Ratio [6]

\subsubsection{Piston Design}

Many different piston design concepts exist; the "Mexican hat" piston bowl design is very common for compression ignition engines due to its swirl invoking nature. Increased swirl in the combustion chamber leads to a more homogenous air and fuel mixture. Some advanced combustion studies rely on flat top pistons for simplicity sake, but the complex geometric shapes of piston bowls can have varying effects on emissions and performance as demonstrated by Benajes et al. [15]. Three different piston bowls as well as the resulting soot, $\mathrm{NO}_{\mathrm{x}}$, and fuel consumption are presented in Figure 11. These results were obtained under a medium load condition and display a tradeoff between $\mathrm{NO}_{\mathrm{x}}$ emissions versus reduced soot and fuel consumption for the differing piston bowl geometries. 


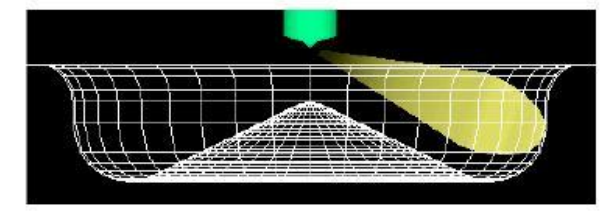

Wide angle nozzle straight wall bowl

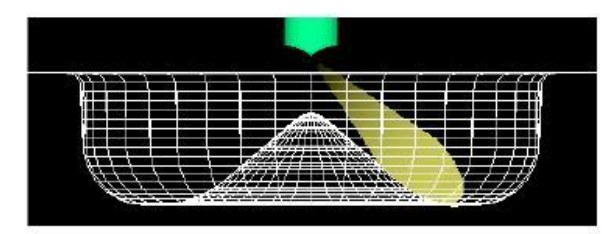

Narrow angle nozzle - straight wall bowl

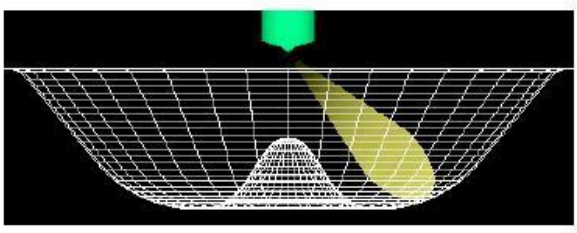

Narrow angle nozzle - Open bowl

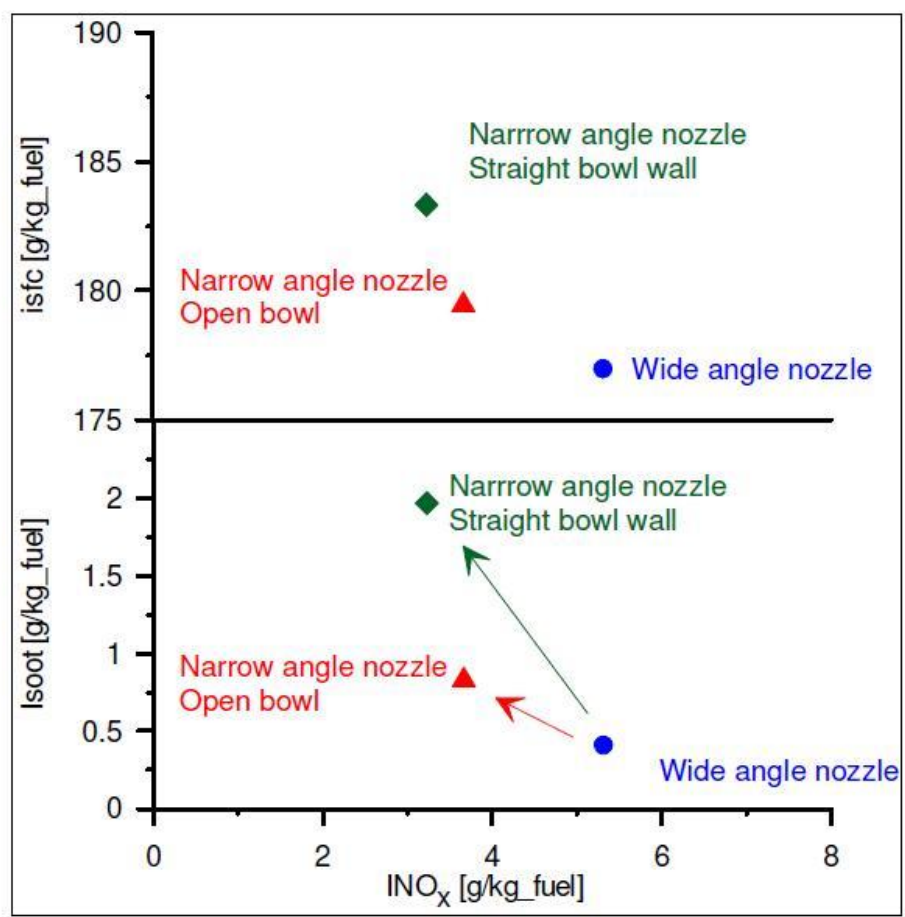

Figure 11: Various Piston Bowl Configurations and their Effects on Soot, Fuel Consumption, and $\mathrm{NO}_{\mathrm{x}}[15]$

\subsubsection{Variable Valve Actuation}

Modern variable valve actuation (VVA) systems are beginning to appear on compression ignition engines, but are generally found on research engines or retrofitted to a production engine for research purposes. The primary research focus of VVA for compression ignition engines is on the intake valve timing for the compression stroke. This variable plays a direct role in determining an engine's dynamic compression ratio. Besides mechanical operation several methods of activating an engine's valves exist, including pneumatic, hydraulic, magnetic, electric, or a combination of these. The method utilized by Nevin et al. [14] and Kawano et al. [8] is an electrically operated high pressure hydraulic actuation method which continues to hold the valve open after the mechanical lift has finished. Kawano et al. found for additional intake valve opening $\mathrm{NO}_{\mathrm{x}}$ emissions decreased, while $\mathrm{HC}$ and $\mathrm{CO}$ emissions increased [8]. Fuel consumption remained fairly constant while smoke increased for the condition of no EGR and heavily extended valve opening. Other benefits include control of combustion phasing and cylinder pressure rise rate demonstrated in Figure 7 and Figure 8, respectively. Increased time 
for mixing was demonstrated by Kulkarni et al. by retarding combustion through the use of "flexible intake intake valve actuation" [16].

\subsubsection{Injection Spray Angle}

Employing an early injection event commonly results in fuel saturating the cylinder walls, piston crown, and accompanying crevices. This phenomenon, known as wall wetting, can heavily increase $\mathrm{HC}$ and $\mathrm{CO}$ emissions and negatively affect engine performance due to copious amounts of unburned fuel. Implementing an injection angle that synchronizes with an early injection strategy greatly reduces the effects of wall wetting. Trends can vary with widening or shortening the injection angle. Buchwald et al. found a wide injection angle resulted in the best overall $\mathrm{NO}_{\mathrm{x}}, \mathrm{PM}$, and fuel consumption, it must be noted though that this is heavily dependent on in-cylinder geometry and engine operating conditions [17]. Similar to these results, Vanegas et al. performed research based around three different injection angles concluding that the narrowest injection angle resulted in the greatest $\mathrm{NO}_{\mathrm{x}}$ emissions and smoke [18]. The greatest fuel consumption is found with the largest injection angle, while $\mathrm{HC}$ emissions are almost unanimously less with the narrow injection angle displayed in Figure 12. This signifies less wall wetting especially at advanced SOI timing (i.e. $50^{\circ}$ BTDC). 


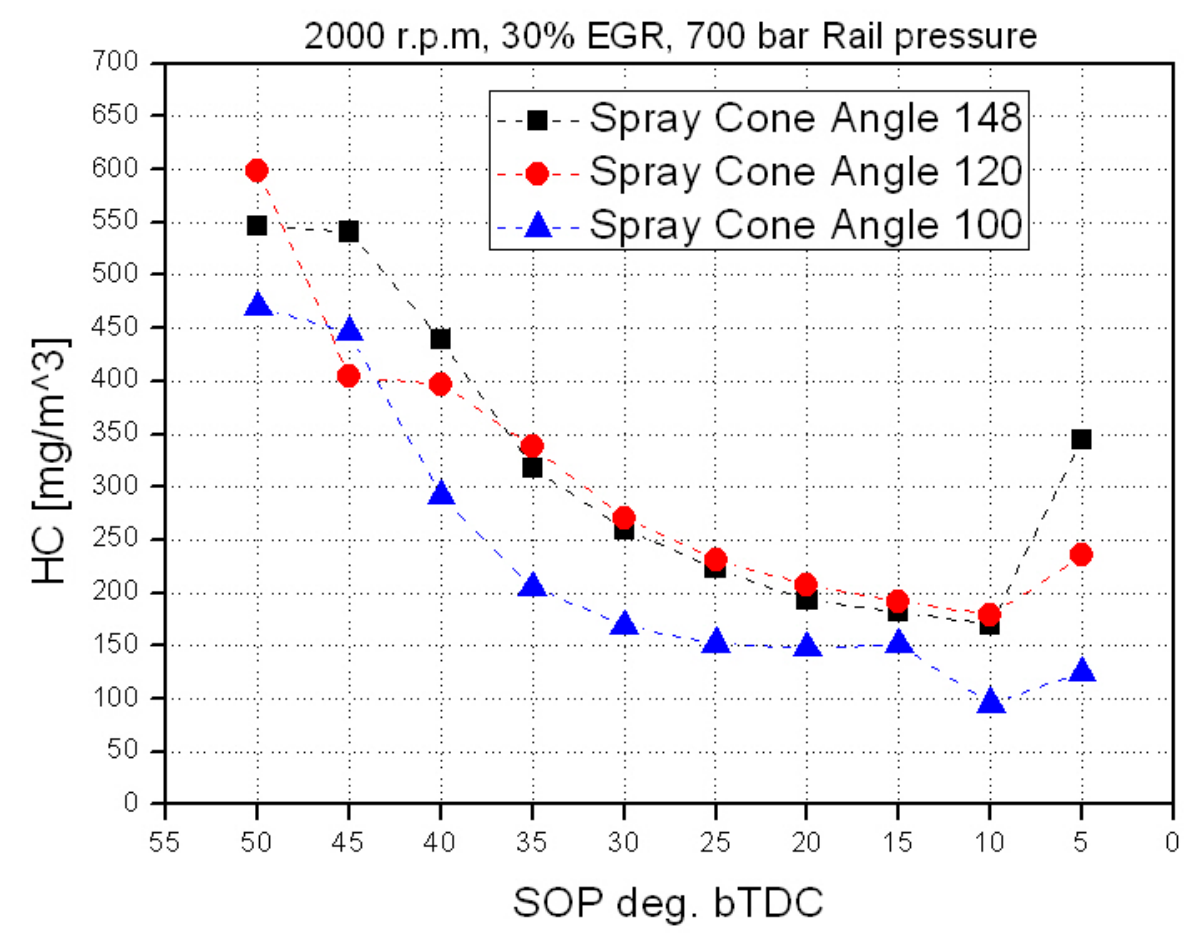

Figure 12: $\mathrm{HC}$ emissions as a function of Start of Injection Pulse for varying Injection Angle [18]

\subsection{Effect of Fuel Properties on Advanced Combustion Strategies}

Fuel properties have a significant impact on the achievement of advanced combustion methods as well as the resulting emissions and engine performance. Methods of control and necessary modification of engine hardware can be solely dependent on the properties of a selected fuel. This has resulted in a considerable amount of research to determine which fuels are best suited for HCCI. The Fuels for Advanced Combustion Engines (FACE) workgroup, a subgroup of the Coordinating Research Council (CRC) Advanced Vehicle, Fuel, and Lubricants (AVFL) committee, has created a matrix of nine diesel fuels for use in advanced combustion research [19]. FACE concluded that the three most important properties for advanced combustion research were cetane number, aromatic content, and 90 percent distillation temperature (T90) which they deem are "a measure of ignition quality," "a measure of chemistry," and a measure of "volatility," respectively [19]. The nine fuels comprising the FACE matrix where manufactured by Chevron Phillips Chemical company and include a mix of high and low cetane number, aromatic content, and T90. Other researchers such as Kawano et al. have blended other fuels with conventional diesel fuel for use in advanced combustion 
research [20]. Kawano et al. blended conventional diesel fuel with iso-octane, iso-paraffins, toluene, and MTBE to create a matrix of test fuels with varying properties.

\subsubsection{Cetane Number}

The ignition delay time of a particular fuel is quantified by its cetane number [21], where a high cetane number results in a shorter ignition delay and low cetane number results in a longer ignition delay. These effects on combustion phasing solidify the importance of a fuel's cetane number to advanced combustion. A study of the FACE matrix by Cho et al. explored the affects of cetane number on high efficiency clean combustion (HECC), a combustion strategy related to LTC and PCCI [22]. Through their research, cetane number proved to be the main factor in determining acceptable injection timings for each fuel. Figure 13 demonstrates the shortest ignition delay for the high cetane fuels (fuels 5 through 9). Due to this the allowable SOI timing range is much more advanced for the low cetane number fuels. For both high and low cetane fuels, Figure 13 shows combustion noise increases as SOI timing is advanced, with a slightly higher peak for the low cetane number fuels. 

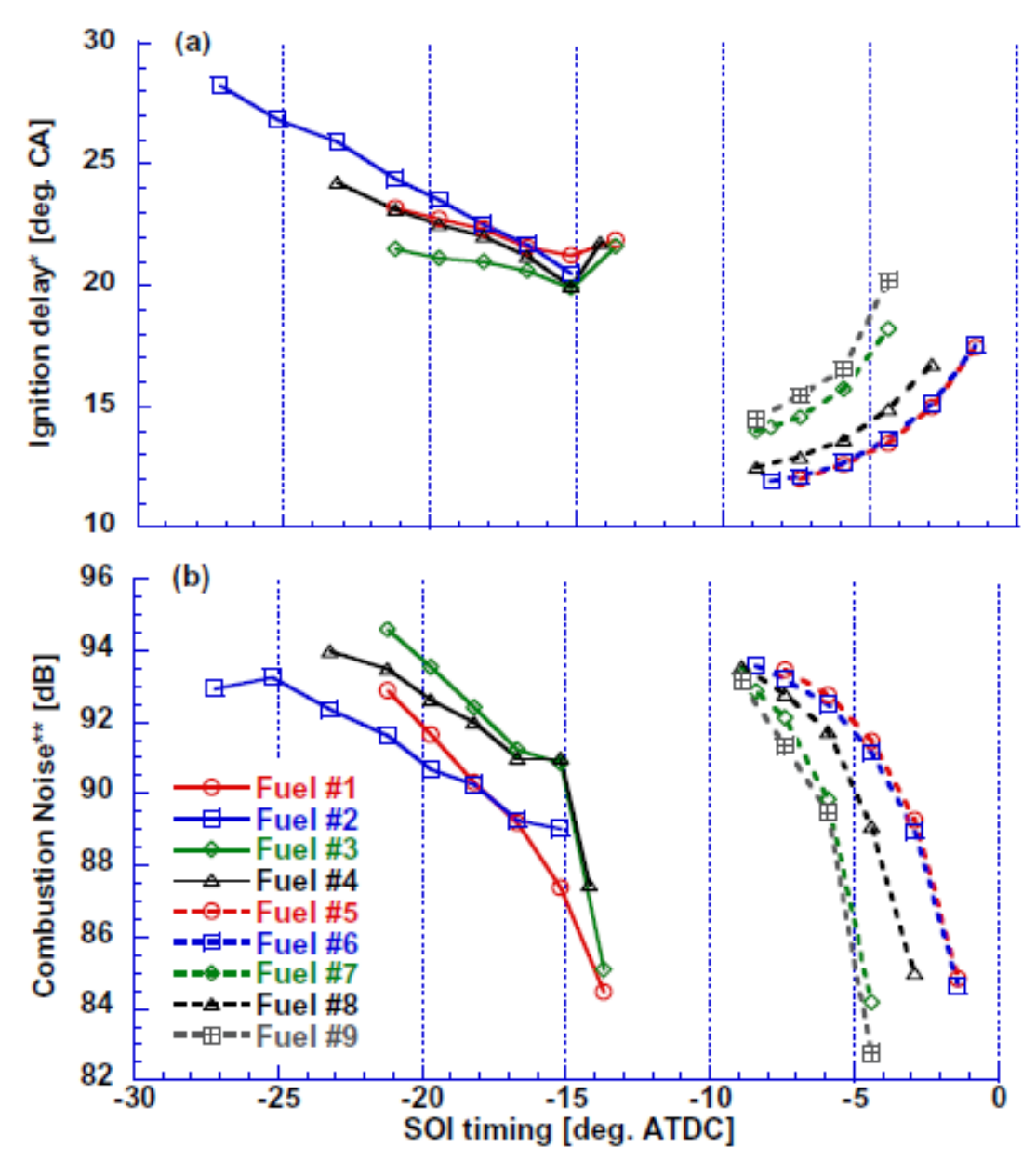

\section{Figure 13: Ignition Delay and Combustion noise as a function of SOI Timing for the FACE Matrix [22]}

Ignition quality and delay has a profound effect on in-cylinder temperatures, pressures, and bulk mixing, lending cetane number to have a direct influence on emissions formation. Results obtained by Bunting et al. (single cylinder HCCI engine) display a trend of decreasing $\mathrm{NO}_{\mathrm{x}}$ emissions for fuels with higher cetane number [23]. This results from a lower combustion temperature due to a greater percent of low temperature heat release and a decreased intake air temperature (the minimum intake air temperature necessary to sustain combustion was employed) [23]. Bunting et al. reported a slight decrease in $\mathrm{HC}$ emissions as cetane number increased while $\mathrm{CO}$ emissions tripled as cetane number rose from 30 to 55. Results in Figure 14 from Cho et al. offer different trends consequently due to differing engines and advanced combustion strategies. Fuels 5 through 9 in Figure 14 have a cetane number greater than 44 . An overall decrease in $\mathrm{NO}_{\mathrm{x}}$ emissions for high cetane fuels is present in both experiments, but Figure 14 demonstrates lower $\mathrm{CO}$ emissions and slightly less $\mathrm{HC}$ emissions for the high cetane 
fuels. PM emissions displayed are much greater for the high cetane fuels while the BSFC for low cetane fuels have a slightly lower maximum.
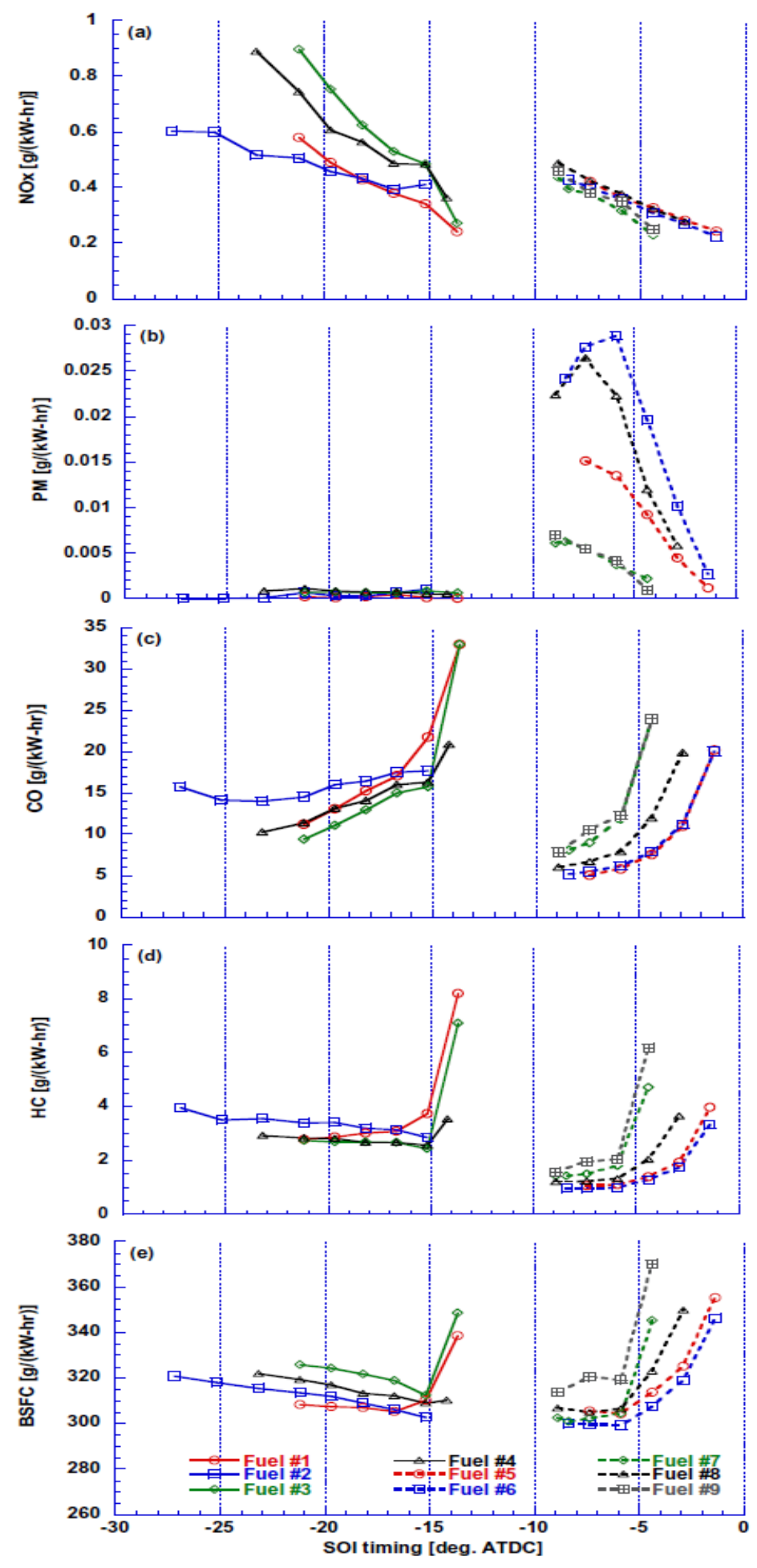

Figure 14: Emissions and Fuel Consumption at varying SOI for the FACE Matrix [22] 


\subsubsection{Aromatic Content}

Described previously as "a measure of chemistry" [19] aromatics "have high densities in the liquid state and thus have high energy content per unit volume" [21]. Due to this, aromatics are normally used in gasoline blends and generally are not blended heavily into diesel fuel. Although aromatics generally offer little trends in combustion phasing, it has been reported that they are a primary influence on $\mathrm{NO}_{\mathrm{x}}$ and $\mathrm{PM}$ emissions [22]. Figure 14 partly disagrees though displaying no trend in PM emissions for fuels with high aromatics and high cetane number (fuels 7 and 8). The only discernible trend for aromatics shown in Figure 14 is regarding $\mathrm{NO}_{\mathrm{x}}$ emissions for fuels 1 and 2 which have a lower aromatic content than fuels 3 and 4. Furthermore, Gibble found that under conventional combustion operation an increase in aromatics content resulted in "a slight increase in $\mathrm{NO}_{\mathrm{x}}$ emissions" [24].

\subsubsection{Percent Distillation Temperature}

The temperature at which 90 percent of the distillation process has occurred for a given fuel is often used to draw conclusions about the volatility of that fuel. A fuel with a lower T90 will be in theory more volatile than that of a fuel with a greater T90. Figure 15 demonstrates the T90 concept for the FACE matrix. An apparent flaw in regarding T90 as a measure of volatility can be seen for fuels 1 and 2 [22]. The temperature curves up to approximately 80 percent distillation are nearly identical. From there fuel 2 nearly plateaus to its T90 of $346{ }^{\circ} \mathrm{C}$. The T90 for fuel $1\left(284^{\circ} \mathrm{C}\right)$ is considerably lower, but its volatility may be similar to fuel 2 due to the close resemblance of their curves. T90 has also been linked to PM formation and this is justified in Figure 14 for the high cetane fuels. Fuels 5 and 7 exhibit a T90 of less than $275^{\circ} \mathrm{C}$, while fuels 6 and 8 have a T90 of approximately $340{ }^{\circ} \mathrm{C}$ and produce nearly double the PM emissions at their peaks. 


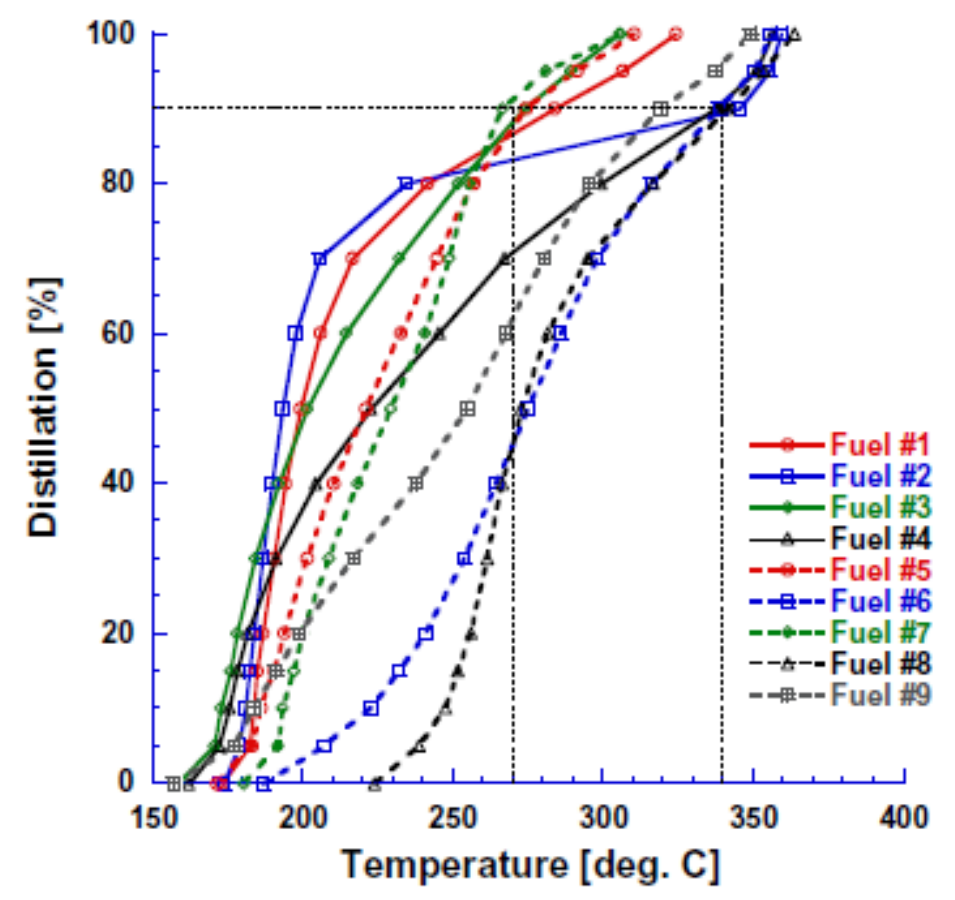

Figure 15: Distillation Percentage as a Function of Temperature for the FACE Matrix [22]. 


\section{Experimental Setup}

\subsection{Introduction}

In order to evaluate the effects of several fuel properties on an advanced combustion strategy, an experiment was developed and performed at the West Virginia University Engine and Emissions Research Laboratory (EERL). The EERL is a facility operated by the West Virginia University Center for Alternative Fuels, Engines, and Emissions (CAFEE) with the capability to measure an engine's emissions and performance under a variety of conditions through engine dynamometer testing. The experiment under discussion was performed utilizing the EERL 2007 CVS tunnel and control system built to comply with Title 40 CFR Part 1065.

\subsection{Engine Hardware}

A General Motors $1.9 \mathrm{~L}$ compression ignition engine was chosen as the research surrogate to conduct the aforementioned experiment. This engine was operated with the assistance of a Medsker Electric Inc. Alternating Current Dynamometer and controlled with an aftermarket Drivven engine controller. Significant specifications and equipment of the engine are presented in Table 1.

Table 1: Engine Specifications and Equipment.

\begin{tabular}{|c|c|}
\hline Engine Model & GM Z19DT \\
\hline Displacement & $1.9 \mathrm{~L}$ \\
\hline Cylinders & 4 \\
\hline Bore & $82 \mathrm{~mm}$ \\
\hline Stroke & $90.4 \mathrm{~mm}$ \\
\hline Compression Ratio & $18: 01$ \\
\hline Valves/Cylinder & 2 \\
\hline Fuel Injection & Bosch Common Rail \\
\hline Turbocharger & Garret VGT \\
\hline EGR & Cooled \\
\hline
\end{tabular}

\subsubsection{Test Engine Specifications}

The research platform is a 4 cylinder $1.9 \mathrm{~L}$ displacement, single over head camshaft, 8 valve, compression ignition engine with a bore of $82.0 \mathrm{~mm}$, a stroke of $90.4 \mathrm{~mm}$, and a compression ratio of 18:1 [25]. General Motors Europe manufactures this engine for small to 
medium coupes and sedans. This particular model is deemed a Z19DT and was removed from a 2005 Vauxhall Vectra C. It features an iron engine block, aluminum alloy dished pistons, and an aluminum alloy cylinder head and intake manifold. Its rated power is $89 \mathrm{~kW}$ (119 HP).

\subsubsection{Fuel Injection System}

The Z19DT employs an electronically controlled Bosch EDC 16C9 high-pressure common rail direct fuel injection system to deliver fuel to the cylinders. A high pressure pump driven at half engine speed by the camshaft timing belt is supplied fuel at approximately $3.3 \mathrm{bar}$ from a lift pump [25]. Three pistons in the high pressure pump compress the fuel up to $1600 \mathrm{bar}$. The highly pressurized fuel is then supplied to the common rail which in turn feeds the direct fuel injectors. Start of injection timing and the pulse width of injection for each fuel injector is controlled by the engine control unit (ECU). To initiate an injection event the ECU sends current to a solenoid valve located on the top of an injector. This solenoid valve opens a path from the control cavity to the fuel return resulting in a pressure drop in the control cavity. This pressure drop allows pressurized fuel in the chamber volume (equal to the rail pressure) to overcome a spring force holding the nozzle closed [27]. The nozzle opens and fuel is then injected directly into the cylinder. Injection pressure is also controlled electronically by the ECU through a bleed valve on the common rail as well as a metering valve on the high pressure pump. Fuel return paths exist on the injectors, high pressure pump and on the common rail. A schematic of the Bosch common rail fuel injection system is provided in Figure 16. 


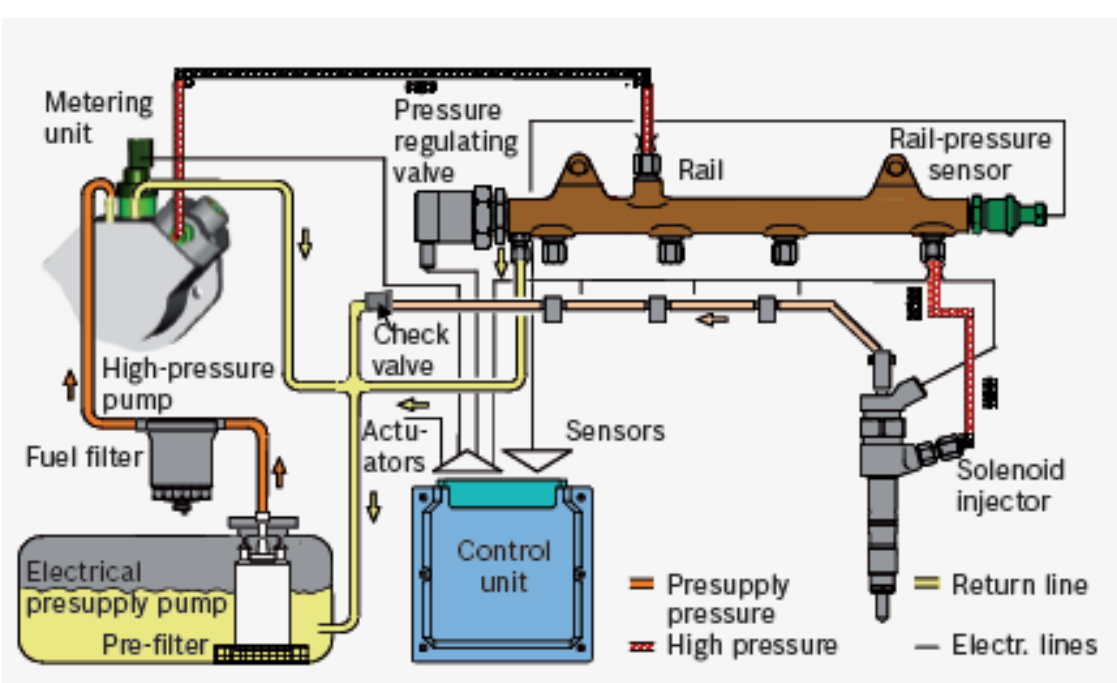

Figure 16: Bosch Common Rail Fuel Injection System Diagram [27]

\subsubsection{Exhaust Gas Recirculation System}

The 1.9 L test engine utilizes a high pressure cooled EGR system. Through the EGR system cooled exhaust gas is reintroduced into the engine's cylinders acting as a diluent. This diluent reduces in-cylinder temperatures and pressures resulting in less $\mathrm{NO}_{\mathrm{x}}$ formation. Once the exhaust gas exits the cylinder a portion is directed through an air to water (exhaust gas to engine coolant) heat exchanger (EGR cooler). The cooled exhaust gas then passes through a metering valve (EGR valve) and back into the engine's intake manifold where it mixes with fresh inlet air. EGR flow is primarily controlled through the EGR valve located on the intake manifold, but is also dependent on the operation of the variable geometry turbo, especially in situations with high boost. Due to the elevated EGR fractions necessary for advanced combustion research, a retrofit heavy duty EGR cooler from a 10.8 liter Mack MP7 was installed to insure sufficient cooling of EGR gases. Figure 17 provides a layout of the EGR system with the larger EGR cooler installed. 


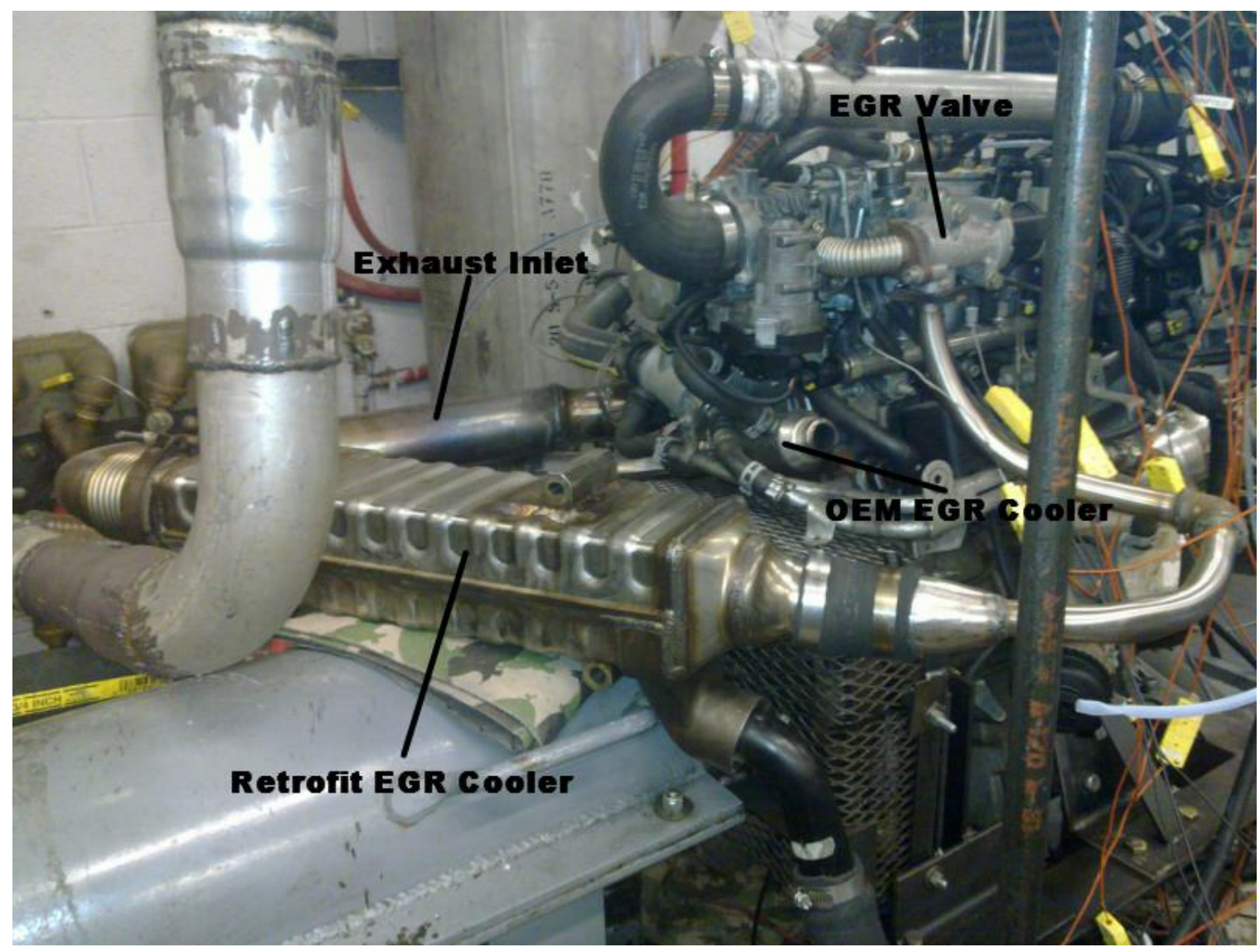

Figure 17: EGR System with Retrofit Heavy Duty EGR Cooler

\subsubsection{Variable Geometry Turbocharger}

Increased intake manifold pressure results from a turbocharger coupled to the engine's exhaust manifold. The exhaust housing of the turbocharger and exhaust manifold are a single cast iron unit. The exhaust and inlet air turbines, bearings, oiling system, and variable geometry turbocharger (VGT) mechanism all bolt onto the exhaust housing comprising the turbocharger system. Distinguishing this turbocharger from older variants is the application of a relatively new technology given the acronym VGT. The VGT mechanism utilized on the test engine is controlled by a vacuum operated actuator that rotationally opens or closes vanes in the exhaust housing. These vanes provide multiple effective aspect ratios (A/R ratio) allowing the turbocharger to operate efficiently at low speeds as well as high speeds without the trade off normally associated with fixed geometry turbochargers. VGT can also be used as a tool to aid in EGR control by regulating the pressure in the exhaust manifold subsequently increasing or decreasing EGR flow. 


\subsubsection{Intake Air Heating System}

Through review of previous advanced combustion studies it was observed that intake air heating was commonly used to help sustain stable combustion especially for low cetane fuels. Due to the varying cetane number of fuels to be utilized in this study an intake air heating system was constructed to elevate the temperature of the fresh air entering the intake manifold ultimately resulting in better fuel atomization in the cylinder. An 1800 watt heater mounted in a circular duct heats passing air supplied by a fan. The heated air travels across the engine's intercooler (air to air heat exchanger) resulting in heat transfer to the engines intake air charge. The intake air heating system employed in this experiment has the capability to increase intake manifold temperatures (IMT) up to approximately $80{ }^{\circ} \mathrm{C}$. A layout of the intake air heating system is displayed in Figure 18.

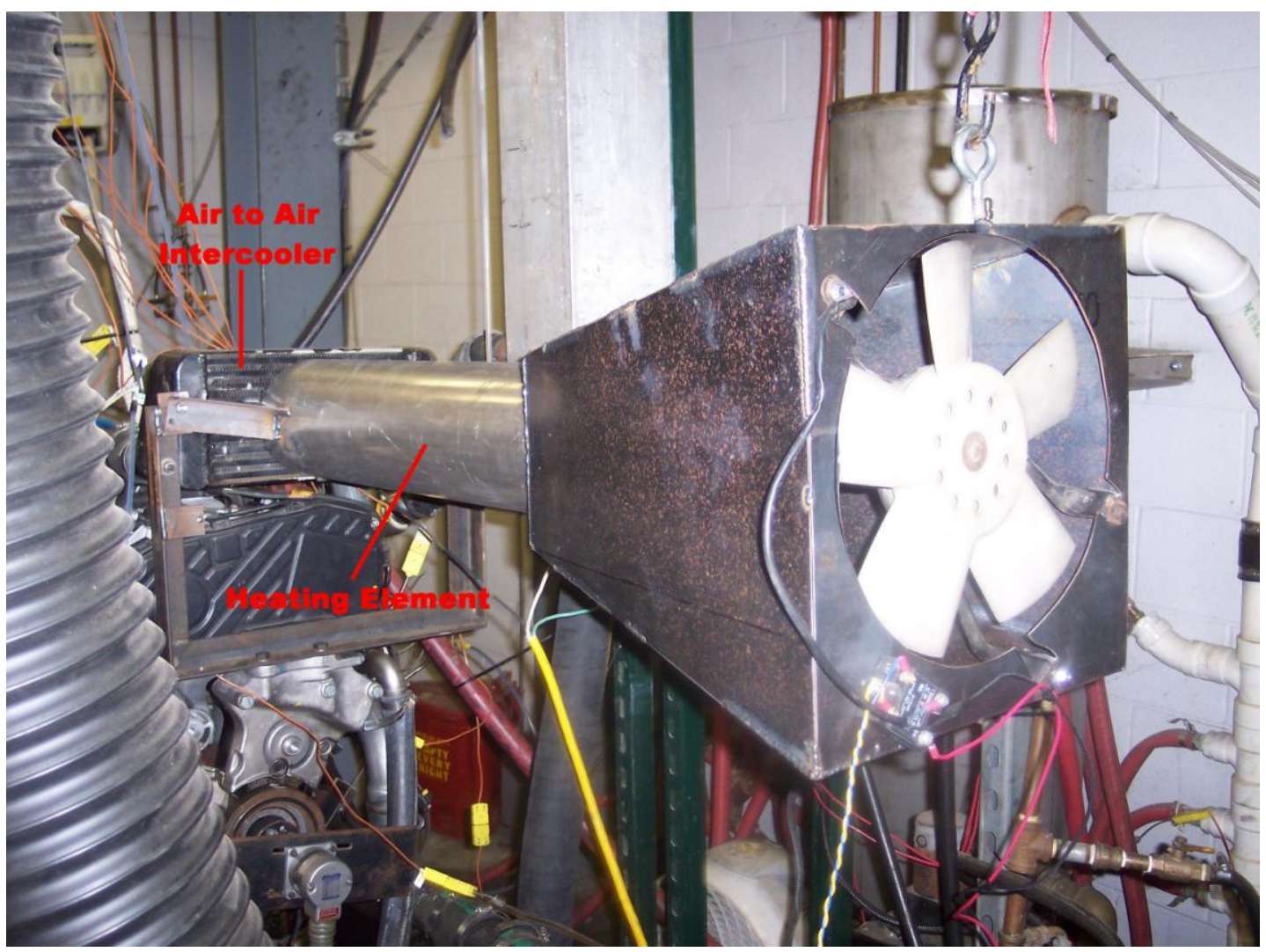

Figure 18: Intake Air Heating System 


\subsubsection{Engine Performance Measurement Sensors}

In order for the ECU to control the fuel injection, VGT, and EGR systems correctly and efficiently several engine performance parameters must be measured. Arguably the most important sensor is the crank position sensor. Typically this is an optical sensor that counts teeth located on the crankshaft. On the test engine, a 60 tooth ring located on the rear of the crankshaft employs two missing teeth to give the ECU an indication of TDC and piston position. Supplementary to the crankshaft sensor a camshaft sensor located on the camshaft timing gear allows the ECU to determine which stroke the engine is on for a given cylinder. Primarily for control of the EGR and fuel injection system, a hot wire mass air flow (MAF) sensor is positioned prior to the turbocharger inlet. The volumetric flow of air through the meter is determined with the use of an open element wire that is heated to a specific temperature. Air flowing past the heated element cools it, effectively reducing the resistance allowing more current to flow through the element. A correlation between this current and the actual air flow provides the information necessary to the ECU for EGR operation and fueling. Other sensors used for fuel injection control as well as VGT control are the intake manifold pressure and temperature sensors. A coolant temperature sensor provides information used to tailor fuel and EGR maps to ensure proper combustion and aid the engine in effectively reaching the optimum operating temperature. Oil pressure and level sensors are also present to warn the ECU of potentially detrimental conditions.

\subsection{Drivven Engine Controller}

Full independent control of each engine system listed in Section 3.2 is necessary to research and achieve an advanced combustion strategy. Consequently the OEM Bosch ECU was replaced with an open engine controller manufactured by Drivven Automotive Control and Data Acquisition Systems. The Drivven controller allows for full control of fuel injection timing, fuel injection duration, fuel injection events, rail pressure, EGR valve position and VGT vane angle.

\subsubsection{Drivven Engine Controller Hardware}

Hardware for the Drivven engine controller is manufactured by National Instruments (NI) or is manufactured specifically to interface with existing NI hardware. The host of the controller is a NI PXI 1042 eight slot chassis with an NI PXI8106 embedded controller. At the core of the 
system is the NI PXI-7813R digital RIO. This card enables the user to program the field programmable gate array (FPGA) through LabVIEW software. In essence the FPGA acts as a reprogrammable micro processor, except that it can handle multiple channels of data and signals in a single instance. This technology is essential for the simultaneous recording and control of the multitude of engine systems utilized on the test engine.

\subsubsection{National Instruments CompactRIO 9151 Expansion Chassis and Drivven Modules}

The actual signals and commands are input and output from the FPGA through NI CompactRIO (CRIO) 9151 expansion chassis shown in Figure 20. TWO NI CRIO 9151 expansion chassis each hold up to four modules that eventually interface with the engine's wiring harness. Two common rail diesel injector (DI) driver modules fire the engine's four fuel injectors. Figure 19 displays an example of a DI driver module. A low side driver module commands the master power relay, VGT actuator solenoid, EGR valve, and the fuel pump metering valve. Port fuel injection (PFI) capabilities are provided by a port fuel injector driver module. The PFI driver module also provides more low side drivers which command the high pressure common rail bleed valve and the throttle valve. For all analog and digital inputs of the various engine sensors described in Section 3.2.6, an AD (analog and digital) combo module is present. To determine oxygen concentration with the use of a zirconium oxide sensor an $\mathrm{O}_{2}$ sensor module also resides in one of the NI CRIO expansion chassis. 


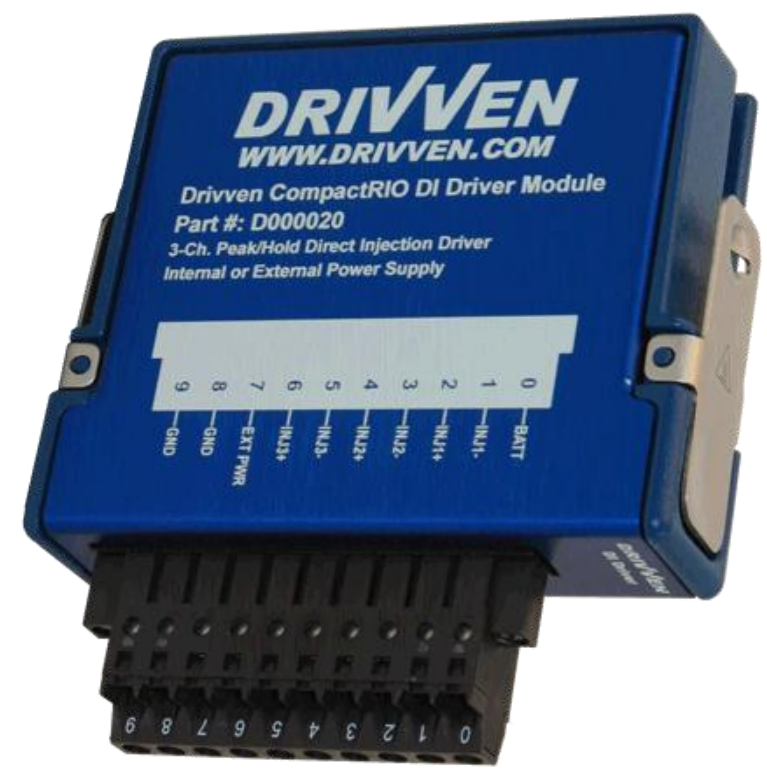

Figure 19: Drivven Common Rail Diesel Injector Driver Module Kit [28]

\subsubsection{Breakout Box and Custom WVU Wiring Harness}

Interfacing the test engine's OEM wiring harness with the Drivven engine controller is a break out box and custom WVU wiring harness. The OEM wiring harness plugs into a circuit board containing the same connectors as the OEM Bosch ECU located in the breakout box. The custom WVU wiring harness connects this circuit with the Drivven modules located in the NI CRIO expansion chassis. This setup allows for quick changing of the OEM ECU and Drivven engine controller. Figure 20 displays the setup and key components. 


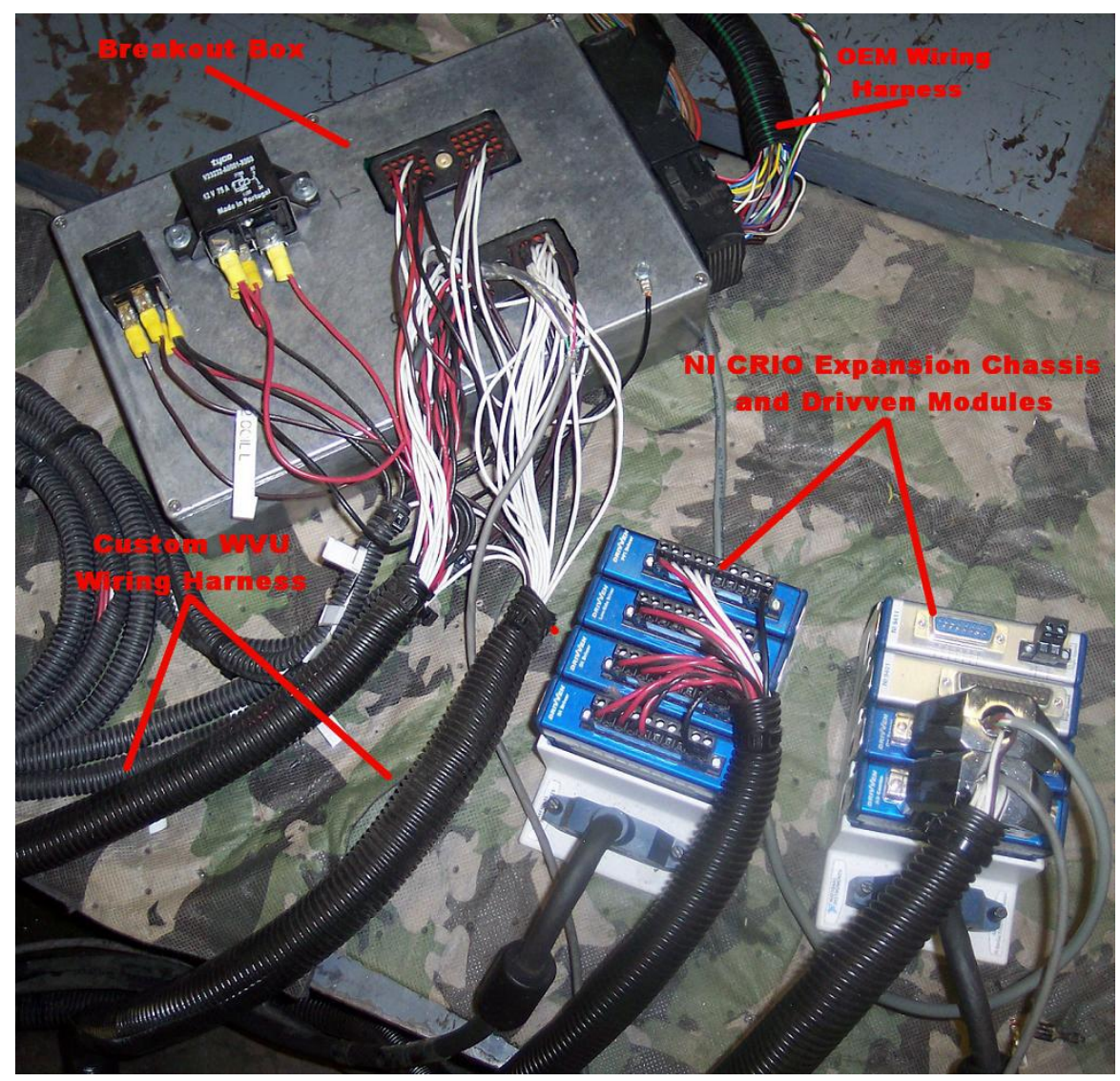

Figure 20: Breakout Box, Wiring Harness, NI CRIO Expansion Chassis and Drivven Modules

\subsubsection{Drivven Engine Controller Software}

As mentioned previously, the Drivven engine controller enables WVU to fully control the fuel injection and other engine systems employed on the GM Z19DT test engine. The user interface to do so is written in National Instruments graphical programming language named LabVIEW. Actual commanding of engine operation is performed through a Drivven program named CalVIEW, based off of NI LabVIEW.

\subsubsection{National Instruments LabVIEW}

At the basis of the Drivven software is NI LabVIEW. To operate the Drivven controller system a LabVIEW virtual interface labeled GM19L_RT.vi (real time) is deployed onto the NI PXI8106 embedded controller. The RT.vi receives and commands signals through the FPGA. These signals are conditioned in the RT.vi to engineering values that the operator can understand and interface with. The graphical view the user sees is displayed in Figure 21, noting that many 
more inputs and control variables are embedded in this virtual interface, yet not displayed in the graphical view presented.

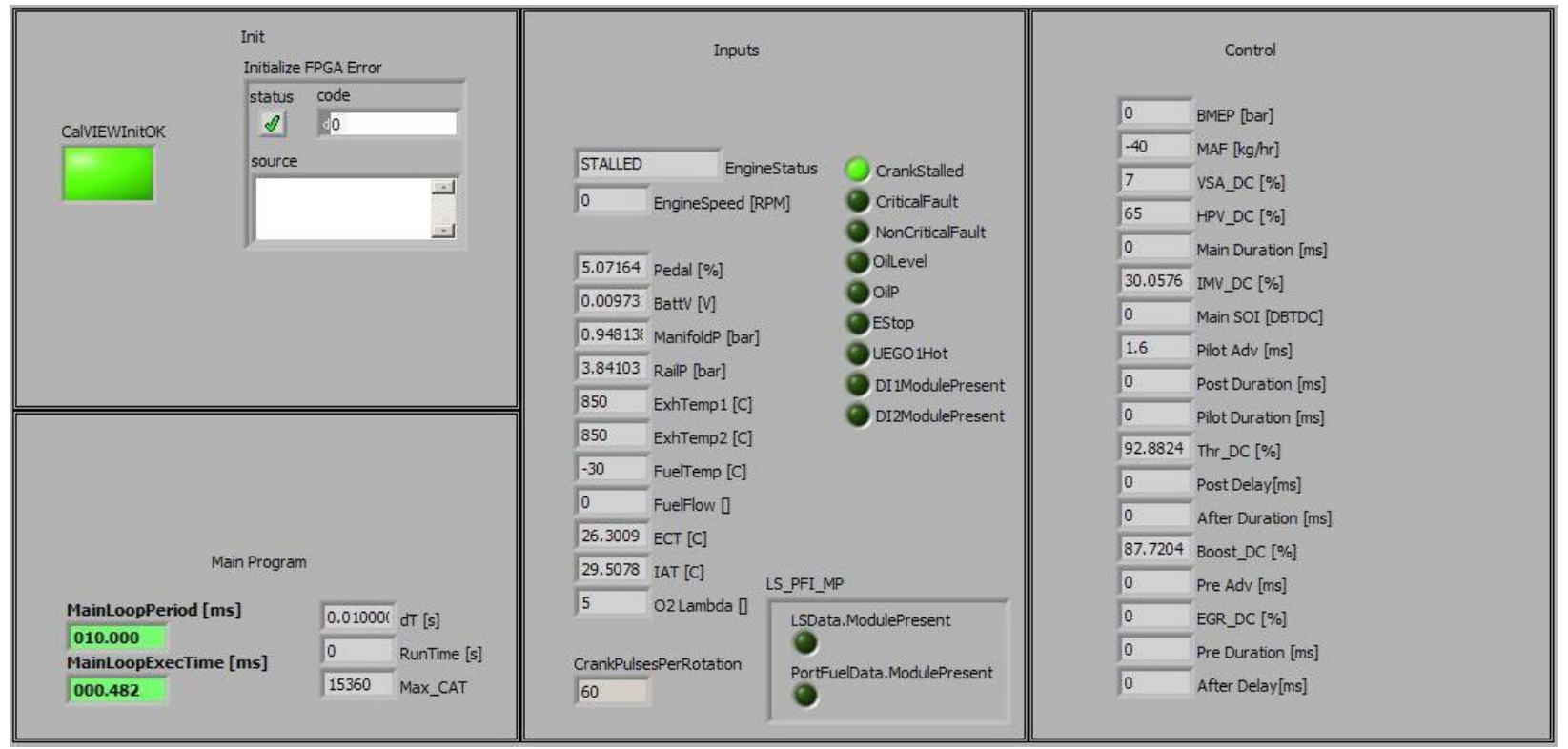

\section{Figure 21: National Instruments LabVIEW Real Time Virtual Interface for the GM 1.9 Liter Engine}

\subsubsection{Drivven CalVIEW}

CalVIEW is a NI LabVIEW based program written by Drivven, which acts as the graphical user interface in which the operator actually controls the surrogate engine. The advantage of using CalVIEW in addition to LabVIEW is engine control parameters, lookup tables, and signal conditioning can all be performed without redeploying software to the embedded controller. CalVIEW communicates the operator's commands and the engine'ss feedback between a host computer and the NI engine side hardware via Ethernet connection. The main operating screen is displayed in Figure 22. 


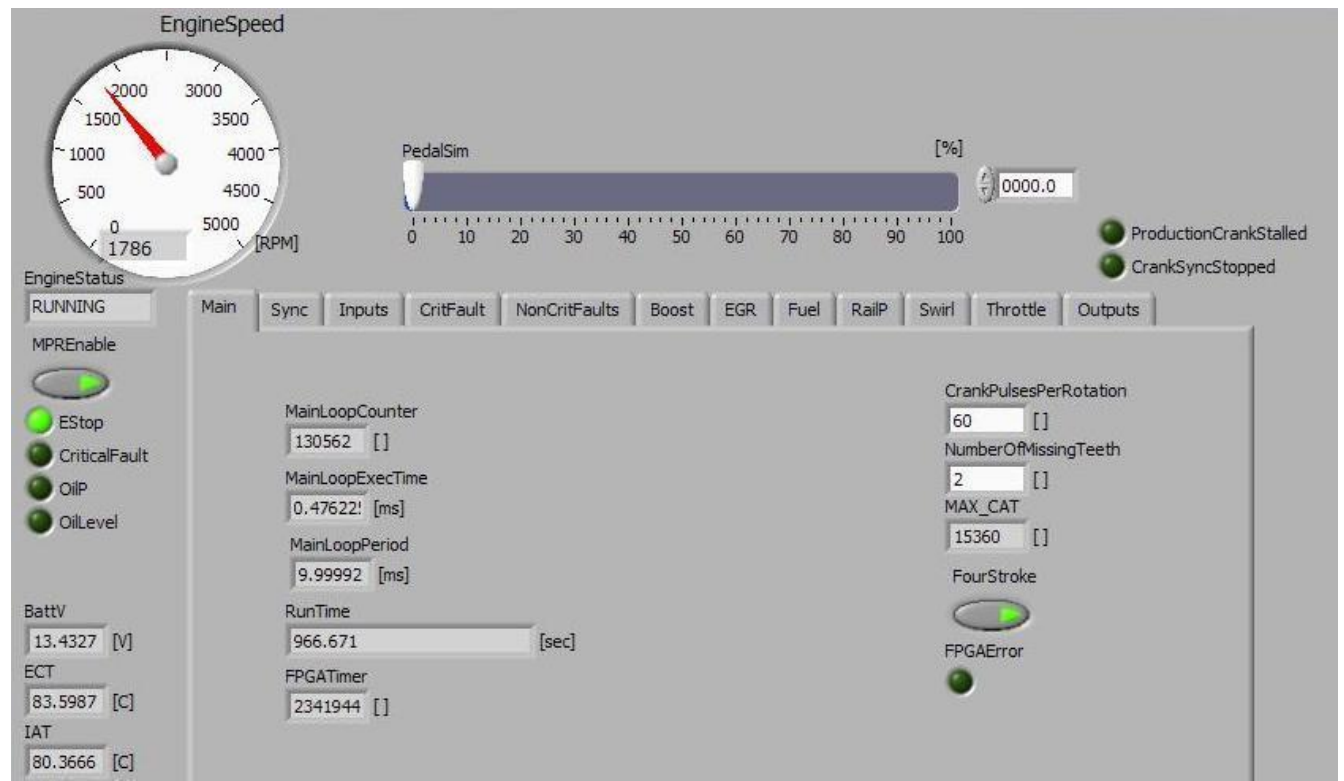

Figure 22: Drivven CalVIEW Main Operating Screen

Through the various tabs in Figure 22 the operator can fully control various aspects of the test engine. The Sync tab allows configuration of crankshaft and camshaft parameters such as top dead center (TDC) for each cylinder, camshaft offset, and accompanying filters to smooth the data. Various inputs are configured and displayed in the inputs tab; including pedal position, rail pressure, manifold air pressure, intake air temperature, coolant temperature, oil level, oil pressure, and mass air flow. Lambda values obtained from the $\mathrm{O}_{2}$ sensor as well as temperature and other parameters from the DI modules can also be obtained through the inputs tab.

The VGT is controlled through the boost tab represented in Figure 23. Based on engine speed and the volume of fuel being injected per cycle a lookup table provides a desired manifold pressure set point. A proportional, integral, derivative (PID) controller then compares this set point to the input value of the intake manifold pressure sensor and adjusts the boost duty cycle to match the actual and set point values. The boost duty cycle refers to the position of the VGT mechanism. A manual boost set point as well as manual VGT position can be fixed by the operator. 


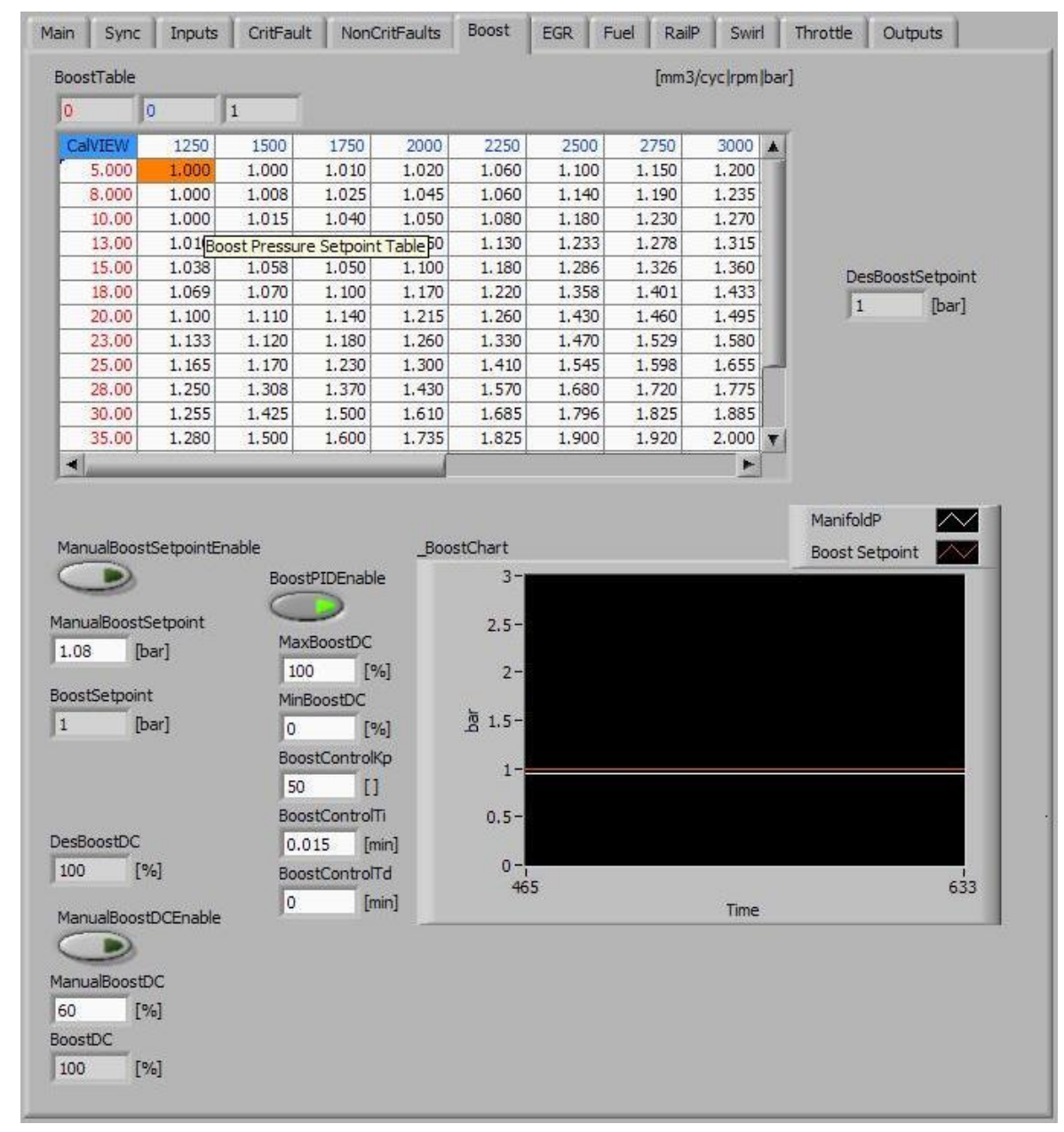

Figure 23: Drivven CalVIEW Boost Tab

Control of the EGR valve is performed with the aid of MAF and engine coolant temperature inputs. When the engine coolant temperature is above $65^{\circ} \mathrm{C}$ a basic air mass flow rate control strategy is utilized. Since the MAF sensor is outside of the EGR loop it only measures the fresh air portion of gas entering the intake manifold. A lookup table with inputs of engine speed and volume of fuel injected per cycle outputs a desired fresh air mass flow rate value. A PID controller then regulates the EGR valve to achieve this MAF set point. When the engine temperature is less than $65^{\circ} \mathrm{C}$ a correction factor is added to the MAF set point calculation. A lookup table based on the engine's coolant temperature outputs a factor of zero to one (one when the engine is coldest). This factor is then multiplied by a value output by the MAF Correction lookup table which has the same inputs as the main MAF based lookup table. The resulting MAF correction value is added to the main MAF set point, therefore limiting EGR and increasing fresh air flow when the engine is not at a warm, stable operating condition. A 
manual MAF set point and a manual EGR duty cycle (EGR valve position) can also be implemented by the operator. Lookup tables and the interface used to control EGR are provided in Figure 24.

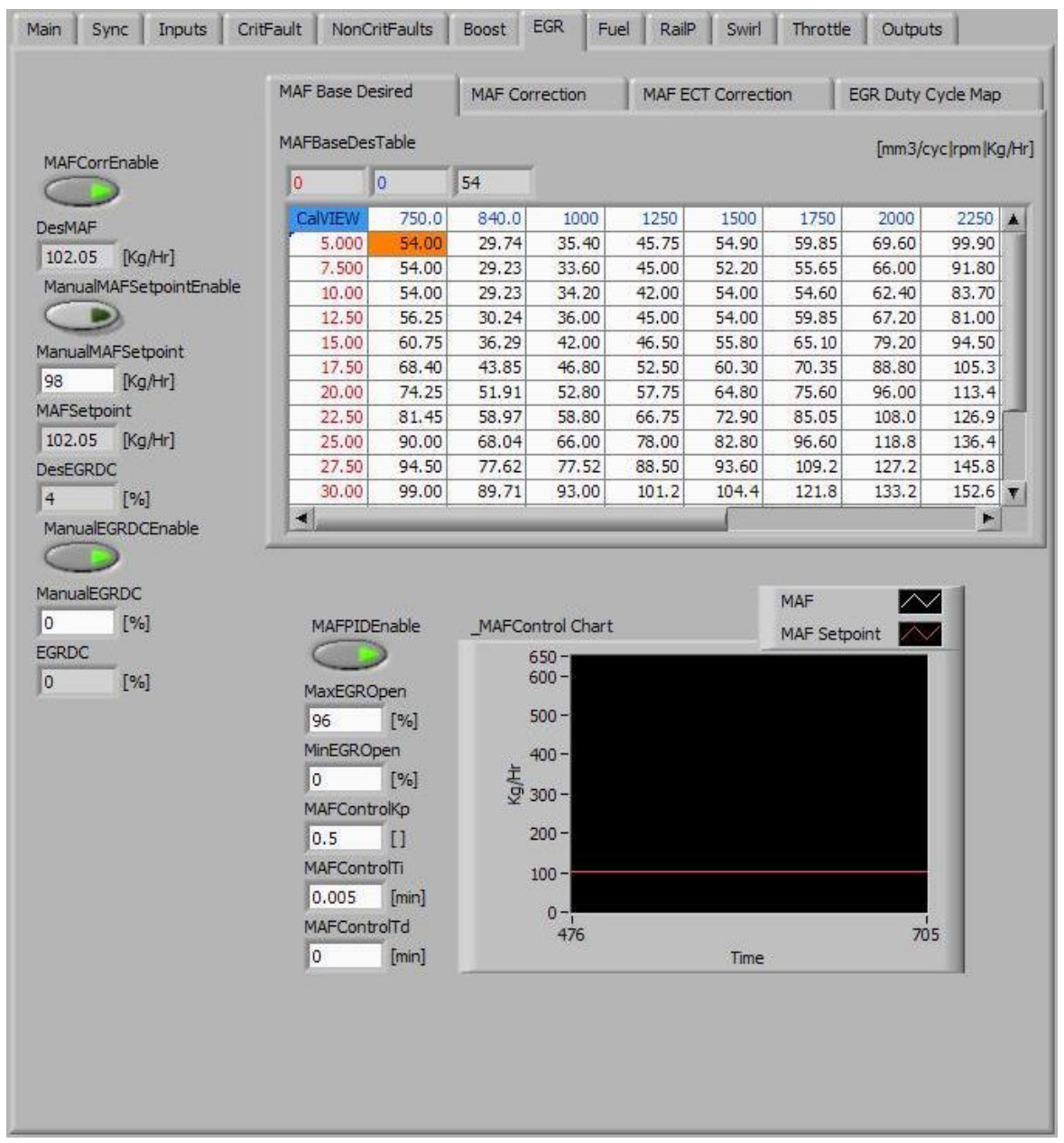

Figure 24: Drivven CalVIEW EGR Tab

Arguably the most important interface for this research in CalVIEW is the fuel tab shown in Figure 25. Calculation of the fuel injection SOI and pulse width begins with a desired torque determined from a lookup table with engine speed and percent pedal position as inputs. This value of determined torque as well as engine speed is then used in another lookup table to output the total volume of fuel per cycle to be injected into the engine. The total fuel proceeds on with engine speed to determine the percentage of fuel injected during the pilot injection in the fuel split lookup table. A lookup table for the main SOI (in units of degrees before top dead center) is operated with values of total fuel volume injected per cycle and engine speed. The pilot advance 
lookup table utilizes identical inputs but the output (pilot SOI) is in units of microseconds before the main injection. Pulse width of injection determined in the injector lookup table relies on rail pressure and the volume of fuel per injection for inputs. Through this series of lookup tables and calculations the appropriate injection timing and pulse width for both the main and pilot injections are determined. Further automated control can be achieved with the closed loop fueling turned on. Based on the lambda lookup table, a lambda set point is derived from volume of fuel injection per cycle and engine speed. A PID controller compares this set point to the actual lambda value input from the heated zirconium oxide sensor and adjusts the fueling accordingly. There are several manual set point controls in the fuel tab which allow the operator to further control fueling through total fuel injected, fuel split, and lambda set point. A very noteworthy feature of the Drivven engine controller is the capability to perform five different injection events per cycle. Only the pilot and main injections are controlled automatically, but manually the operator can control each of the 5 injections through time advance or delay from the main SOI and the pulse width of each injection. 


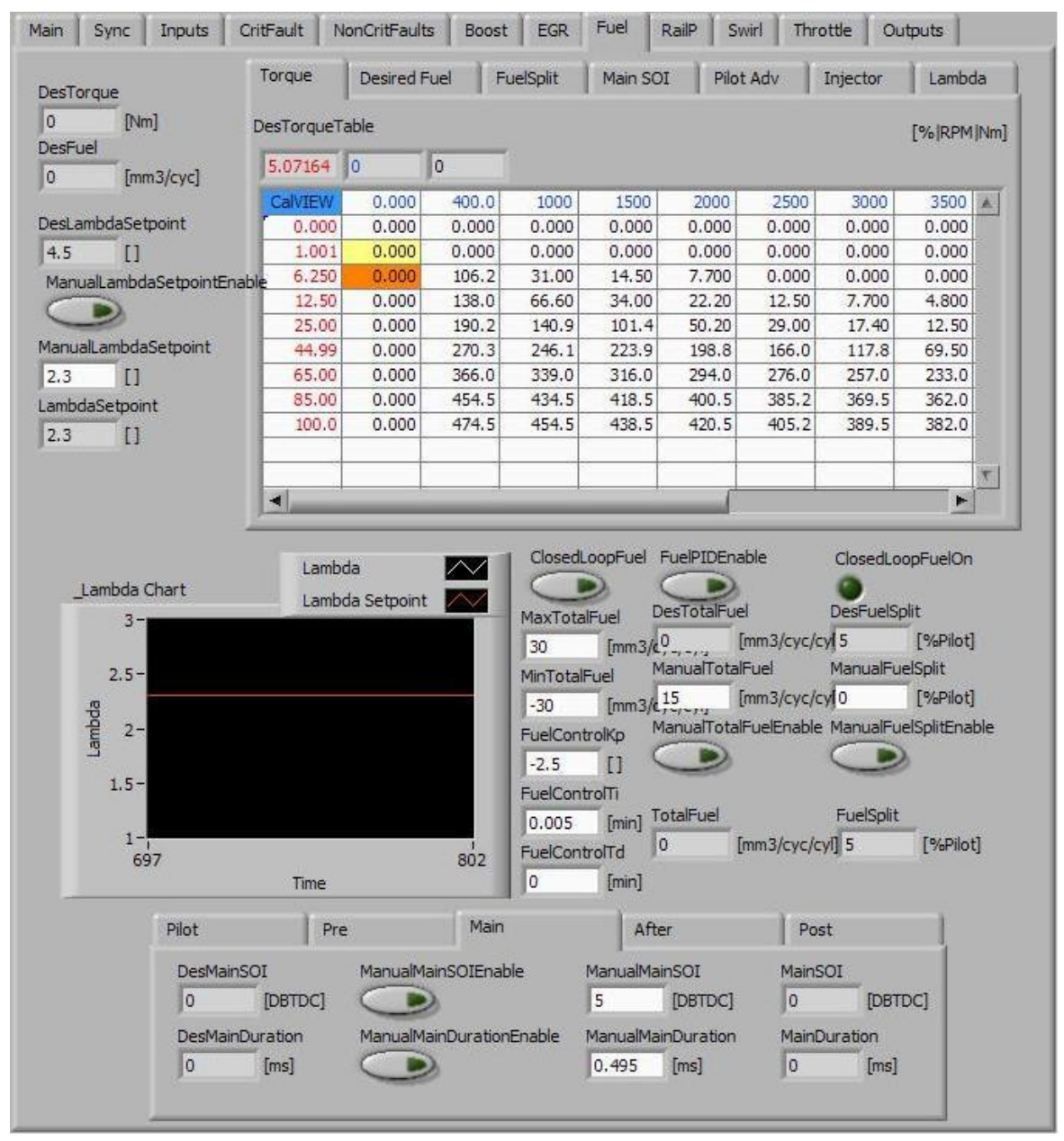

Figure 25: Drivven CalVIEW Fuel Tab

To determine the appropriate rail pressure a lookup table with inputs of fuel volume per cycle and engine speed is utilized in the RailP tab displayed in Figure 26. Once this set point is compared to the actual rail pressure a PID controller is used to adjust a metering valve in the high pressure pump. This strategy differs slightly from the OEM Bosch ECU which also dynamically controls the high pressure valve (bleed valve) on the rail. The Drivven engine controller relies on an operator fixed value of the high pressure valve only limiting the maximum at which it can be set. In addition to this user control, the operator can fix a specific position on the high pressure pump metering valve or simply input a manual rail pressure set point for the PID controller to obtain. 


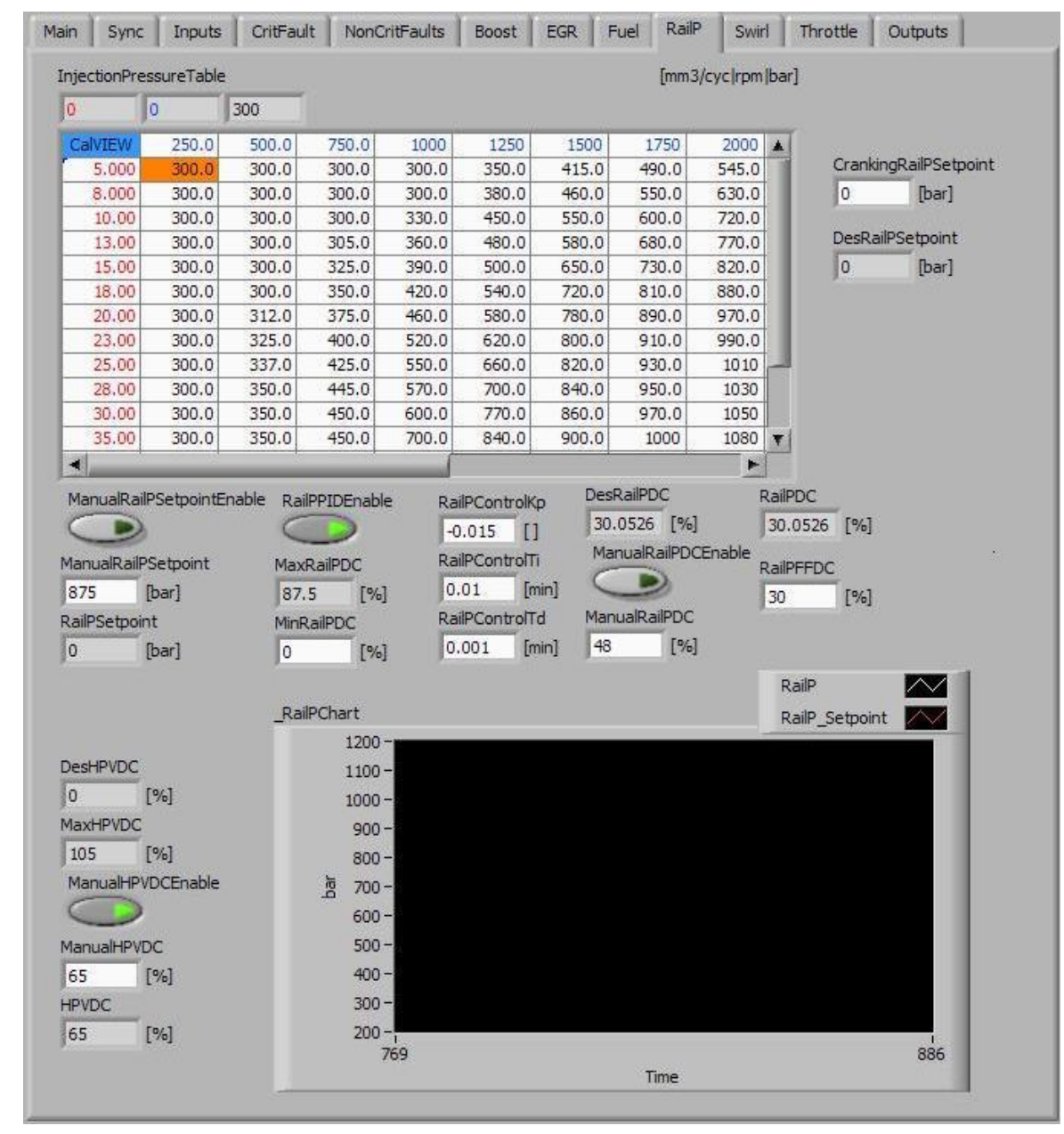

Figure 26: Drivven CalVIEW RailP Tab

Other tabs with less significance to the dynamic operation of the Drivven controller are Swirl, Throttle, and Outputs. The single overhead camshaft Z19DT does not use swirl valves like its dual overhead camshaft variant, the Z19DTH. A throttle valve controls fresh air flow at the inlet to the intake manifold, before the EGR valve. This throttle valve has no automated control programmed with the Drivven controller, but can be controlled manually by the operator. The OEM Bosch ECU closes this valve partially at low speeds to limit air flow and regulate EGR. Inside the Outputs tab are switches to activate the various engine systems described in 3.2 as well as port fuel injectors and the in-cylinder diesel injectors.

\subsection{Environment Conditioning}

In order to ensure repeatable engine testing environmental factors that an engine would normally experience must be replicated and held constant throughout the engine testing process. 
Related to this research these factors include engine air intake temperature and humidity, fuel temperature, and coolant temperature. In addition to concerns over repeatability, alternative engine cooling systems must also be employed to ensure durability while an engine is tested on a dynamometer.

\subsubsection{Engine Intake Air Temperature and Humidity}

As dictated by the Title 40 Code of Federal Regulations (CFR) Part 1065 Subpart B the engine intake air temperature is conditioned to $25^{\circ} \mathrm{C} \pm 5{ }^{\circ} \mathrm{C}$. This set point demonstrates a real world intake air temperature as well as ensuring minimal variance between test runs. The WVU EERL utilizes an air handling system to control and keep the intake air temperature within specifications. This system doubles as the supply of dilution air for the CVS dilution tunnel. During hot and humid days, outside air is drawn into the system and passes through two air conditioning systems. These systems remove the majority of the moisture out of the air and also significantly drop the temperature. A temperature controller box then measures the air temperature and controls a steam valve used to inject steam into a heat exchanger until the air temperature is within specification. Additional steam valves at the air handling unit and intake air plenum allow for further control of intake air temperature and humidity, especially during winter months when the ambient temperature and humidity are low. The relative humidity is targeted at 50 percent to obtain a $\mathrm{NO}_{\mathrm{x}}$ correction factor close to one as defined by the Title 40 CFR Part 1065 Subpart G.

\subsubsection{Engine Cooling System}

The GM Z19DT test engine utilized in this study was originally manufactured for a European passenger vehicle. It featured an air to liquid (ethylene glycol coolant) heat exchanger (radiator) cooling system which air passes over when the vehicle is at speed, or fans "push" or "pull" air over when the vehicle is sitting idle. In a laboratory environment where the engine remains stationary while being tested on a dynamometer, there is no forced air flow due to a vehicle's speed to cool the engine especially at high load conditions. To remedy this issue' as well as narrow the engine coolant temperature fluctuation' two liquid to liquid heat exchangers are used. The first heat exchanger is a long tube unit which has engine coolant and house water (primary cooling water) traveling through its separate passages. This water then flows through a flat plate heat exchanger. The opposing passage of the flat plate heat exchanger is controlled by 
a temperature controller. This temperature controller regulates hot or cold water valves depending on the set point and temperature of the primary cooling water. The primary cooling water then flows into a large tank where a pump propels the water back to the long tube heat exchanger.

\subsubsection{Fuel Conditioning System}

The temperature at which fuel is delivered can become elevated especially after a long day of testing if no temperature control apparatus is employed. The test engine utilizes a return fuel system to bleed off unused fuel from the common rail fuel injection system. Some of this fuel is highly pressurized increasing its temperature and also passes through fueling components with increased temperatures. The result is fuel at a greater temperature returned to the tank increases the overall temperature of the fuel in that tank. The solution to this problem is a flat plat heat exchanger system that has the capability to cool or heat the fuel. A temperature controller regulates valves that allow hot or cold house water to pass through the heat exchanger regulating the temperature of the fuel input into the engine. The target fuel temperature at the inlet to the engine for this study was $34^{\circ} \mathrm{C}$.

\subsection{Performance and Environmental Conditions Measurement}

Various measurements throughout the lab are required for control of environment systems, test and data validation, and engine performance calculations. Many of these measurement devices are simple pieces of equipment while others are complex systems comprised of multiple pieces of equipment. In certain situations where similar equipment from different manufacturers exists, the measurement principle presented is a general description.

\subsubsection{Temperature}

Omega K type thermocouples are the most commonly used temperature sensor throughout the EERL. The actual element performing the temperature measurement is a joint of two different metals which produces a voltage relative to temperature when heated. $\mathrm{K}$ type thermocouples are the EERLs most popular temperature measurement device due to their relatively low costs, easy installation, and wide temperature range $\left(-200{ }^{\circ} \mathrm{C}\right.$ to $\left.1250{ }^{\circ} \mathrm{C}\right)$. For conditions where accuracy, stability, repeatability, and relative immunity to electrical noise are important a Resistance Temperature Detector (RTD) is employed. RTDs use a single pure 
material normally coiled around a ceramic or glass core [29]. Similar to a thermocouple, as the temperature of this material changes, its resistance changes providing a correlation between resistance and temperature. RTDs are used in the CVS system to provide quick and precise temperature measurements for air flow calculation and control.

\subsubsection{Pressure}

Pressure transducers provide an automated method of pressure measurement that can be digitalized through a data acquisition system. The EERL employs absolute and differential pressure transducers where any dynamic pressure measurement is necessary. Applications of absolute pressure transducers are normally instances where less precise, but a wide operating range is necessary such as intake manifold pressure. Differential pressure transducers, as the name implies are capable of measuring small to large pressure differences such as the pressure across a flow measurement device. Another application of differential pressure transducers is to vent one port to atmosphere and connect the other port where a precise relatively low vacuum or pressure measurement is necessary. Several different manufacturers and models of pressure transducers are used in the EERL, but all work on a similar principle utilizing a diaphragm that deflects against a strain gauge providing an output that can be linearly correlated to pressure.

\subsubsection{Intake Air Flow}

Measurement of the test engine's intake air flow is performed by a NIST (National Institute of Standards and Technology) traceable laminar flow element (LFE). An LFE utilizes a multitude of internal flow straighteners (multiple parallel tubes) to eliminate any turbulent flow. An absolute pressure transducer positioned before and differential pressure transducer positioned across the flow straightening mechanism provides the measurements necessary to calculate the flow of air passing through the LFE. Included with the LFE is the NIST traceable calibration curve that provides a volumetric flow rate of air when the pressures are input. For the test engine a 4 inch Meriam Instrument 50MC2-4 LFE measures intake air flow up to 386.13 SCFM at a differential pressure of nine inches of water.

\subsubsection{Humidity}

Humidity measurements of the intake air and dilution air (for the CVS system) are provided by hygrometers. The primary hygrometers used for the 2007 tunnel and engine testing 
system are General Eastern Chilled Mirror hygrometers model Dew 10-2A1. Two units are utilized and placed sufficiently downstream of the steam injection points. Each unit reports the dew point temperature of the air flowing through a duct. Utilizing dew point temperature of the air, the saturation vapor pressure of the air and subsequently the absolute humidity can be calculated. The chilled mirror hygrometer employs a metallic mirror that is chilled using a "solid state heat pump" to measure the dew point temperature of the surrounding air [30]. When the dew point temperature is reached a film of condensation forms on the mirror that is optically detected. The temperature of the mirror is measured by a platinum RTD and the solid state heat pump is controlled with a PID controller to retain a film of moisture on the mirror. An Edgetech Dewprime II hygrometer operating on the same principle is also placed in the intake air plenum to verify the GE chilled mirror hygrometer measurement.

\subsubsection{Data Acquisition}

The 2007 engine testing system, based on the Title 40 CFR Part 1065, utilizes two National Instruments SCXI 1001 chassis with removable modules for a wide variety of signal input and output configurations. Signals are input to the modules residing in the SCXI 1001 chassis, conditioned and then travel to the data acquisition (DAQ) computer through a NI PCI 6052E card. A program written in Microsoft Visual Basic (VB) by members of CAFEE faculty, staff and students then acquires these signals. Besides data collection and processing, the CAFEE laboratory program also controls many aspects of the lab including the CVS tunnel flow, PM sampling system, gaseous emissions sampling systems, engine throttle (pedal position), and the engine dynamometers. The engine dynamometers operate in speed mode, more specifically the dynamometer controller will hold an input speed, while the CAFEE laboratory program uses engine throttle to achieve a given torque. After an engine test has been performed, the CAFEE laboratory program post-processes the data, and saves a report which among many parameters includes brake specific and mass rate emissions values and averaged performance data.

\subsubsection{Fuel Consumption}

Three methods of fuel consumption measurement were applied for this research. An Ohaus CD-11 scale with a resolution of five grams was utilized for a gravimetric based measurement. Due the test engine's relatively small displacement and limited fuel consumption a better scale resolution would have been desirable, but five grams was finest resolution 
achievable with that scale. Fuel consumption can also be calculated through an emissions based carbon recovery method. The carbon balance determines fuel consumption from carbon and hydrogen based emissions species concentrations, fuel properties and exhaust flow. A final method of fuel consumption calculation is from the Drivven controller software. If the engine is operating at a semi steady state, the volume of fuel injected for each cycle can be used in conjunction with engine speed and specific gravity of the fuel to calculate fuel mass flow rate and consumption.

\subsubsection{Engine Speed and Torque}

Engine speed is measured and reported to the DAQ system by a BEI optical shaft encoder. This encoder is actually mounted on the opposite side of the dynamometer as the engine, but in the absence of a gear train it represents actual engine speed. Engine torque is measured by a strain gage connected to a moment arm attached to the dynamometers electrical windings. As more torque is produced the moment arm deflects and the strain gage is compressed. The inertia of the dynamometer is also taken into consideration for the engine torque measurement, but should be insignificant at steady state operation.

\subsection{Emissions Measurement}

An important indicator of advanced combustion is an engine's emissions. Through advanced combustion methods, achievement of very low emissions is possible and therefore a laboratory's emissions measurement devices must be extremely precise, reliable, and contain as little error as possible. The WVU EERL implements a multitude of emissions measurement devices, all of which are calibrated and serviced to provide the most accurate measurements possible. Table 2 provides a short summary of the emissions measurement devices in use for this research. 
Table 2: Emissions Measurement Devices

\begin{tabular}{|c|c|c|}
\hline Location & Emissions Species & Measurment Device \\
\hline \multirow{9}{*}{ 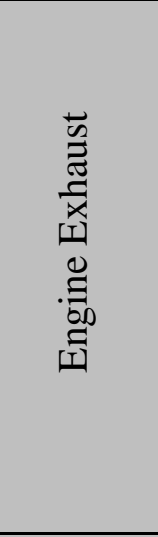 } & $\mathrm{CO}^{*}$ & Mexa 7200D NDIR \\
\hline & $\mathrm{CO}_{2 *}$ & Mexa 7200D NDIR \\
\hline & $\mathrm{NO}_{\mathrm{x}} *$ & Mexa 7200D Hot CLD \\
\hline & $\mathrm{NO}^{*}$ & Mexa 7200D Cold CLD \\
\hline & THC* & Mexa 7200D FID 1 \\
\hline & $\mathrm{CH}_{4} *$ & Mexa 7200D FID 2 \\
\hline & $\mathrm{O}_{2}$ & Mexa $720 \mathrm{ZrO}_{2}$ \\
\hline & $\mathrm{PM}^{*}$ & WVU Gravimetric Collection System \\
\hline & Soot & AVL 483 Micro Soot Sensor \\
\hline \multirow{3}{*}{ 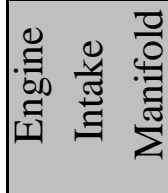 } & $\mathrm{CO}_{2}$ & Horiba NDIR \\
\hline & $\mathrm{O}_{2}$ & Mexa $720 \mathrm{ZrO}_{2}$ \\
\hline & $\mathrm{O}_{2}$ & Rosemont 755R Paramagnetic \\
\hline
\end{tabular}

* Measurement sample taken from CVS tunnel after exhaust gas has been diluted.

\subsubsection{Constant Volume Sampling System}

An integral part of the EERL emissions measurement system is the constant volume sampling system. In order to more closely replicate emissions formation in the real world environment a dilution tunnel is used. After exiting the engine, exhaust gases travel through exhaust pipes and into the dilution tunnel. As the exhaust gas enters the dilution tunnel it mixes with conditioned air. This conditioned air is from the same source as the engine intake air as described in Section 3.4.1, but before entering the CVS tunnel it passes through a series of high efficiency particulate air (HEPA) filters. After a length deemed sufficient for mixing (approximately $20 \mathrm{ft}$ for a 20 inch diameter tunnel), samples of the diluted exhaust gas are pulled for gaseous and PM emissions measurement. To normalize and quantify these emissions concentrations the tunnel flow rate must be calculated. A subsonic venturi (SSV) manufactured by Flow Dyne Engineering measures the tunnel flow rate with the assistance of an RTD, differential and absolute pressure transducer. This SSV has an upstream diameter of 4.87 inches and throat diameter of 3.65 inches, with an acceptable measurement range of 200 SCFM to 1000 SCFM verified by propane injection and recovery as defined by the Title 40 CFR Part 1065 Subpart D. A Cincinnati Fan RBE-19 blower draws air flow through the entire CVS system. Utilizing a desired flow rate, input by the operator, a PID controller commands the blower to 
match the desired flow rate to a calculated flow rate obtained through pressure measurements taken on the SSV.

\subsubsection{Gaseous Emissions Measurement}

Gaseous emissions measured and recorded during this experiment include total hydrocarbons, methane, oxides of nitrogen, nitric oxide, oxygen, carbon monoxide and carbon dioxide. Gaseous emissions measurements are performed on the diluted exhaust gases in the CVS system, raw exhaust gases, and gases in the intake manifold by several separate analyzers.

\subsubsection{MEXA 7200D}

Dilute exhaust emissions sampled from WVU's CVS system are analyzed by a Horiba MEXA 7200D. The MEXA 7200D contains several gaseous analyzers and accompanying equipment necessary to perform gaseous emissions measurements, analyzer calibrations and verifications.

A sample handling system (SHS) pumps sample exhaust gas from the CVS system through a heated filter and heated line. The SHS also contains an internal oil catcher, filter and dehumidifier (chiller) to remove water vapor for dry measurements. Heated analyzers reside in a separate rack know as the OVN which contains its own sample handling system similar to the SHS. The OVN provides a heated environment greater than the samples dew point temperature to ensure condensation does not occur inside the analyzers. A solenoid valve unit (SVS) is employed to provide zero, span, or sample gas to the analyzers. For linearizations and converter checks, an internal fully automated gas divider resides in the main MEXA rack.

Total hydrocarbon and methane concentrations are measured through the use of two flame ionization detector (FID) analyzers located in the OVN. The primary hydrocarbon analyzer is a FIA-725A capable of only measuring total hydrocarbon concentration, while the secondary FID, a FIA-721A is capable of measuring total hydrocarbon or methane concentration. Both analyzers employ the same FID measurement strategy, in which a sample is introduced to a hydrogen fuel flame. As the hydrocarbon species in the sample enter the flame, they burn and release ions. This release of ions is linearly proportional to the amount of carbon atoms in the sample. Two electrodes reside on either side of the flame and collect these ions; when a voltage is applied the ions result in an increased current corresponding to a carbon atom measurement [31]. Measurement of methane is also performed using the FID principle, but the sample is 
diverted through a non methane cutter before entering the measurement chamber. The non methane cutter is a catalyst that oxidizes non methane hydrocarbon species.

Oxides of nitrogen are quantitatively determined through the use of chemiluminescence detection (CLD). The MEXA 7200D utilizes two CLD analyzers, a hot $\mathrm{NO}_{\mathrm{x}} / \mathrm{NO}$ analyzer residing in the $\mathrm{OVN}$, and a cold $\mathrm{NO}_{\mathrm{x}} / \mathrm{NO}$ analyzer located in the main analyzer rack (ANR). As a rule of practice, the hot CLD analyzer measures $\mathrm{NO}_{\mathrm{x}}$ while the cold CLD analyzer measures only NO. The principle behind this practice lies in the solubility of $\mathrm{NO}_{2}$ in water. If the sample temperature is not held above its dew point temperature before passing through the converter (described later in this paragraph) $\mathrm{NO}_{2}$ will dissolve in condensate. The removal of water by the chiller also removes the dissolved $\mathrm{NO}_{2}$ from the sample, but since the measured species is only $\mathrm{NO}$ this loss of $\mathrm{NO}_{2}$ is irrelevant. Additionally any CLD analyzer only measures $\mathrm{NO}$ with the assistance of an ozone $\left(\mathrm{O}_{3}\right)$ generator. When $\mathrm{O}_{3}$ and $\mathrm{NO}$ react the $\mathrm{NO}$ is oxidized and transformed to $\mathrm{NO}_{2}$ [32]. A portion of the $\mathrm{NO}_{2}$ is in an excited state $\left(\mathrm{NO}_{2}\right.$ existing previously in the sample is not excited, nor becomes excited when mixed with $\mathrm{O}_{3}$ ) and emits energy through light. The measurement of this light is directly proportional to the concentration of NO in a sample. Measurement of the total oxides of nitrogen is performed through the use of a $\mathrm{NO}_{\mathrm{x}}$ converter. The $\mathrm{NO}_{\mathrm{x}}$ converter is a primarily carbon based catalyst which reacts with $\mathrm{NO}_{2}$ to form NO. Once the sample is comprised solely of NO, it's measurement by the CLD analyzer represents the total oxides of nitrogen in the sample.

Measurement of carbon dioxide and carbon monoxide concentrations are attained from a duo of non dispersive infrared (NDIR) analyzers. An AIA721-A NDIR analyzer handles CO concentrations less than 5000 ppm, while an AIA722 measures higher $\mathrm{CO}$ and $\mathrm{CO}_{2}$ concentrations. A NDIR analyzer is capable of measuring multiple species of gas through the theory that different gas species "absorb infrared energy at specific wavelengths and that the degree of absorption is proportional to the concentration at constant pressure" [33]. The measurement chamber of the NDIR analyzer consist of two cells each utilizing an infrared beam of appropriate wavelength (matched to the species of gas to be measured). A flexible membrane separates the two cells; the sample gas resides on one side, while an infrared neutral gas resides on the other. Each gas absorbs heat from the infrared beam and expands, as the concentration of the measured species increases more heat is absorbed and the pressure of the cell increases. This 
results in a displacement of the flexible membrane which can be detected electrically and correlated to a concentration [33].

\subsubsection{Horiba AIA-210}

The primary method of determining EGR fraction relies partly on a raw $\mathrm{CO}_{2}$ sampling system which is part of CAFEE's modular emissions testing system. This $\mathrm{CO}_{2}$ analyzer and accompanying equipment are plumbed into the engine's intake manifold. Although a sample of gas is pulled from the intake manifold possibly affecting other measurements, the portion of flow removed is less than 1 percent of the total flow in the intake manifold and is considered negligible. A pressure regulator and one way bypass valve in series with the heated sample line ensure that the analyzer only samples intake manifold gases and its measurement cell does not become over pressurized at high intake manifold pressures. Upon entering the $\mathrm{CO}_{2}$ sampling system, the sample is drawn through a heated filter by a heated pump. After passing through a rotameter to regulate flow the sample gas' $\mathrm{CO}_{2}$ concentration is measured by a Horiba AIA-210 nondispersive infrared analyzer. The operating principle behind the Horiba AIA-210 NDIR is the same as that listed in Section 3.6.2.1. Utilizing the intake $\mathrm{CO}_{2}$ concentration provided and dividing by the raw exhaust $\mathrm{CO}_{2}$ concentration (calculated from exhaust flow and diluted exhaust emissions measurement), a relatively accurate EGR fraction can be determined under steady state conditions.

\subsubsection{MEXA 720}

Intake manifold and raw exhaust oxygen concentrations are measured by a MEXA-720 analyzer. Through the use of a heated zirconium oxide sensor the MEXA-720 can provide $\mathrm{O}_{2}$ and $\mathrm{NO}_{\mathrm{x}}$ concentrations as well as air to fuel and lambda measurements. Zirconium oxide is a ceramic with excellent oxygen ion conduction properties especially under high temperatures [34]. In the presence of increased or decreased $\mathrm{O}_{2}$ concentration the current passing through the ceramic element changes due the varying attraction of oxygen ions. This change in current is linearly proportional to the oxygen concentration of the sample. During this experiment the measured intake and exhaust oxygen concentrations were used as a secondary EGR fraction calculation. 


\subsubsection{Rosemont 755R}

A secondary measurement of intake manifold $\mathrm{O}_{2}$ concentration is provided by a Rosemount 755R paramagnetic oxygen analyzer. This analyzer shares sample conditioning, flow and pressure regulating equipment located in the $\mathrm{CO}_{2}$ sampling system described in Section 3.6.2.2. The principle of operation for the Rosemont 755R analyzer relies on oxygen's high paramagnetic susceptibility in comparison with other gas species [35]. Internally the 755R contains a magnet that exhibits a non-uniform magnetic field. Located in the middle of this magnetic field is a test body located on a platinum suspension in which sample gas flows across [35]. Depending on the paramagnetic value of the gas (gas more paramagnetic than the test body results in an attraction of the test body by the magnetic field, vice versa for gas less paramagnetic than the test body) the test body, containing a mirror with photocells, rotates in its suspended plane. A light source is focused directly on the photocells when the magnetic force is neutral; as the test body rotates a variation in current between the photocells provides a linear correlation between magnetic force and feedback current. Through calibration this feedback current can then be associated with an accurate oxygen concentration.

\subsubsection{Background Gaseous Emissions Measurement}

In order to compensate for background emissions concentrations, conditioned air (prior to entering the dilution tunnel) is pumped into a Tedlar@ bag during gaseous emissions sampling. A valve and pump system controlled by the CAFEE laboratory program through NI hardware transfers this stored background sample to the MEXA 7200D for analysis after an engine test has been completed. The background emissions concentrations are then utilized in calculation of mass and brake specific emissions.

\subsubsection{Particulate Matter and Soot Emissions Measurement}

The Title 40 CFR Part 1065 classifies particulate matter as any mass collected on a filter through an emissions sampling system outlined as well in Part 1065. For certification of an engine, fuel, or after treatment device this gravimetric method is the sole method accepted. Most if not all previous advanced combustion studies rely on an optical or photo acoustic method of measuring PM or soot. In this experiment both a gravimetric PM sampling system and a photo acoustic soot sensor were used to evaluate PM emissions. 


\subsubsection{Gravimetric PM Sample Measurement}

Collection of a gravimetric PM sample is performed with a heated PM "box" located in the EERL. A dilute exhaust gas sample is drawn from the CVS system and mixed with additional secondary dilution air if necessary. The sample then passes through a one inch heated line serving as the secondary dilution tunnel and into a URG cyclone particle separator. As the sample passes into the side of the cyclone, a circular motion of the gas separates particles larger than 2.5 micrometers (dependent on flow rate) which fall into a catcher, while allowing finer particles to flow out through the top of the cyclone. The refined sample then enters a URG filter holder, containing a Pall Life Sciences TX40 filter element. Ideally any particulate matter is deposited on the TX40 filter. A Sierra mass flow controller dictates and records the mass flow rate through the PM measurement system. Once the test is completed the TX40 filter element is then transferred to a class 1000 clean room. After conditioning at an approximate ambient air temperature of $22{ }^{\circ} \mathrm{C}$ and a dew point temperature of $9.5^{\circ} \mathrm{C}$ for at least an hour the filter can be weighed to produce a net weight. Weighing is performed by a Satorius SE-2F microbalance controlled and recorded through another proprietary CAFEE program. Utilizing dilution ratios, flow and other laboratory measurements as well as the net weight of PM deposited on the filter, a mass rate and brake specific PM emissions calculation can be performed.

\subsubsection{AVL 483 Micro Soot Sensor}

Soot concentration of raw exhaust gases are measured with the use of an AVL 483 Micro Soot Sensor. The AVL 483 employs a photo acoustic method to measure and quantify soot concentration. In a measurement chamber, an exhaust sample enters containing soot particles and is exposed to a modulated laser beam [36]. The heat transfer from the laser beam to the sample results in an expansion and contraction of the sample gas, producing a sound wave that can be measured with a highly precise microphone. The frequency of the sound wave measured with the microphone is proportional to the soot concentration of the sample. A drawback of this measurement strategy is the window in which the modulated laser beam passes through can become polluted decreasing the intensity of the laser beam and ultimately skewing the measurement. To compensate for degrading light source intensity, the micro soot sensor is zeroed with dilution air between measurements, and the measurement chamber is periodically cleaned. 


\subsection{Combustion Analysis}

In-cylinder combustion analysis is performed with the aid of a system originally designed and constructed by Dr. John Nuszkowski of West Virginia University. Kistler piezoelectric pressure sensors perform the actual in-cylinder measurement. The pressure sensors are installed into adapters which replace the engine's glow plugs. A charge in coulombs corresponding to a pressure is output from the pressure transducers to a Kistler charge amplifier type 5010. The signal is amplified and related to a voltage, then output to a national instruments SCB-68 DAQ card. In addition to pressure, a BEI shaft encoder measures engine speed at the crankshaft pulley on the front of the engine and transmits it to the NI DAQ card. Intake and exhaust temperature is also measured for the combustion analysis via thermocouples and input into the NI DAQ card. A PCI-6250 card conveys the analog signals into an analysis PC.

A Matlab based program written by Dr. Nuszkowski obtains, interprets and operates on the data to provide combustion analysis information. Employing various assumptions, the ideal gas law, and the first law of thermodynamics as well as engine geometry and specifications, combustion parameters such as in-cylinder pressure, in-cylinder temperature, finite heat release, and mass fraction burned are calculated. From this data other parameters such as pressure rise rate, combustion duration, maximum burn rate, 50 percent mass fraction burned, etc. can be determined. 


\section{Discussion of Results}

\subsection{Introduction}

A single and a split fuel injection strategy was employed to determine the effects of fuel injection and EGR configuration on advanced combustion. A total of four fuels were tested during the exploration of these strategies, yet for some experiments only certain fuels were utilized. Initially the single injection strategy was implemented for advanced combustion exploration. SOI timing and EGR fraction were investigated for the shakedown fuel and FACE 1. Additionally, FACE 6 was tested at a lower engine speed and BMEP with varying EGR fraction. As a result of intense PRR, $\mathrm{HC}$ emissions, and $\mathrm{CO}$ emissions the split injection strategy was developed. All fuels were tested during the exploration of this strategy. An optimal condition determined through the operation with the shakedown fuel was deemed the base configuration from which all other fuels would begin initial testing. From this configuration, SOI timing sweeps, rail pressure sweeps, and fuel split sweeps were performed for select fuels.

\subsection{Summary of Fuel Properties}

Described in Section 2.3 the FACE matrix of fuels was designed to exploit the effects of three designated properties on advanced combustion strategies. Two of these FACE fuels have been tested along with a certification ULSD and a commercially available ULSD. Known properties of these fuels are compiled in Table 3. The first fuel coined the shakedown fuel is a commercially available ULSD provided by the Guttman Oil Company. Unfortunately a detailed analysis of this fuel is unavailable, but it is manufactured to the specifications listed for number two diesel with a sulfur content of less than 15 ppm (No. 2-D S15) in the ASTM D975-10b document [36]. Where applicable this document provides a minimum, maximum, or range of acceptable measurements for a given property. It is known that this fuel was blended for colder weather, probably more closely resembling a number one diesel (1-D), but still adhering to the standards of 2-D ULSD. The low specific gravity confirms this assumption, and from previous analyses of Guttman diesel it is estimated that the cetane number is likely 50 or above. A study involving local fuels by Gibble [24] provided an analysis of Guttman diesel fuel with a specific gravity of .81 (very similar to the fuel under consideration) and a cetane number of 58.4. Other analyses, both with less than $15 \mathrm{ppm}$ sulfur and adhering to 2007 plus fuel standards are located 
in the Appendices. Each of these analyses displays a low specific gravity and a cetane number greater than 56. While the absence of a true analysis is not ideal, the information in Table 3 and assumptions made from previous analyses can aid in quantifying the effects of this fuel in regards to others tested.

A Chevron Phillips Chemical Company Certification ULSD deemed the check fuel was used to establish another baseline and expose any degradation of the engine after operation with fuels comprising the FACE matrix. A detailed analysis of this fuel was provided and is included in the Appendices. Experiments have also been performed with FACE 1 and FACE 6. FACE 1 was designed to have a low cetane number, low aromatic content, and a low 90 percent distillation temperature. FACE 6 exhibits a high cetane number, low aromatic content, and a high 90 percent distillation temperature. Other properties listed in Table 3 help to compare the FACE fuels against each other and conventional fuels. Specific gravity of the check fuel and FACE 6 are significantly greater than that of FACE 1. Additionally the T90 distillation temperature of FACE 1 is lower than all other fuels. Sulfur content of all the fuels is below the 2007 standard, and the net heat of combustion is relatively similar for the fuels listed. The ASTM method for which each property was measured is located in the Appendices in Table 5.

Table 3: Fuel Properties

\begin{tabular}{|c|c|c|c|c|c|c|c|}
\hline Fuel & $\begin{array}{c}\text { Cetane } \\
\text { Number }\end{array}$ & $\begin{array}{c}\text { Aromatics } \\
(\text { Volume \% })\end{array}$ & $\begin{array}{c}\text { T 90 } \\
\text { Distillation } \\
\text { Temperature } \\
\left({ }^{\circ} \text { C }\right)\end{array}$ & $\begin{array}{c}\text { Specific } \\
\text { Gravity }\end{array}$ & $\begin{array}{c}\text { Flash Point } \\
\left({ }^{\circ} \mathrm{C}\right)\end{array}$ & $\begin{array}{c}\text { Sulfur } \\
(\mathrm{ppm})\end{array}$ & $\begin{array}{c}\text { Net Heat of } \\
\text { Combustion } \\
(\mathrm{MJ} / \mathrm{kg})\end{array}$ \\
\hline Shakedown & $55^{\mathrm{c}}$ & $35^{\mathrm{b}}$ & $282-338$ & 0.8095 & $52^{\mathrm{a}}$ & $15^{\mathrm{a}}$ & $43.26^{\mathrm{d}}$ \\
\hline Check & 44 & 28.8 & 307 & 0.8496 & 70 & 8.4 & 42.86 \\
\hline FACE 1 & 30.3 & 23.5 & 274 & 0.8081 & 58.7 & 1.8 & 42.80 \\
\hline FACE 6 & 53.7 & 20.4 & 340 & 0.8411 & 74.4 & 8.2 & 42.80 \\
\hline
\end{tabular}

a) Minimum value allowed per ASTM regulation listed in the Appendices.

b) Maximum value allowed per ASTM regulation listed in the Appendices.

c) Based on previous analyses it is likely that the cetane number of the shakedown fuel is above 55 .

d) Based previous analyses it is expected that the shakedown fuel has a net heat of combustion close to $43.26 \mathrm{MJ} / \mathrm{kg}$.

Net heat of combustion presented in Table 3 is very similar for the check fuel, FACE 1 and FACE 6. Additionally the value presented for the shakedown fuel is an estimate, but ultimately unknown. Due to these circumstances brake thermal efficiency (BTE) is not 
presented in the following results; instead, as a measure of efficiency brake specific fuel consumption (BSFC) is presented. The following equation used for BTE demonstrates that with similar net heat of combustion values $\left(\mathrm{Q}_{\mathrm{HV}}\right)$, BTE will be an inverse of BSFC.

$$
B T E=\frac{1}{B S F C * Q_{H V}}[21]
$$

\subsection{Single Injection}

Conventional compression ignition engines, especially older mechanical fuel injection equipped models, commonly utilize a single injection event. Generally this injection event is performed relatively close to TDC, and almost without exception, advancing this injection event before TDC (to a specific threshold) results in an exponential increase in $\mathrm{NO}_{\mathrm{x}}$ and significantly greater pressure rise rates. Many studies of advanced combustion have explored the effects of advancing a single injection event beyond this threshold to achieve a more homogeneous air and fuel mixture to reduce $\mathrm{NO}_{\mathrm{x}}$ and $\mathrm{PM}$ emissions while retaining or even increasing efficiencies. Unless otherwise noted all experiments presented in this section were performed at an engine speed of 2100 RPM while targeting a BMEP of 3.5 bar.

\subsubsection{Initial Exploration of Single Injection Events}

In the initial stages of the CRC AVFL-16 project a single injection strategy was explored with the shakedown fuel in an attempt to achieve advanced combustion. Similar to other studies and the conventional wisdom on advanced SOI timing, an exponential increase in $\mathrm{NO}_{\mathrm{x}}$ emissions and pressure rise rates were observed. High EGR rates were implemented to reduce the increased $\mathrm{NO}_{\mathrm{x}}$ emissions and slow down pressure rise rates. Subsequently $\mathrm{HC}$ and $\mathrm{CO}$ emissions became significantly elevated. Single injection strategy tests presented were performed over two separate experiments. An enlarged EGR cooler was utilized during both experiments, but for the first test set the liquid to air heat exchanger was plumbed to house water while the second test set employs the engine coolant to cool the exhaust gas passing through the heat exchanger. This resulted in an average IMT of $37^{\circ} \mathrm{C}$ and $51^{\circ} \mathrm{C}$, respectively. The switch to engine coolant as the cooling fluid was performed to minimize variance in temperature which was an issue with the house water. 


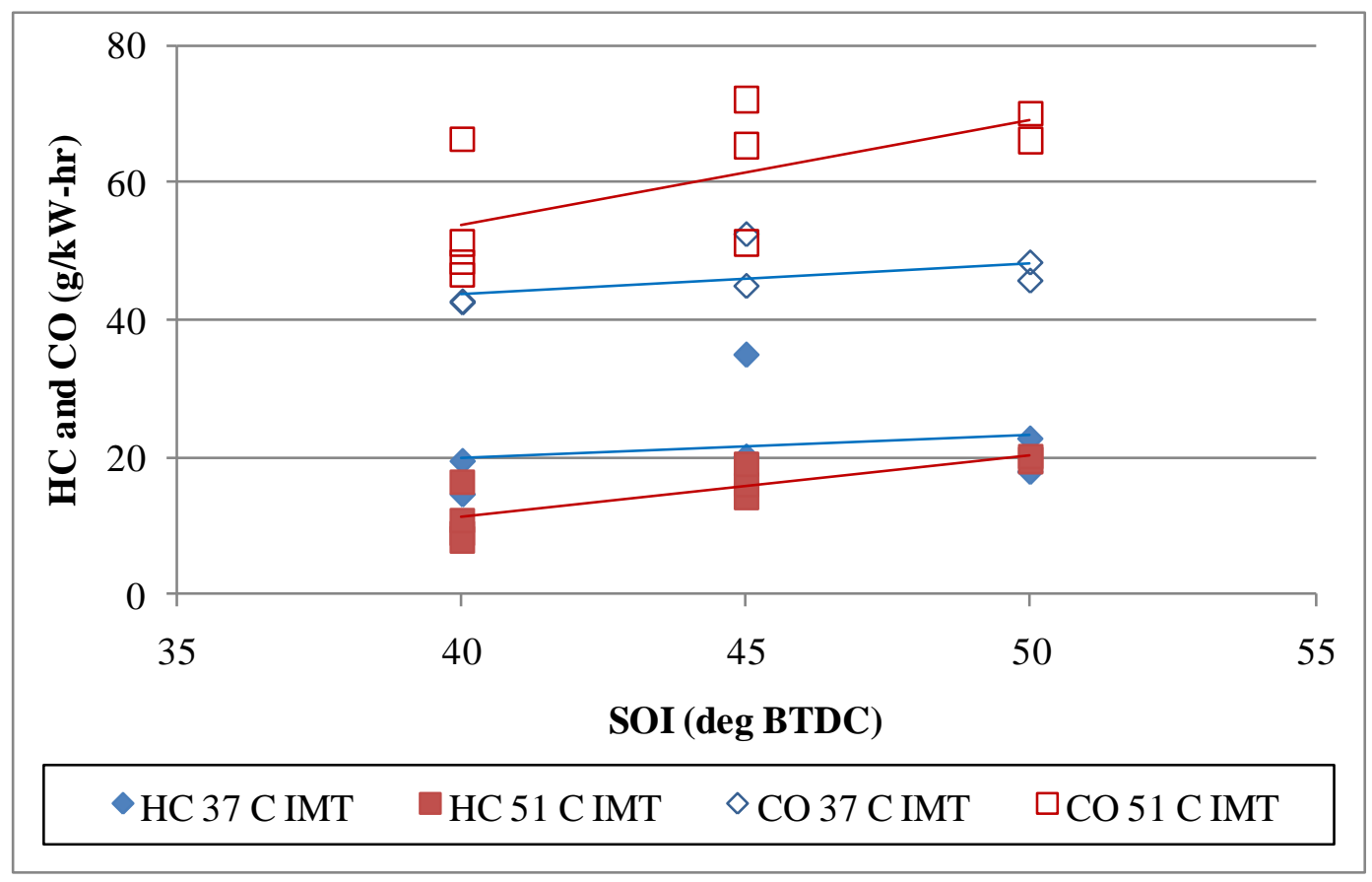

Figure 27: HC and CO Emissions as a Function of SOI Timing during Single Injection Operation for Two Different IMT

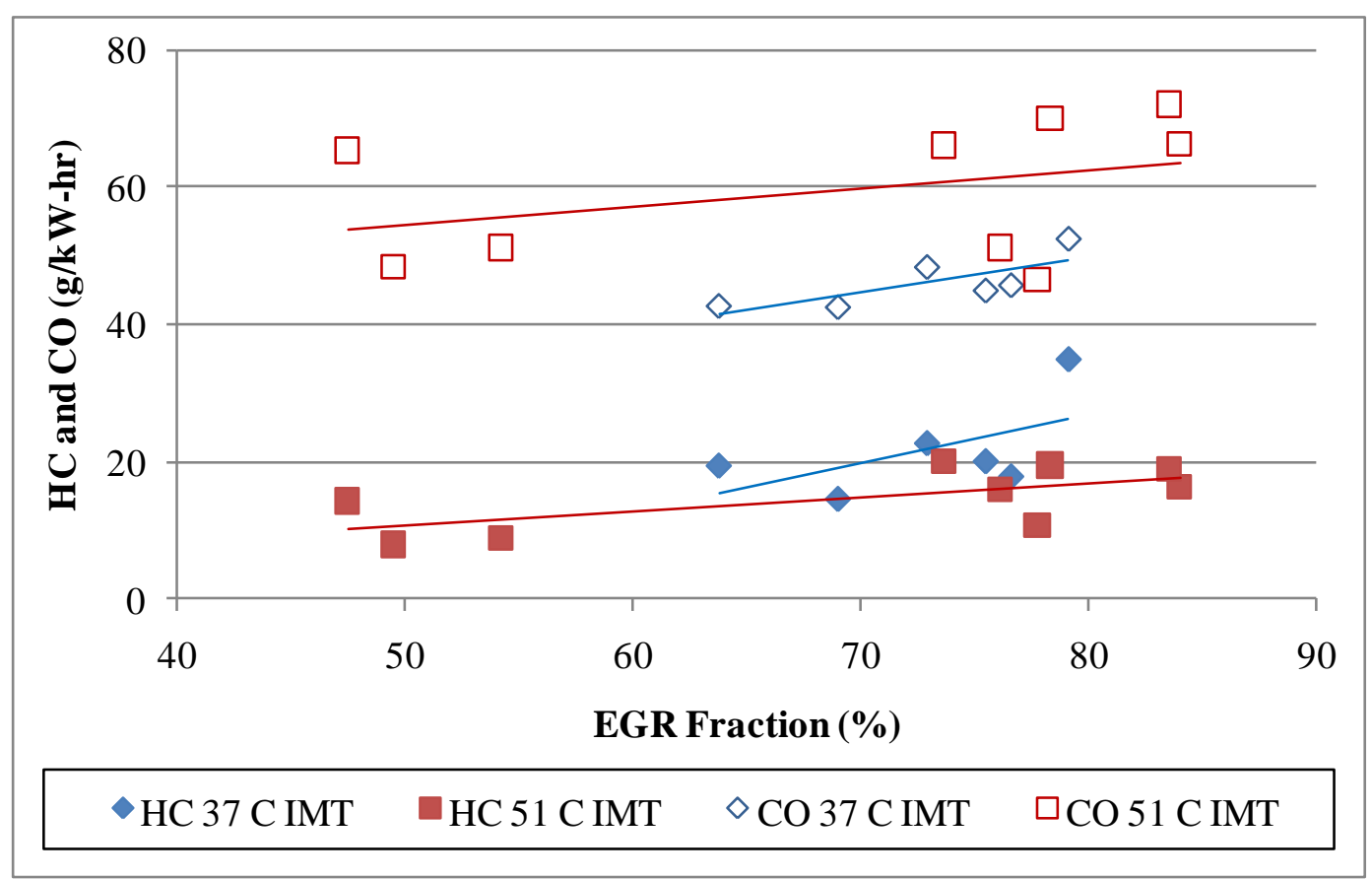

Figure 28: $\mathrm{HC}$ and CO Emissions as a Function of EGR Fraction during Single Injection Operation for Two Different IMT

SOI timing for tests presented in Figure 27 ranged from $40^{\circ}$, BTDC to $50^{\circ}$ BTDC in an increment of $5^{\circ}$. At the higher IMT, advanced SOI timing resulted in a trend of increasing CO 
and $\mathrm{HC}$ emissions. Lower IMT tests did not result in as significant of $\mathrm{HC}$ and $\mathrm{CO}$ emissions increases most likely due to erratic combustion dominating the level of HC emissions. Trends of increasing $\mathrm{CO}$ and $\mathrm{HC}$ emissions with greater EGR levels are expected and demonstrated in Figure 28, yet the trends are not as clear and concise of those displayed in Figure 27. Regardless of EGR fraction, the fuel injection spray angle and significantly advanced SOI timing contribute substantially to the $\mathrm{HC}$ and $\mathrm{CO}$ emissions. The spray angle of the stock fuel injectors is assumed to be $148^{\circ}$ through research of similar engine models produced by GM; with a cylinder bore of $82 \mathrm{~mm}$ and a stroke of $90.4 \mathrm{~mm}$ simple geometry dictates that at SOI timings greater than approximately $25^{\circ}$ the fuel jet greater than $43 \mathrm{~mm}$ in length will contact the cylinder wall. Even considering the height of the clearance volume, it is almost guaranteed that the spray angle and advanced SOI utilized resulted in wall wetting. This wall wetting condition creates locally rich zones near the cylinder walls further increasing $\mathrm{CO}$ and $\mathrm{HC}$ emissions.

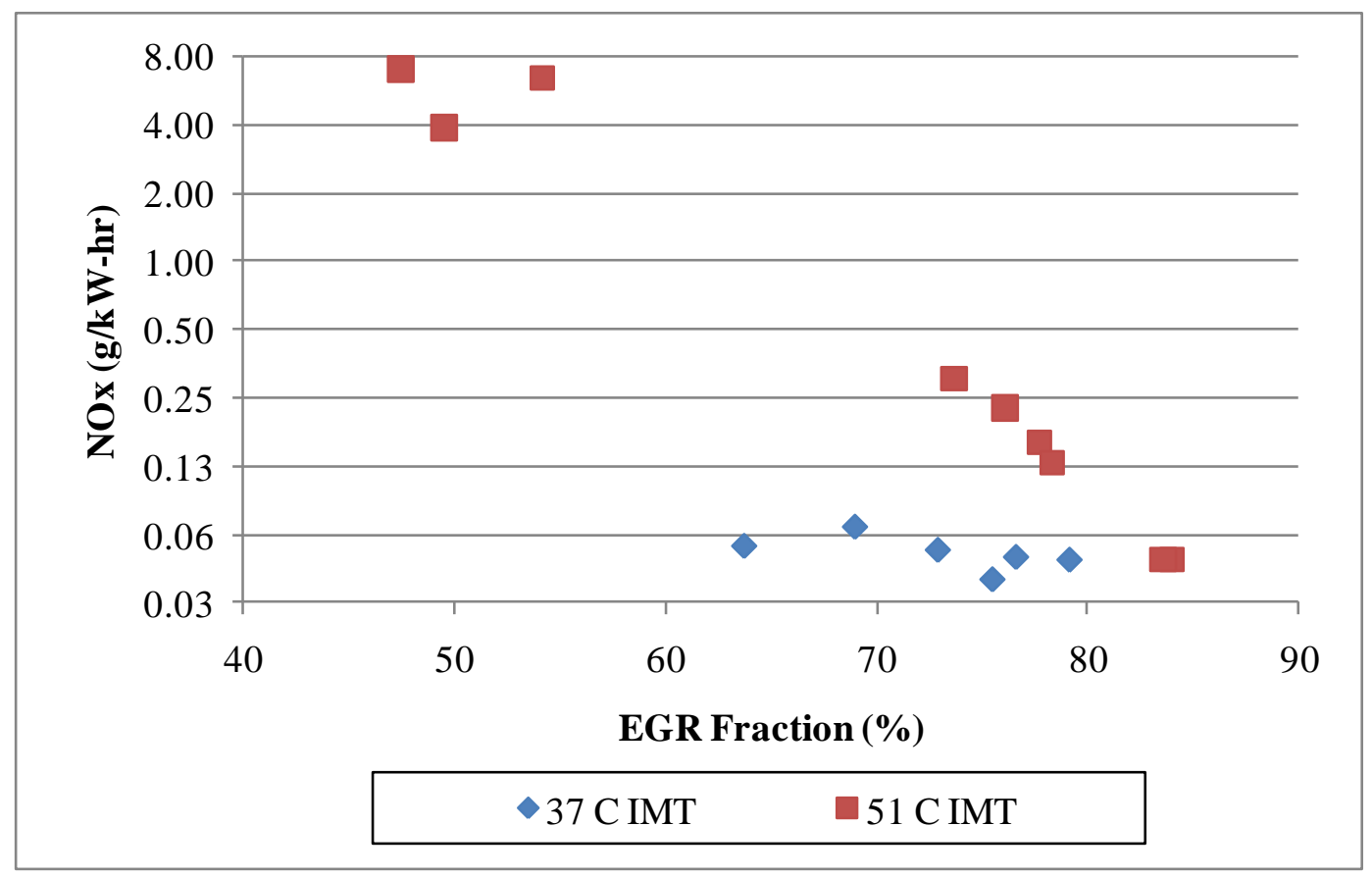

Figure 29: $\mathrm{NO}_{\mathrm{x}}$ Emissions during Single Injection Operation 


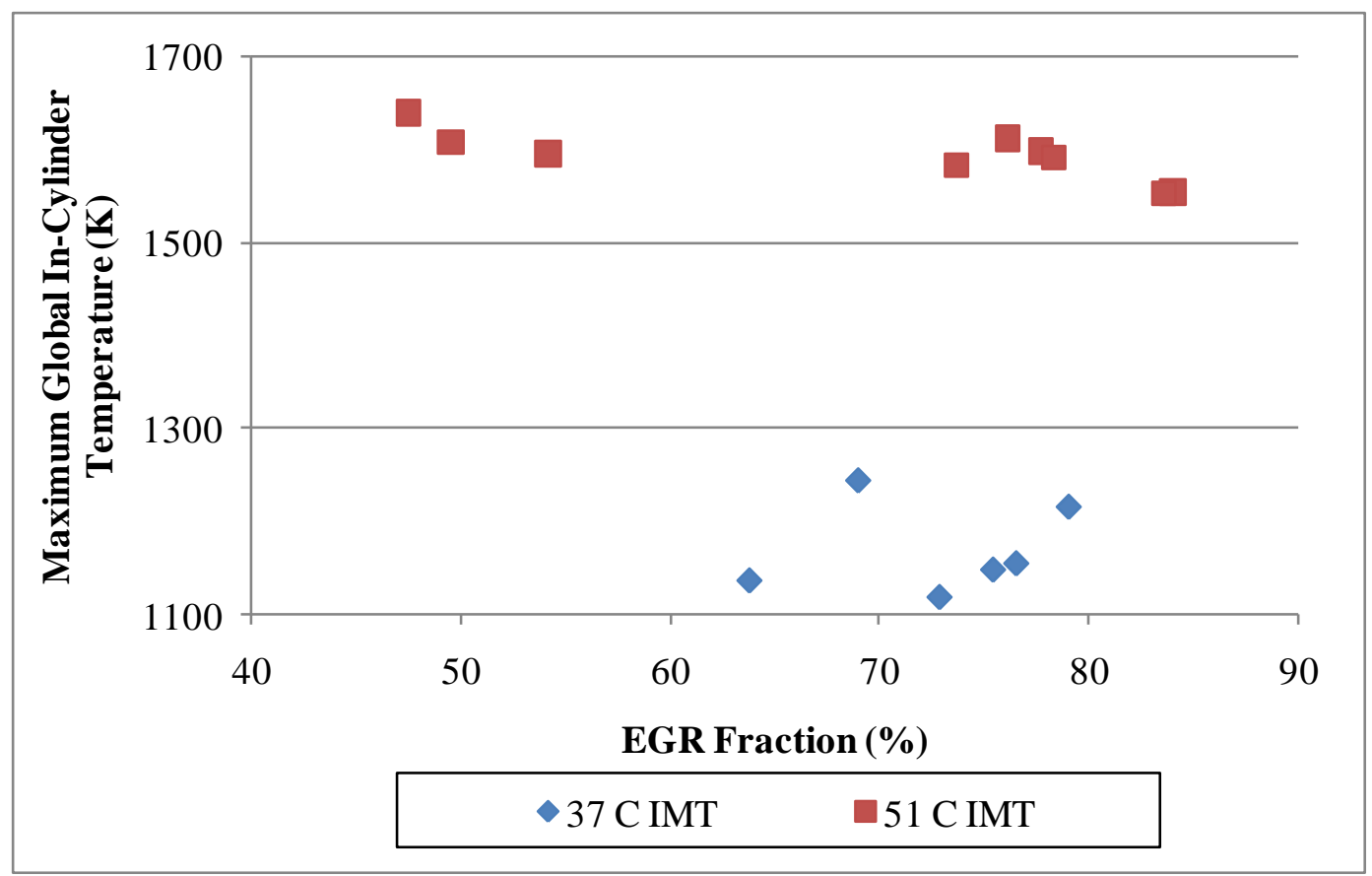

Figure 30: Maximum In-Cylinder Temperature during Single Injection Operation

Figure 29 presents $\mathrm{NO}_{\mathrm{x}}$ emissions on a logarithmic scale due to the vast range of measurements. Additionally, $\mathrm{NO}_{\mathrm{x}}$ emissions are presented as a function EGR fraction as it was found that narrow range of SOI timings tested has little affect on $\mathrm{NO}_{\mathrm{x}}$ emissions. Through the re-introduction of more exhaust gas into the cylinder $\mathrm{NO}_{\mathrm{x}}$ emissions trend downwards. The substantial difference in $\mathrm{NO}_{\mathrm{x}}$ formation between the hotter and colder IMT conditions may be contributed to the appearance of misfire. Cooler in-cylinder temperatures displayed in Figure 30, will result in significantly less $\mathrm{NO}_{\mathrm{x}}$ formation. Interestingly, maximum in-cylinder temperature for the higher IMT condition changes very little through the range of EGR fraction employed, yet an exponential decrease in $\mathrm{NO}_{\mathrm{x}}$ was observed in Figure 29. Given that $\mathrm{NO}_{\mathrm{x}}$ formation is closely related to local temperatures in the combustion chamber, it is expected that a decrease in global in-cylinder temperature would be present at high EGR fractions. Although a clear and concise behavior of $\mathrm{NO}_{\mathrm{x}}$ emissions with temperature is unknown for this application it is possible that $1600 \mathrm{~K}$ is a temperature region on the cusps of severe $\mathrm{NO}_{\mathrm{x}}$ formation. Small decrements from this temperature may result in the substantial $\mathrm{NO}_{\mathrm{x}}$ reduction observed in Figure 29. Additionally, this temperature is calculated from in-cylinder pressure measurements, intake manifold temperature, and exhaust manifold temperature. This results in an estimated global incylinder temperature which may not be truly representative of the flame temperature. The flame temperature ultimately dictates the amount of $\mathrm{NO}_{\mathrm{x}}$ formed by the thermal $\mathrm{NO}_{\mathrm{x}}$ mechanism. 


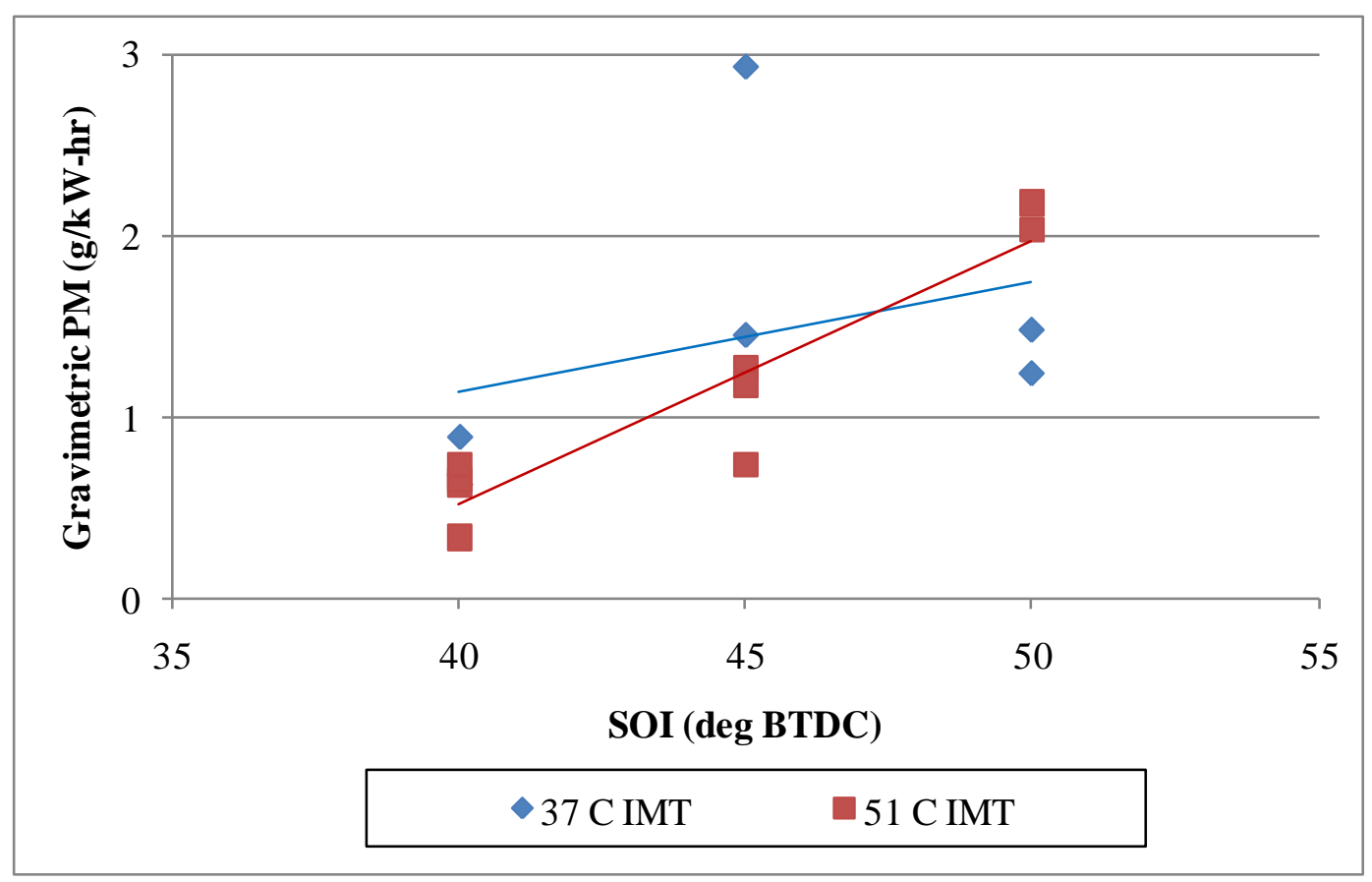

Figure 31: PM emissions during Single Injection Operation

Gravimetric based PM measurements presented in Figure 31 demonstrate greater PM emissions at more advanced SOI timing. Through visual inspection of the PM collection filter, elevated $\mathrm{HC}$ emissions, and later comparison of tests with AVL 483 soot sensor measurements, it is assumed that the vast majority of PM collected falls into the category of soluble organic fraction (SOF). In this instance, the SOF collected is primarily composed of unburnt fuel collected on the PM filter. The significant SOF portion of gravimetric PM is a result of fuel impingement on the cylinder wall which is increasing as the SOI timing is advanced. 


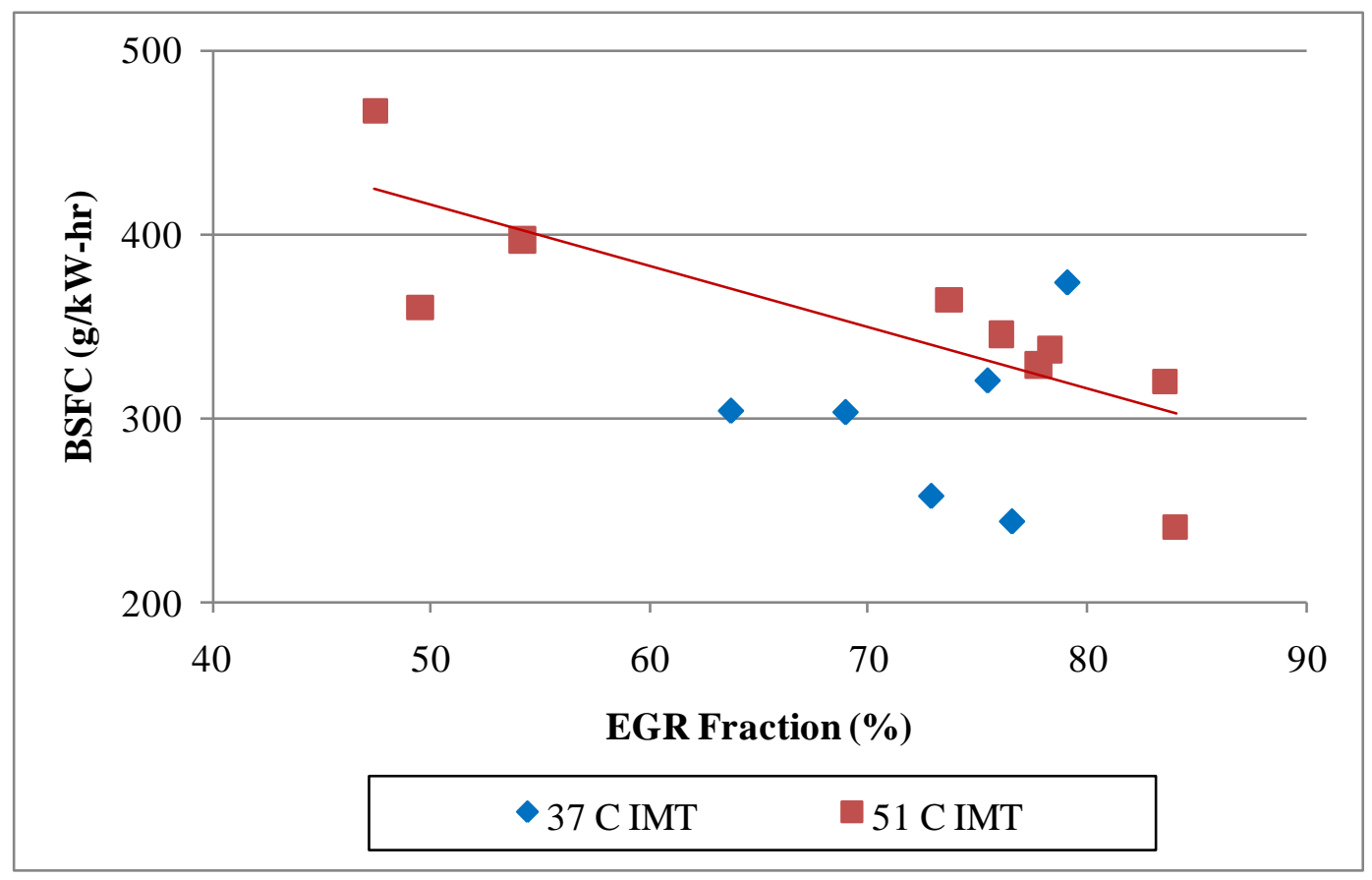

Figure 32: Fuel Consumption during Single Injection Operation

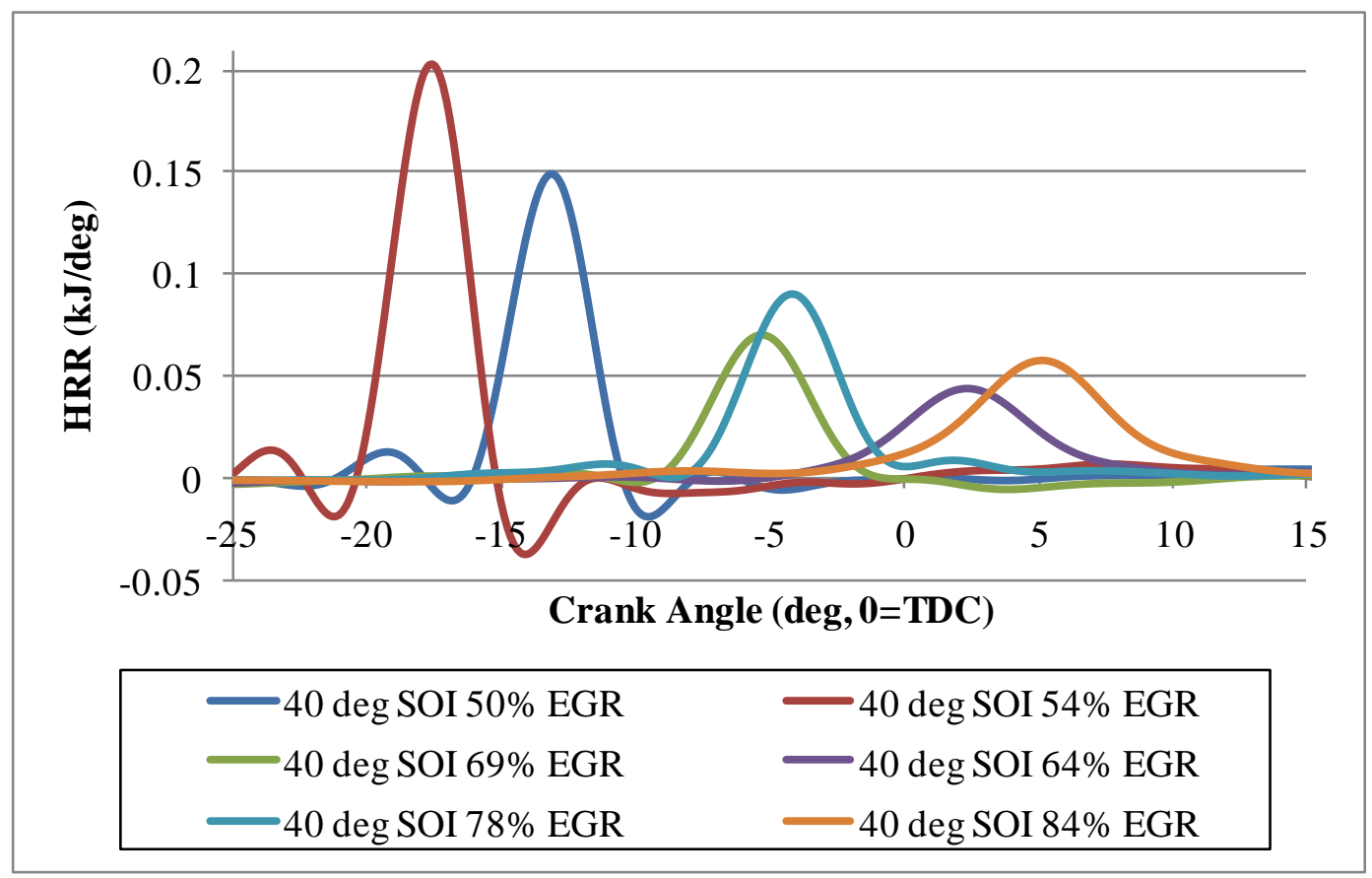

Figure 33: Heat Release Rate during Single Injection Operation

Fuel consumption data, presented Figure 32, provide no discernable trend for the lower IMT condition. At the higher IMT condition, the fuel consumption trends downward as the EGR fraction increases. This observation directly conflicts the conventional notion that fuel 
consumption increases with increased EGR levels. An explanation of this phenomenon can be found in Figure 33 which plots HRR for different EGR fractions. As EGR fraction is increased combustion is phased closer and even past TDC. At lower EGR fractions combustion occurs well before TDC resulting in the combustion event fighting the piston as it proceeds to TDC. This un-optimal condition no doubt causes the increase in fuel consumption at lower EGR fractions.

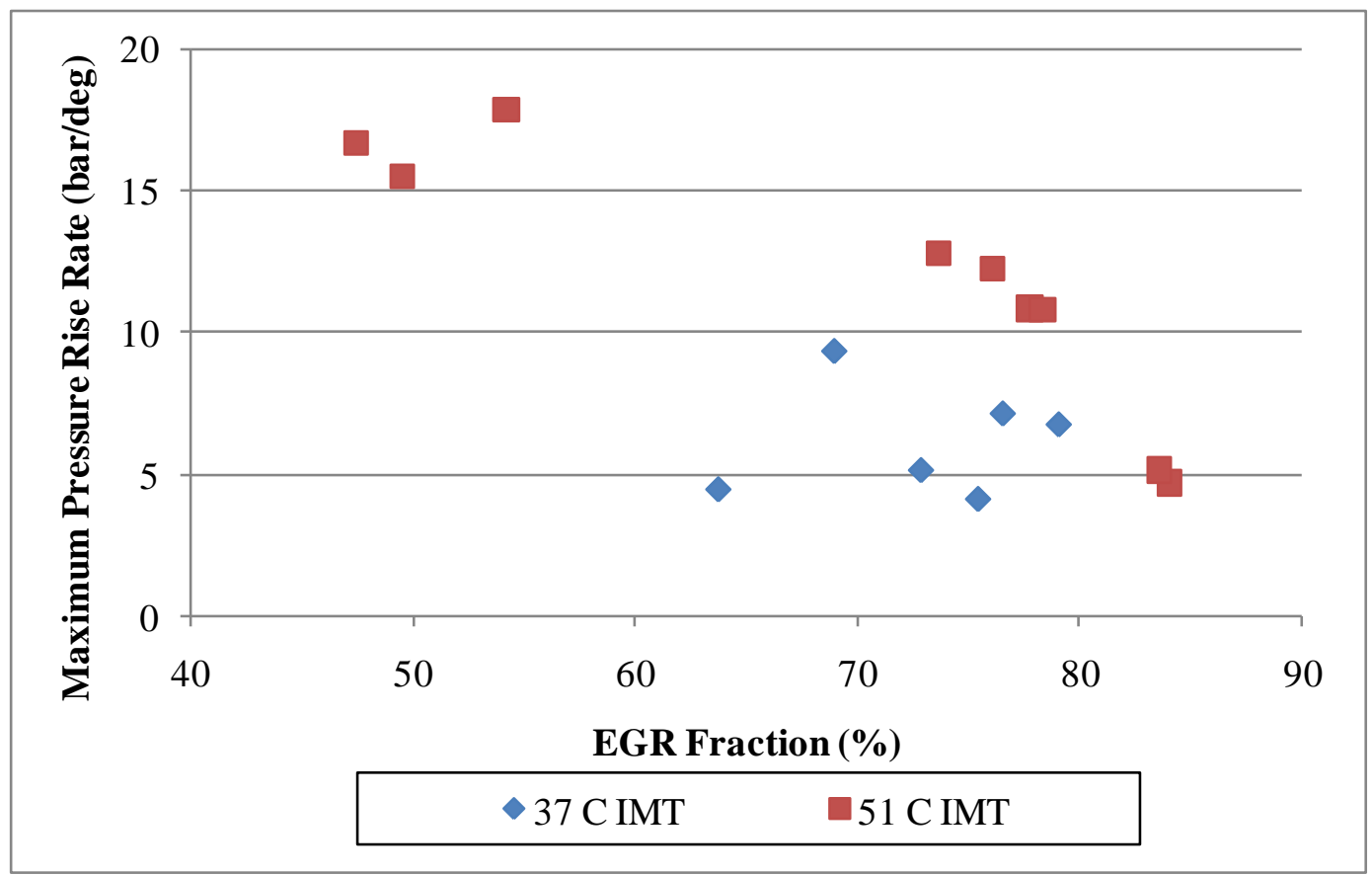

Figure 34: Pressure Rise Rate during Single Injection Operation

The addition of more exhaust gas to the cylinder significantly reduces the maximum pressure rise rate (PRR) demonstrated for the higher IMT condition in Figure 34. Extreme pressure rise rates, such as those shown around 50\% EGR, can be a major concern for engine durability. The single injection strategy, especially with this fuel and engine configuration, requires a significant amount of diluent to reduce these pressure rise rates to a safer level. Erratic combustion is likely the cause of lower and inconsistent PRR for the lower IMT condition.

\subsubsection{Shakedown Fuel and FACE 1 Fuel Single Injection Comparison}

Due to the above mentioned high HC emissions, CO emissions, and PRR very few single injection strategy tests were performed after progressing from the shakedown fuel. Two tests performed with FACE 1 comprise the remainder of single injection strategy tests. It is less than ideal to only compare a select few tests to make judgments on fuel properties, but none the less 
some conclusions can be formed. Note that the SOI timing for the shake down fuel tests ranged from $40^{\circ} \mathrm{BTDC}$ to $50^{\circ} \mathrm{BTDC}$ in increments of $5^{\circ}$, while the tests utilizing FACE 1 were $35^{\circ}$ $\mathrm{BTDC}$ and $40^{\circ} \mathrm{BTDC}$. The rail pressure for the shakedown fuel tests was $1000 \mathrm{bar}$, while the rail pressure for FACE 1 tests were 1200 bar.

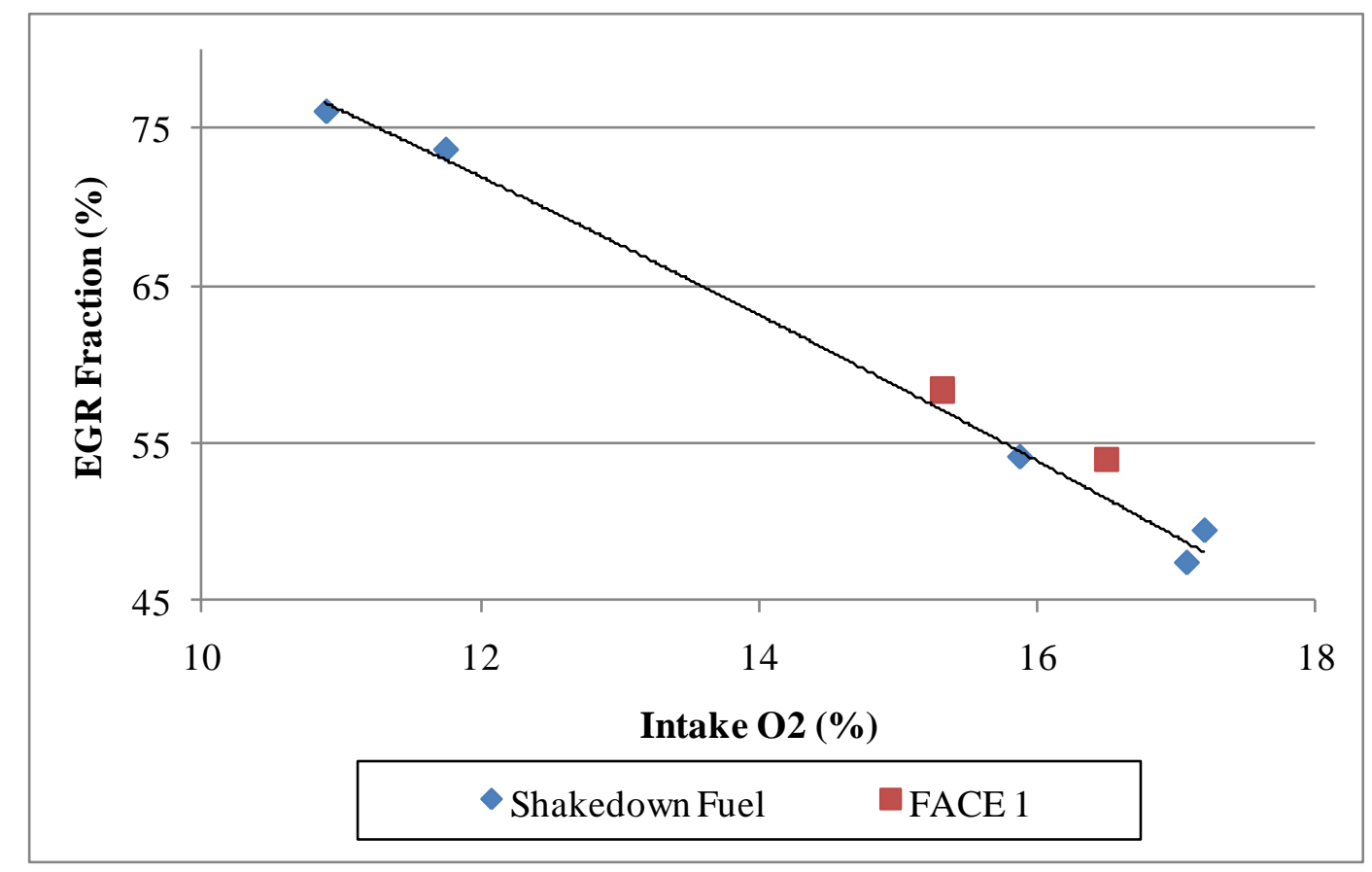

Figure 35: Intake Oxygen versus EGR Fraction for Shakedown Fuel and FACE 1

It is important to have confidence in the EGR fraction (equation presented in the Appendices), especially since it was the primary variable during the testing of these fuels. Intake $\mathrm{O}_{2}$ concentration is directly proportional to the EGR fraction. By comparing the results shown in Figure 35 a relative confidence is gained and it is expected that errors in EGR measurement do not exist between tests of the different fuels. 


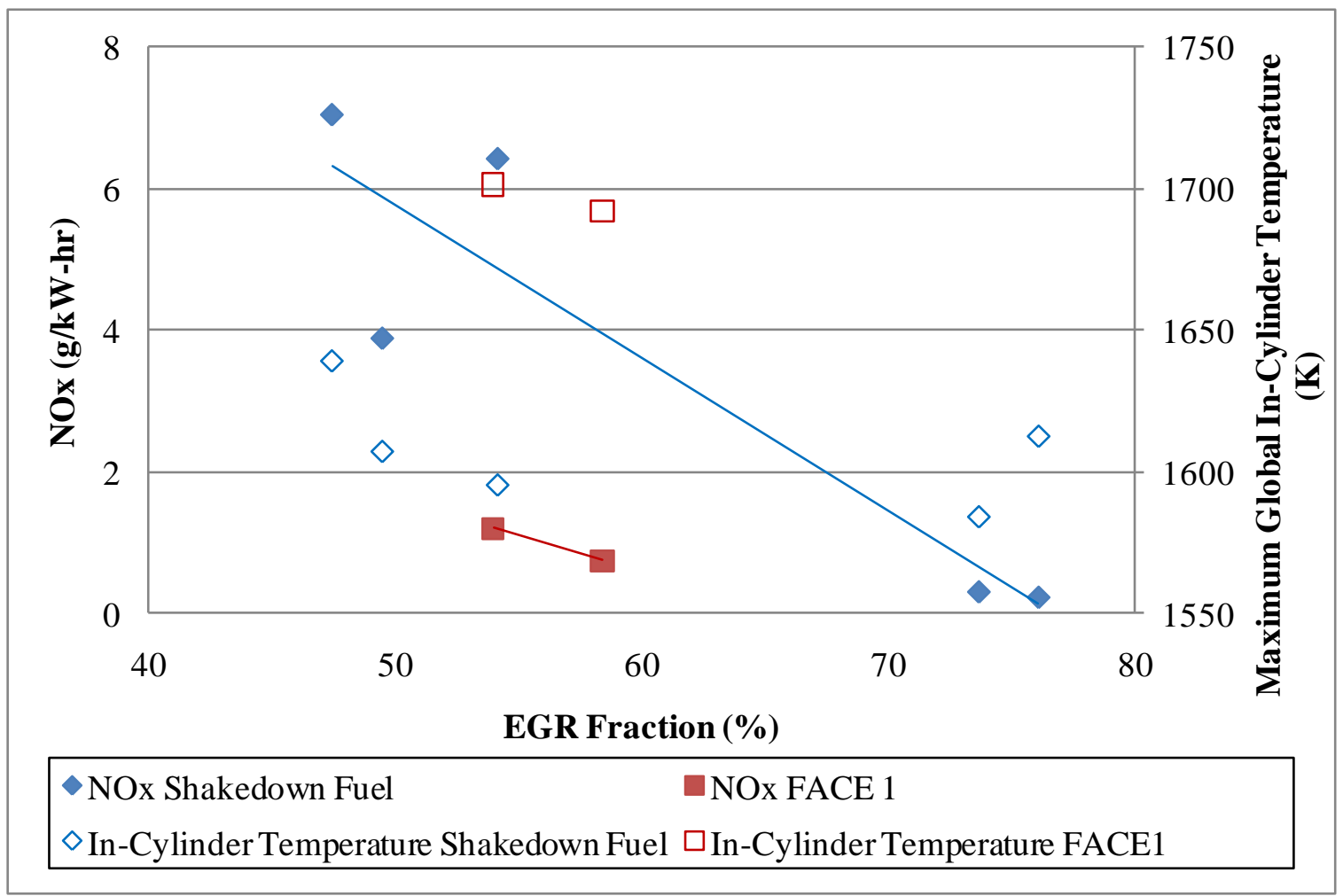

Figure 36: $\mathrm{NO}_{\mathrm{x}}$ Emissions and Maximum In-Cylinder Temperature for Shakedown Fuel and FACE 1

For similar EGR fractions, Figure 36 demonstrates significantly lower $\mathrm{NO}_{\mathrm{x}}$ emissions when the engine is operated with FACE 1 versus the shakedown fuel. At extreme levels of EGR the $\mathrm{NO}_{\mathrm{x}}$ emissions for the shakedown fuel tests do become less than that of FACE 1. Confidence in the trend-lines is less than optimal due to the limited number of experiments, but the slope of the trend-lines insinuate that $\mathrm{NO}_{\mathrm{x}}$ emissions for FACE 1 would be less throughout the range of EGR fractions. Noting this observation, the lower cetane number and aromatics content of FACE 1 compared to the shakedown fuel likely provide the reasoning for the $\mathrm{NO}_{\mathrm{x}}$ formation decrease. This explanation is supported by the literature presented in Sections 2.3.1 and 2.3.2. Furthermore, in-cylinder temperatures for FACE 1 plotted in Figure 36 are greater than the incylinder temperatures of the shakedown fuel regardless of EGR fraction. This condition should result in higher $\mathrm{NO}_{\mathrm{x}}$ emissions for FACE 1 when compared to the shakedown fuel and again reaffirms the hypothesis that lower $\mathrm{NO}_{\mathrm{x}}$ emissions for FACE 1 are related heavily to cetane number and aromatics content. 


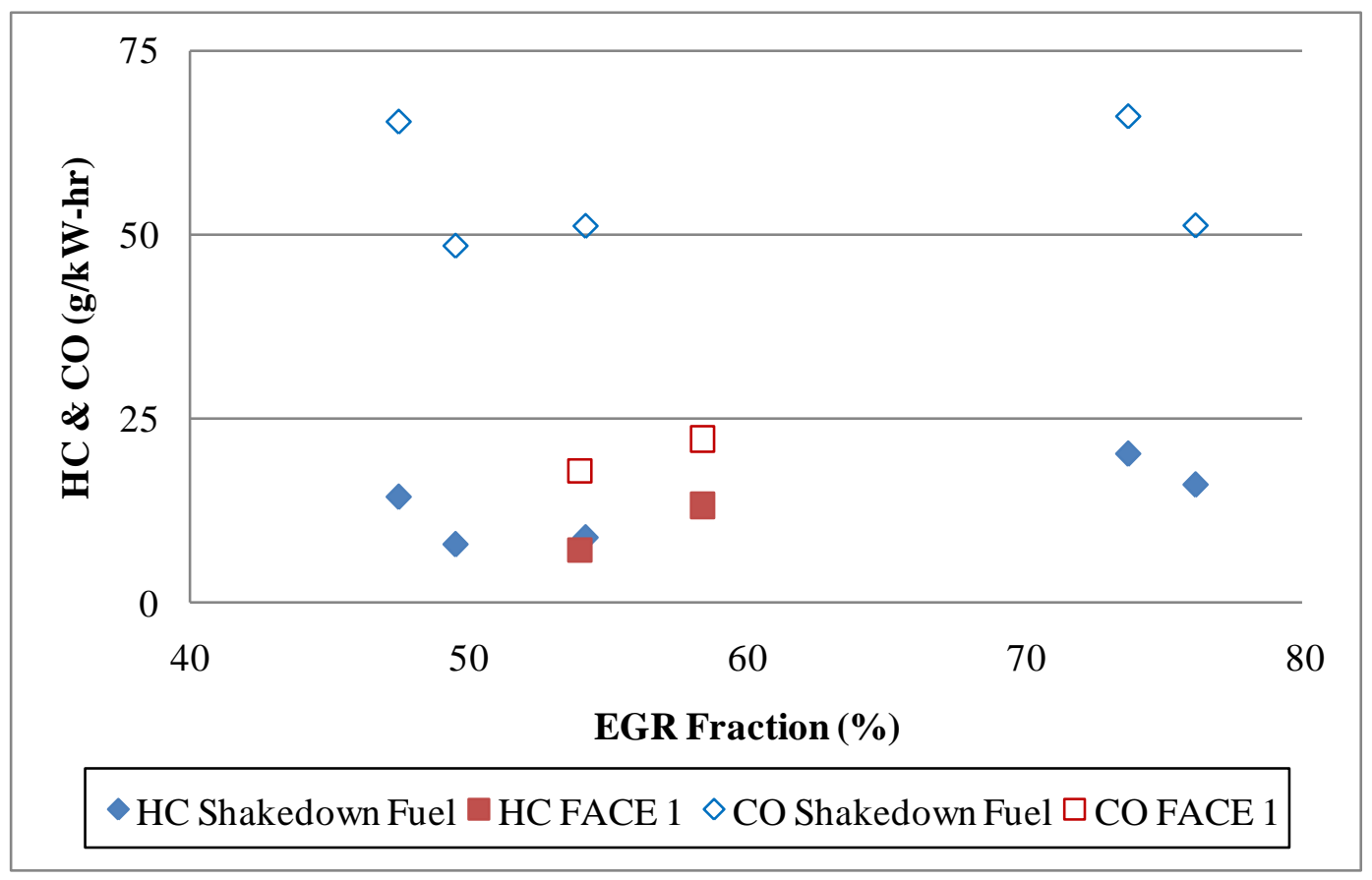

Figure 37: HC Emissions and CO emissions for Shakedown Fuel and FACE 1

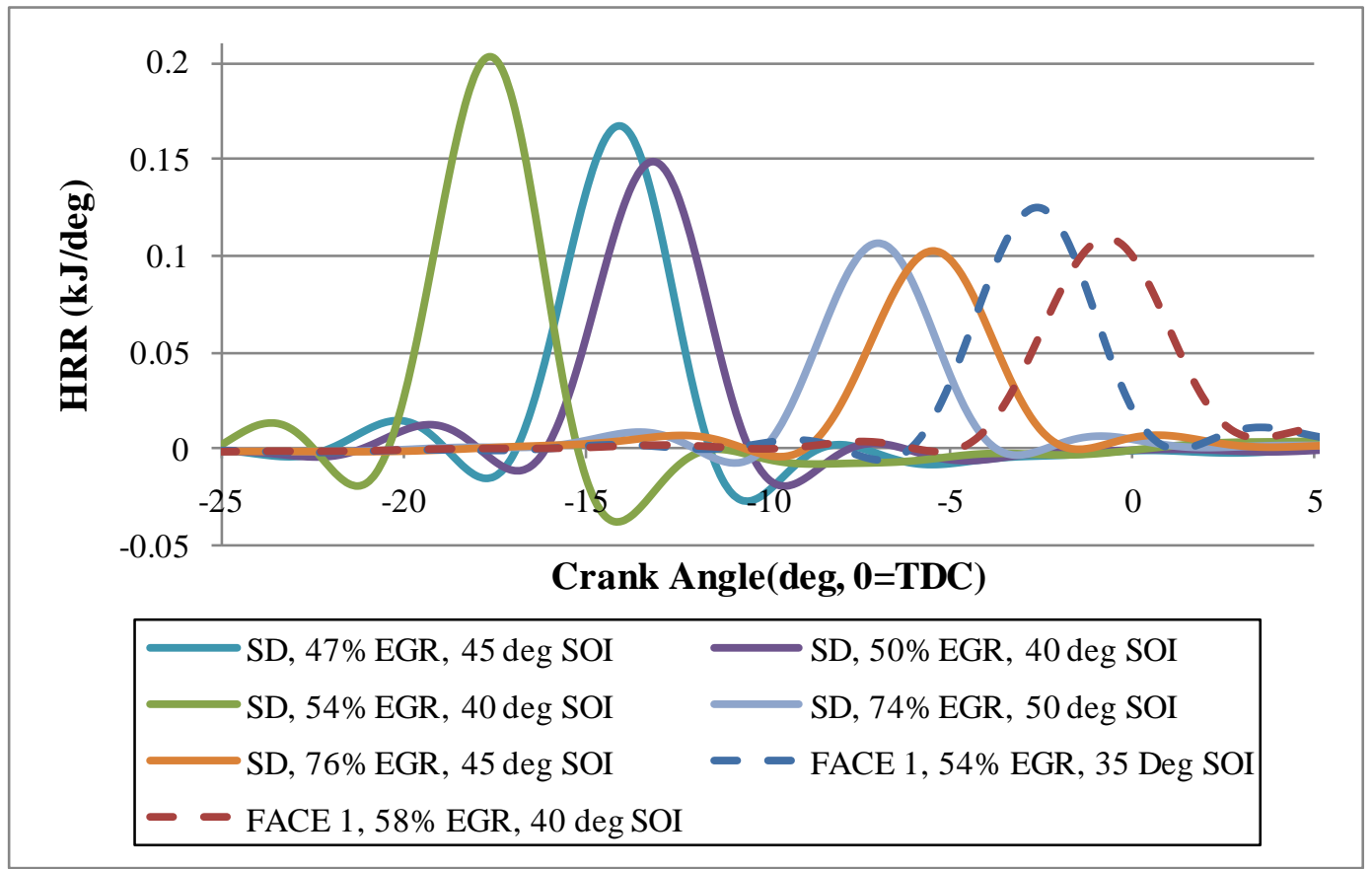

Figure 38: Heat Release Rate for Shakedown Fuel (SD) and FACE 1

Both fuels exhibit greater HC emissions at higher EGR fractions shown in Figure 37. Comparing the two fuels, there appears to be no distinguishable fuel property effects on $\mathrm{HC}$ emissions, although conclusions from a larger test set may prove different. CO emissions for FACE 1 trend upwards with greater EGR levels as might be expected. No trend is observable for 
the shakedown fuel, although it is very interesting to note the greater $\mathrm{CO}$ emissions for the shakedown fuel compared to FACE 1. One contribution, but doubtfully the entire reason, could be the IMT for the FACE 1 tests averaged $72{ }^{\circ} \mathrm{C}$ while the shakedown fuel test average $49{ }^{\circ} \mathrm{C}$. This elevated IMT may promote better fuel atomization and mixing resulting in less locally rich zones in the combustion chamber. Additionally, Figure 38 demonstrates that combustion of FACE 1 is phased much closer to TDC than that of the shakedown fuel (SD). Explanation of this lies in the lower cetane number of FACE 1 and its accompanying longer ignition delay. This allows for more mixing time under the operation of FACE 1 presumably limiting locally rich regions in the combustion chamber.

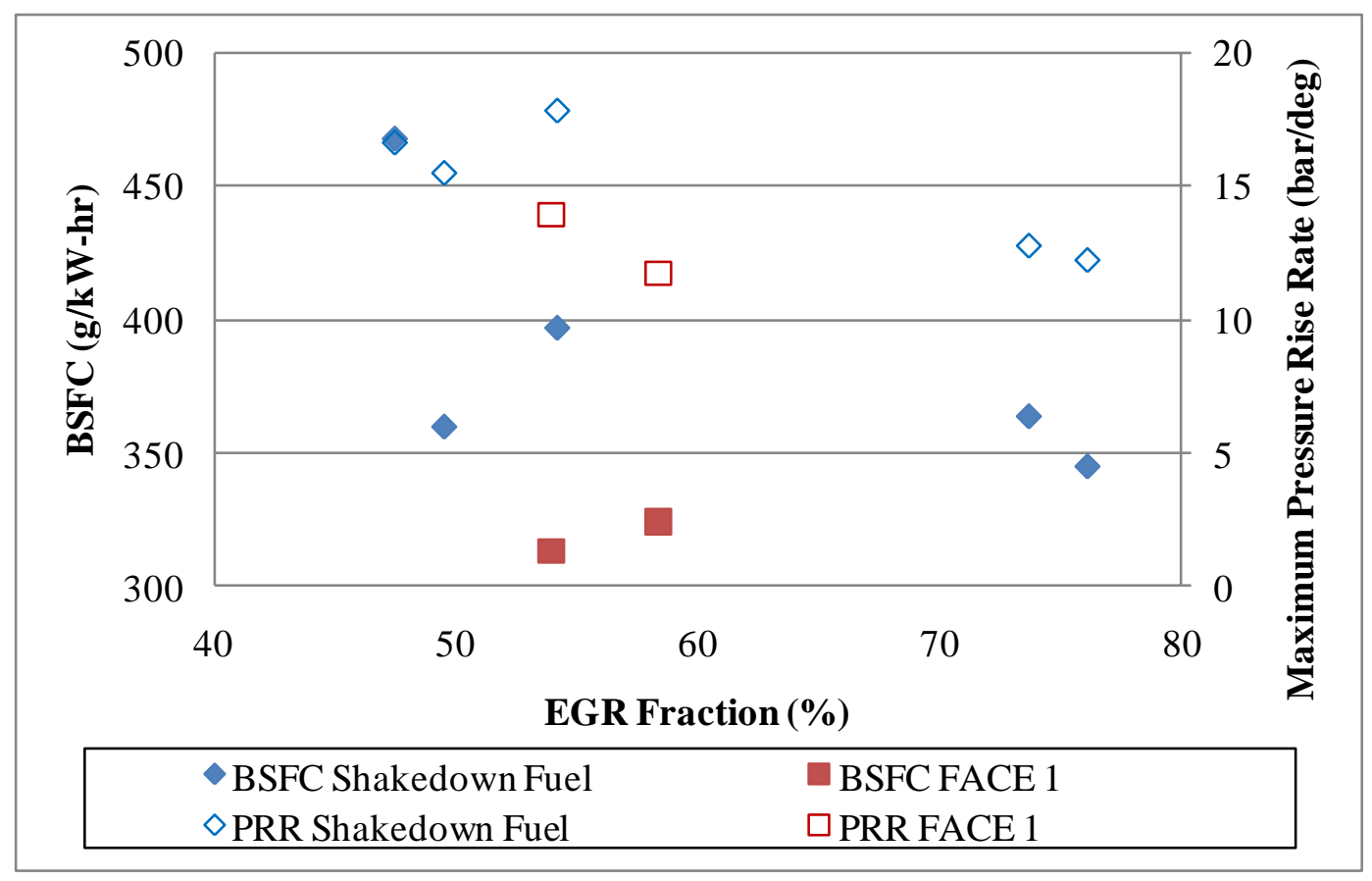

Figure 39: Fuel Consumption and Pressure Rise Rate for Shakedown Fuel and FACE 1

Regardless of EGR fraction, fuel consumption, plotted in Figure 39, is unanimously less for FACE 1. Subsequently, the utilized SOI timing for the cetane number of the shakedown fuel may not be optimal regarding fuel consumption. Concurrent with a higher cetane number is a shorter ignition delay. If a significant portion of the fuel is combusting before TDC, fuel consumption and efficiency will certainly be negatively affected. This condition is present in Figure 38 for the shakedown fuel. FACE 1 with its lower cetane number exhibits a longer ignition delay phasing combustion close to TDC resulting in less fuel consumption. The ignition delay characteristics of the fuels due to cetane number also play a significant role on in-cylinder 
pressure rise rate. A low cetane fuel with a long ignition delay demonstrates lower PRR than a high cetane fuel, especially at heavily advanced injection timing. This phenomenon can be observed in Figure 39. The pressure rise rate of FACE 1 is less than that of the shakedown fuel for similar EGR fractions. While the EGR fractions utilized for the shakedown fuel are greater than FACE 1, it is shown that to achieve comparable pressure rise rates, the EGR fraction for the shakedown fuel must be greater than 70 percent.

The absence of a figure presenting PM emissions is due to the lack of gravimetric PM measurements for FACE 1. Photo acoustic soot measurements were performed on FACE 1, yet are lacking for the shakedown fuel. PM emissions for the shakedown fuel ranged from 340 to over 2000 (mg/kW-hr) increasing with EGR fraction. Much of this contribution was assumed to be the effect of SOF due to the strong presence of un-burnt fuel. Soot measurements for FACE 1 resulted in near zero values. The largest brake specific soot measurement was $7.4 \mathrm{mg} / \mathrm{kW}$-hr. Consistent measurement techniques would be necessary to make an accurate comparison, but it is evident a large void exists between total PM emissions and soot emissions.

\subsubsection{RPM 2.6 bar BMEP}

A final exploration of the single injection strategy was performed at $1500 \mathrm{RPM}$, targeting a BMEP of 2.6 bar with FACE 6. The SOI timing was fixed at $5^{\circ} \mathrm{BTDC}$ and the rail pressure was set to 875 bar. This configuration was first explored by ORNL with several fuels comprising the FACE matrix [22]. WVU experimented with this configuration to attempt to determine the effects of a two valve per cylinder head design (WVU test engine) versus a 4 valve per cylinder head design (ORNL test engine). During the experiment the EGR fraction was the sole variable, held at approximately 40 percent, except during the last test where EGR fraction was increased to 62 percent. 


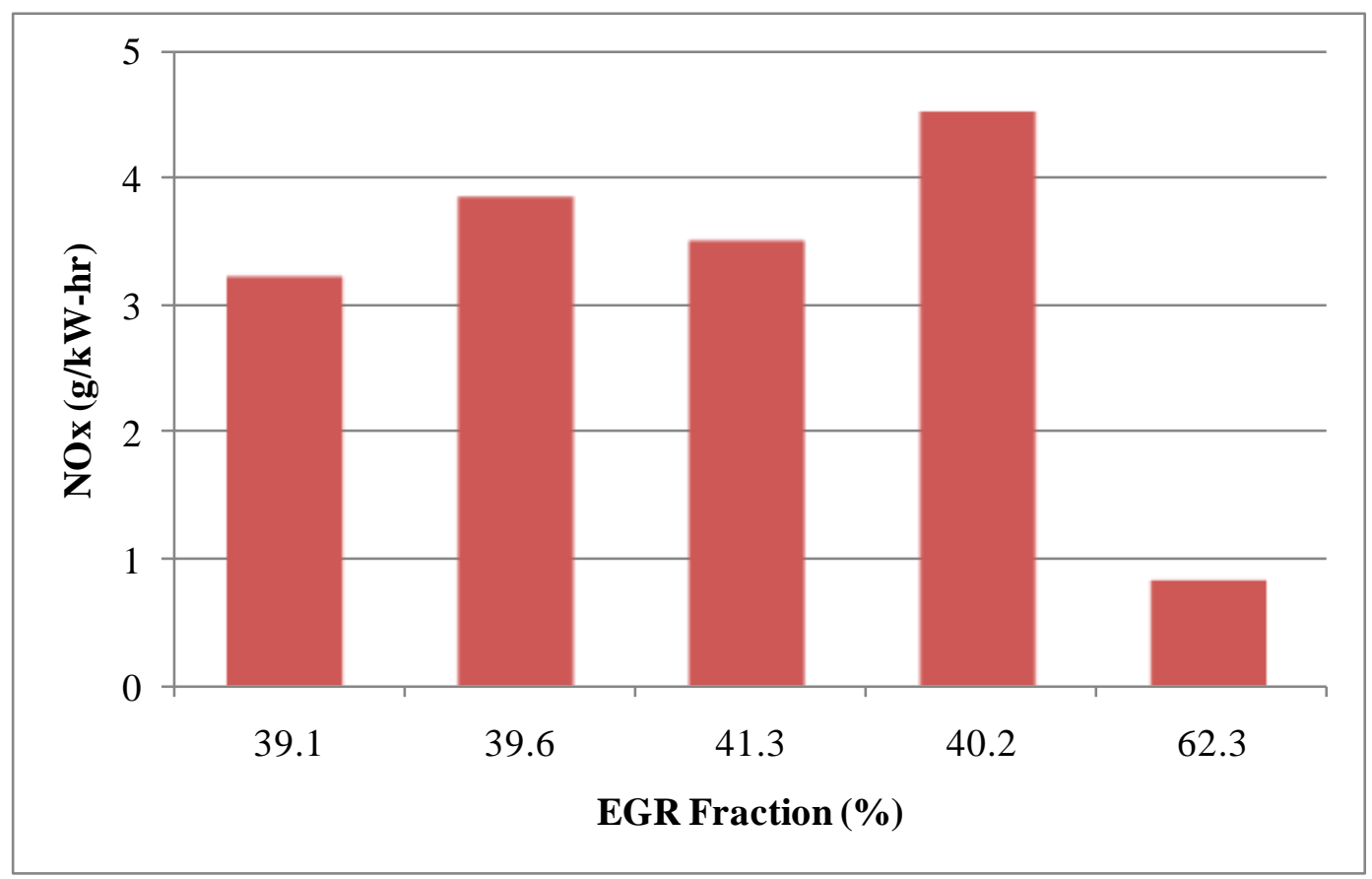

Figure 40: $\mathrm{NO}_{\mathrm{x}}$ Emissions for $5^{\circ} \mathrm{BTDC}$ Single Injection

Brake specific $\mathrm{NO}_{\mathrm{x}}$ emissions, presented in Figure 40, remain relatively constant for similar EGR fractions. Significant reductions in $\mathrm{NO}_{\mathrm{x}}$ formation do not appear until the EGR fraction is increased to 62 percent. This insinuates that the combustion occurring for these tests may be more representative of conventional combustion than a form advanced combustion. Also considering the proximity of the injection event relative to TDC, it is not surprising that a relatively large amount of EGR is necessary to reduce $\mathrm{NO}_{\mathrm{x}}$ emissions. 


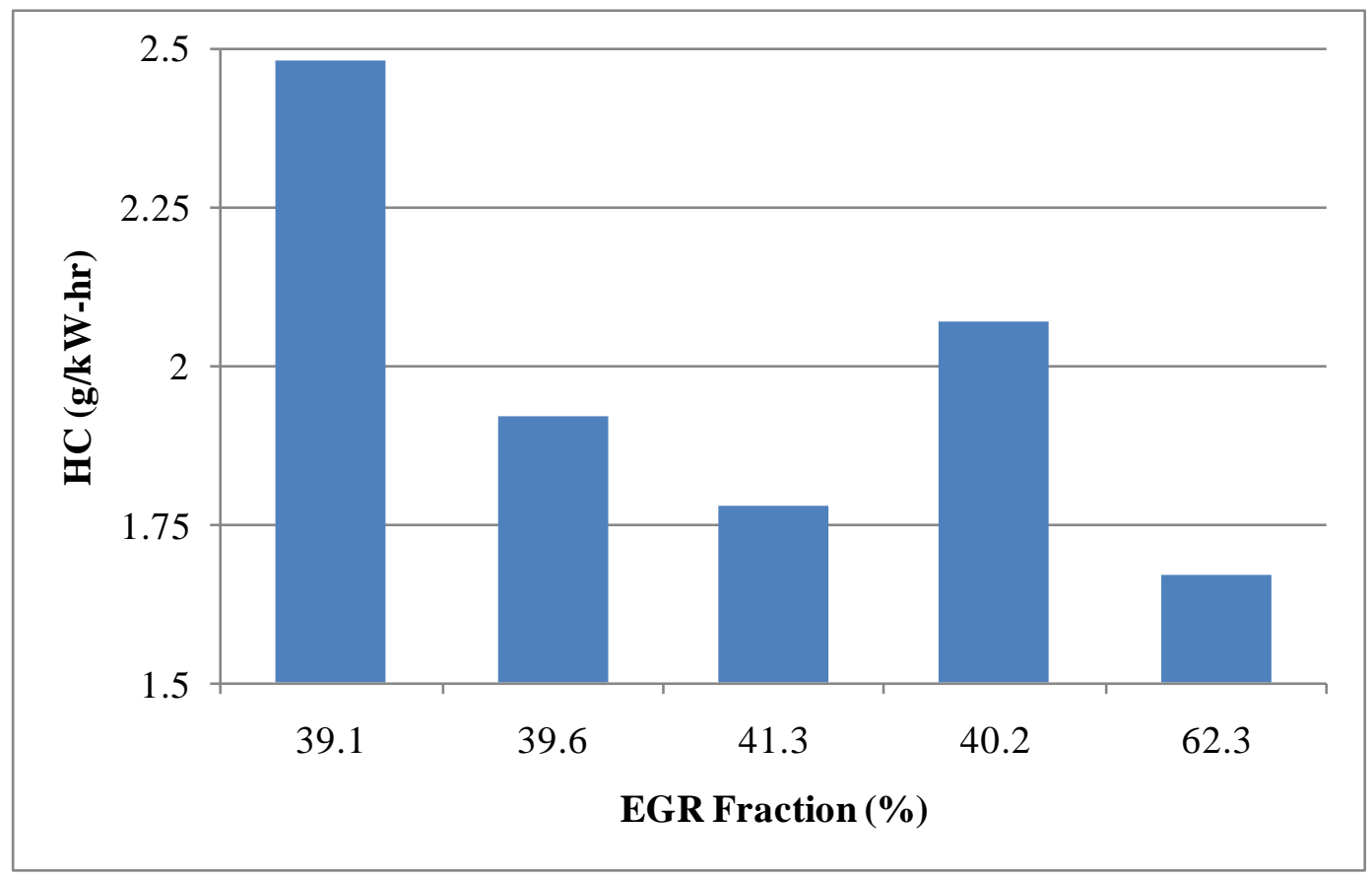

Figure 41: HC Emissions for $5^{\circ}$ BTDC Single Injection

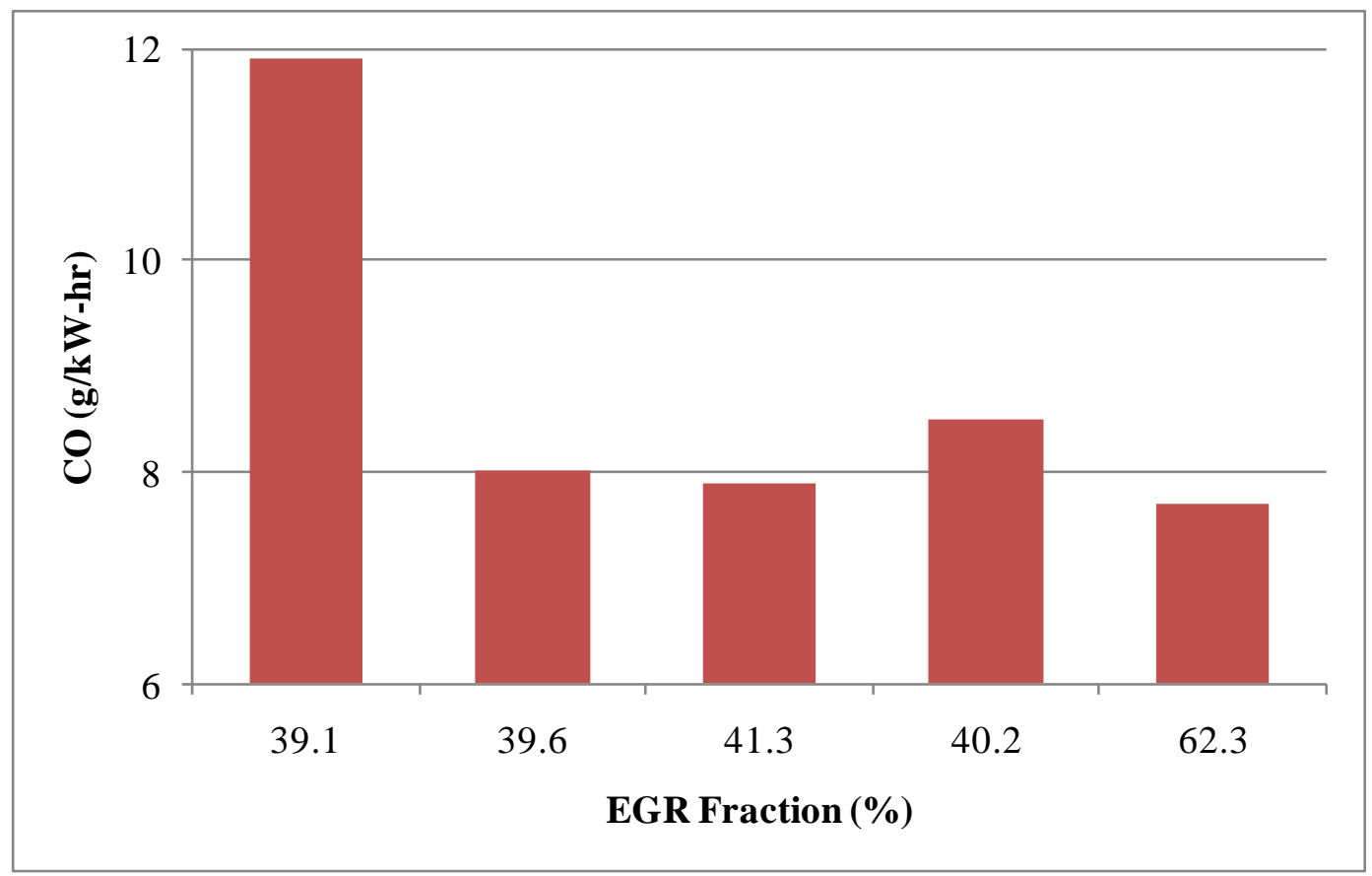

Figure 42: CO Emissions for $5^{\circ}$ BTDC Single Injection 


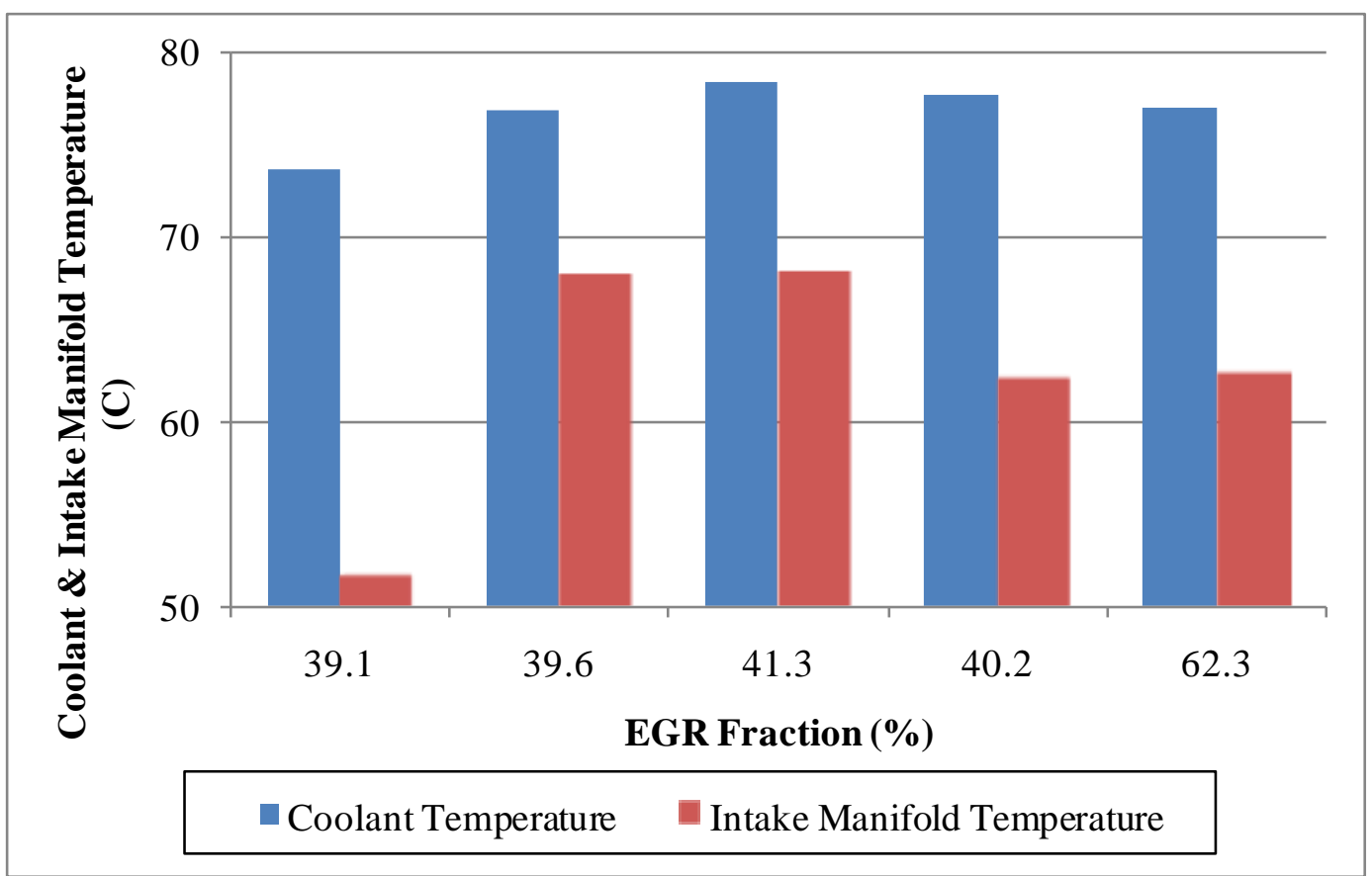

Figure 43: Coolant and Intake Manifold Temperature for $5^{\circ}$ BTDC Single Injection

$\mathrm{HC}$ and $\mathrm{CO}$ emissions are quantified in Figure 41 and Figure 42 respectively. Unconventionally, $\mathrm{HC}$ emissions are greatest for the condition with the least EGR. This is explained through a lower coolant temperature (approximately $5{ }^{\circ} \mathrm{C}$ lower than the average) and a significantly lower IMT (approximately $15{ }^{\circ} \mathrm{C}$ lower than the average) shown in Figure 43. It is also interesting to note that the test with the largest EGR rate also has the lowest brake specific $\mathrm{HC}$ and $\mathrm{CO}$ emissions. This is likely due to a greater BMEP for the last test , approximately 3 bar, compared to the other tests which held a BMEP very close to 2.6 bar. These measurements are displayed in Figure 44. 


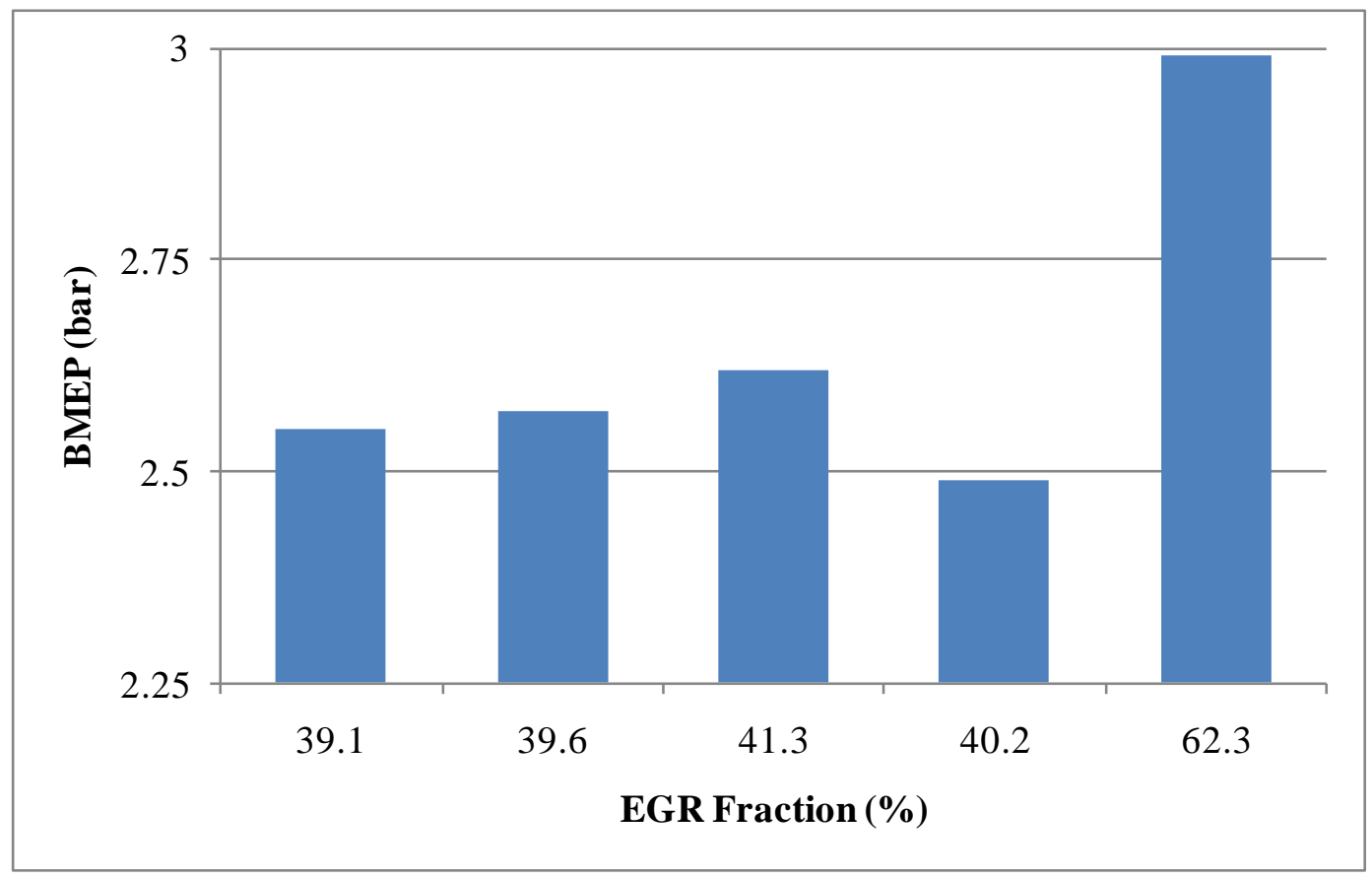

Figure 44: BMEP for $5^{\circ}$ BTDC Single Injection

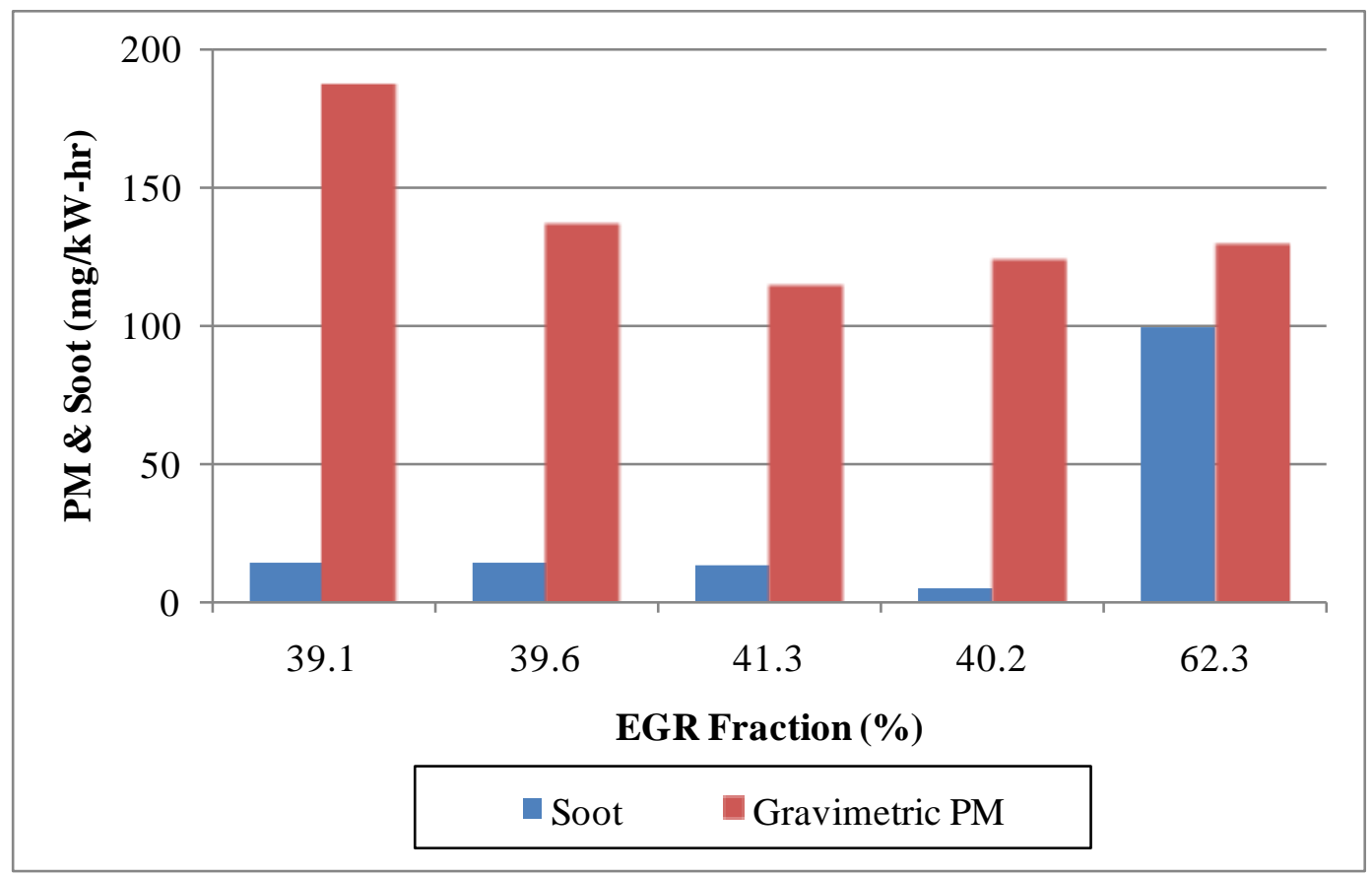

Figure 45: Soot and PM Emissions for $5^{\circ}$ BTDC Single Injection

EGR fractions close to 40 percent resulted in minimal soot formation shown in Figure 45. At an EGR fraction of 62.3 percent the soot emissions are significantly elevated and compare much closer to the gravimetric based PM. Gravimetric based PM measurements for tests other 
than 62.3 percent EGR are much greater when compared to the soot emissions. The discrepancy can be found in the collection of SOF on the filter, namely $\mathrm{HC}$ or un-burnt fuel. Note that the first test presented had the greatest HC emissions over the test set, while the last test had the lowest, contributing to its much better soot and gravimetric PM correlation. The soot versus NOx tradeoff visualized by comparing Figure 45 and Figure 40 supports the theory that this combustion relates closer to conventional combustion than a form of advanced combustion.

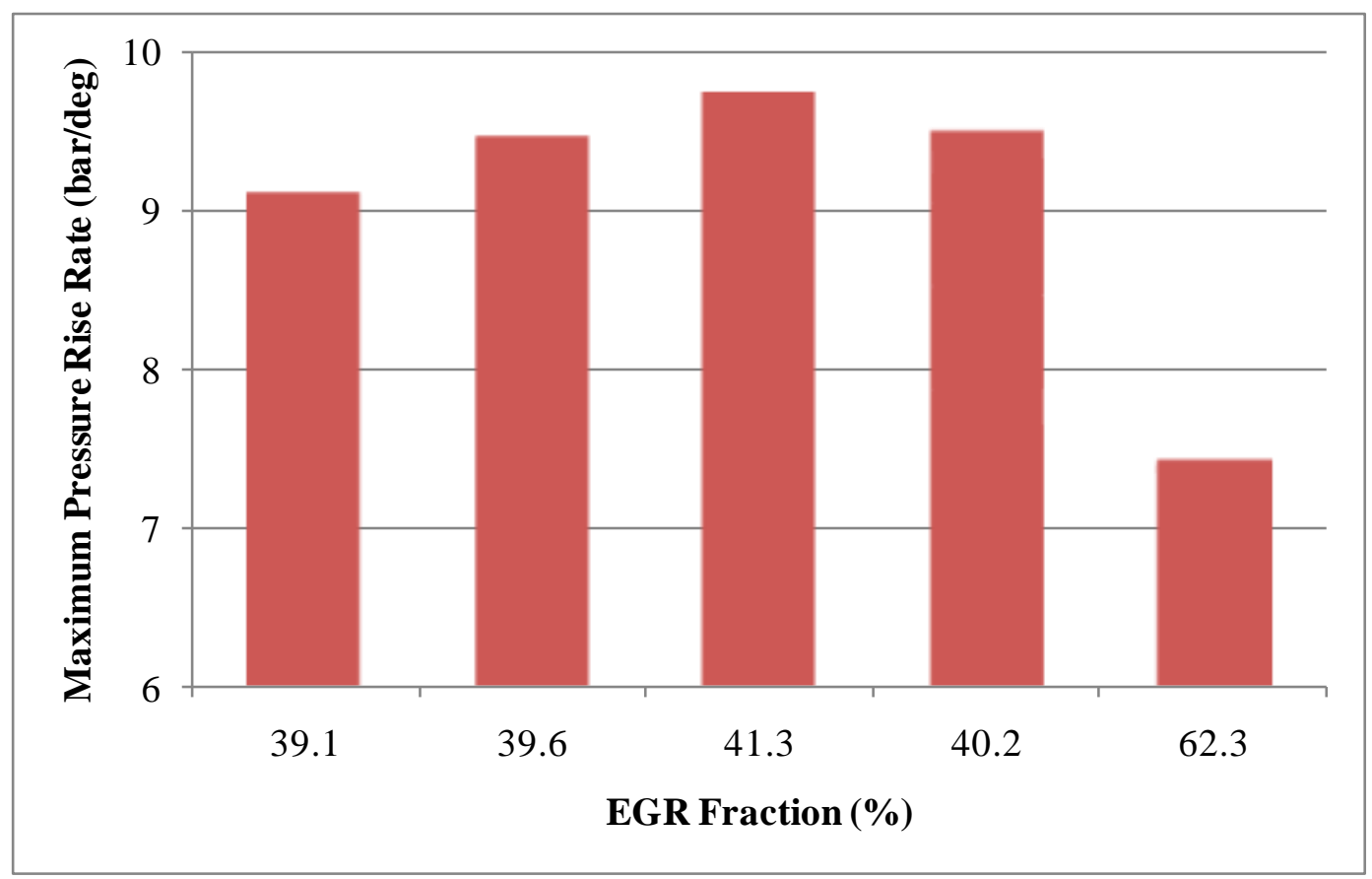

Figure 46: Pressure Rise Rate for $5^{\circ}$ BTDC Single Injection

PRR for EGR fractions around 40 percent average close to $9.5 \mathrm{bar} / \mathrm{deg}$ as presented in Figure 46. This certainly is not a low PRR, but it is much more acceptable than the PRR displayed in Figure 34. Regarding the 62.3 percent EGR fraction test, PRR is relatively less than the other tests comprising the set. This is obviously an effect of the increased EGR level, especially since the BMEP is largest in magnitude for this test as shown in Figure 44. 


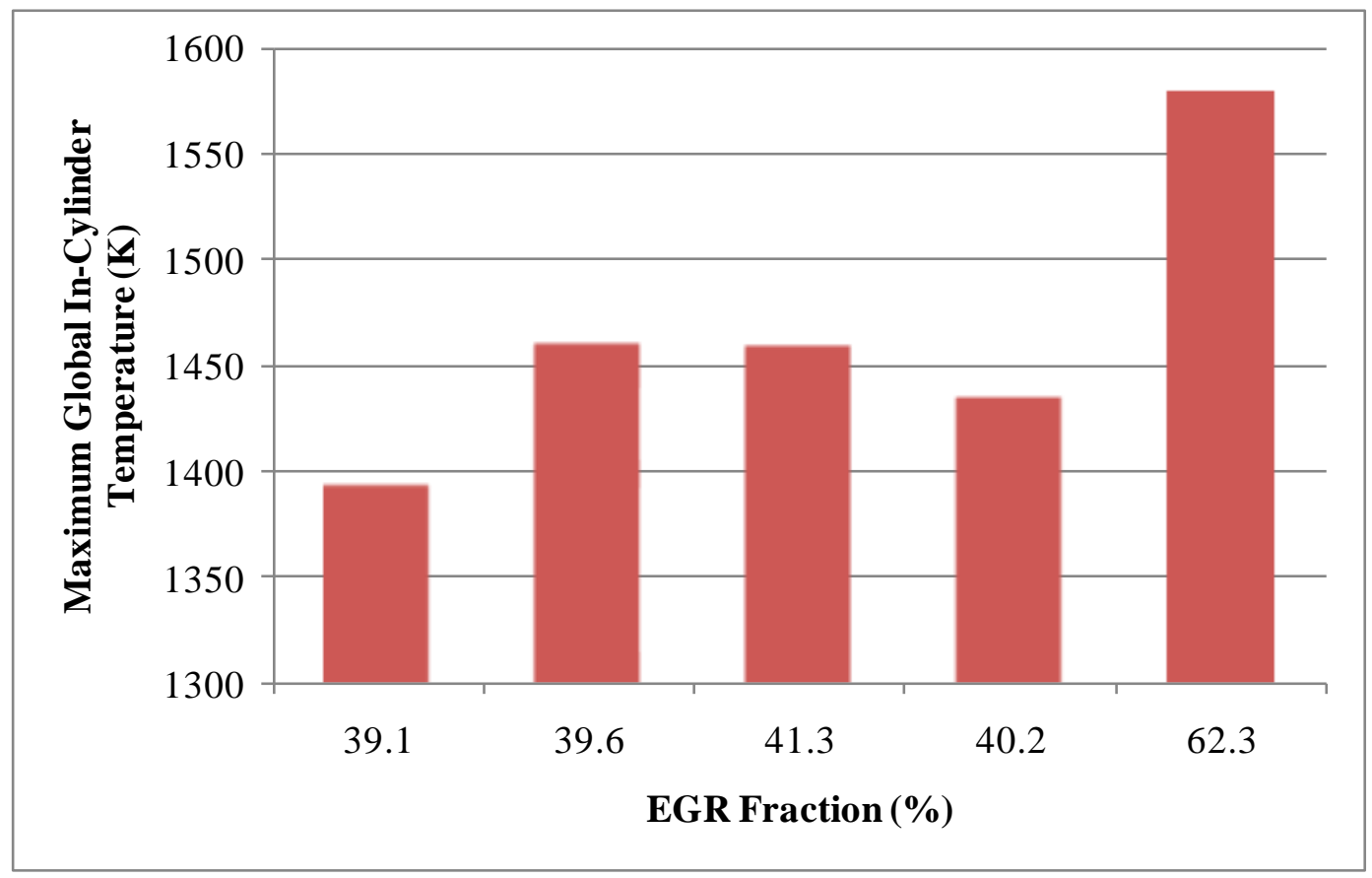

Figure 47: Maximum In-Cylinder Temperature for $5^{\circ}$ BTDC Single Injection

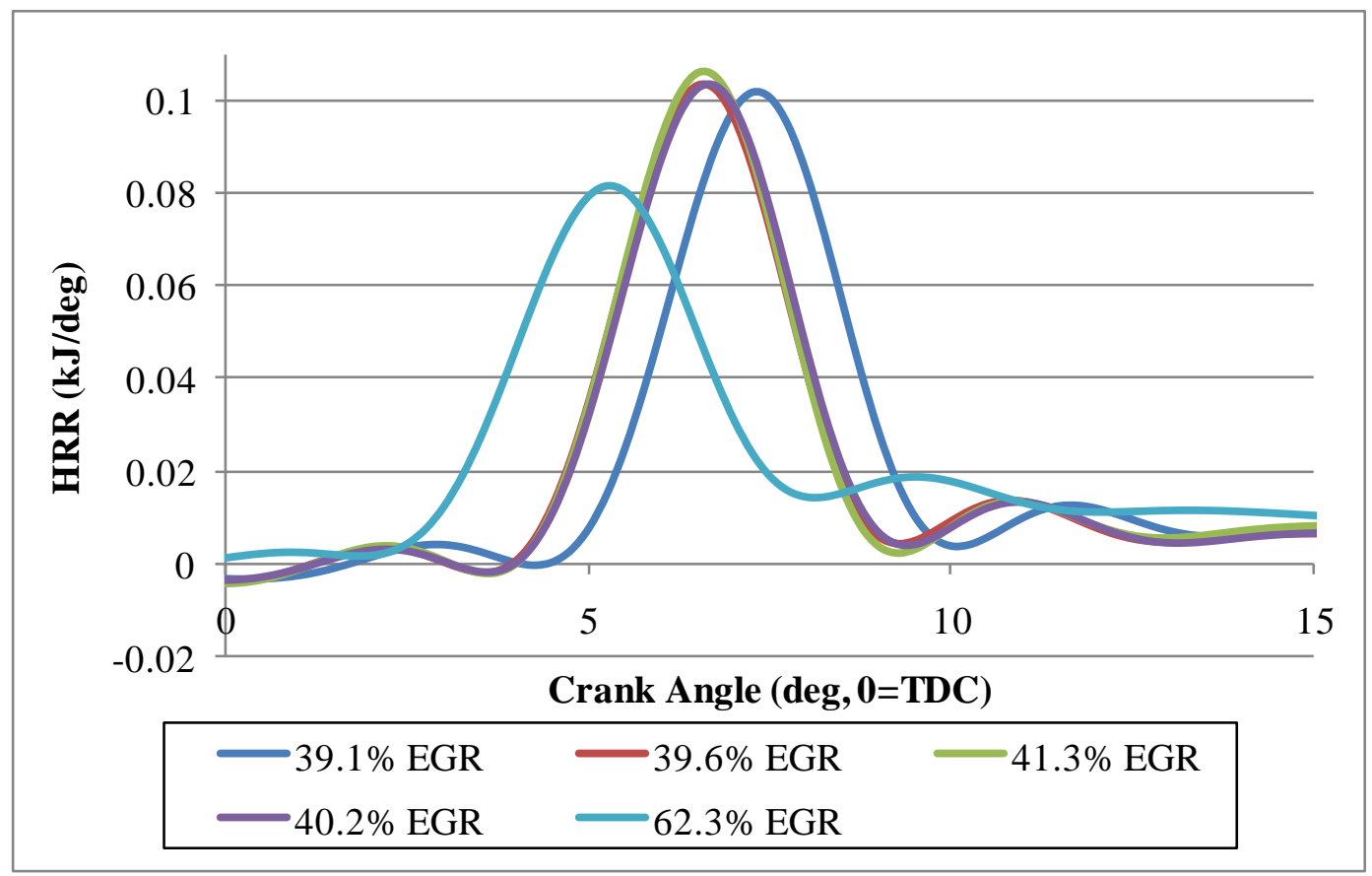

Figure 48: Heat Release Rate for $5^{\circ}$ BTDC Single Injection

The in-cylinder temperature calculation for the test with 62.3 percent EGR fraction results in a much greater value compared to other tests shown in Figure 47. Considering the $\mathrm{NO}_{\mathrm{x}}$ emissions and PRR displayed in Figure 40 and Figure 46, respectively, it would be assumed that 
this temperature would be close to if not lower than its companions. An explanation for this can be in Figure 44 representing BMEP. Since the BMEP of this test is larger than others it is concluded that a greater amount of fuel was burned in turn producing higher in-cylinder temperatures. Supporting this is the fact that the tests with 62.3 percent EGR fraction had the highest maximum in-cylinder pressure despite its lower PRR. Additionally, the heat release rate (HRR) displayed by Figure 48, is advanced from the other tests. Moving the combustion event closer to TDC, as hinted above, will certainly result in a higher combustion temperature and pressure.

\subsection{Split Injection}

Exploration of a split injection strategy was a direct result of concern over the extreme pressure rise rates and gross $\mathrm{HC}$ emissions during the advanced single injection operation. Information and guidance on this type of injection strategy was obtained from Hasegawa et al. [10]. After initial scoping of a split injection strategy with the shakedown fuel, an optimum base configuration was determined. Starting from this configuration, EGR fraction sweeps, main and pilot SOI timing sweeps, rail pressure sweeps, and fuel injection split sweeps were performed on the different fuels. All results presented in this section were performed at an engine speed of 2100 RPM and a BMEP of 3.5 bar.

\subsubsection{Base Configuration Comparison}

Through experimentation with the shakedown fuel a base configuration for the split injection strategy exploration was created. A 50 percent fuel injection split utilizing a pilot SOI timing of $40^{\circ}$ BTDC and a main SOI timing of TDC was deemed the optimum configuration for the shakedown fuel. Rail pressure was set at a baseline value of 800 bar and the VGT duty cycle was fixed at 100 percent. This strategy was implemented for each fuel as a starting point to tailor the injection strategy to the specific characteristics of that fuel. While this configuration may not contain the optimum set point of variables for a specific fuel, it establishes a consistency among fuels that can be used to evaluate fuel properties. 


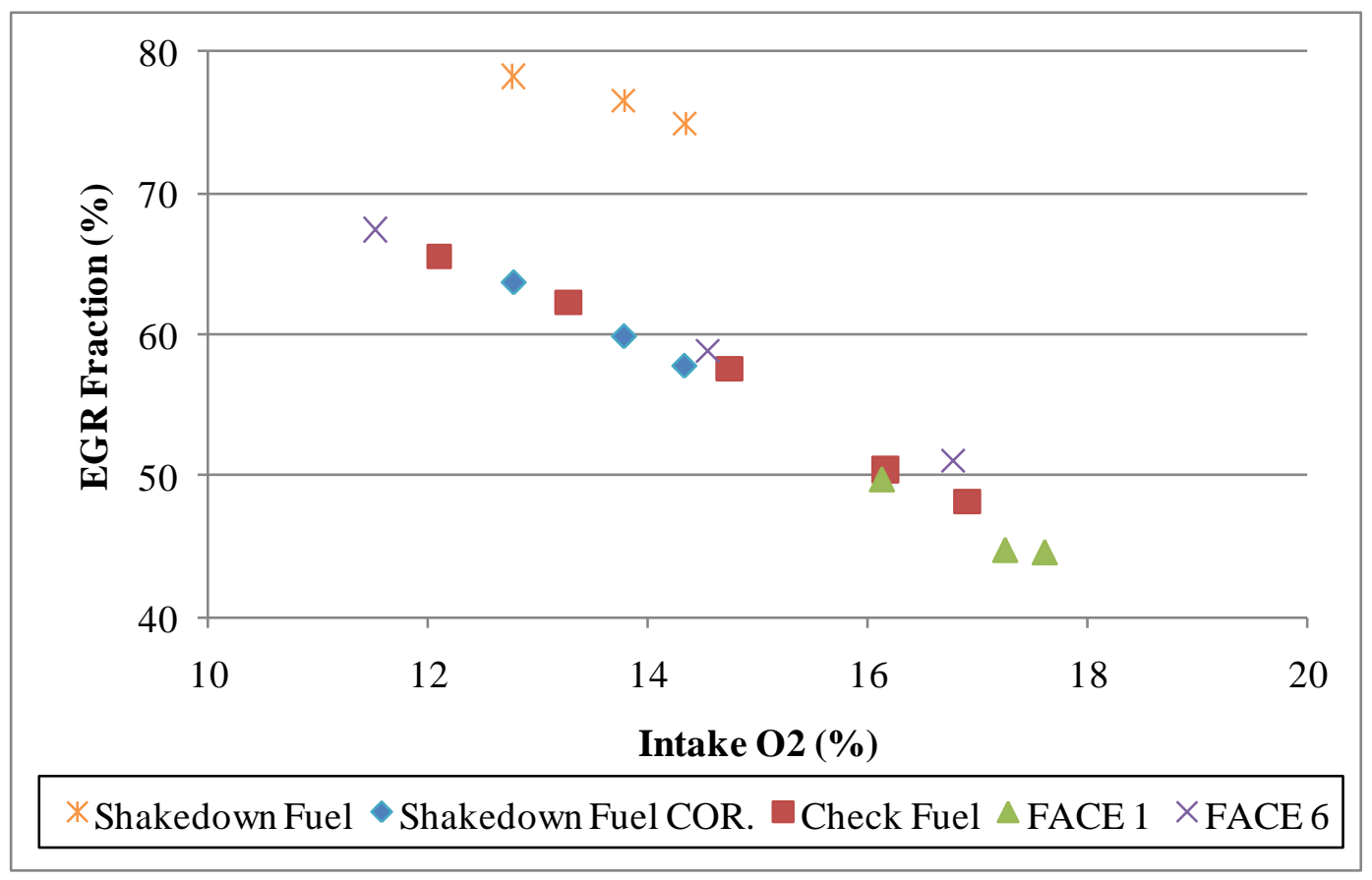

Figure 49: Intake Oxygen versus EGR Fraction for the Base Configuration

Emissions and performance data for differing fuels is plotted against EGR fraction throughout this section. This is due to the observed dominant influence of EGR fraction on performance and emissions measurements, as well as its position as the primary variable for these tests. As a result it is essential that a high level of confidence exists in this EGR fraction calculation $\left(\mathrm{CO}_{2}\right.$ concentration based). A secondary measure of EGR level was obtained through intake $\mathrm{O}_{2}$ concentration which is proportional to EGR fraction. Figure 49 demonstrates an acceptable level of confidence for the Check Fuel, FACE 1 and FACE 6. A significant offset in EGR fraction is observed when comparing the shakedown fuel to the other fuels. Upon further investigation it was found that for tests between the shakedown fuel and others with similar $\mathrm{O}_{2}$ concentrations, the exhaust $\mathrm{CO}_{2}$ concentration was also very similar, but the intake $\mathrm{CO}_{2}$ concentration was nearly one percent lower. To compensate for this presumed measurement error, a linear fit was obtained through the data points of fuels other than the shakedown fuel. The resulting formula was applied to the oxygen concentrations for the shakedown fuel providing a corrected EGR fraction displayed in Figure 49. Only the corrected EGR fractions for the shakedown fuel are presented in the remainder of the base configuration section. 


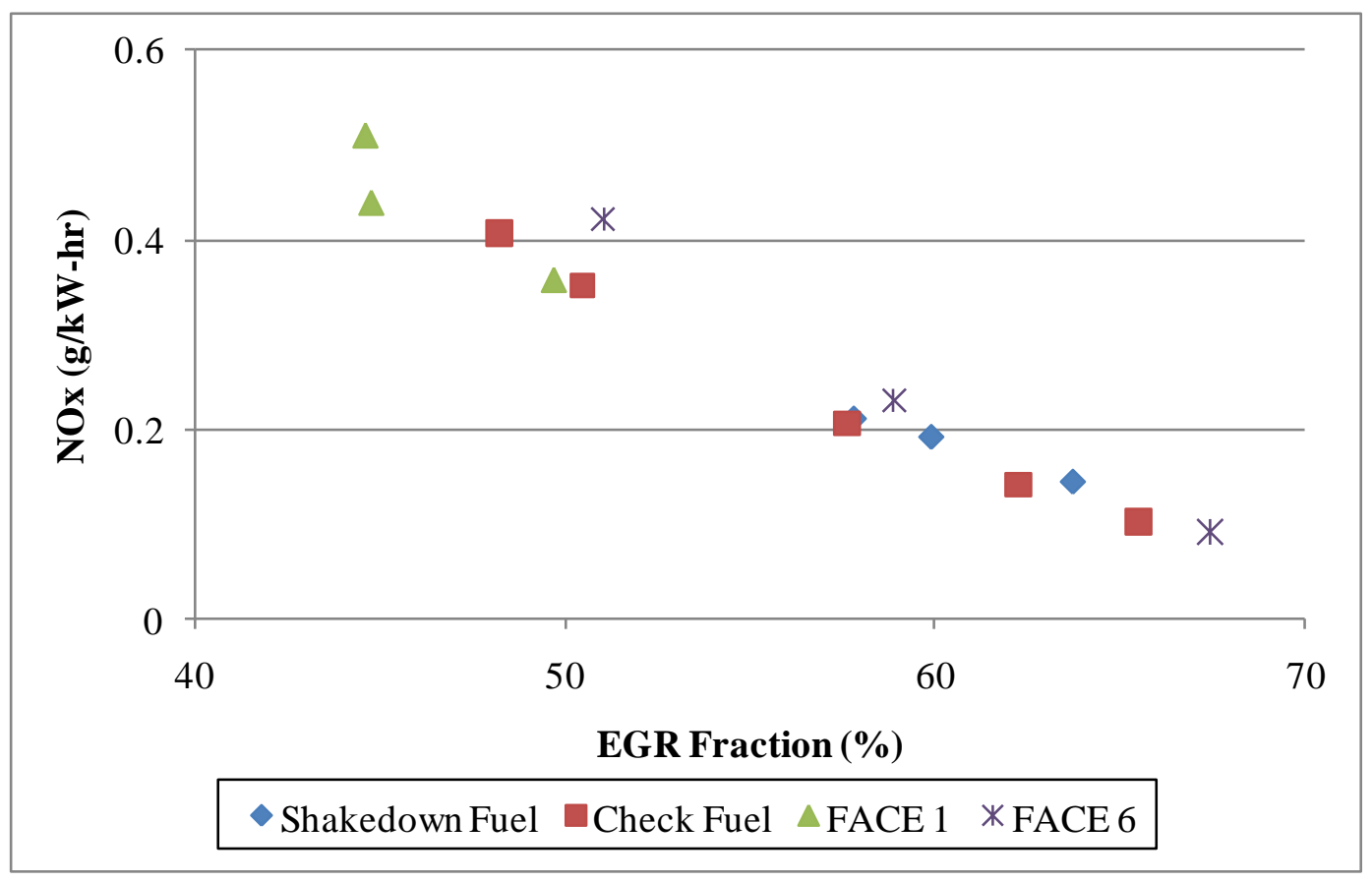

Figure 50: $\mathrm{NO}_{\mathrm{x}}$ Emissions for the Base Configuration

Figure 50 displays an expected trend of decreased $\mathrm{NO}_{\mathrm{x}}$ emissions as EGR levels are increased. At this operating condition, results for all the fuels essentially fall on the same trend line leaving no discernable differences due to fuel properties evident. While EGR fraction appears to be the only variable effecting $\mathrm{NO}_{\mathrm{x}}$ emissions in Figure 50, the effect of fuel properties can be seen on the allowable ranges of EGR fraction to drive NOx emission down. The low cetane fuel (FACE 1), cannot sustain nearly as much EGR as that of higher cetane fuels due to the prevalence of erratic combustion. This results in FACE 1 having the highest "minimum" $\mathrm{NO}_{\mathrm{x}}$ measurement, yet still comparable $\mathrm{NO}_{\mathrm{x}}$ emissions to other fuels at similar EGR fractions. 


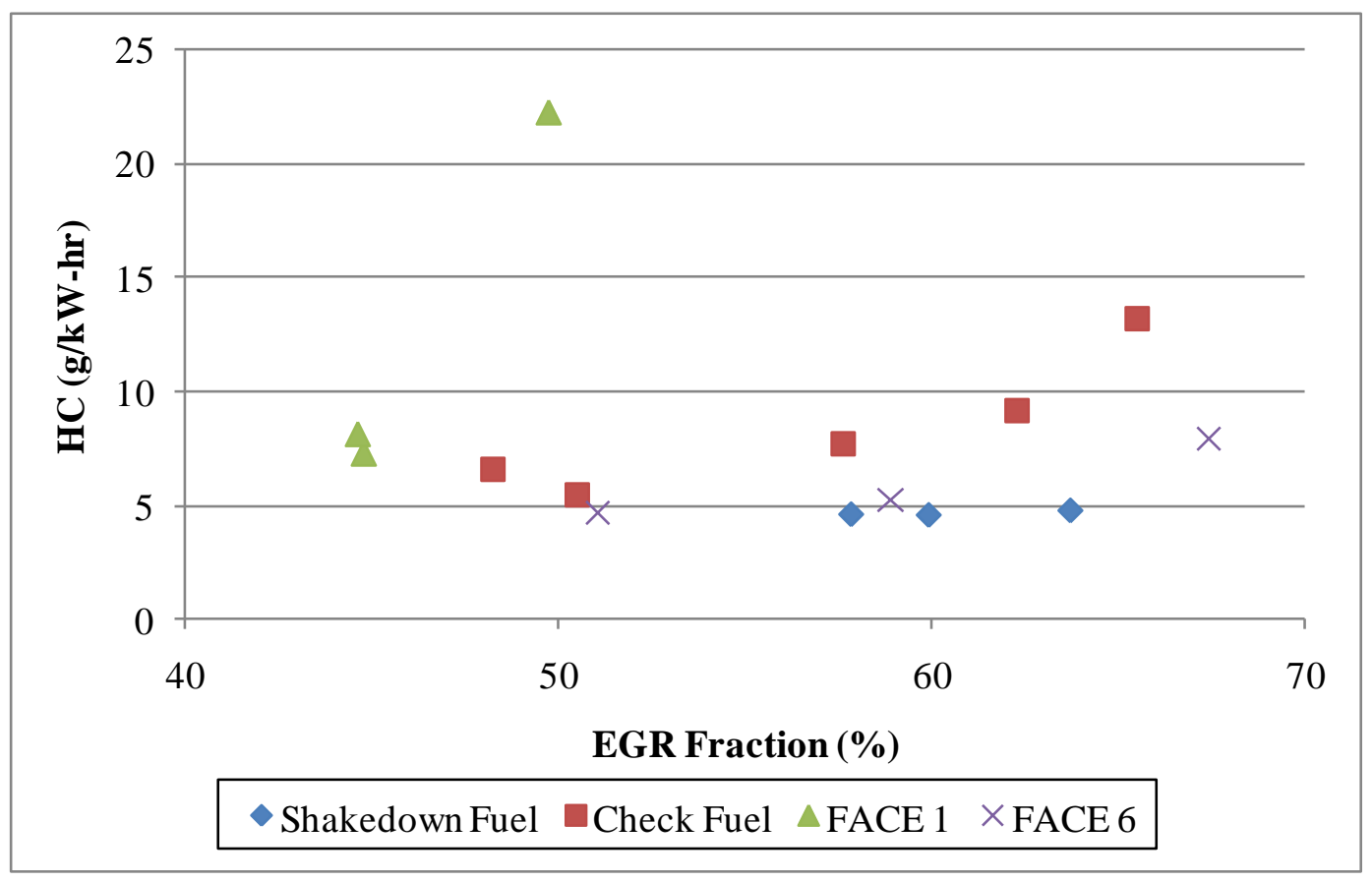

Figure 51: HC Emissions for the Base Configuration

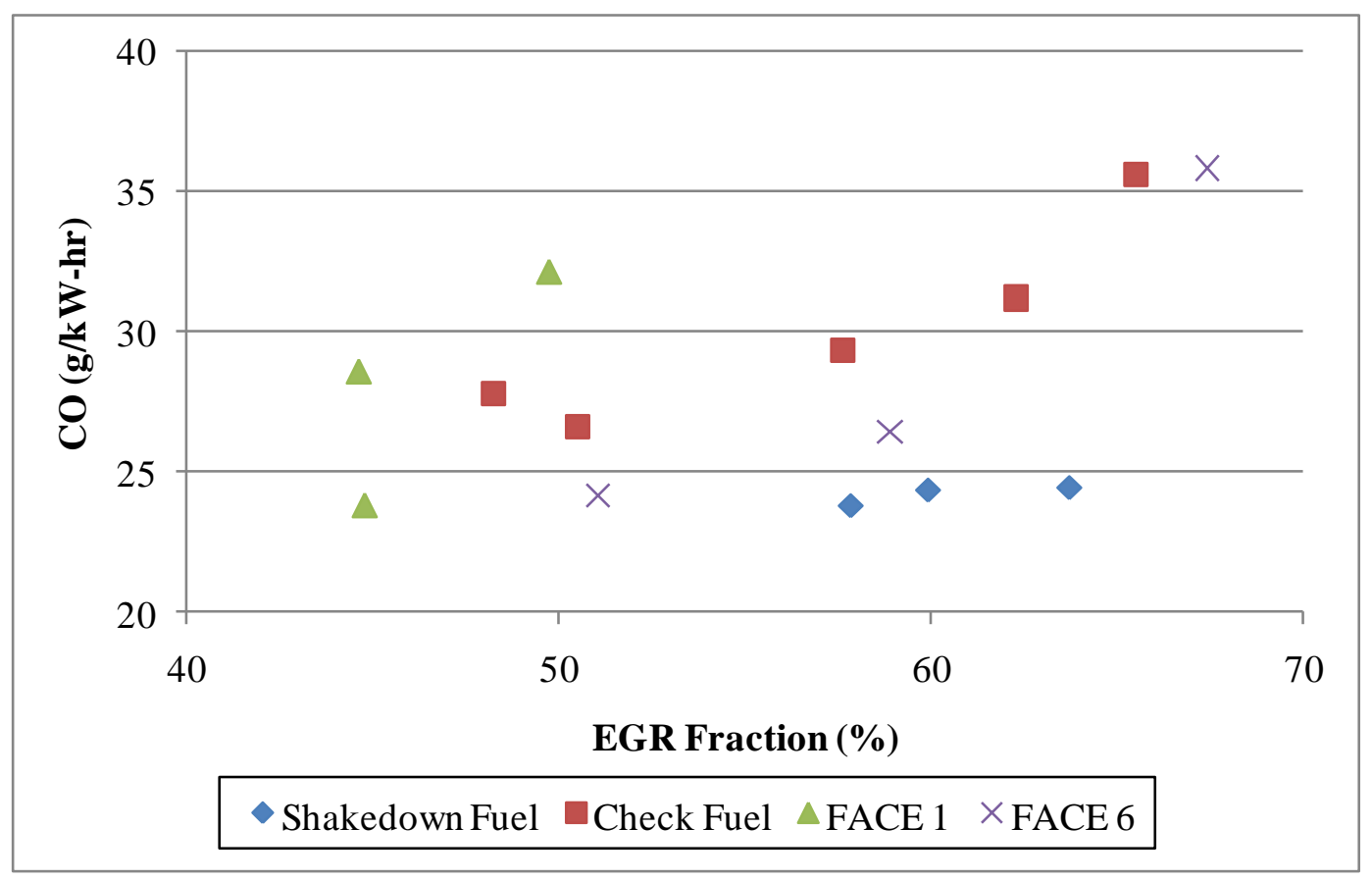

Figure 52: CO Emissions for the Base Configuration

Figure 51 demonstrates that the shakedown fuel exhibits the lowest overall $\mathrm{HC}$ emissions. HC emissions for FACE 1 are difficult to compare due to the appearance of misfire at high EGR rates. The low cetane number of FACE 1 limits the amount of EGR that can be 
utilized and at approximately 50 percent EGR fraction significantly elevated HC emissions and pressure traces mimicking motoring curves were observed. These two criteria comprise the definition of misfire used in this research. The operation of FACE 6 displays less HC emissions than that of the check fuel, lending itself to be more receptive of higher EGR fractions due to its increased cetane number. Complementing this observation is the measurement of $\mathrm{HC}$ emissions for the shakedown fuel and its assumed high cetane number.

$\mathrm{CO}$ emissions presented in Figure 52 display a trend of reduced $\mathrm{CO}$ formation depending on the fuel combusted. FACE 1 retains the highest CO emissions for similar EGR fractions, followed by the Check Fuel, and subsequently FACE 6. The shakedown fuel shows minimal CO emissions in comparison and also does not display as strong of a positive slope with increasing EGR fraction. As CO emissions are reduced from FACE 1 to the check fuel, and the check fuel to FACE 6; cetane number increases, as well as T90 and the flash point temperature. From literature presented in Section 2.3, the trends in distillation temperature and flash point temperature appear less likely to affect $\mathrm{CO}$ emissions compared to cetane number.

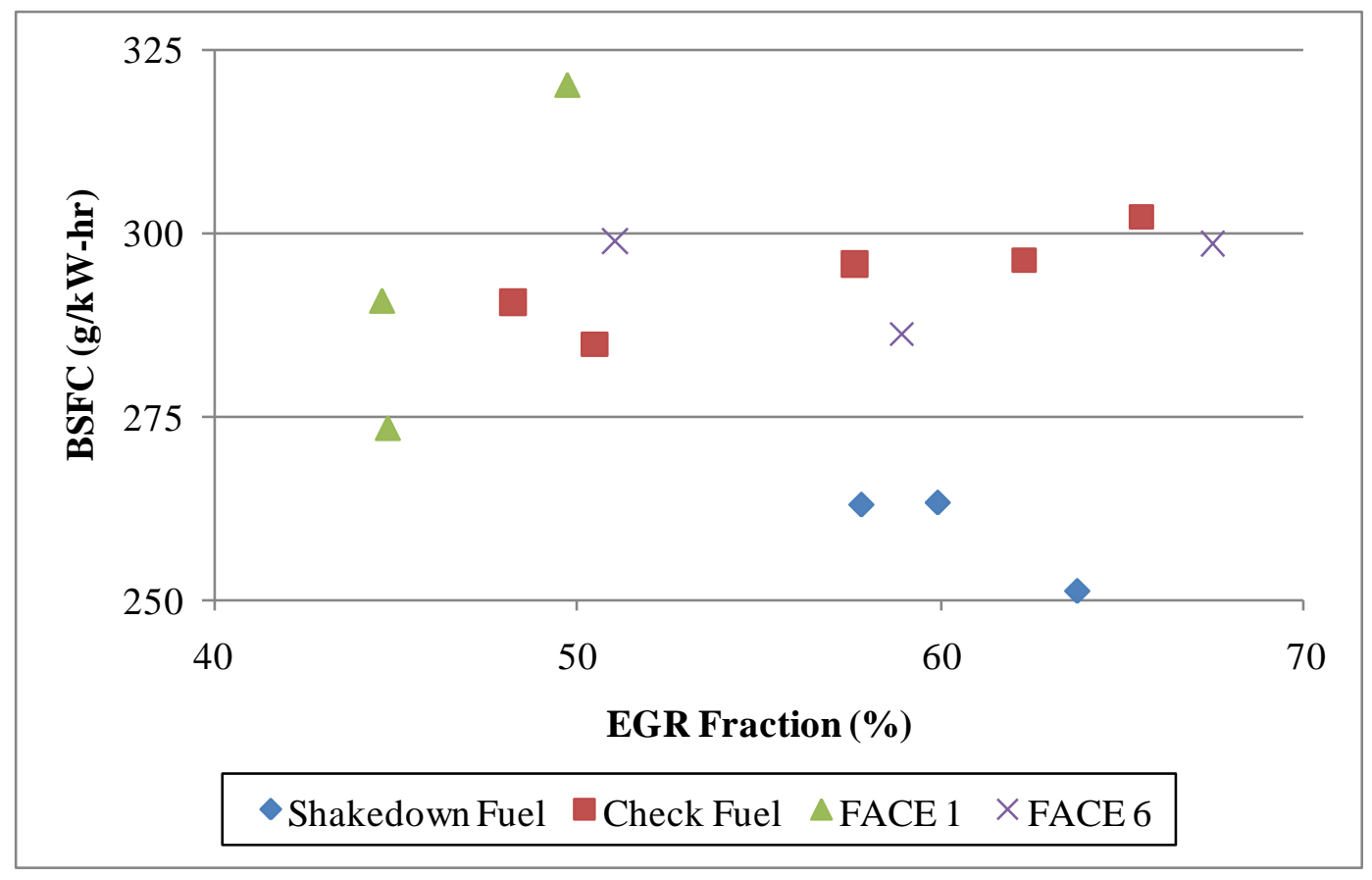

Figure 53: Fuel Consumption for the Base Configuration 


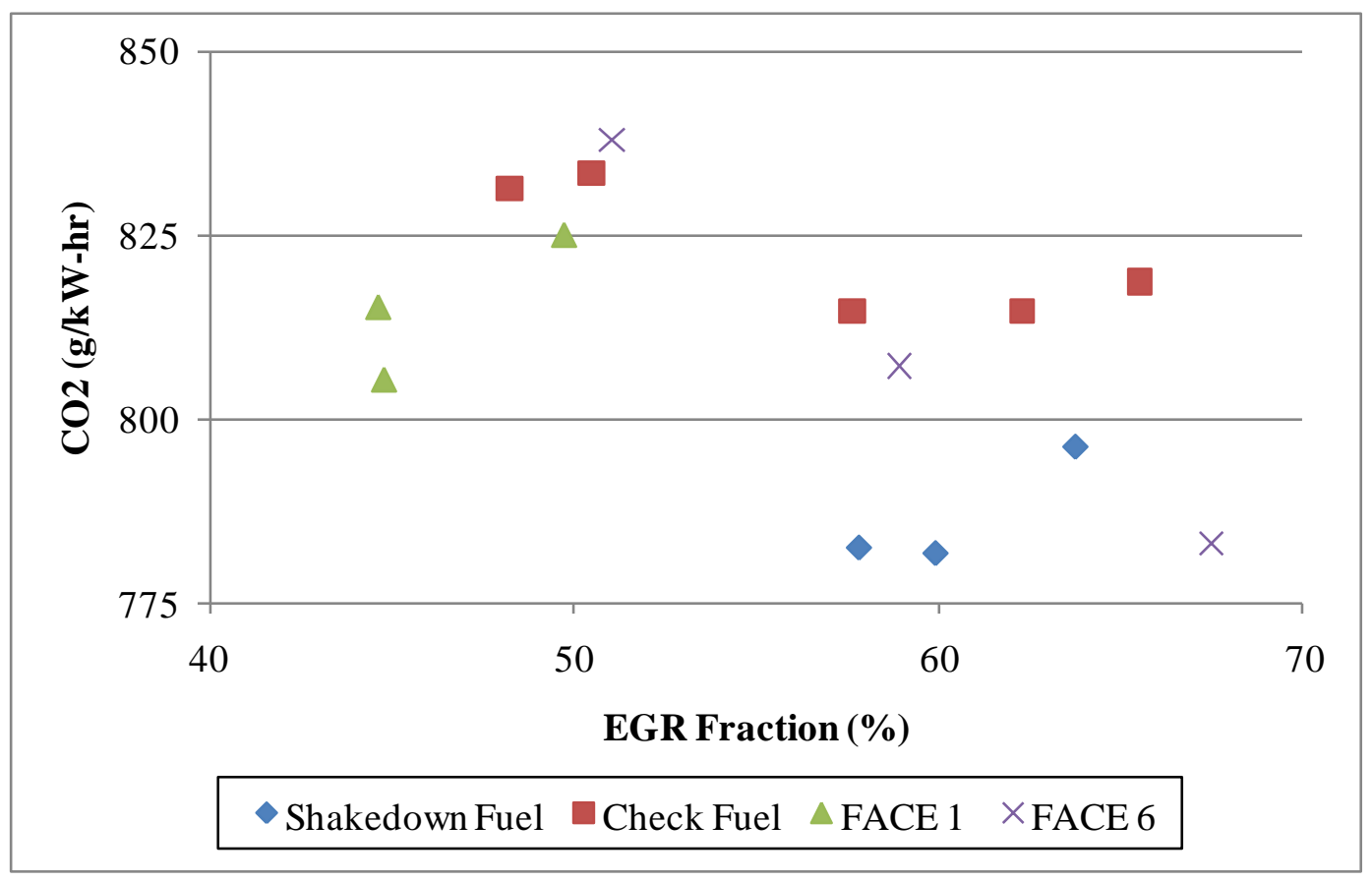

Figure 54: $\mathrm{CO}_{2}$ Emissions for the Base Configuration

Fuel consumption data presented in Figure 53 show no true distinguishable trends based on fuel properties for the check fuel, FACE 1, and FACE 6. Slightly increasing fuel consumption is apparent for the check fuel as EGR fraction increases. An interesting observation is the shakedown fuel exhibits the lowest BSFC. A measurement error or different calibration of the fuel scale load cell could attribute to this low measurement. However the accuracy of the shakedown fuel's low BSFC is further confirmed by the $\mathrm{HC}, \mathrm{CO}$, and $\mathrm{CO}_{2}$ emissions presented in Figure 51, Figure 52, and Figure 54, respectively. The measurements of these species for the shakedown fuel were minimal or very close to the minimum eluding to a low fuel consumption calculation via the carbon balance method. 


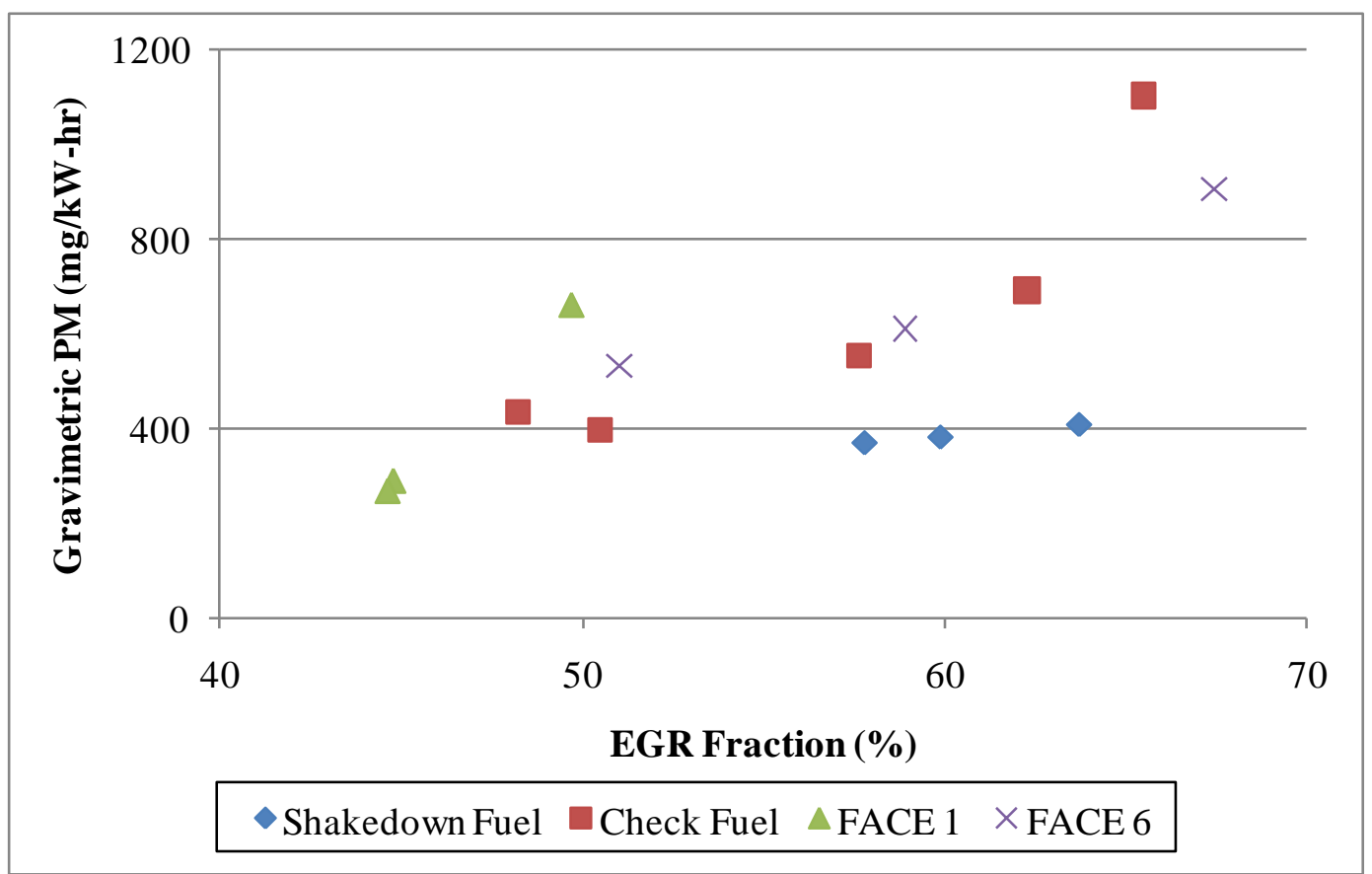

Figure 55: Gravimetric Based PM Emissions for the Base Configuration

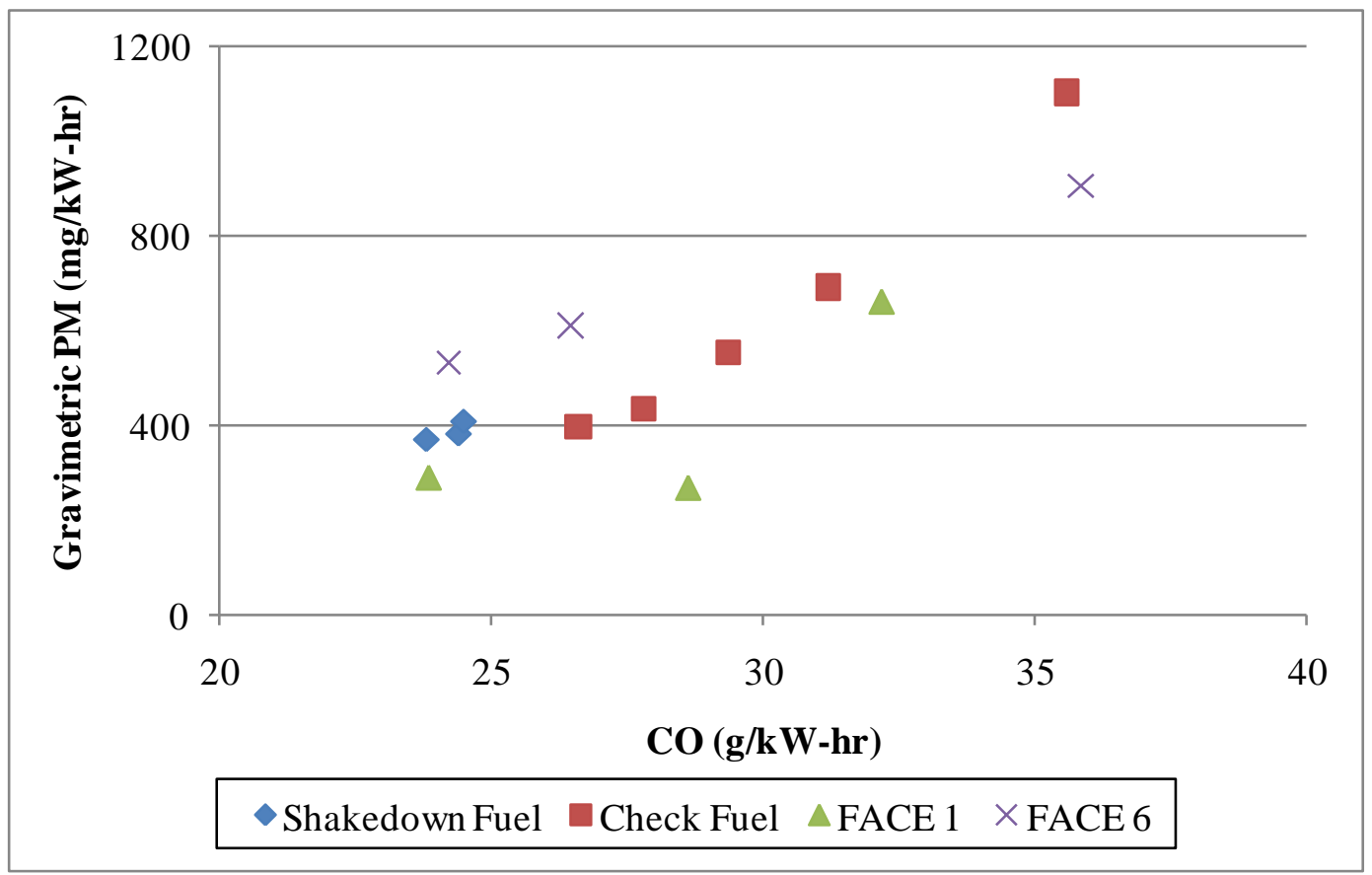

Figure 56: Gravimetric Based PM Emissions as a Function of $\mathrm{CO}$ emissions for the Base Configuration

PM emissions represented in Figure 55 display similar trends to the $\mathrm{HC}$ and $\mathrm{CO}$ emissions shown in Figure 51 and Figure 52, respectively. It is believed that a significant portion of the PM emissions are SOF based, more specifically, the affect of raw fuel on the 
filters. This is supported by tests with large $\mathrm{HC}$ emissions also exhibiting high PM emissions. A black carbon measurement for these tests such as the soot sensor (data displayed in Figure 45) would likely provide a soot measurement significantly less than the PM measurements presented due to the absence of SOF consideration when measuring soot. $\mathrm{CO}$ emissions partly contradict this prediction. Elevated $\mathrm{CO}$ emissions are generally regarded as a decent estimator of high soot emissions ( $\mathrm{CO}$ and soot emissions both heavily depend on locally rich regions in the combustion chamber) contributing to the total PM emissions. Trends of PM and CO for each of the fuels compare rather closely insinuating that PM and soot emissions increase synonymously. This is displayed in Figure 56 which demonstrates increased PM emissions with greater $\mathrm{CO}$ formation.

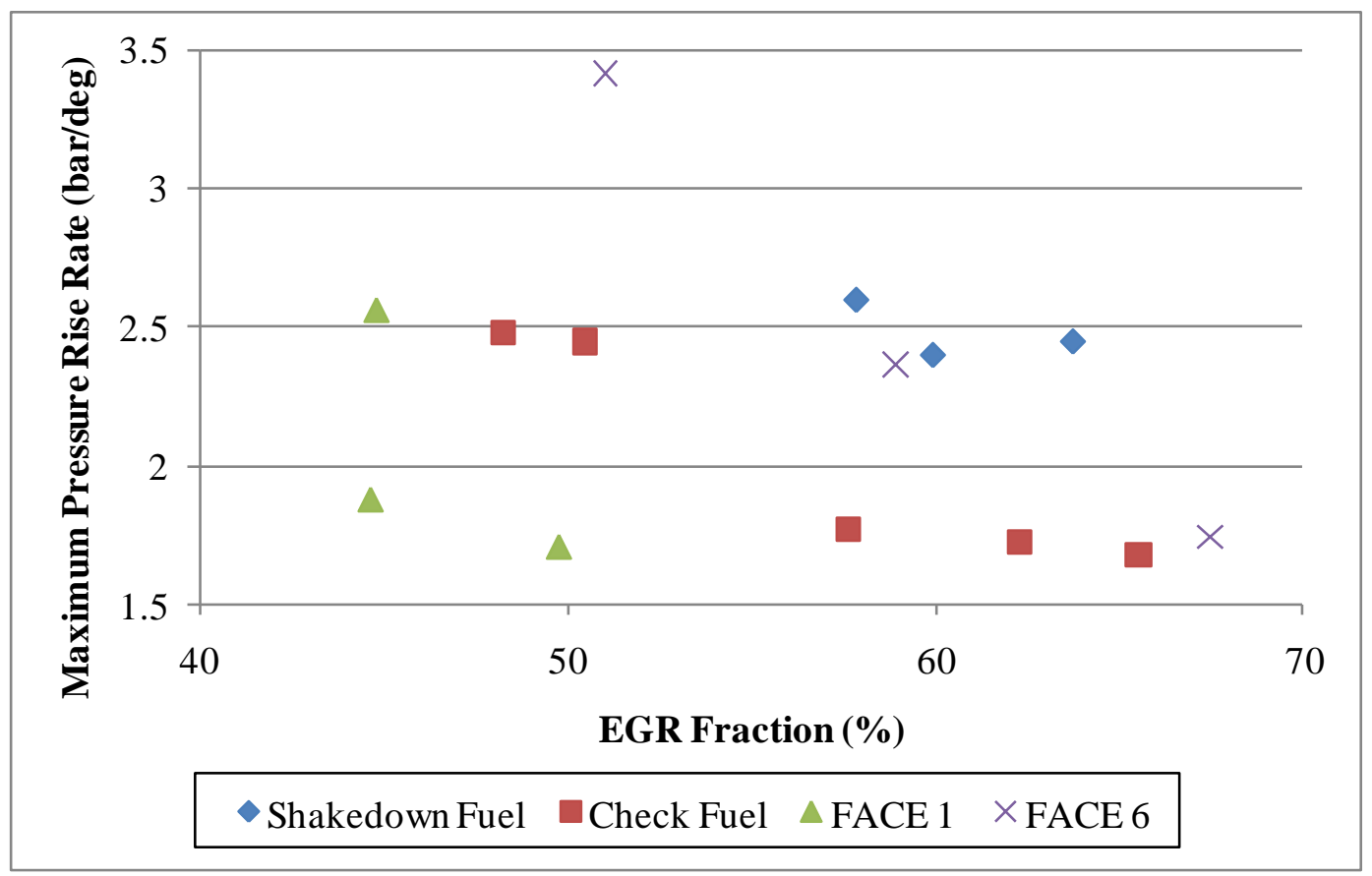

Figure 57: Pressure Rise Rate for the Base Configuration

Figure 57 visually quantifies the maximum in-cylinder pressure rise rate experienced during the testing of various fuels. The obvious and expected trend is reduced PRR concurrent with increased EGR levels. At relatively high EGR levels, the low PRR results in lower incylinder temperatures, while increasing fuel consumption and $\mathrm{CO}, \mathrm{HC}$, and PM emissions. This is especially apparent for the "mid" cetane number check fuel. Higher cetane number fuels such as FACE 6 and the shakedown fuel exhibit a much larger pressure rise rate at synonymous EGR fractions. Notice the low PRR for FACE 1 at an EGR fraction of 50 percent. Increasing this 
EGR level anymore would most certainly result in complete misfire. Besides EGR fraction it is safe to say that the PRR is predominantly affected by the cetane number of the fuels.

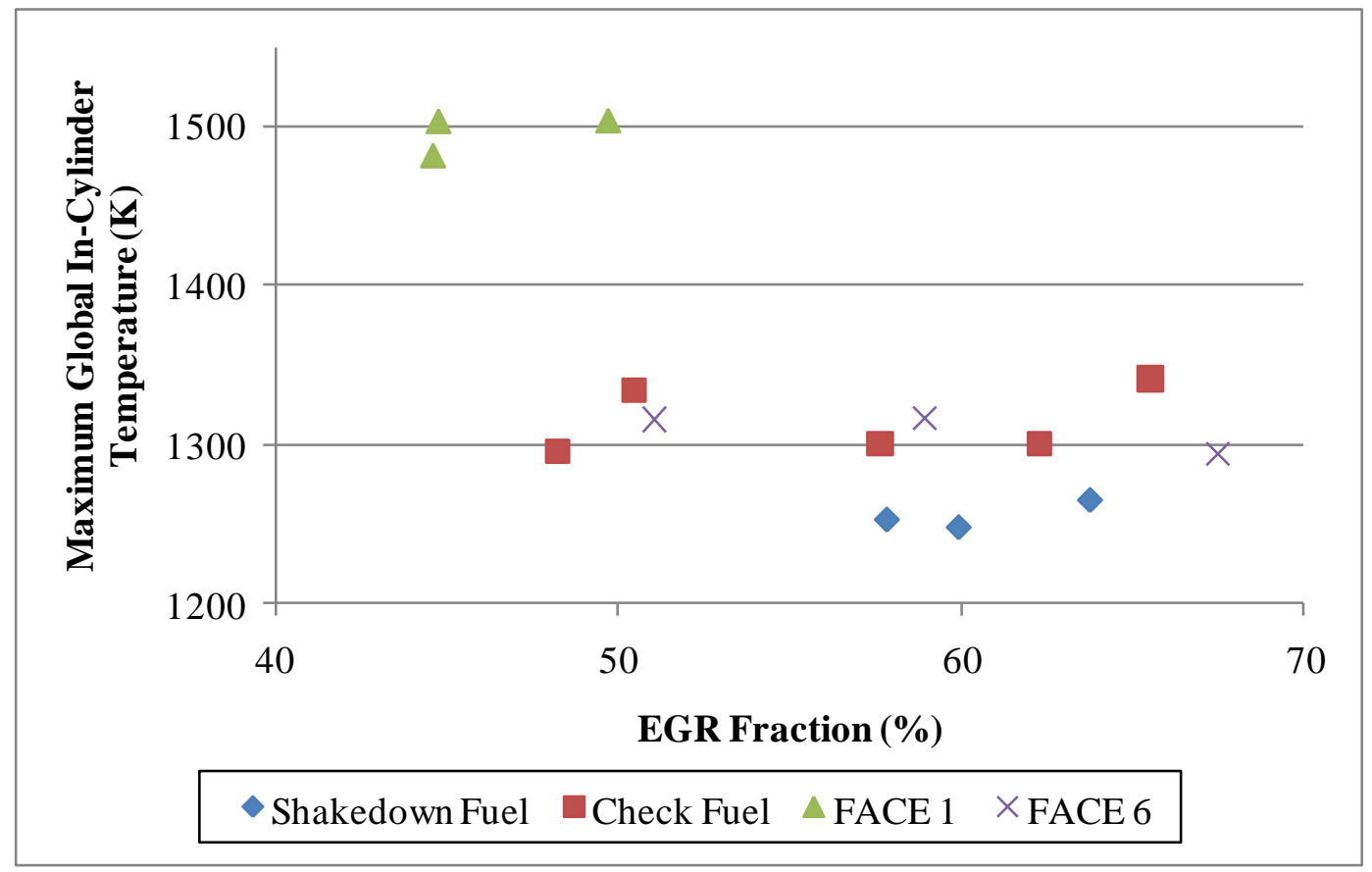

Figure 58: Maximum In-Cylinder Temperature for the Base Condition

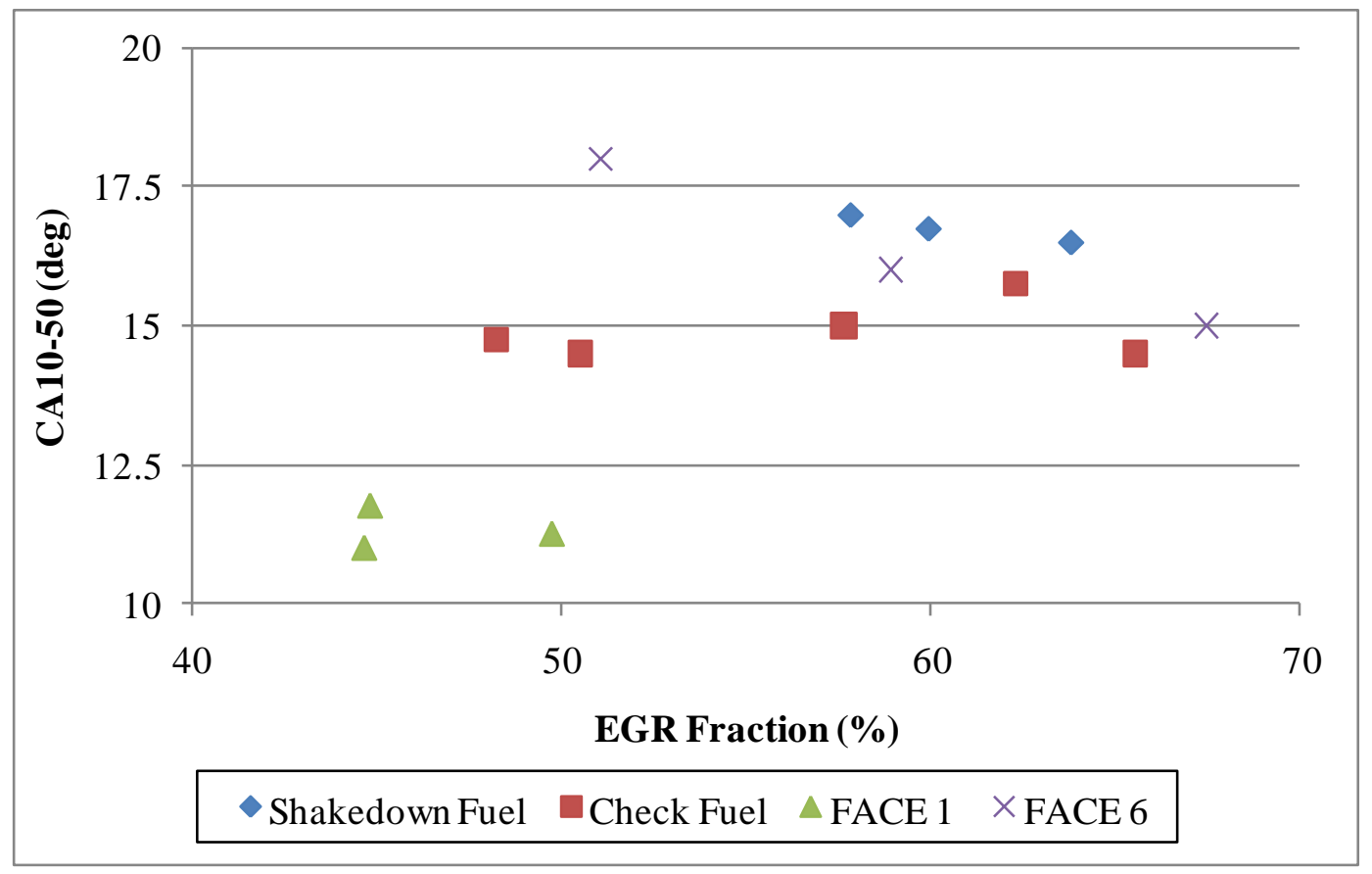

Figure 59: CA10-50 for the Base Condition

Maximum global in-cylinder temperatures plotted in Figure 58 do not exhibit a trend similar to the $\mathrm{NO}_{\mathrm{x}}$ emissions displayed in Figure 50, as might be expected during conventional 
combustion. Note that this calculation is an average temperature and may not be fully representative of the flame temperature on which $\mathrm{NO}_{\mathrm{x}}$ formation depends. Combustion of FACE 1 results in the highest in-cylinder temperature of all fuels. This is likely due to the necessity of intake air heating for this fuel. IMT averages around $70{ }^{\circ} \mathrm{C}$ for this fuel while averaging approximately $50^{\circ} \mathrm{C}$ for other fuels. Complementing the in-cylinder combustion data, the duration from 10 percent to 50 percent mass fraction burned (CA10-50), presented in Figure 59, gives further insight on the combustion event occurring for each fuel. This measurement is significantly lengthened by the dual heat release rate events observed during the split injection strategy. If 50 percent of the mass is not burned during the first heat release rate event, the CA10-50 is drastically increased. This is apparent for all the tests presented. Regardless of this measurement phenomenon, it is displayed that a quicker burn (low CA10-50) results in greater in-cylinder temperatures. This is exemplified by FACE 1 and in part by the shakedown fuel, which both exist at other ends of the in-cylinder temperature spectrum.

\subsubsection{Start of Injection Sweeps}

\subsubsection{Pilot SOI Sweeps}

While retaining a main SOI timing of TDC for all tests, the pilot SOI timing was swept from $25^{\circ}$ to $45^{\circ} \mathrm{BTDC}$ and $30^{\circ}$ to $55^{\circ} \mathrm{BTDC}$ in increments of $5^{\circ}$ for FACE 1 and FACE 6 , respectively. The allowable range of pilot SOI timing was dictated by considering reasonable $\mathrm{NO}_{\mathrm{x}}$ emissions, PRR at retarded SOI timings and the limits of combustion based on misfire at advanced SOI timings. Rail pressure during testing of FACE 1 and FACE 6 was held at 800 bar and 1200 bar respectively. The intake air heater was utilized during the testing of FACE 1 to prevent misfire, while fresh air was cooled for FACE 6 with the use of a fan propelling air across the intercooler. Average IMT for FACE 1 tests was $71^{\circ} \mathrm{C}$ and $52^{\circ} \mathrm{C}$ for FACE 6 tests. Variance of IMT was less than 5 percent from the average for both fuels. Average exhaust temperature for FACE 1 and FACE 6 tests were nearly identical; $339^{\circ} \mathrm{C}$ and $338^{\circ} \mathrm{C}$ respectively. Variance of exhaust temperatures measured during testing of FACE 1 was approximately 12 percent of the average and 10 percent of the average for FACE 6. 


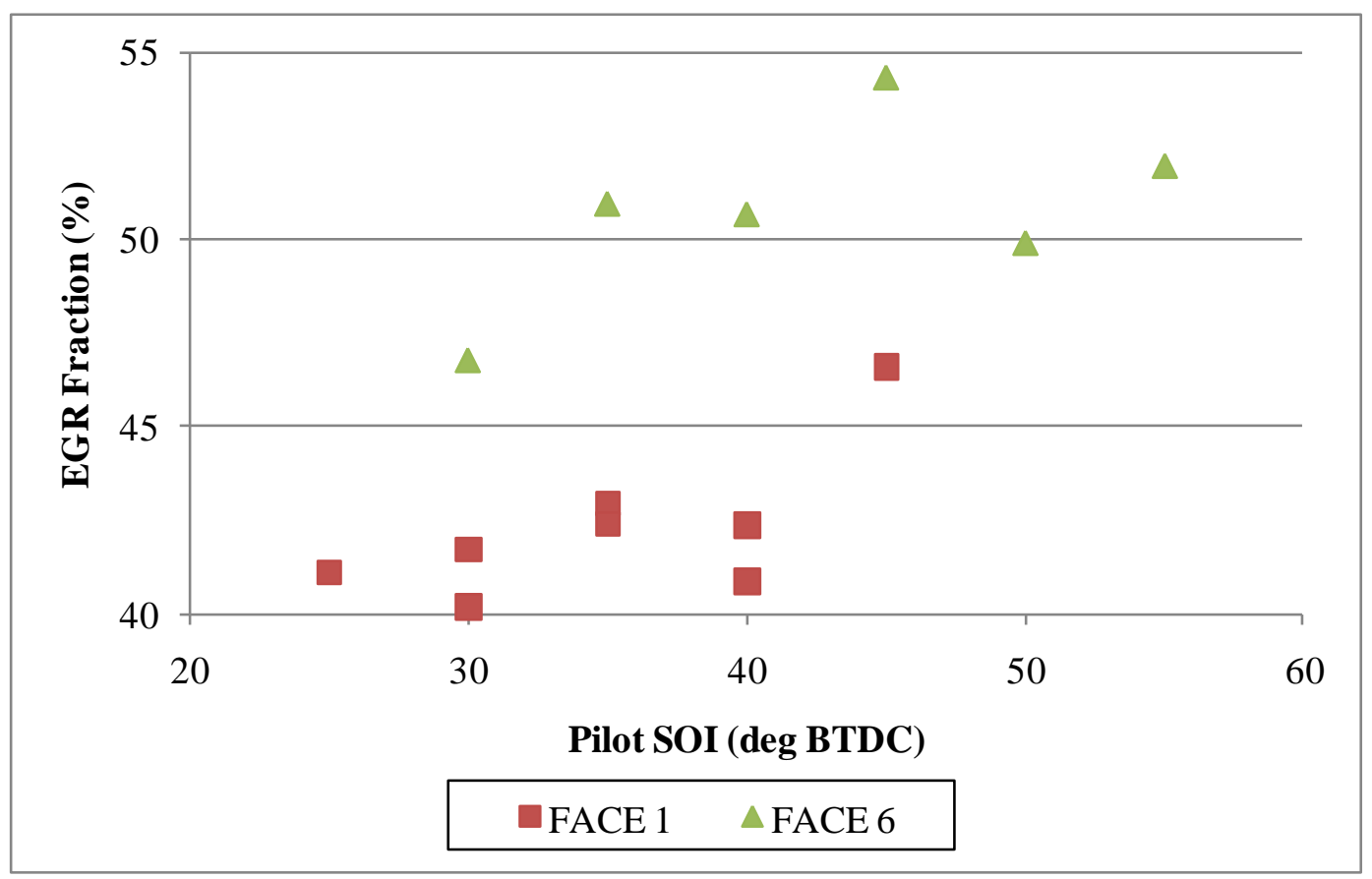

Figure 60: EGR Fraction during Pilot SOI Sweeps

Allowable EGR levels of various fuels have been discussed previously. FACE 1 tests were performed at an EGR fraction of 40 to 43 percent except for the $45^{\circ}$ SOI which utilized an EGR fraction slightly greater than 46 percent exhibited in Figure 60. EGR levels for FACE 6 ranged from 46 to 55 percent, with the majority of tests operating at an EGR fraction of 49 to 52 percent. Due to the dominance of EGR on combustion and its resulting effects on emissions and performance it is important to consider the effects of EGR in addition to pilot SOI timing, especially for tests with significantly lower or higher EGR fractions. 


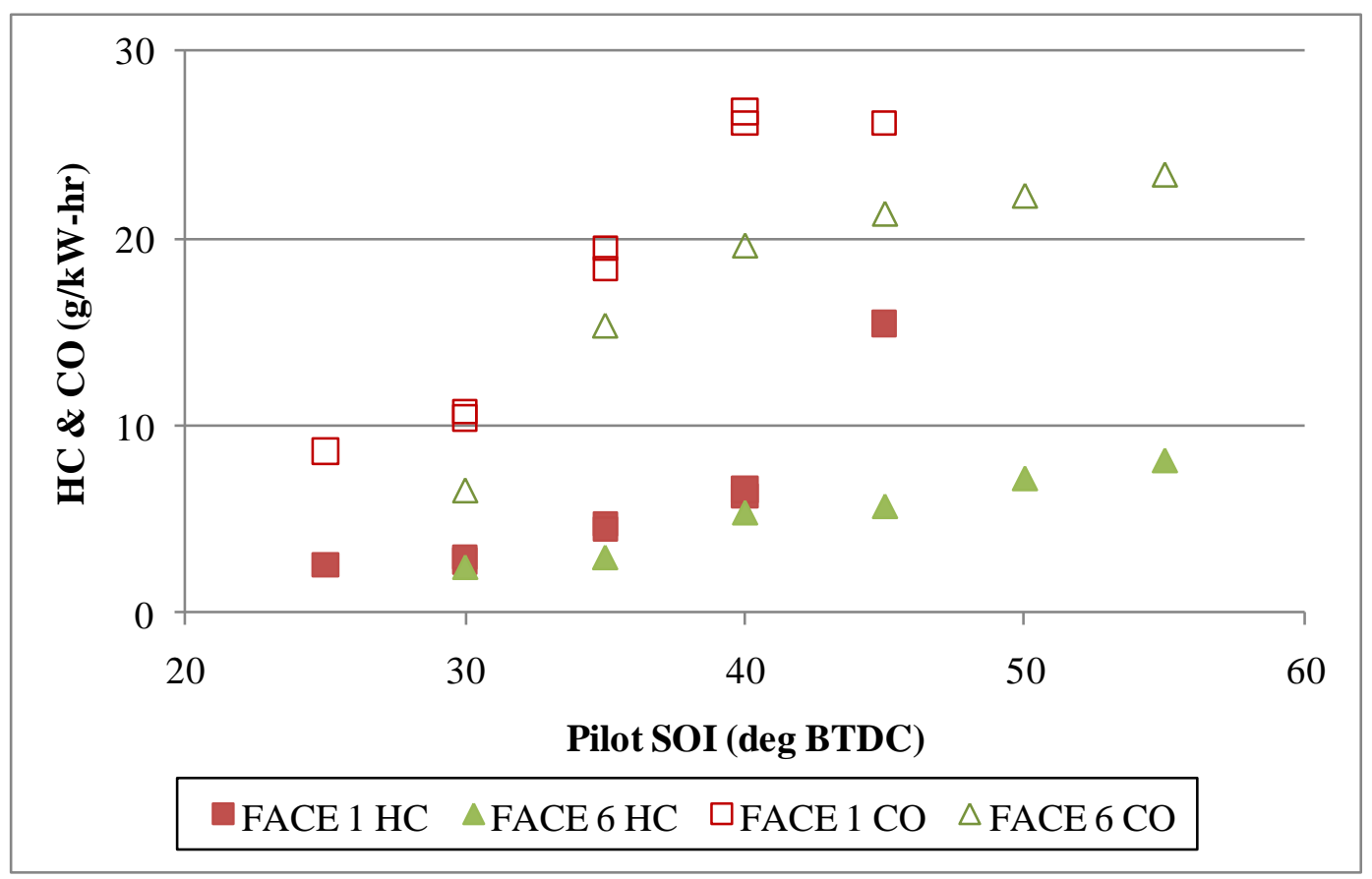

Figure 61: HC and CO Emissions during Pilot SOI Sweeps

Synonymous with many forms of advanced combustion, an increase in $\mathrm{HC}$ and $\mathrm{CO}$ emissions displayed in Figure 61 is observed as the pilot SOI timing is advanced. The increasing trend of $\mathrm{HC}$ emissions can be contributed to increased wall wetting as the SOI timing is significantly advanced. Additionally, this growth in $\mathrm{HC}$ emissions also provokes a lower local equivalence ratio providing a mechanism of increased $\mathrm{CO}$ formation. Realtively linear trends are observed for both fuels and both emissions species, noting that deviations from the linear trend are due to significantly different EGR levels. 


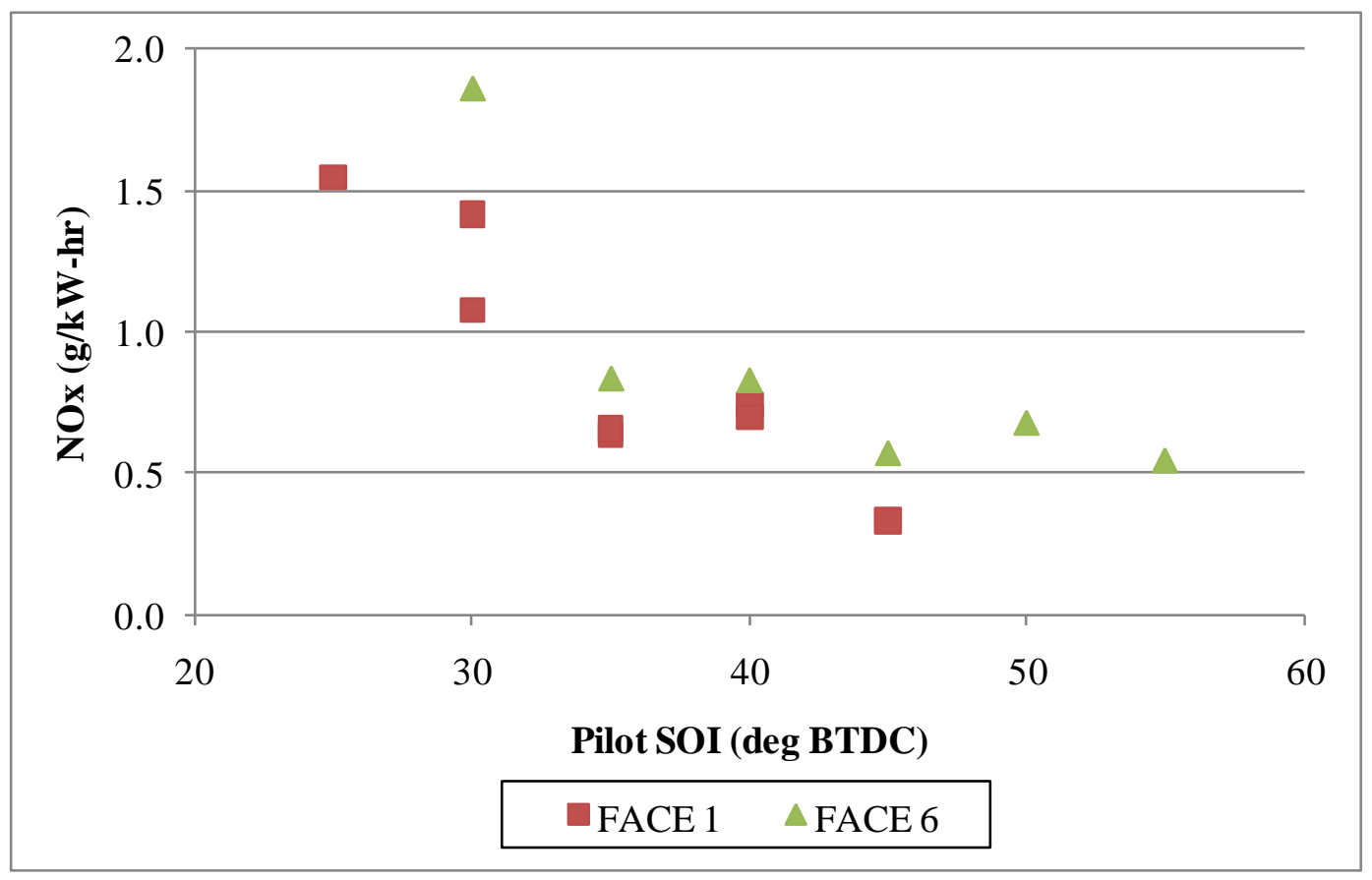

Figure 62: $\mathrm{NO}_{\mathrm{x}}$ Emissions during Pilot SOI Sweeps

Presented in Figure 62, a decrease in $\mathrm{NO}_{\mathrm{x}}$ emissions is present as the pilot SOI timing is advanced. Outliers from the trends can once again be considered an effect of differing EGR levels from the sought fraction. Hypotheses on the reduction of $\mathrm{NO}_{\mathrm{x}}$ emissions with advancing pilot SOI include the sought after homogeneous charge resulting from more time for mixing, and lower in-cylinder temperature due to lower in-cylinder pressures. By advancing the pilot SOI timing, additional time is provided for mixing of the air and fuel mixture resulting in a more homogenous charge. This better mixed air and fuel charge combusts quicker with less flame propagation allowing less time for $\mathrm{NO}_{\mathrm{x}}$ formation. The second hypothesis relates to the reduced in-cylinder PRR (possibly linked to better mixing) as pilot SOI timing is advanced. Burn duration for the tests comprising each fuel data set are similar; coupling this with a lower PRR displayed in Figure 66, lower maximum in-cylinder pressures will be present with accompanying lower maximum in-cylinder temperatures. 


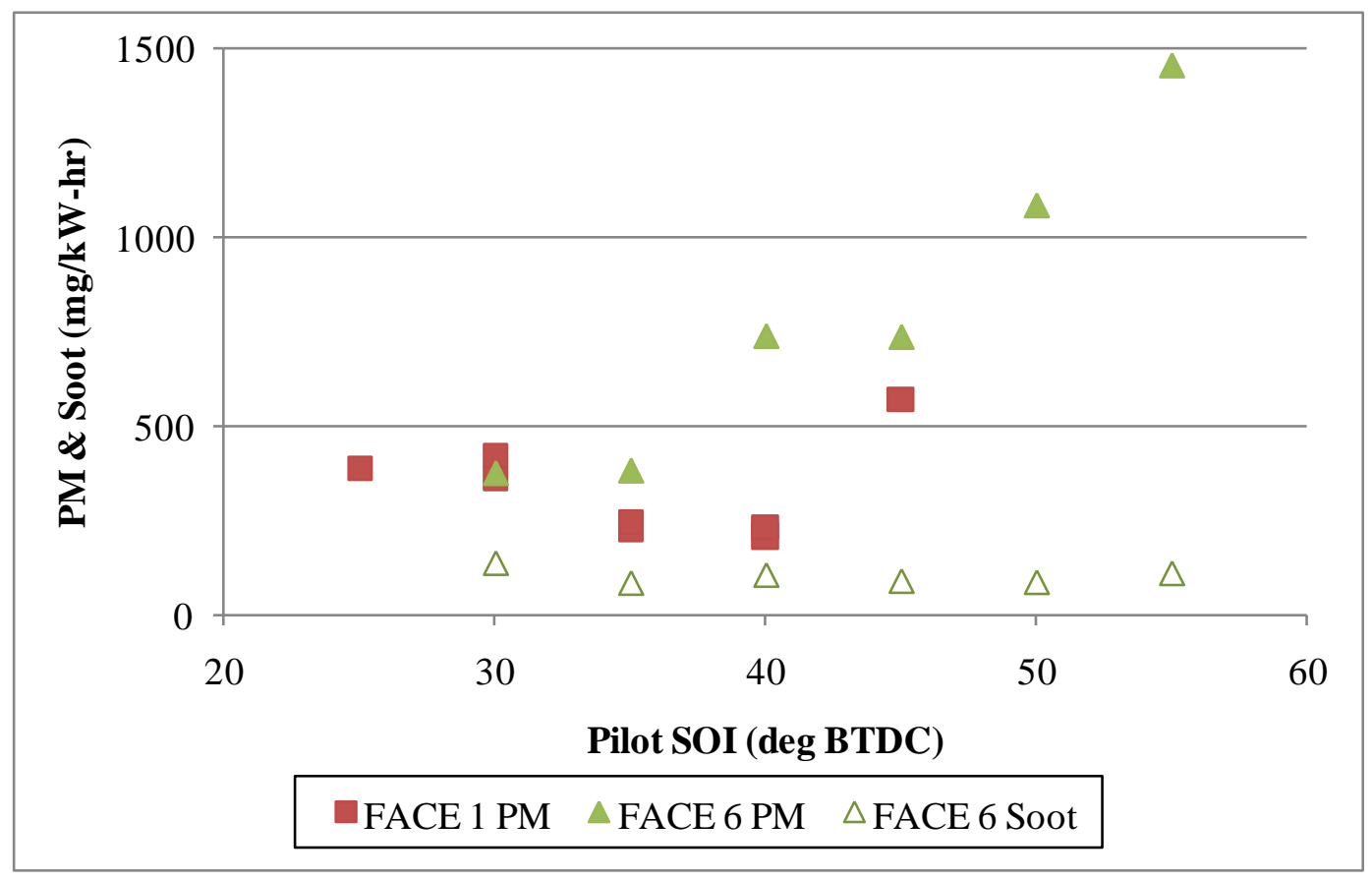

Figure 63: PM \& Soot Emissions during Pilot SOI Sweeps

Gravimetric based PM measurements and photo acoustic soot measurements (only for FACE 6) are compared in Figure 63. Similar to the affect of high EGR levels on PM emissions (raw fuel deposited on filters), significantly advanced pilot SOI timings exhibit the same phenomenon. This is especially apparent when moving beyond $45^{\circ}$ BTDC pilot SOI for FACE 6. The black carbon based soot measurements displayed are substantially lower than the gravimetric based PM measurement. Note that the soot measurements for FACE 6 exhibit a nearly horizontal slope while the PM measurements for FACE 6 have a considerable positive slope. This insinuates that the effect of SOF on total PM emissions is increasing as the pilot SOI timing is advanced. Regarding FACE 1 PM emissions, at pilot SOI timings less than $35^{\circ}$, darker filters were observed hinting that more soot was measured. As the SOI timing is advanced the PM measurements drop until $45^{\circ}$ BTDC were they are elevated again due to increased SOF (namely unburned fuel inferred from very light filter coloring). 


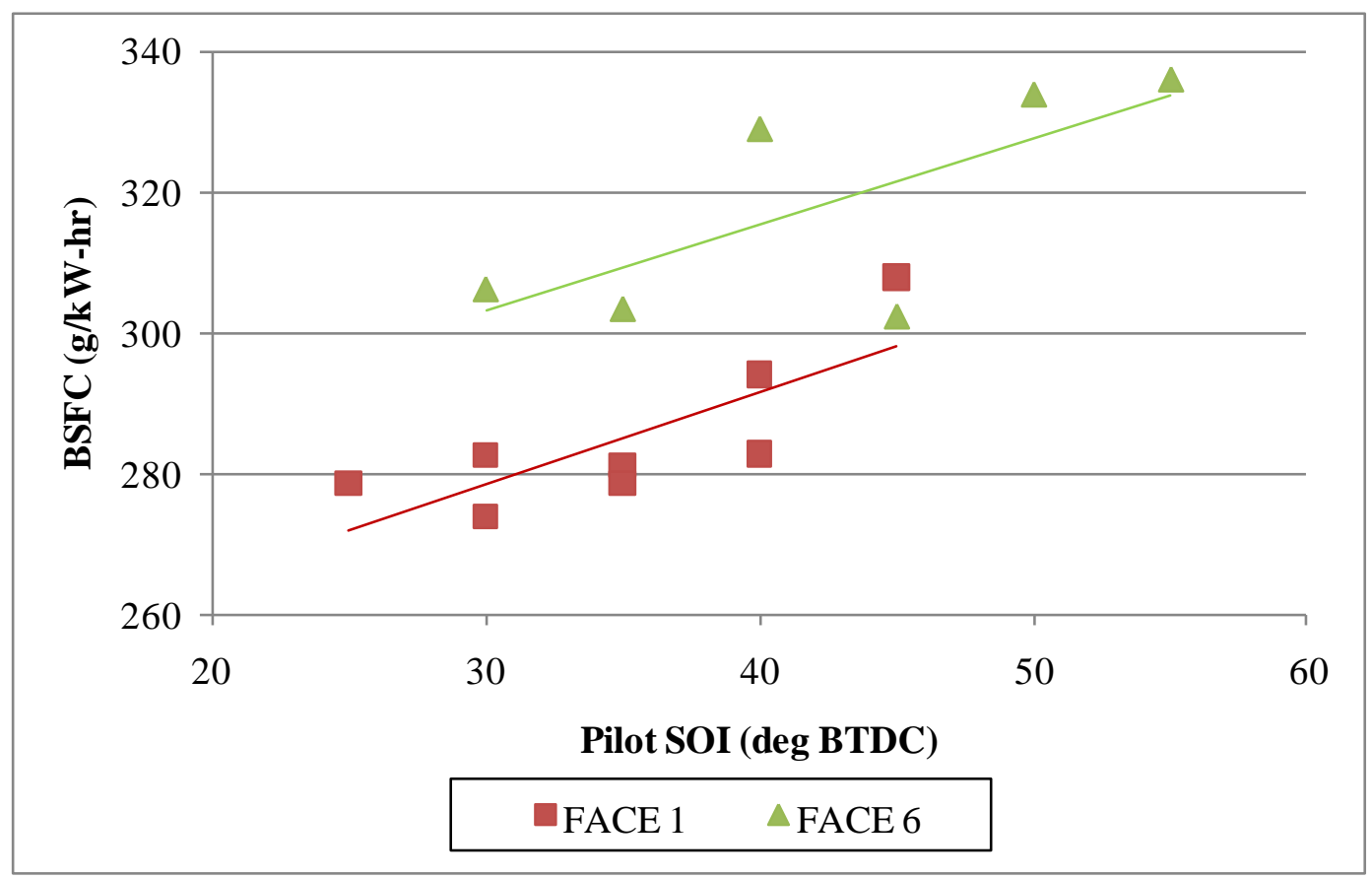

Figure 64: BSFC during Pilot SOI Sweeps

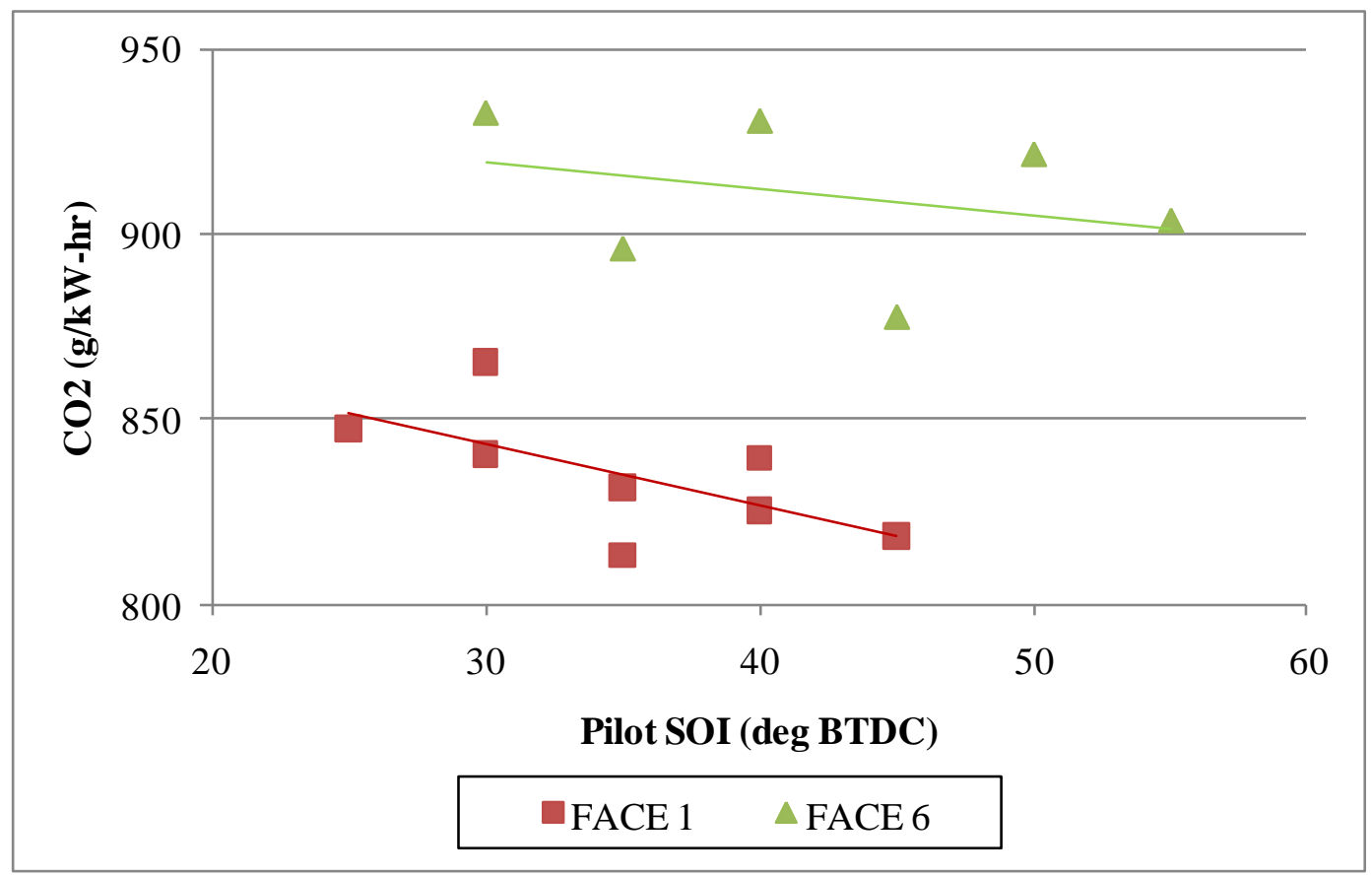

Figure 65: CO2 Emissions during Pilot SOI Sweeps

Gravimetric based fuel consumption measurements, displayed in Figure 64, are contradicted by $\mathrm{CO}_{2}$ emissions measurements shown in Figure 65. Fuel consumption demonstrates a positive linear trend as the pilot SOI timing is advanced for both fuels. Although this slope is very minimal, its cause is most likely due to fuel wasted from wall wetting resulting 
in the need for more fuel to achieve the target BMEP. Alleviating or reducing the amount of wall wetting by catering the injection spray angle to the SOI timing could possibly result in a negative slope if better mixing is indeed being achieved at further advanced pilot SOI timings. $\mathrm{CO}_{2}$ emissions do not display as clear of a trend. If any trend exists at all, $\mathrm{CO}_{2}$ emissions are decreasing slightly as the pilot SOI timing is advanced contradicting the increasing fuel consumption trend. A noteworthy point regarding fuel consumption and $\mathrm{CO}_{2}$ emissions is FACE 1 exhibits overall lower measurements than FACE 6.

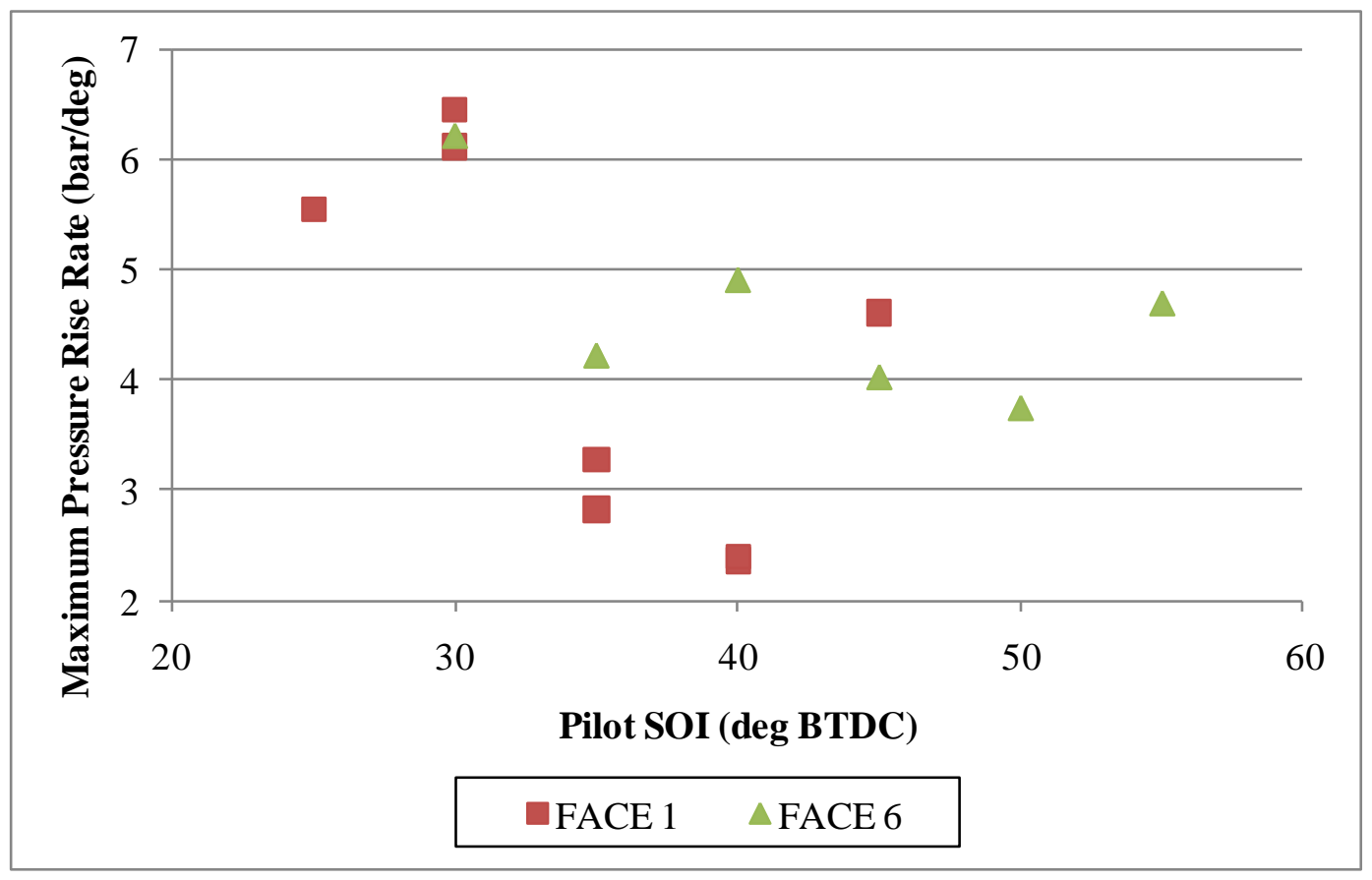

Figure 66: Maximum Pressure Rise Rate during Pilot SOI Sweeps

Pressure rise rates for pilot SOI timings greater than $30^{\circ} \mathrm{BTDC}$ are limited to a safe value below 5 bar/degree displayed in Figure 66. The PRR for SOI timings of $30^{\circ}$ BTDC and less are higher, yet still not breaching a dangerous threshold. Higher PRR at $35^{\circ}$ and $40^{\circ}$ BTDC pilot SOI timing for FACE 6 versus that of FACE 1 are likely a direct result of the higher cetane number, especially considering that FACE 6 tests were performed at a larger EGR fraction. Reasoning behind this lies in the combustion phasing for each fuel. The higher cetane number for FACE 6 results in a shorter ignition delay. This phases the combustion of FACE 6 before TDC equating in a higher PRR. This phenomenon is demonstrated in Figure 69 and Figure 70. 


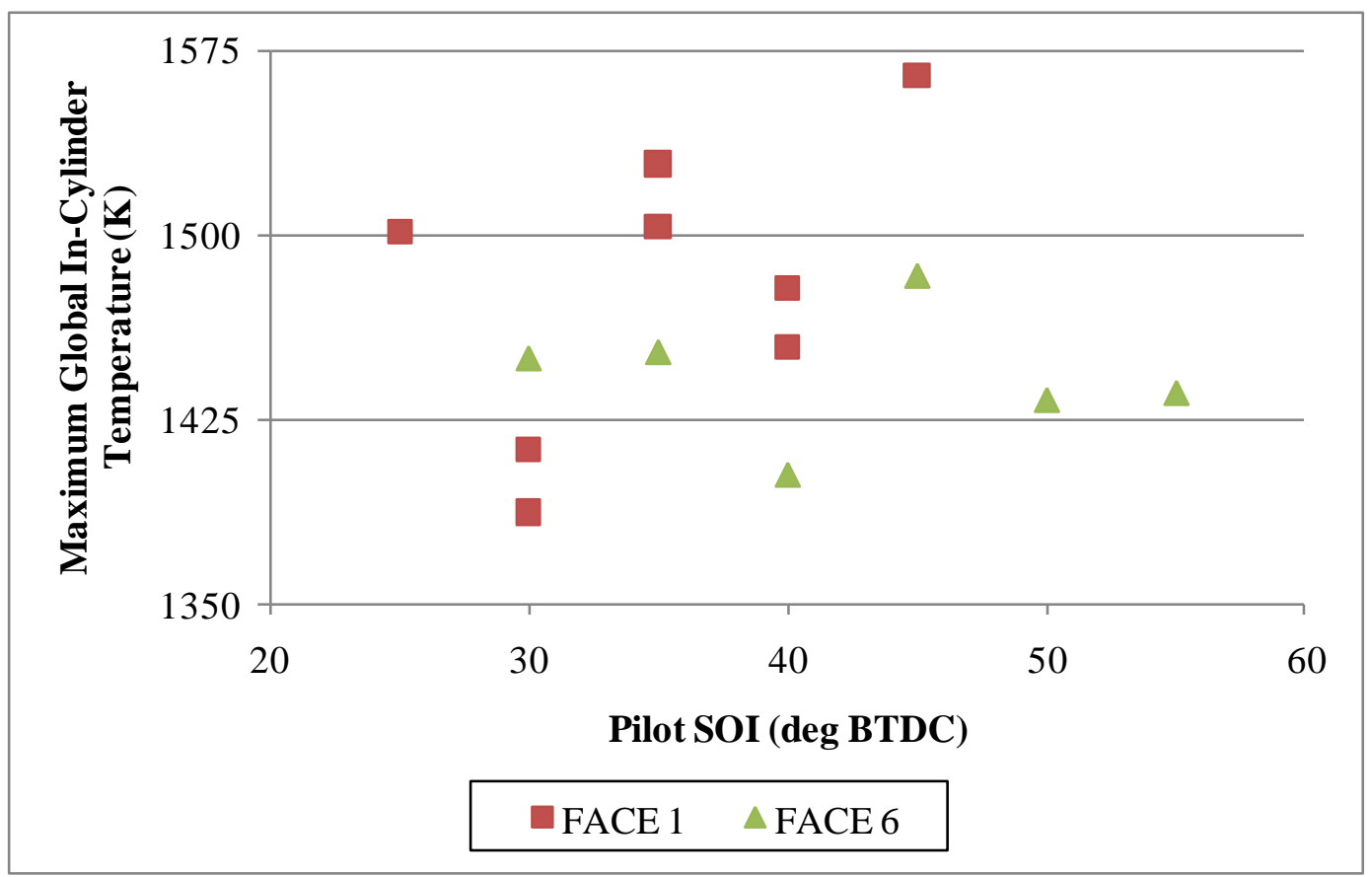

Figure 67: Maximum In-Cylinder Temperature during Pilot SOI sweeps

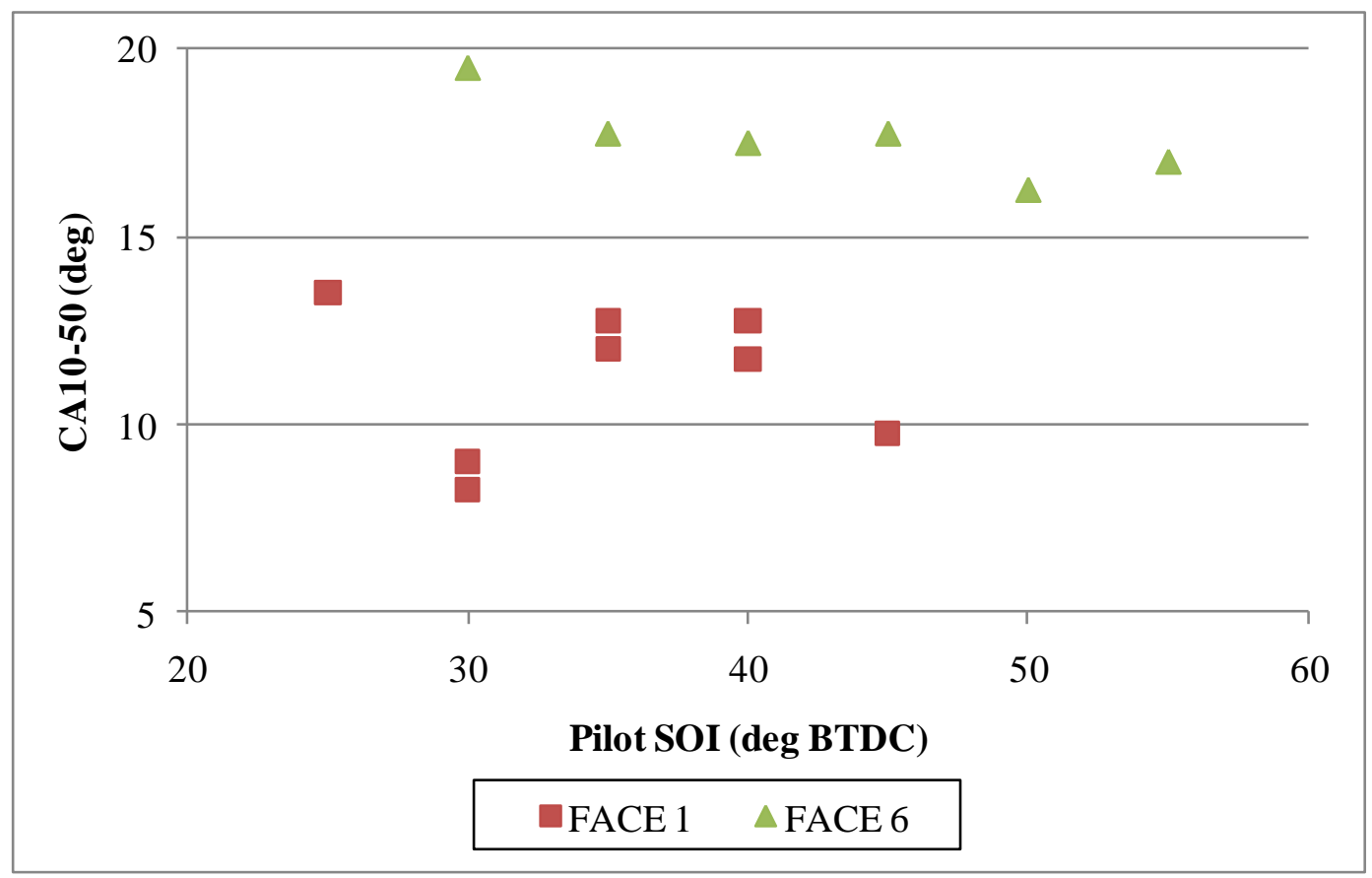

Figure 68: CA10-50 during Pilot SOI Sweeps

Previously observed during other injection strategies, FACE 1 exhibits the highest incylinder temperature and shortest CA10-50, demonstrated by Figure 67 and Figure 68, respectively. Trends of in-cylinder temperature with respect to pilot SOI timing are not apparent. With the exception of a couple outliers (reason for outlier described in Section 4.4.1), CA10-50 
decreases as pilot SOI timing is advanced. An earlier pilot SOI allows more time for mixing of the charge, the resultant less stratified mixture will undoubtedly burn quicker providing the logic for the aforementioned trend.

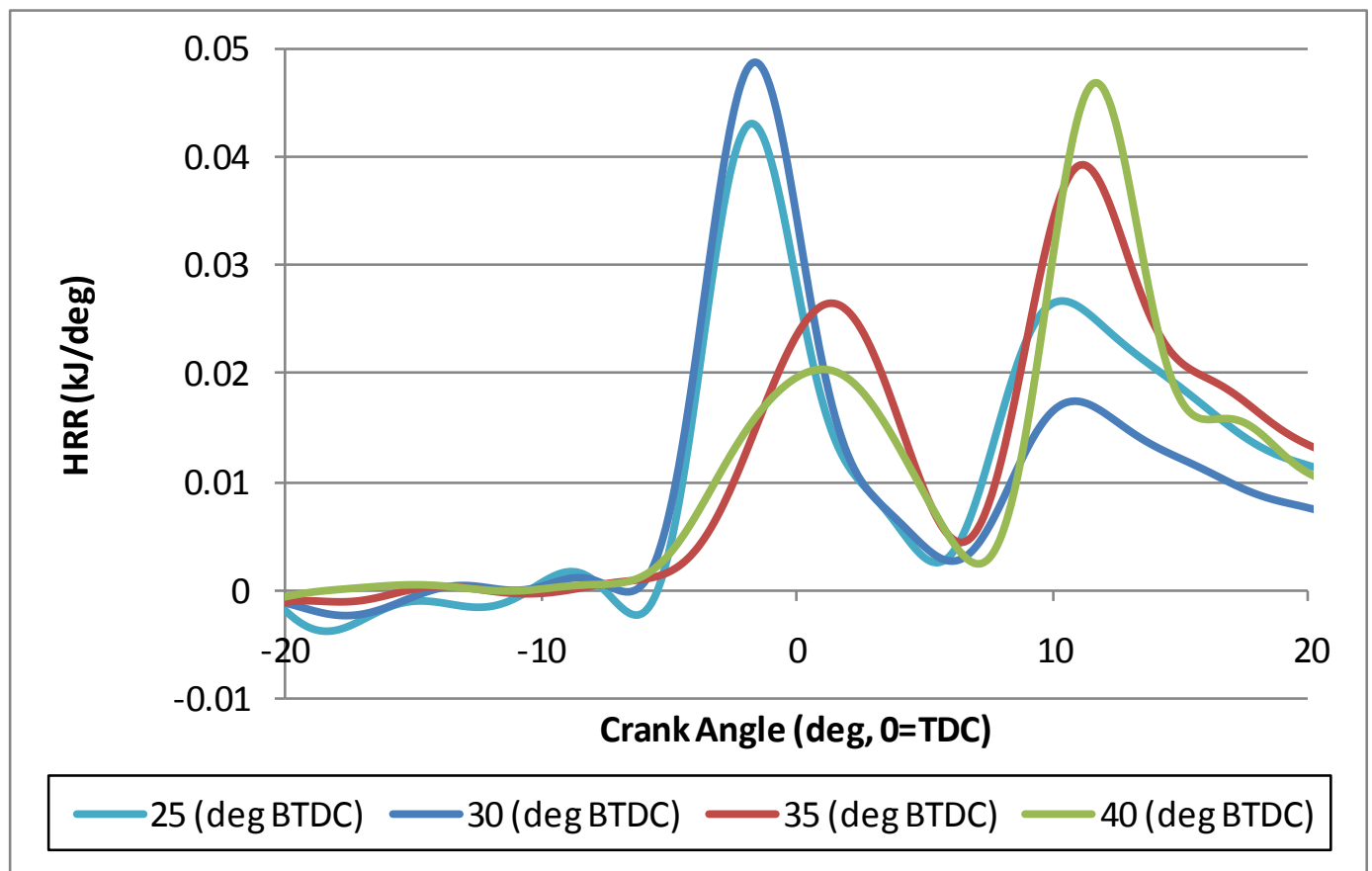

Figure 69: Heat Release Rate for FACE 1 during Pilot SOI sweeps

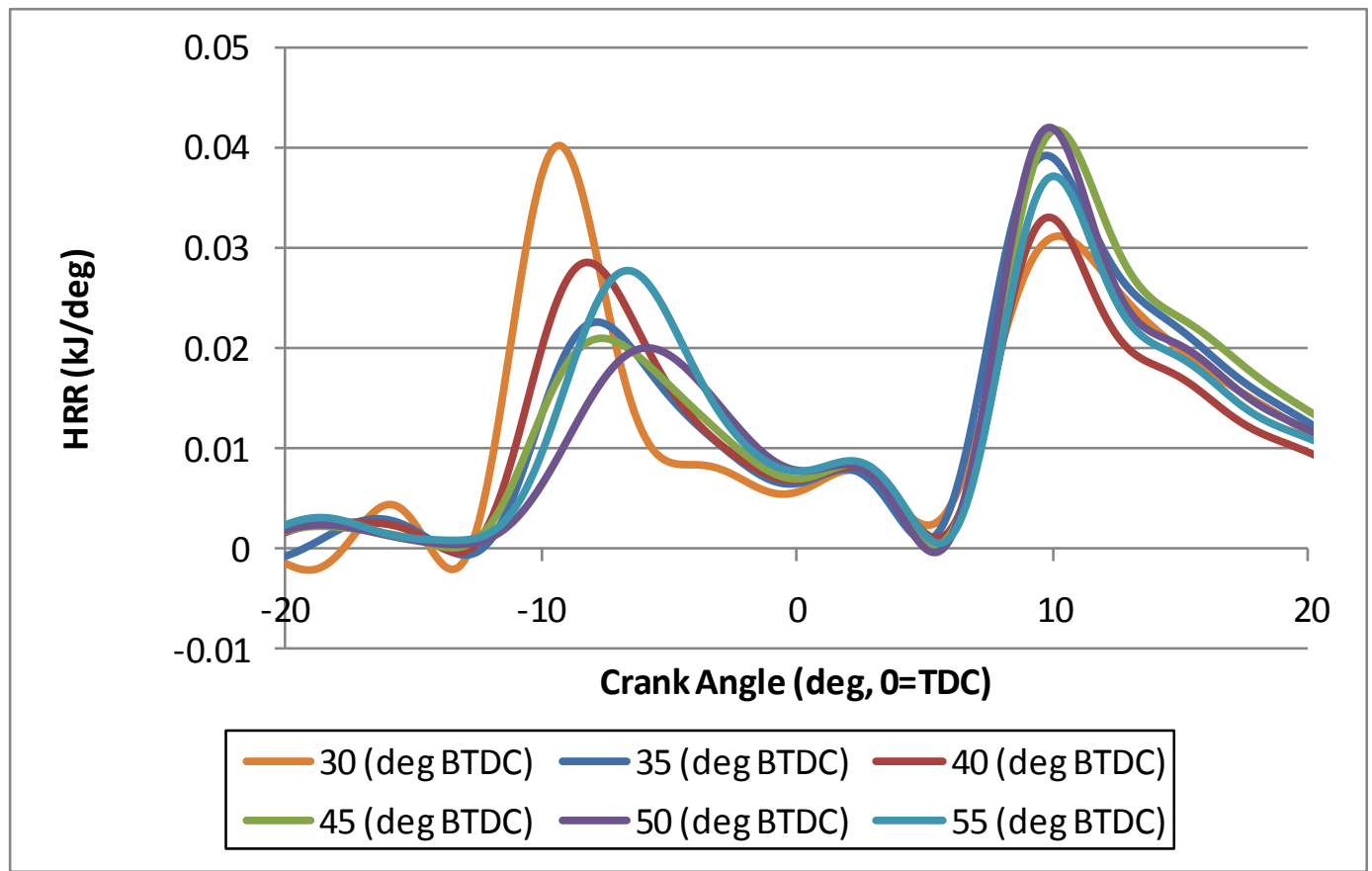

Figure 70: Heat Release Rate for FACE 6 during Pilot SOI sweeps 
The lower cetane number of FACE 1 and its affect on ignition delay results in the initial HRR curve occurring right around TDC shown in Figure 69. Demonstrated by Figure 70, the higher cetane number of FACE 6 and accompanying shorter ignition delay causes combustion to begin sooner than FACE 1 despite utilizing a higher EGR fraction. FACE 1 plots of HRR present a trend of decreased and retarded first stage heat release as pilot SOI timing increases.

\subsubsection{Main SOI Sweeps}

In an effort to gain perception on the effect of the main SOI timing, sweeps were performed from $5^{\circ}$ to $20^{\circ}$ BTDC. During this experimentation, an EGR fraction of 50 percent was targeted; actual values were held within five percent of the target. Rail pressure was fixed at 1200 bar and the pilot SOI timing was held at $60^{\circ}$ BTDC in conjunction with a 20 percent pilot fuel injection split. By reducing the percentage of fuel injected during the pilot, the effects of altering the main injection become much more apparent. This experiment was performed solely on the check fuel.

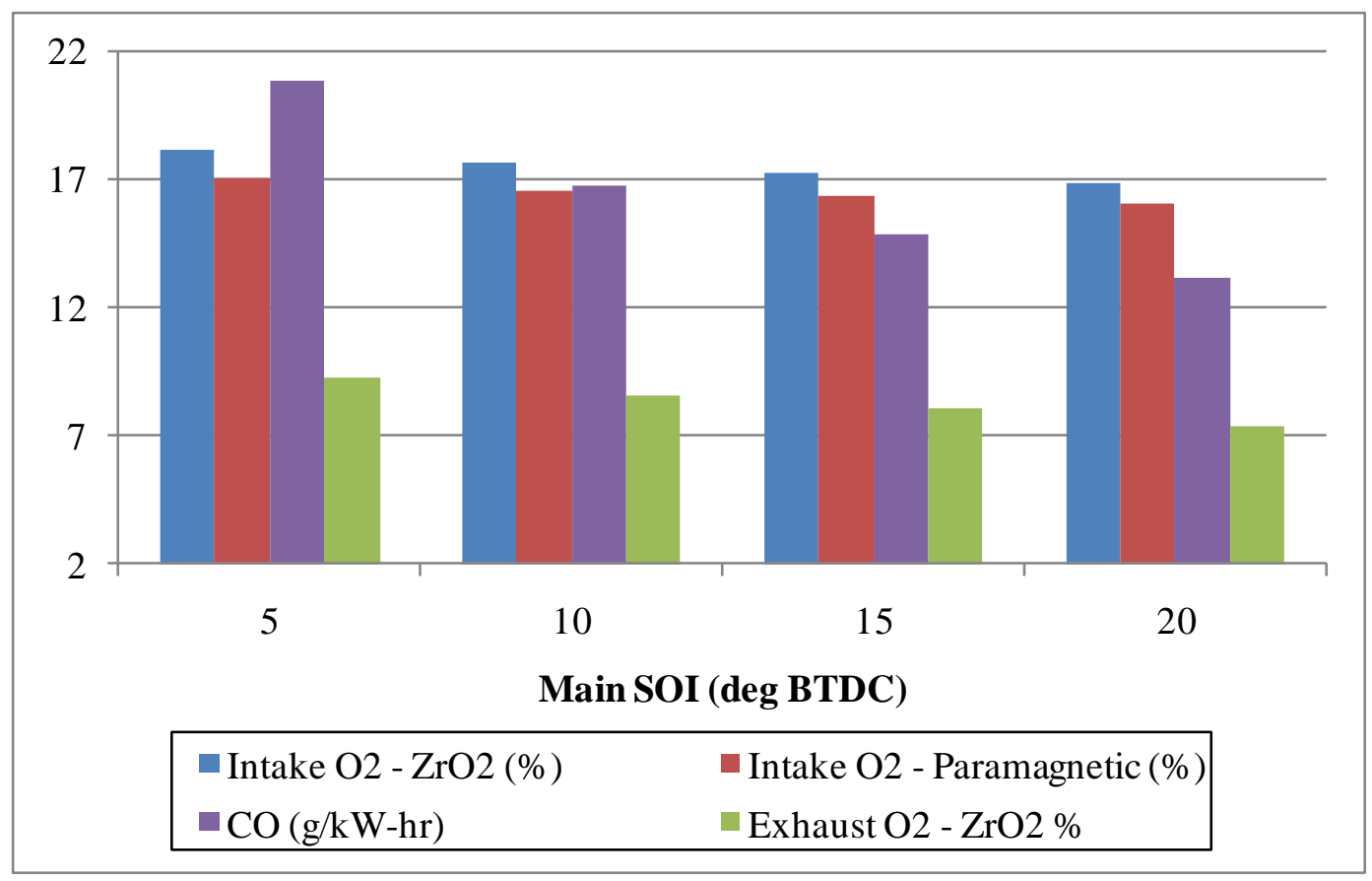

\section{Figure 71: Intake and Exhaust $\mathrm{O}_{2}$ Concentrations and $\mathrm{CO}$ emissions during Main SOI Sweeps}

Intake oxygen was measured through two different methods as displayed in Figure 71; a heated zirconium oxide sensor and a paramagnetic oxygen analyzer. Concerns over odd intake $\mathrm{O}_{2}$ measurements especially at low EGR levels provided the motivation for a secondary 
measurement. It is shown that the paramagnetic measurement is approximately 5 percent lower than the zirconium oxide sensor. This is not surprising due to the inherent errors and capabilities associated with both technologies. A decreasing trend of intake and exhaust oxygen measurements exists in Figure 71 with more advanced main SOI timing. CO emissions also decrease as main SOI timing is advanced insinuating less locally rich regions in the combustion chamber.

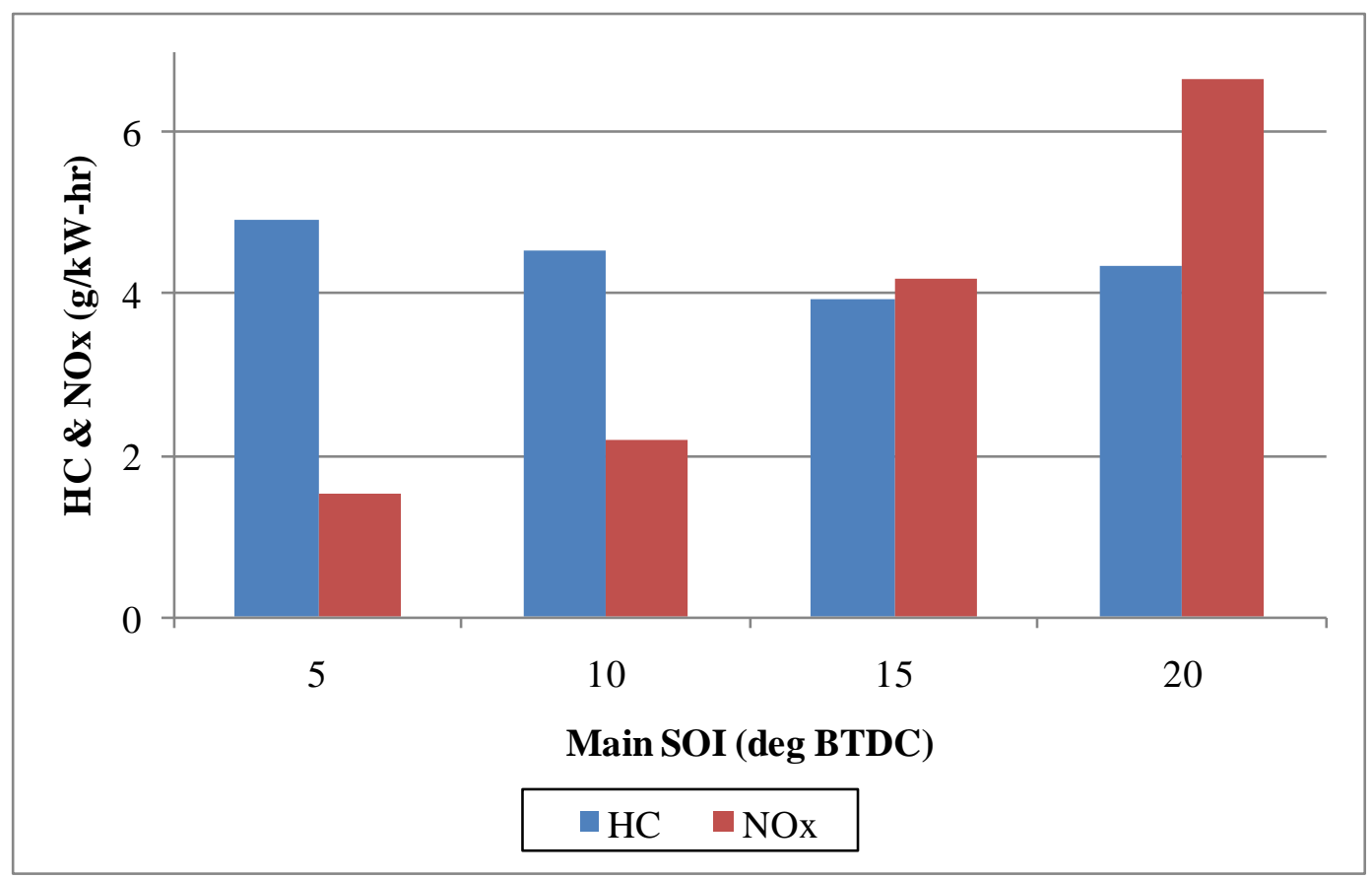

Figure 72: $\mathrm{HC}$ and $\mathrm{NO}_{\mathrm{x}}$ Emissions during Main SOI Sweeps 


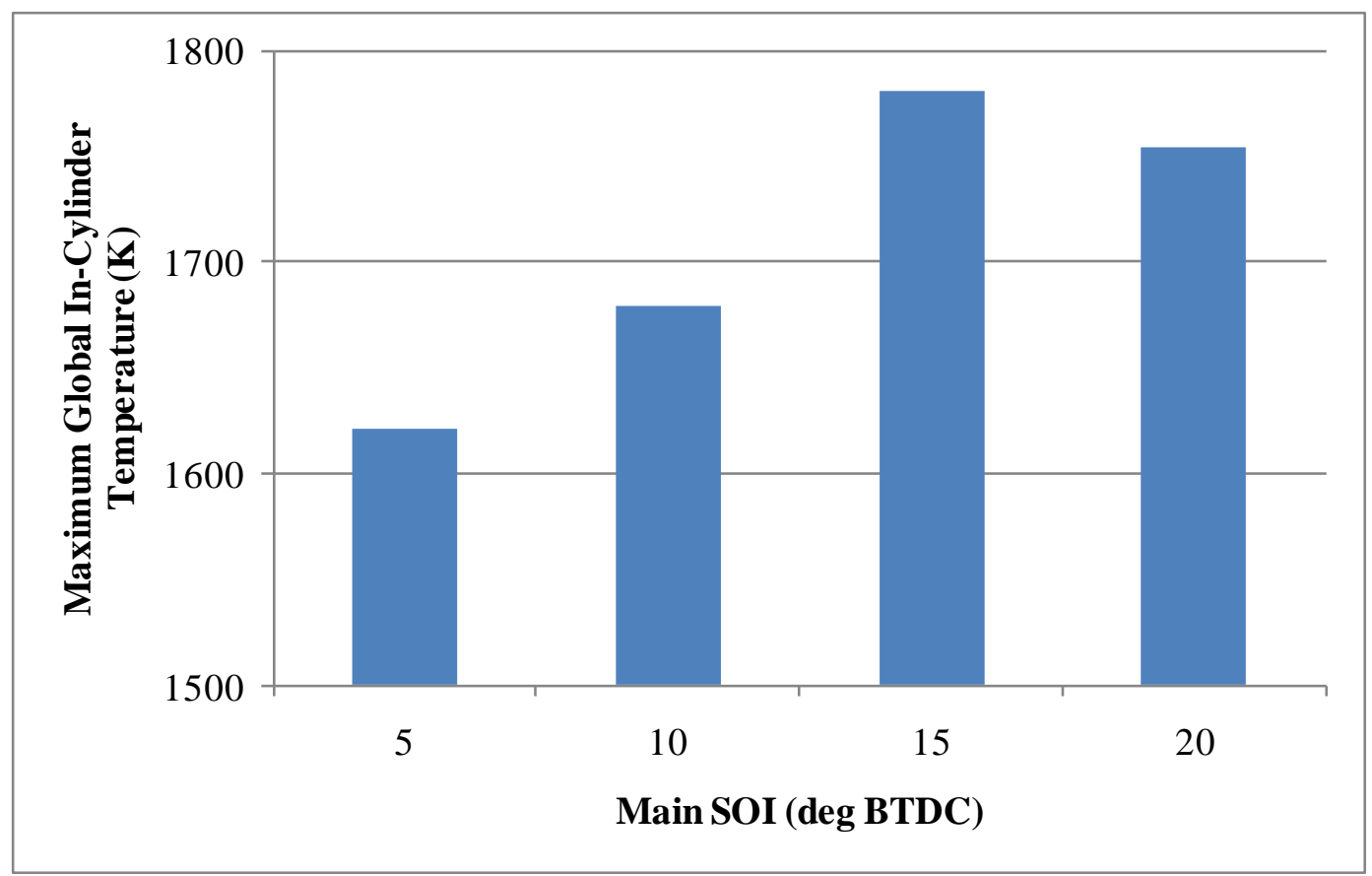

Figure 73: Maximum In-Cylinder Temperature during Main SOI Sweeps

HC emissions presented in Figure 72 show little deviation throughout the main SOI sweep. On the contrary $\mathrm{NO}_{\mathrm{x}}$ emissions experience significant growth as the main $\mathrm{SOI}$ timing is advanced. This is a generally accepted characteristic of conventional combustion, as the SOI timing advances beyond $\mathrm{TDC}, \mathrm{NO}_{\mathrm{x}}$ formation increases. The explanation for this phenomenon can be explained through the results of Figure 73. A significant temperature increase occurs between $10^{\circ}$ and $15^{\circ}$ BTDC main SOI timing, coinciding with an exponential trend of increasing $\mathrm{NO}_{\mathrm{x}}$ emissions. It is interesting that the in-cylinder temperature for $15^{\circ} \mathrm{BTDC}$ main SOI timing is greater than the $20^{\circ} \mathrm{BTDC}$ condition. This is probably attributed to the method of calculation. Shown in Figure 75 , the combustion duration for the $20^{\circ}$ BTDC main SOI timing condition is close to half of its predecessor. Since the in-cylinder temperature is a global average, shorter time is available in this case to obtain data that might be more representative of the actual combustion temperature. 


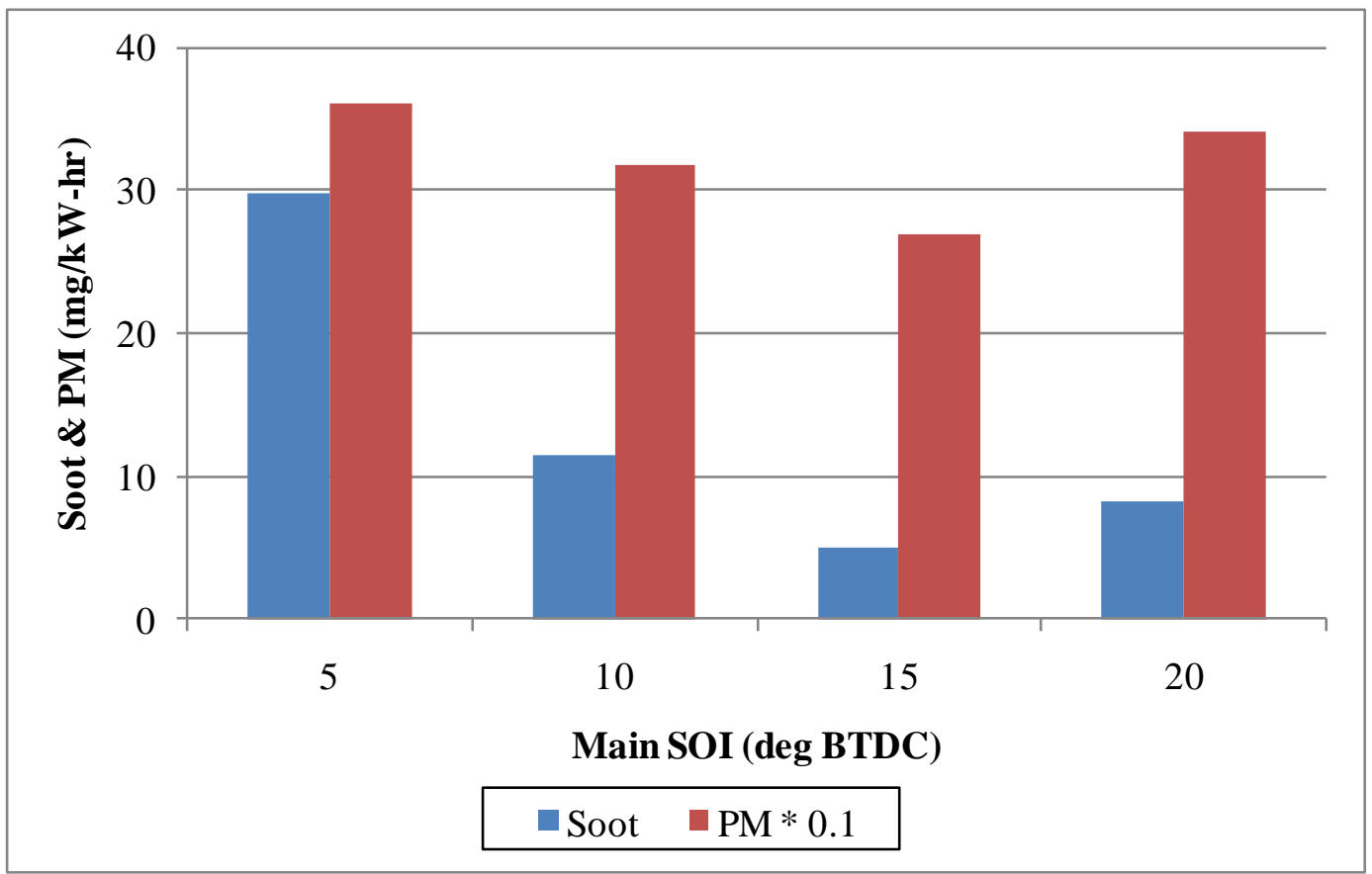

Figure 74: Soot and PM Emissions during Main SOI Sweeps

As previous figures of soot and PM emissions have shown, the soot emissions are exorbitantly less than the PM emissions. To aid in visual comparison the PM emissions were divided by 10. As demonstrated by Figure 74, advancing the main SOI results in very low soot emissions. The PM emissions follow the same trend, but are offset by an order of magnitude. The decrease in soot emissions is expected with less locally rich zones in the combustion chamber, as well as higher temperatures equating to greater soot oxidation. 


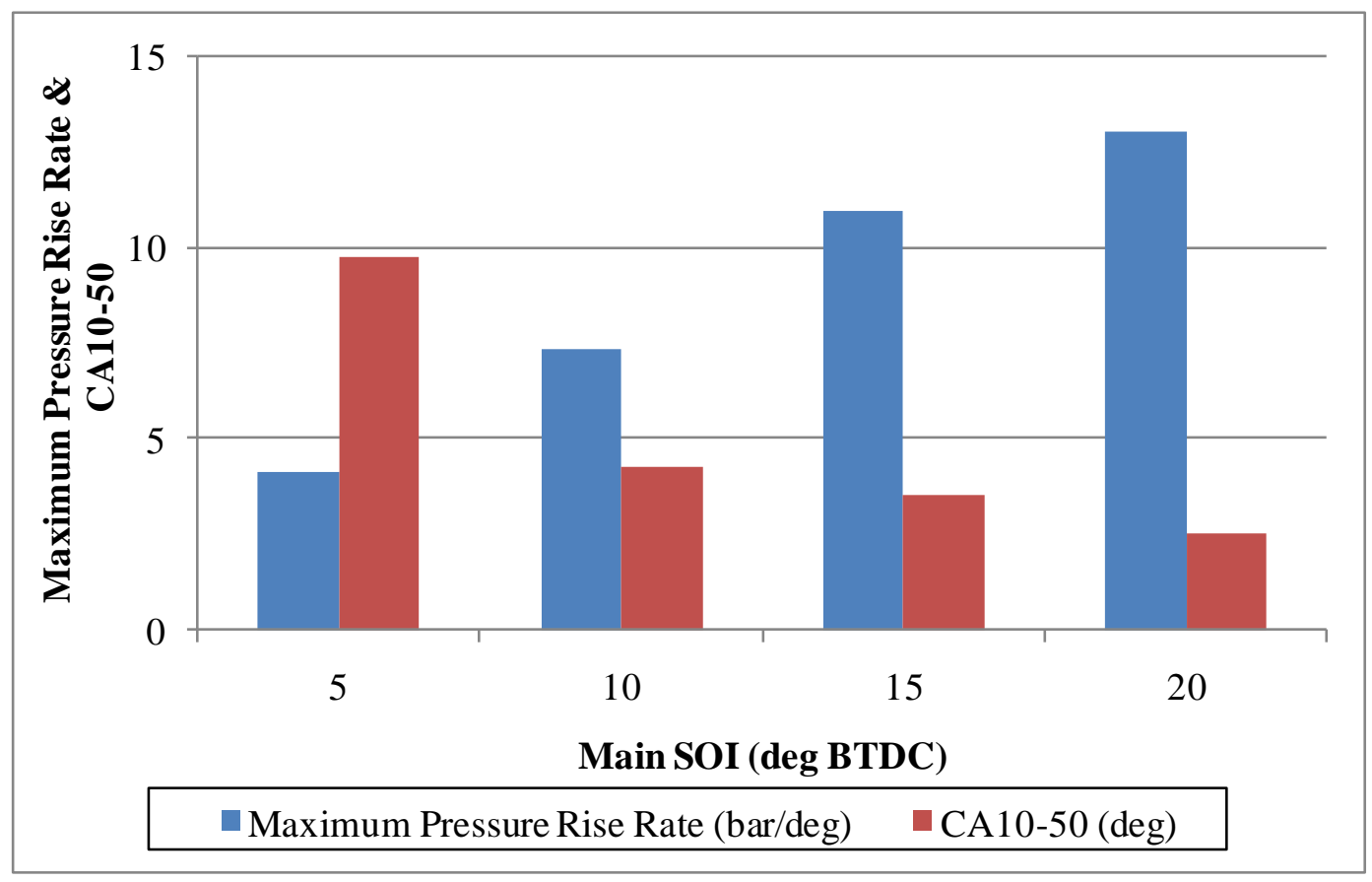

Figure 75: Max Pressure Rise Rate and CA10-50 during Main SOI Sweeps

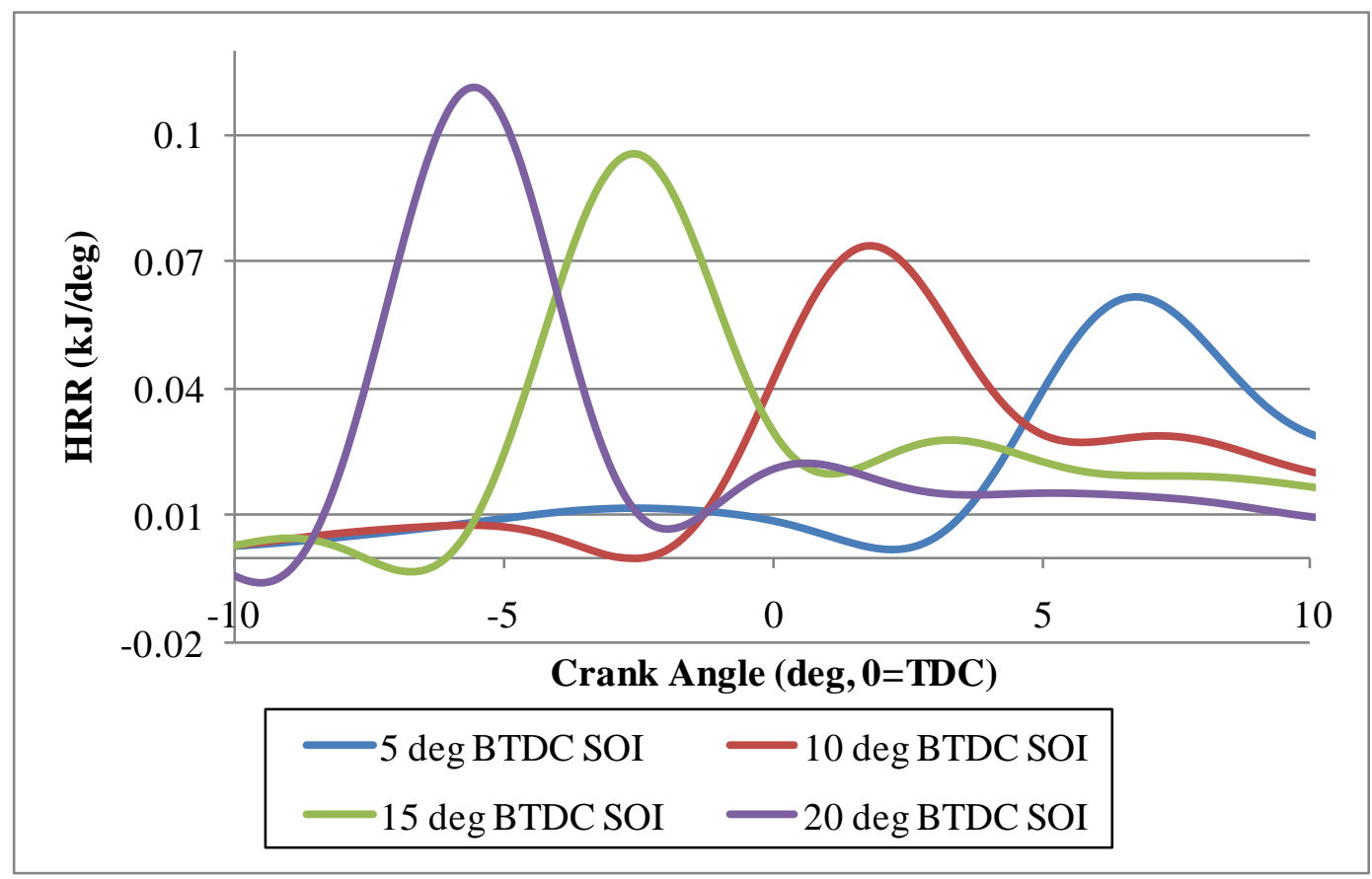

Figure 76: Heat Release Rate during Main SOI Sweeps

As expected after considering the effects of main SOI timing on other previously presented measurements, the PRR shown in Figure 75 increases proportionally with the advance of the main SOI. This is a common observation when advancing the injection timing in an engine operating under "conventional" combustion. By injecting the fuel earlier (to an extent) 
combustion is advanced toward and even beyond TDC creating significantly higher in-cylinder pressures and PRR demonstrated in Figure 76. Also presented in Figure 75, the CA10-50 is an inverse of the max pressure rise rate. A quicker pressure rise will undoubtedly shorten the combustion time as represented by the CA10-50 calculations.

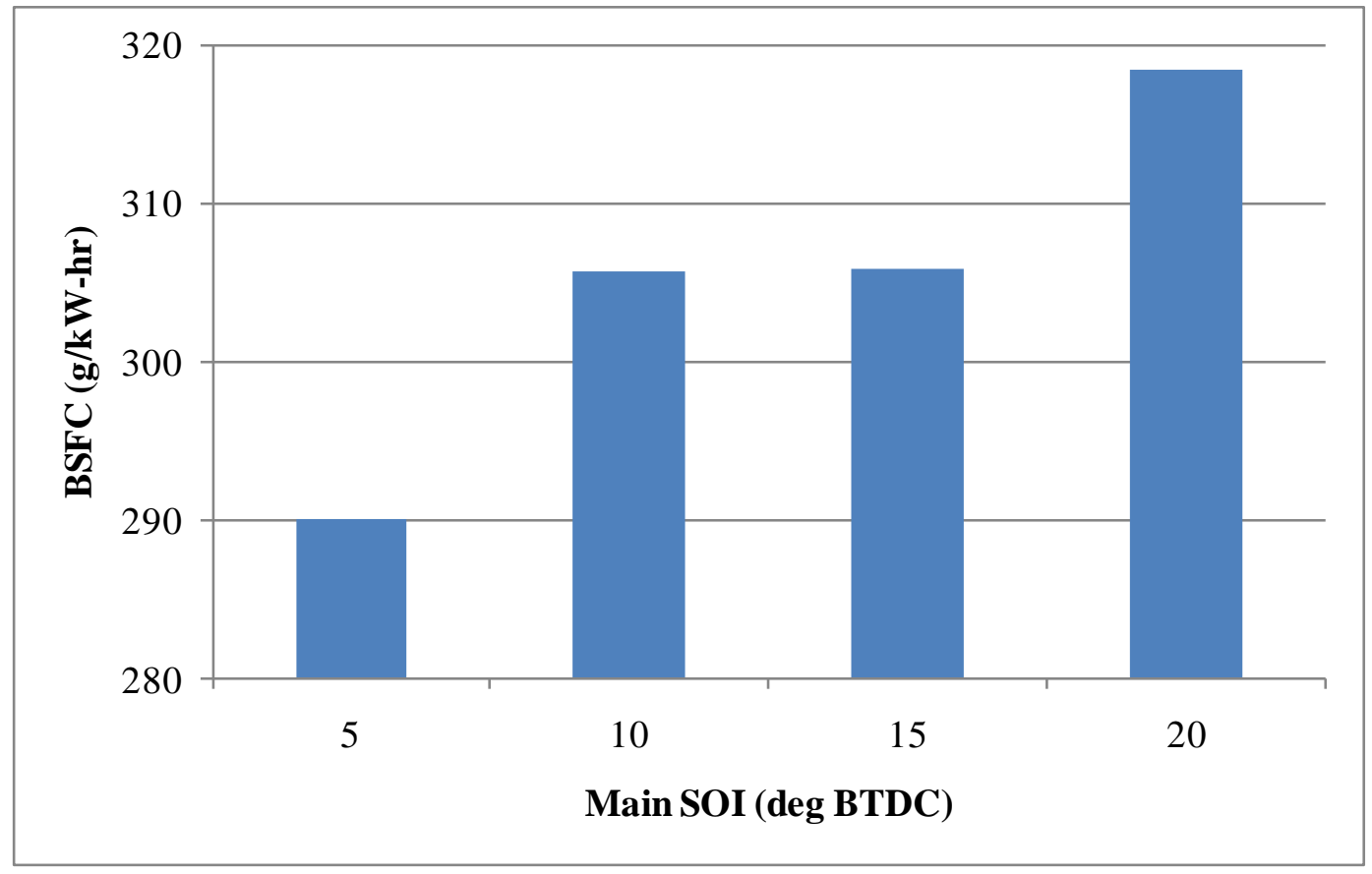

Figure 77: Fuel Consumption during Main SOI Sweeps

Less locally rich regions in the combustion chamber with advanced main SOI timing (as hinted at by the $\mathrm{CO}$ and soot emissions presented in Figure 71 and Figure 74, respectively) could insinuate less fuel consumption. Contradicting this assumption, Figure 77 shows an increase in fuel consumption as main SOI is advanced. This is a result of combustion phasing presented in Figure 76. When combustion is phased before TDC, it opposes the motion of the piston approaching TDC resulting in a loss of efficiency.

\subsubsection{Rail Pressure Sweeps}

Increasing rail pressure and subsequently injection pressure will in theory promote better atomization of the fuel leading to better mixing of the air and fuel charge. In order to evaluate the effects of rail pressure, sweeps were performed from 800 bar to 1600 bar for the check fuel and FACE 1, and 800 bar to 1800 bar for the shakedown fuel. During these sweeps, the shakedown fuel and check fuel retained a pilot SOI timing of $40^{\circ}$ BTDC, a main SOI timing of 
TDC, and a 50 percent fuel injection split. FACE 1 utilized a similar fuel injection configuration, except pilot SOI timing was held at $35^{\circ}$ BTDC.

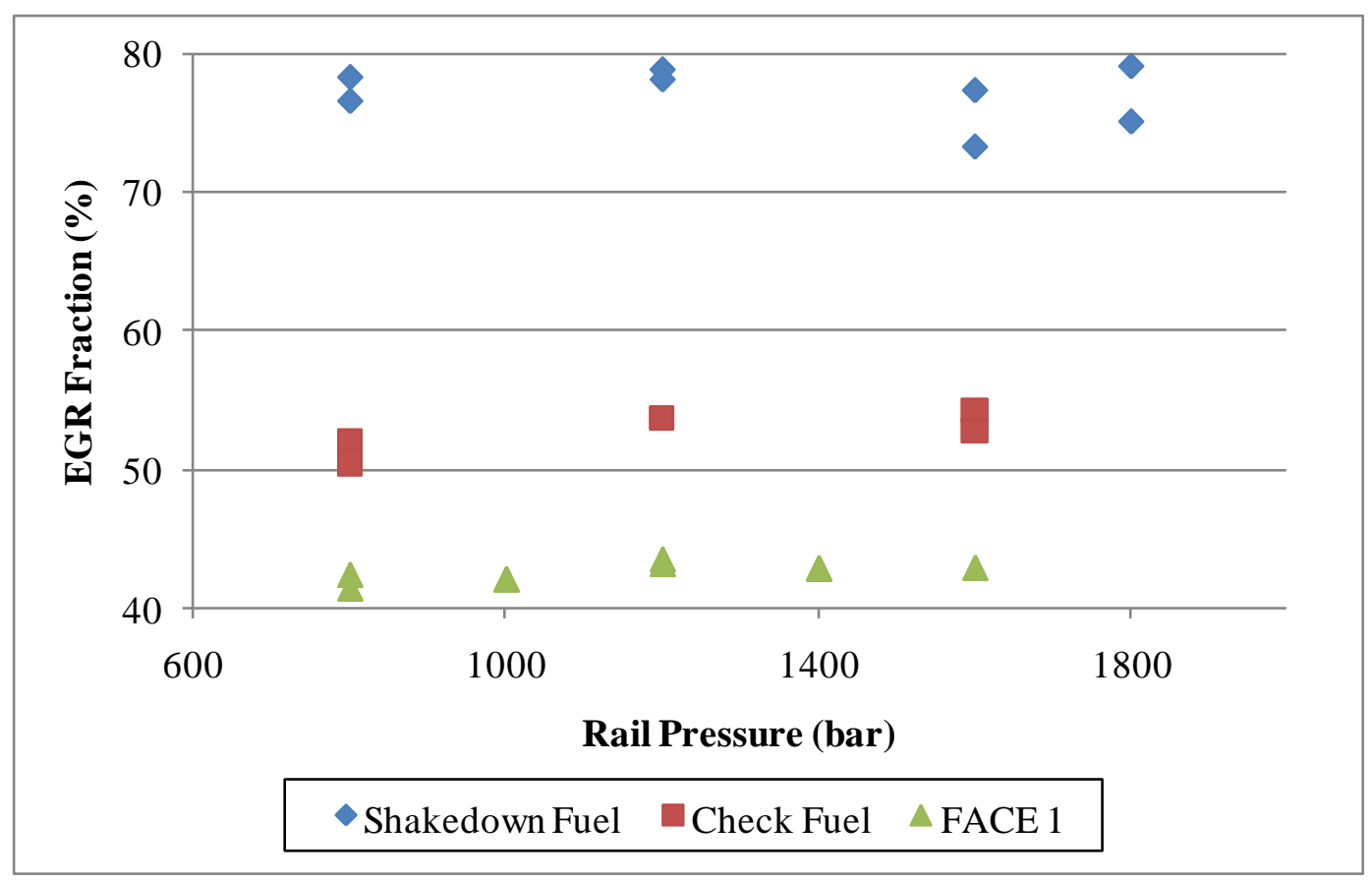

Figure 78: EGR Fraction during Rail Pressure Sweeps

Due to fuel properties, acceptable EGR levels vary for each fuel. As cetane number increases, higher EGR fractions are used as shown in Figure 78. Ideally, the percentage of variation between tests of EGR fraction would be held to less than five percent, but due to the multitude of influences on EGR fraction, variance was held to eight percent, seven percent, and five percent, for the shakedown fuel, check fuel, and FACE 1, respectively. Thus it is important to consider EGR fraction when determining emissions and performance trends resulting from rail pressure. 


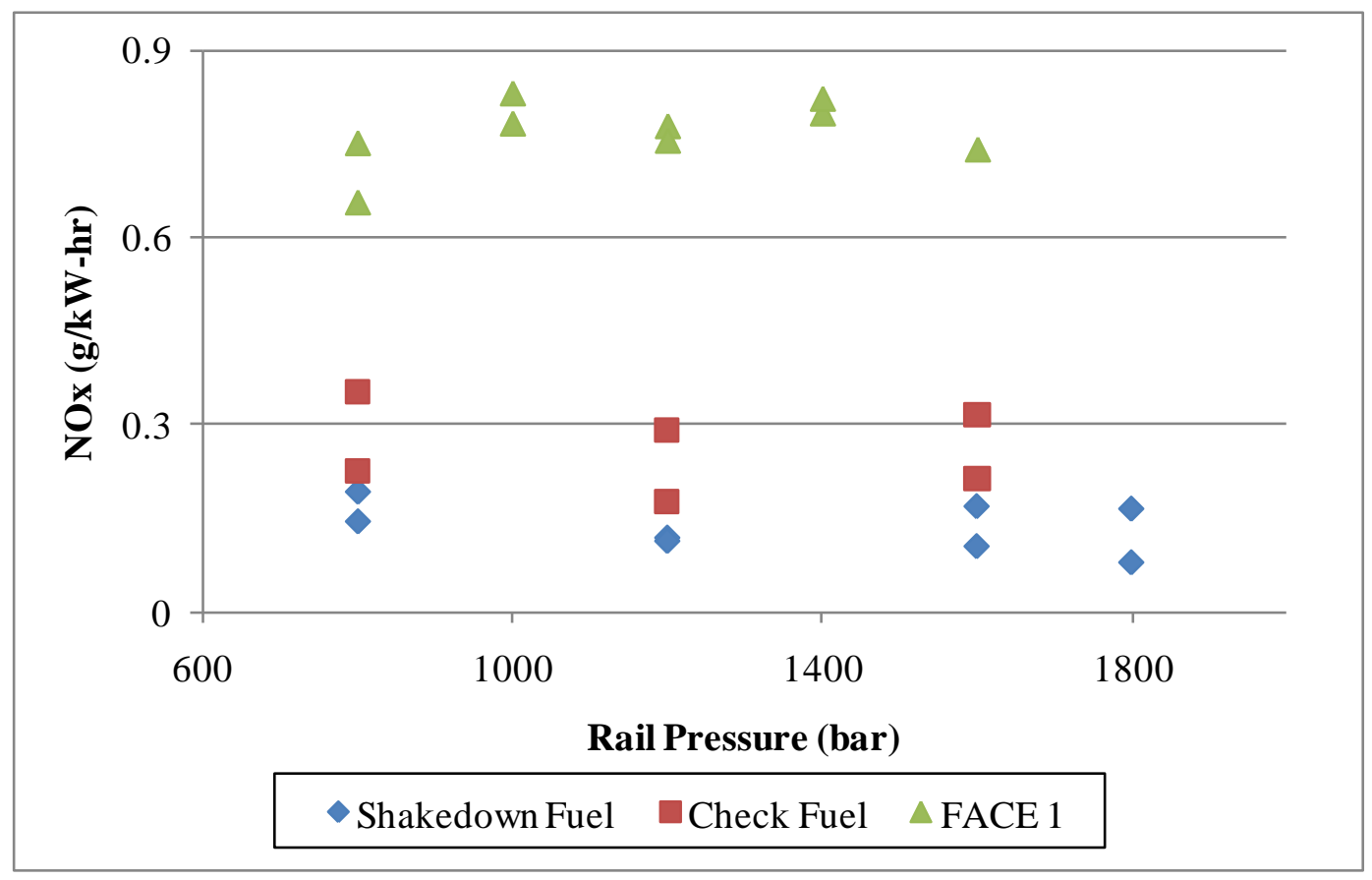

Figure 79: $\mathrm{NO}_{\mathrm{x}}$ Emissions during Rail Pressure Sweeps

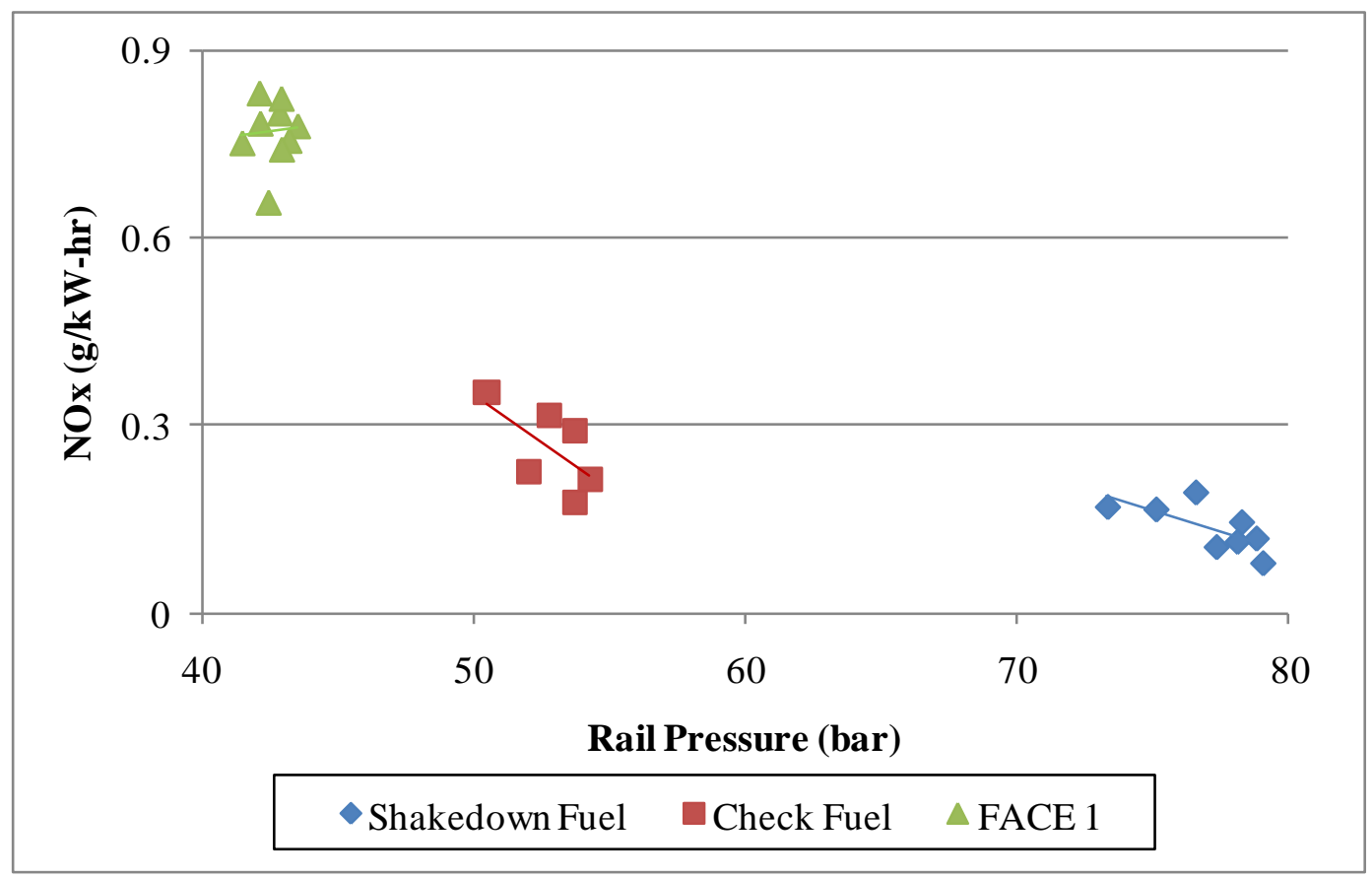

Figure 80: $\mathrm{NO}_{\mathrm{x}}$ Emission as a Function of EGR fraction during Rail Pressure Sweeps

Boosting rail pressure appears to have little effect on $\mathrm{NO}_{\mathrm{x}}$ emissions as presented in Figure 79. It is apparent that EGR fraction has a much more significant impact on $\mathrm{NO}_{\mathrm{x}}$ emissions than rail pressure. This is demonstrated for the check fuel and the shakedown fuel in Figure 80. If significantly better mixing were achieved through the increase of rail pressure, less 
flame propagation and less time spent at higher combustion temperatures should result in lower $\mathrm{NO}_{\mathrm{x}}$ emissions. Hardware limits could be prohibiting the achievement of such a rail pressure set point. As noted before the difference in $\mathrm{NO}_{\mathrm{x}}$ emissions between fuels is a function of the allowable EGR levels pertaining to the properties of the specific fuels.

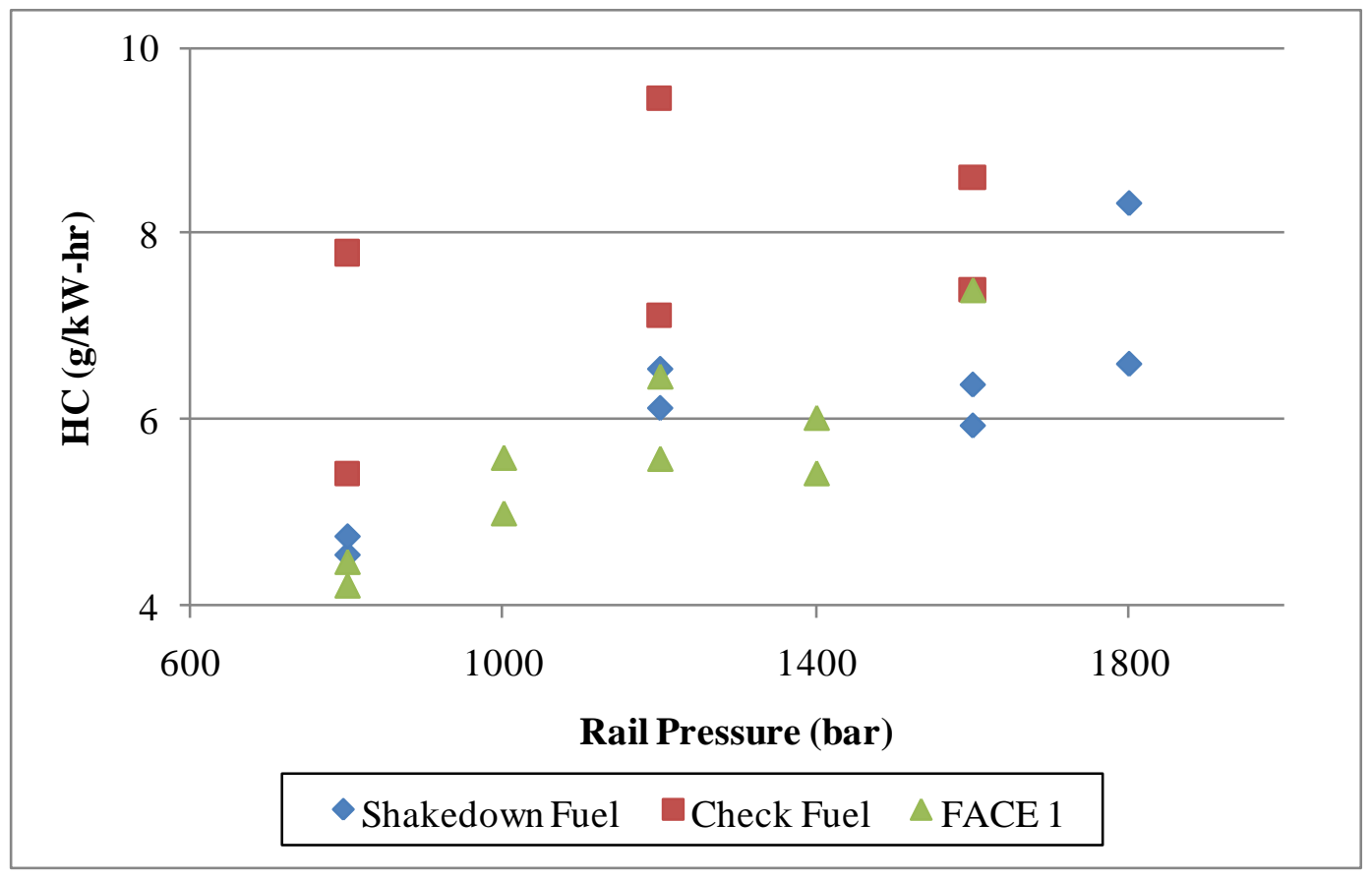

Figure 81: HC emissions during Rail Pressure Sweeps

Increased $\mathrm{HC}$ emissions result from higher rail pressure displayed by Figure 81 . All fuels exhibit a positive slope although differences on repeated points are likely the effect of EGR. During actual testing, less volume of fuel per cycle was commanded as the rail pressure increased, but the mass of fuel injected remained consistent or even increased. While in theory the increased rail pressure should promote better atomization, reducing locally rich regions and subsequently HC emissions, the fuel spray jet length fuel should be considered. With increased pressure, a longer fuel spray jet length would encourage more impingement of fuel on the cylinder walls and increase $\mathrm{HC}$ emissions as seen in Figure 81. 


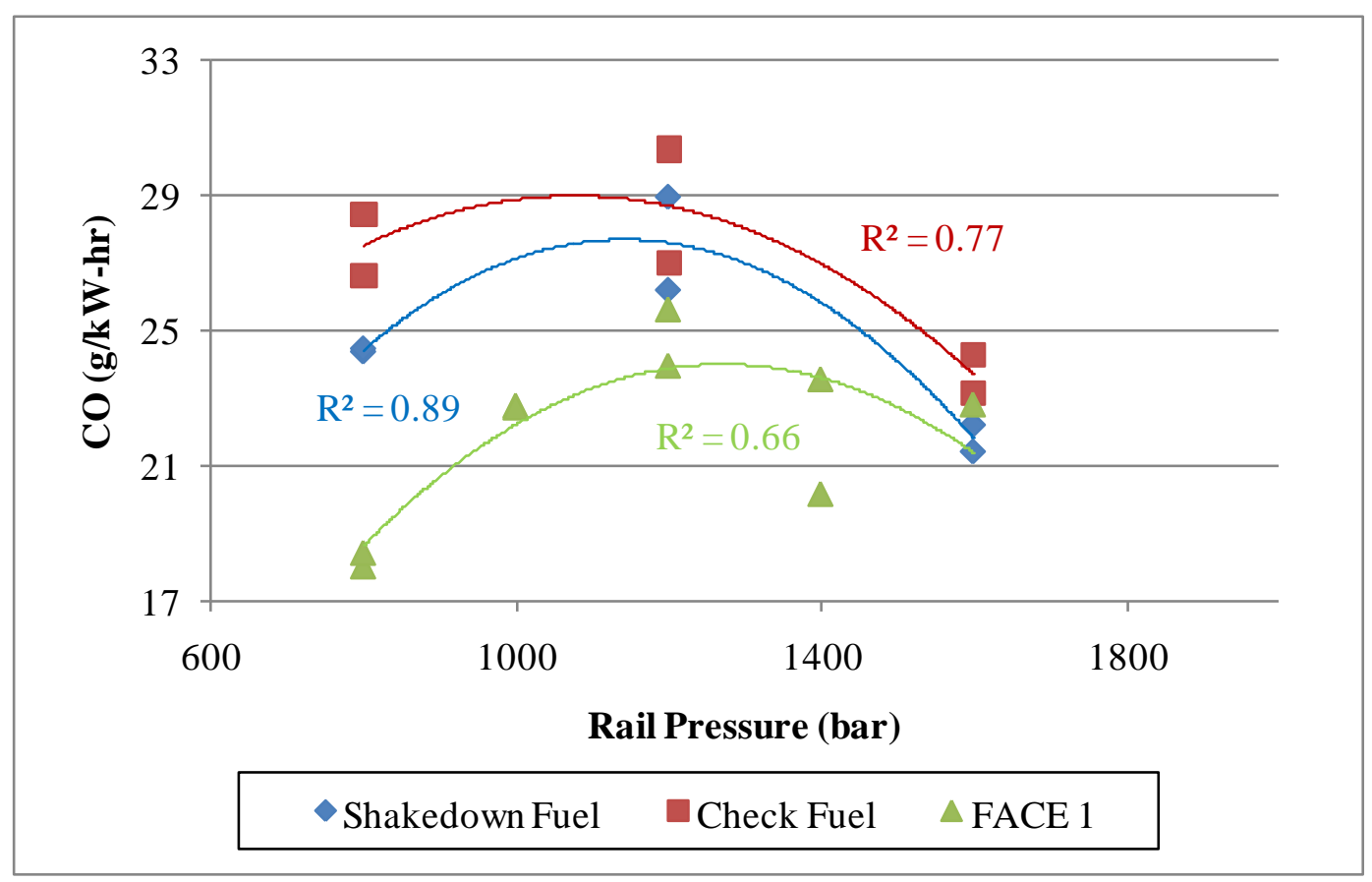

Figure 82: CO emissions during Rail Pressure Sweeps

Parabolic trends of $\mathrm{CO}$ emissions plotted against rail pressure exist for all fuels demonstrated by Figure 82. The parabolic trend-lines signify that at elevated rail pressures greater fuel atomization and mixing is present. Through this better mixing less locally rich zones exists in the combustion chamber, ultimately reducing $\mathrm{CO}$ emissions. With hardware upgrades, the achievement of even higher rail pressures might promote even further mixing. This would likely come at the expense of greater wall wetting; therefore an accompanying change in injection spray angle may be necessary. 


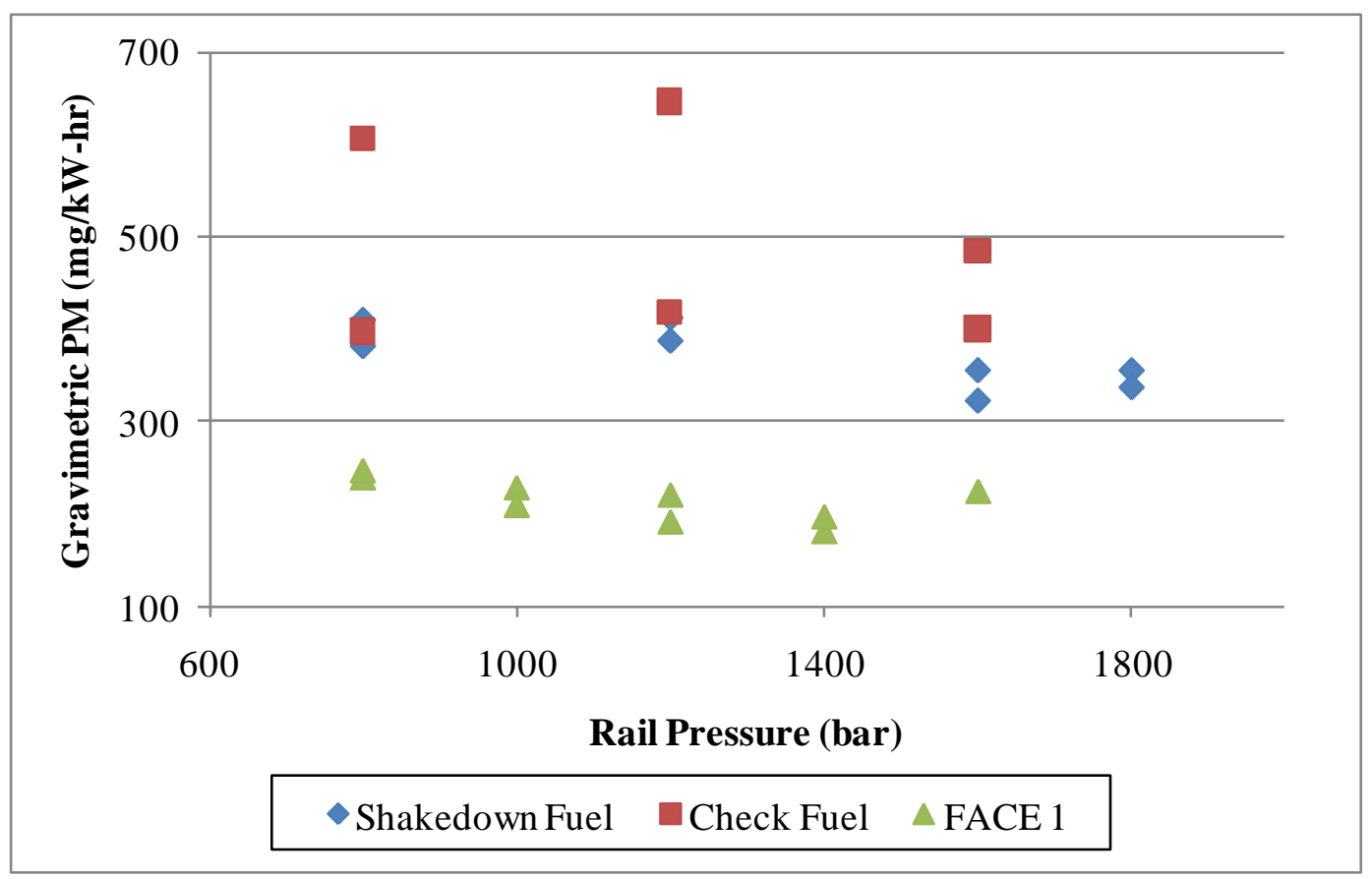

Figure 83: Gravimetric Based PM during Rail Pressure Sweeps

A trend of decreasing PM emissions was expected at elevated rail pressures. This is not supported by the data shown in Figure 83, yet can be explained through the possible increase of SOF with higher rail pressure. Greater HC emissions were also observed at elevated rail pressures, hinting that black carbon (soot) may have been decreasing, but was offset by the addition of SOF (comprised mainly of unburnt fuel) deposited on the PM filter. Unfortunately the soot sensor measurement was not present during these experiments, but during subsequent tests, it was found that increasing the rail pressure significantly reduced soot at many operating conditions. This hypothesis is also supported by Figure 82, where $\mathrm{CO}$ emissions can used as an indicator of soot formation. 


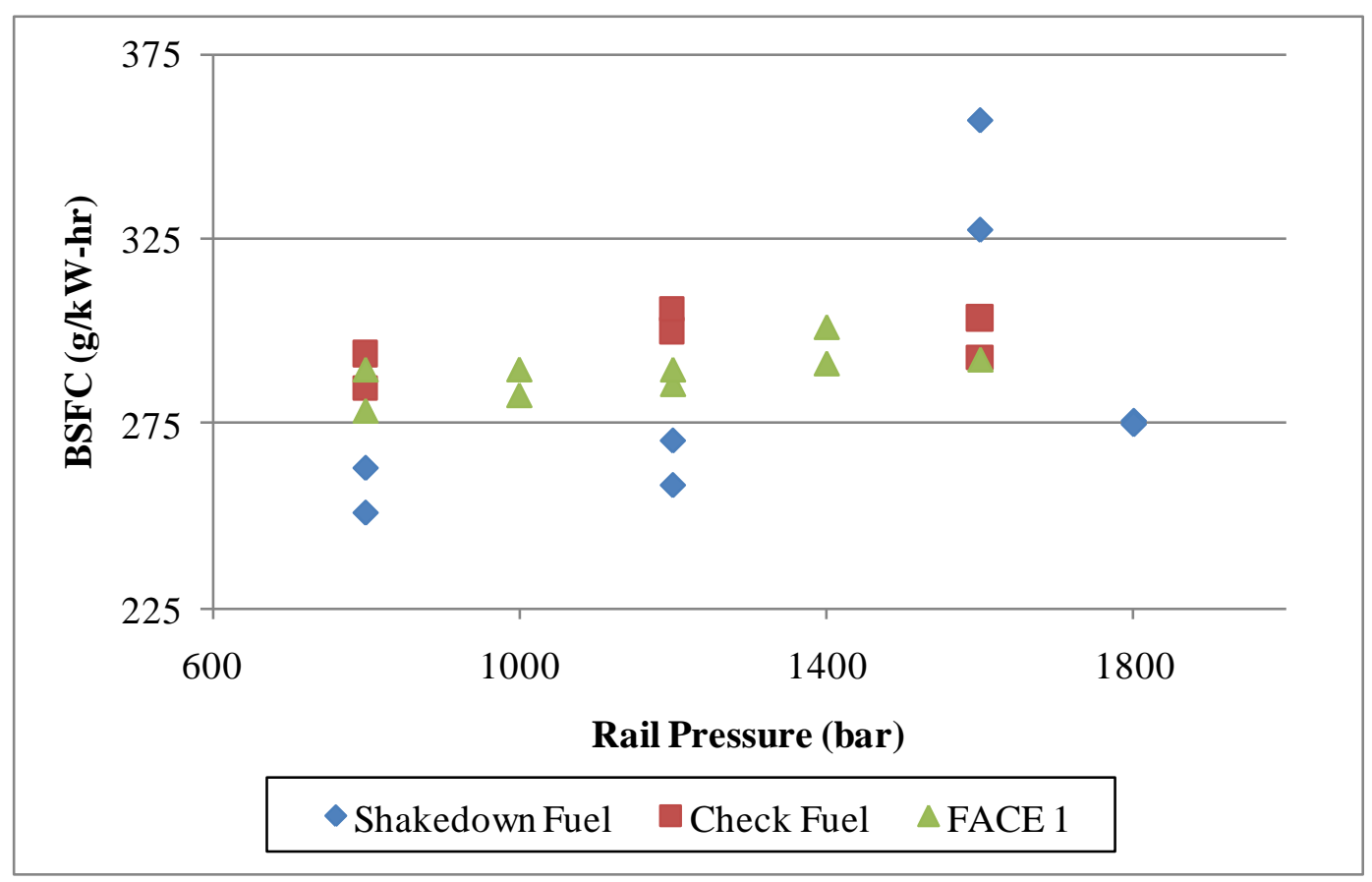

Figure 84: Fuel Consumption during Rail Pressure Sweeps

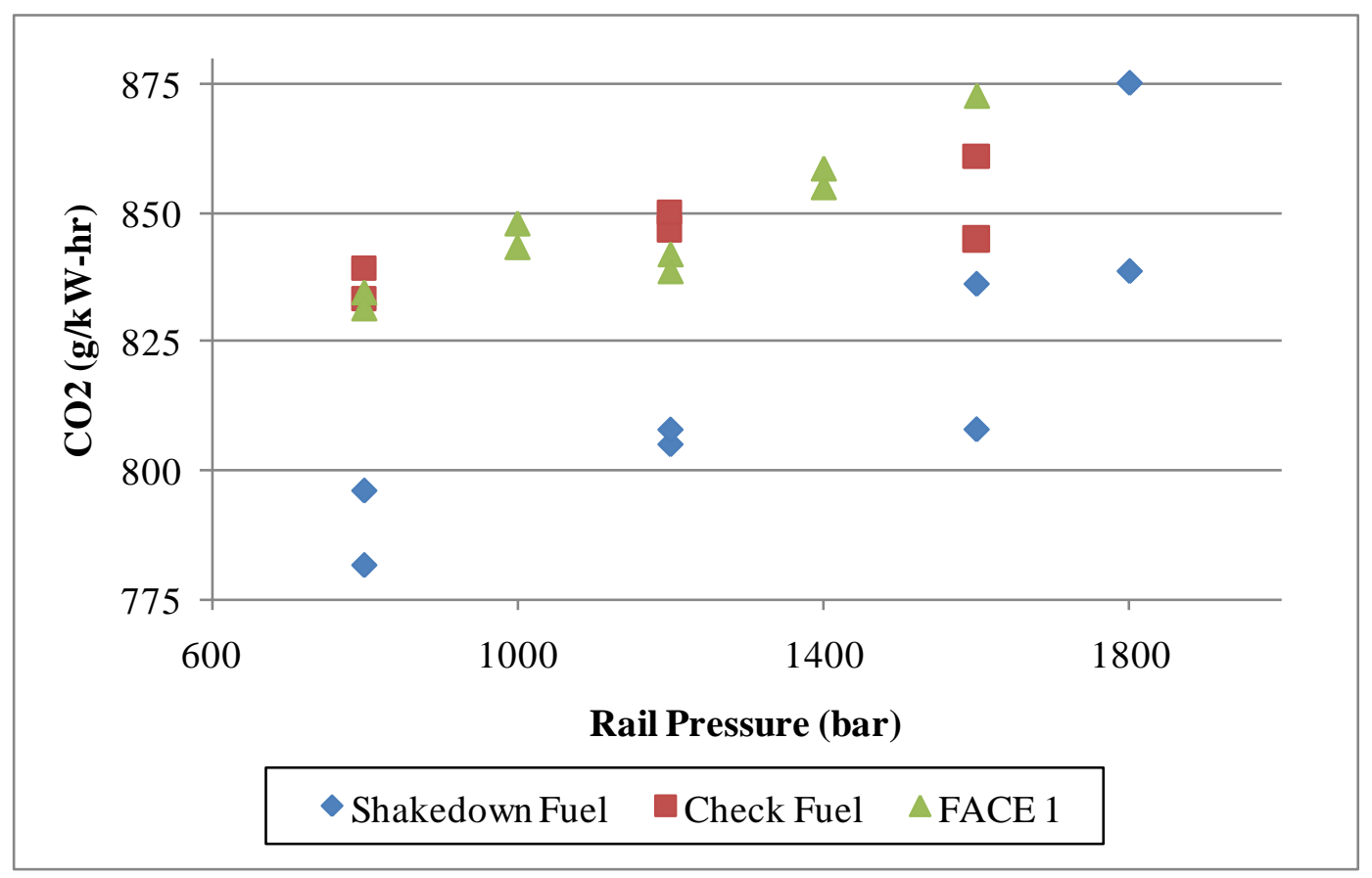

Figure 85: $\mathrm{CO}_{2}$ Emissions during Rail Pressure Sweeps

Observations of fuel consumption trends in Figure 84 are supported by $\mathrm{CO}_{2}$ emissions presented in Figure 85. A general increase in fuel consumption is observed as the rail pressure grows larger. While better mixing should promote lower fuel consumption, the impact of 
increased wall wetting may negate this effect. As mentioned before a strong fuel spray jet would force more fuel to collide with the boundaries of the combustion chamber especially at advanced SOI timings. Note that varying the rail pressure displayed no trends in PRR, and any variation in PRR was assumed to be related to EGR fraction.

\subsubsection{Fuel Split Sweeps}

Experiments to determine the effect of varying the percentage of fuel injected during the pilot event in relation to the main injection were performed on the shakedown fuel, check fuel and FACE 1. The fuel split percentage ranged from 40 percent to 70 percent, 30 percent to 50 percent, and 40 percent to 60 percent pilot injection for the shakedown fuel, check fuel and FACE 1, respectively. Note that with a fuel split greater than 50 percent, the pilot injection should actually be referred to as the main injection. To remain consistent, the first injection will always be referred to as the pilot injection for this research. A main SOI timing of TDC and $-5^{\circ}$ BTDC with a consistent pilot of $40^{\circ}$ BTDC was implemented for the shakedown fuel. The check fuel retained a main SOI timing of TDC while a pilot SOI of $40^{\circ}, 50^{\circ}$, and $60^{\circ} \mathrm{BTDC}$ was utilized. Only three tests were performed for FACE 1, all with a main SOI of TDC and a pilot SOI of $35^{\circ}$ BTDC. Rail pressure for tests performed with the shakedown fuel was 800 bar, while tests for all other fuels were administered at a rail pressure of 1200 bar. As a result of the significant differences in the fuel injection strategy for each fuel, it is difficult to make comparisons among the fuels, yet general trends on the effects of varying the fuel split can be observed. The injection configuration for each fuel is summarized in Table 4.

Table 4: Injection Configuration for Each Fuel Tested

\begin{tabular}{|c|c|c|c|c|}
\hline Fuel & $\begin{array}{c}\text { Fuel Split } \\
(\% \text { Pilot })\end{array}$ & $\begin{array}{c}\text { Main SOI } \\
(\text { deg BTDC) }\end{array}$ & $\begin{array}{c}\text { Pilot SOI } \\
(\text { deg BTDC })\end{array}$ & $\begin{array}{c}\text { Rail } \\
\text { Pressure }\end{array}$ \\
\hline Shakedown & $40-70$ & $-5,0$ & 40 & 800 \\
\hline Check & $30-50$ & 0 & $40-60$ & 1200 \\
\hline FACE 1 & $40-60$ & 0 & 35 & 1200 \\
\hline
\end{tabular}




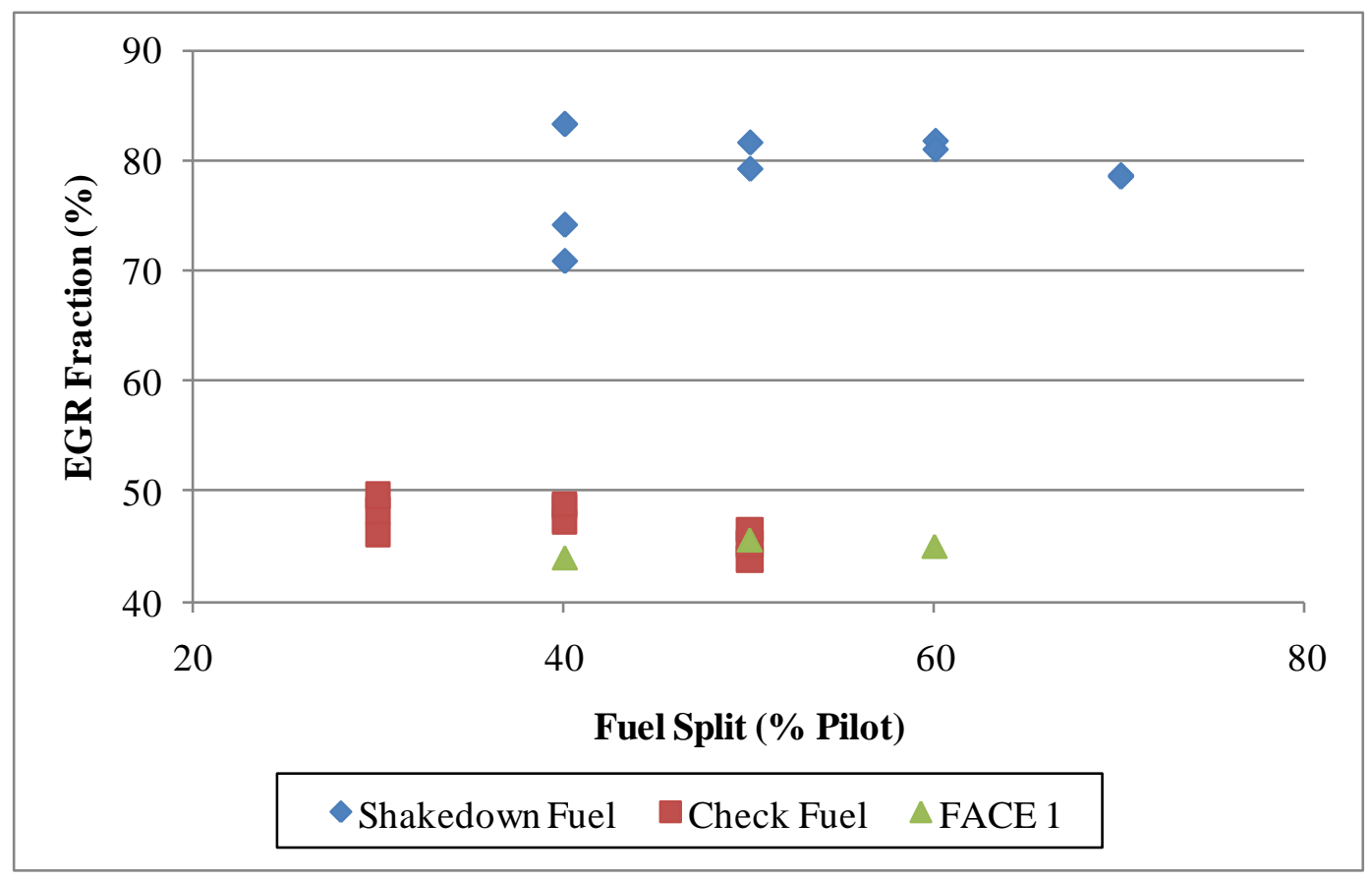

Figure 86: EGR Fraction during Fuel Split Sweeps

EGR fraction was tailored to suit the characteristics of each fuel. A target EGR fraction for all tests of a specific fuel was strived for, but there is variation and outliers as demonstrated by Figure 86. Thus it is essential to consider the possible effects of varying EGR fraction when drawing conclusions about the fuel split effects, due to the dominating nature of EGR fraction on emissions and performance measurements. Additionally, it has been mentioned that EGR fraction for many of the shakedown fuel split injection strategy tests appears to be offset when compared with intake $\mathrm{O}_{2}$ concentrations. The intake $\mathrm{O}_{2}$ concentration is lower for the shakedown fuel tests in comparison to the tests of other fuels, verifying that EGR fraction is greater, but most likely not to the magnitude presented in Figure 86. Ultimately this measurement error is not of concern when attempting to determine overall effects of fuel split sweeps. 


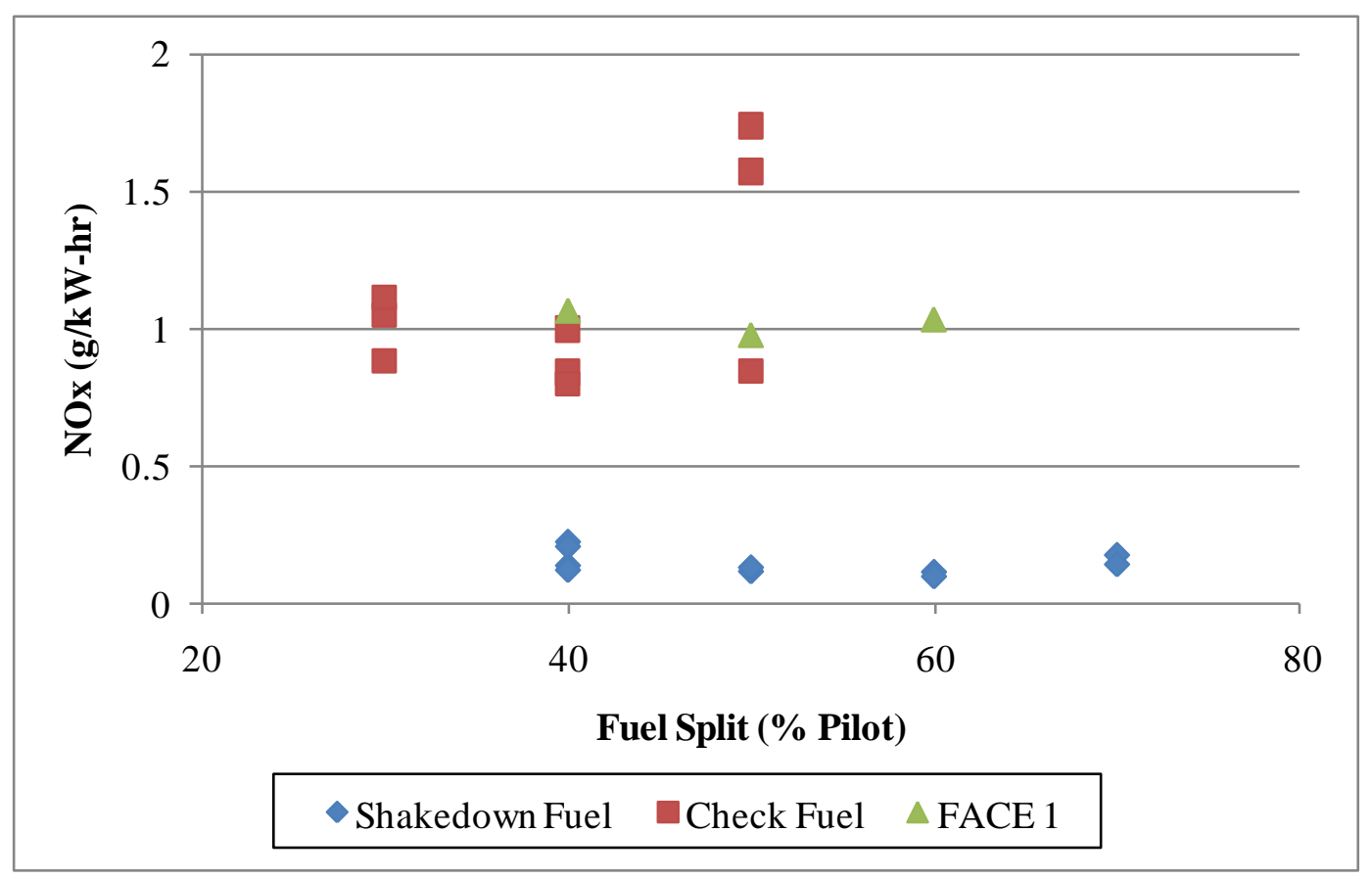

Figure 87: $\mathrm{NO}_{\mathbf{x}}$ Emissions during Fuel Split Sweeps

As presented in Figure $87 \mathrm{NO}_{\mathrm{x}}$ emissions remain relatively consistent for the shakedown fuel and FACE 1 among the range of fuel split percentage tested. A trend of decreasing $\mathrm{NO}_{\mathrm{x}}$ emissions as the percentage of fuel injected during the pilot increases appears under initial consideration of check fuel tests results. Under further scrutiny while considering EGR fractions presented in Figure 86, this phenomenon seems much more likely to be an effect of EGR fraction than fuel split quantities. 


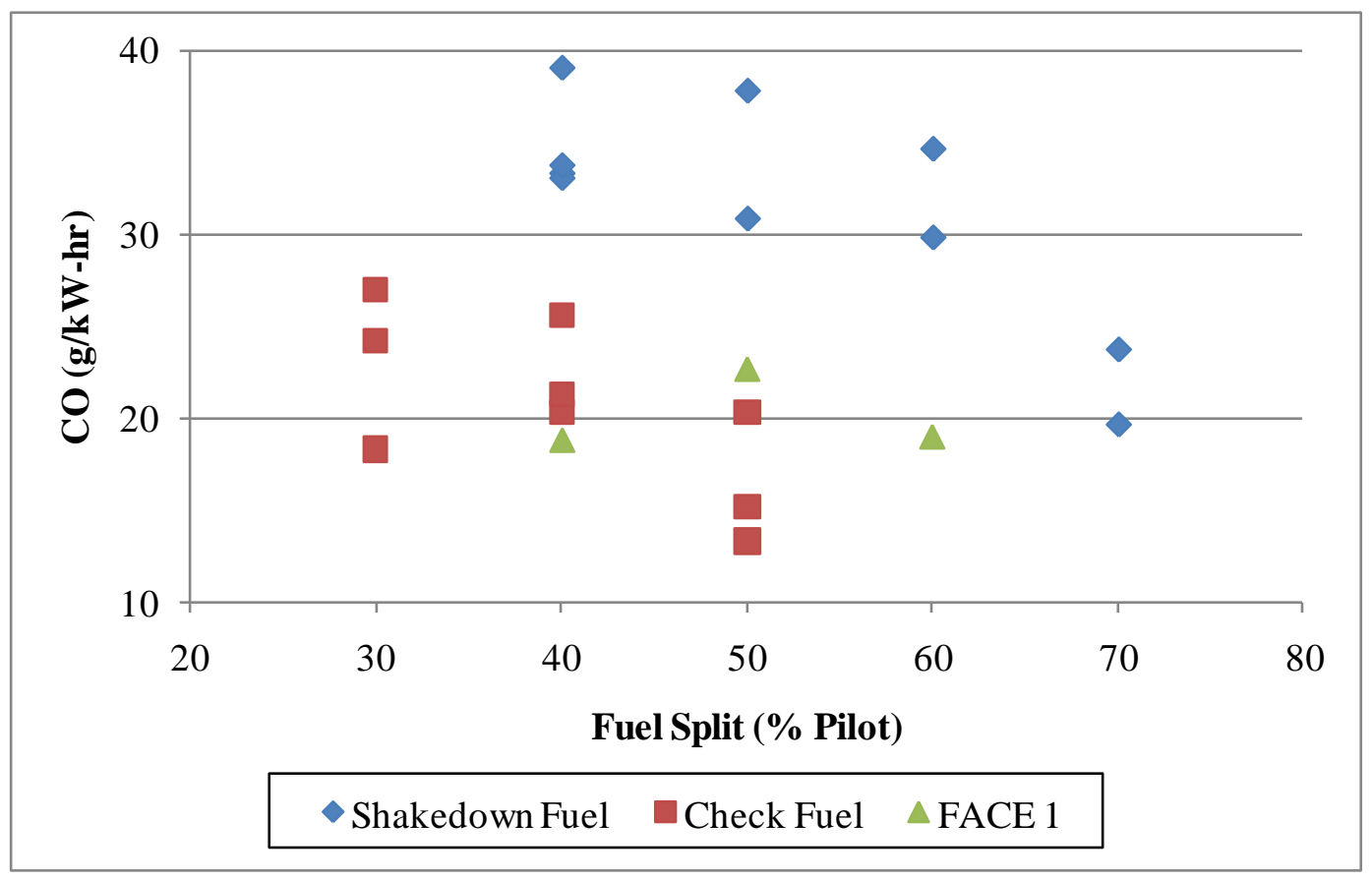

Figure 88: CO Emissions during Fuel Split Sweeps

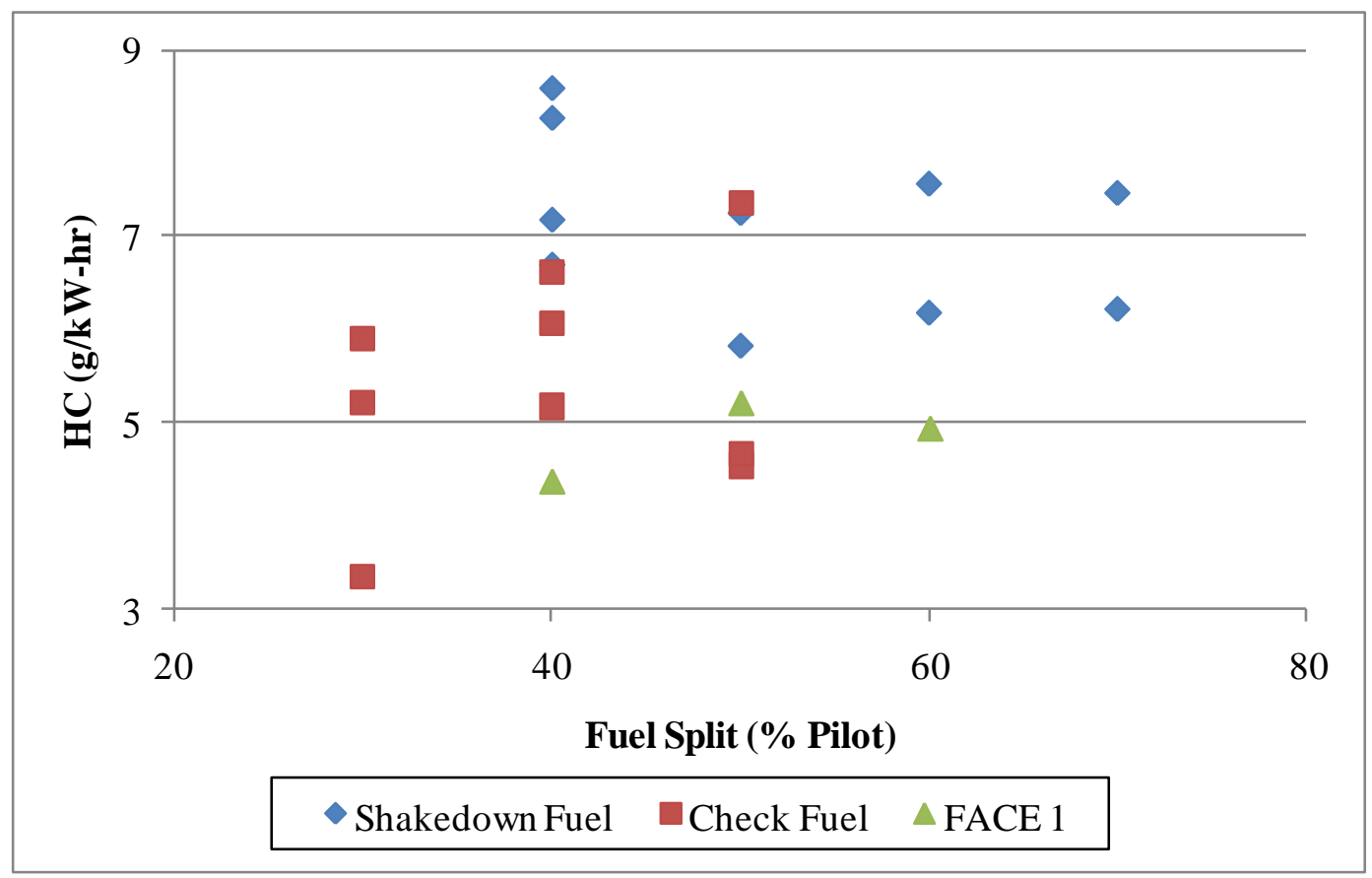

Figure 89: HC Emissions during Fuel Split Sweeps

Trends presented prior to this section have generally displayed similar trends for $\mathrm{HC}$ and $\mathrm{CO}$ emissions. It is clear in Figure 88 that $\mathrm{CO}$ emissions exhibit an overall trend of decreased measurement with the increase of pilot injection percentage. Contrary to this, the $\mathrm{HC}$ emissions, 
exhibit a trend of increased measurement with the advent of a greater pilot injection quantity. An explanation of this situation is that while some local equivalence ratios may be decreasing with greater pilot injection quantity due to more time for mixing (effectively reducing $\mathrm{CO}$ emissions), the effect of wall wetting is increasing because of the pilot injection's advanced SOI timing.

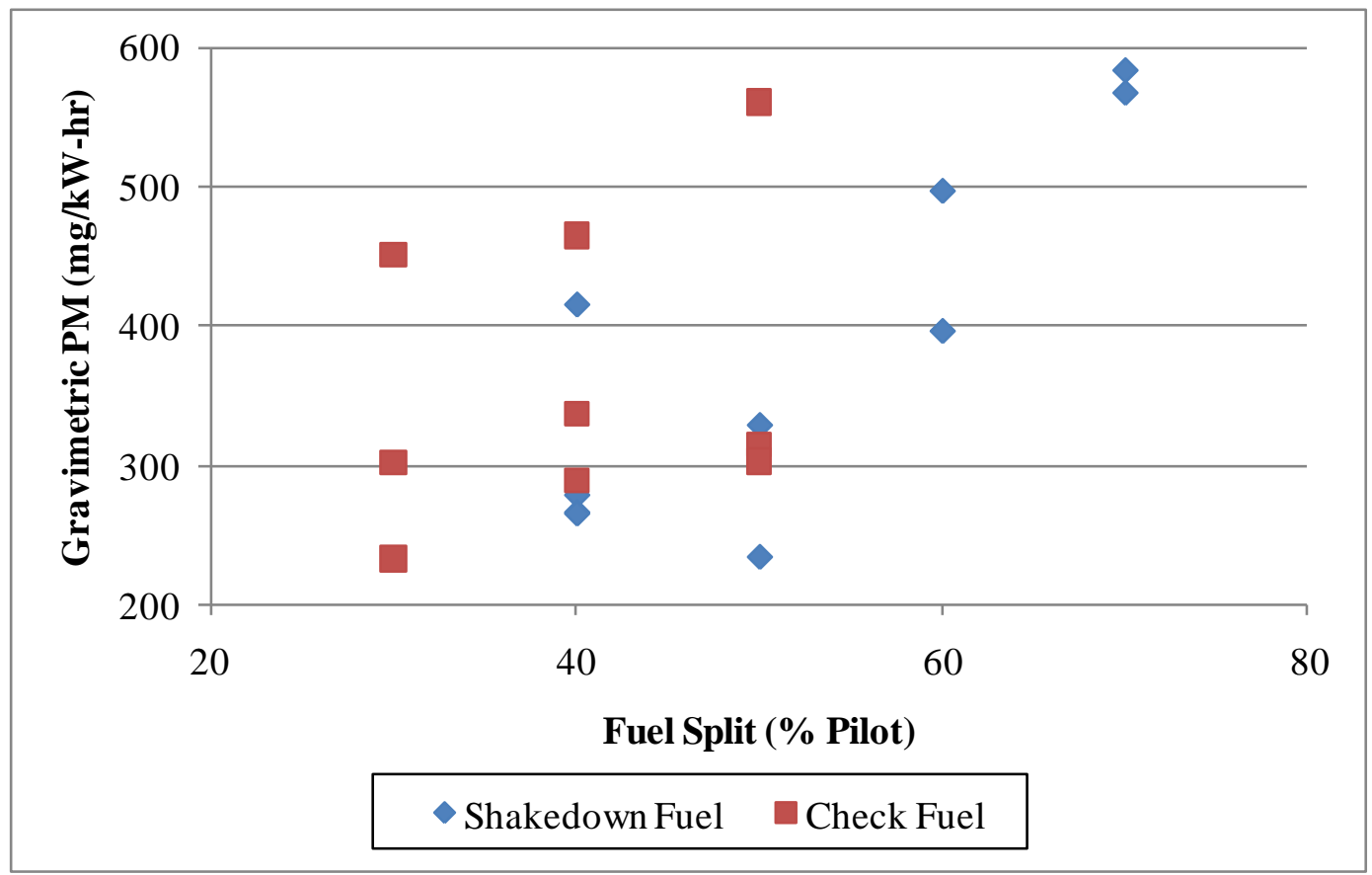

Figure 90: Gravimetric PM Emissions during Fuel Split Sweeps 


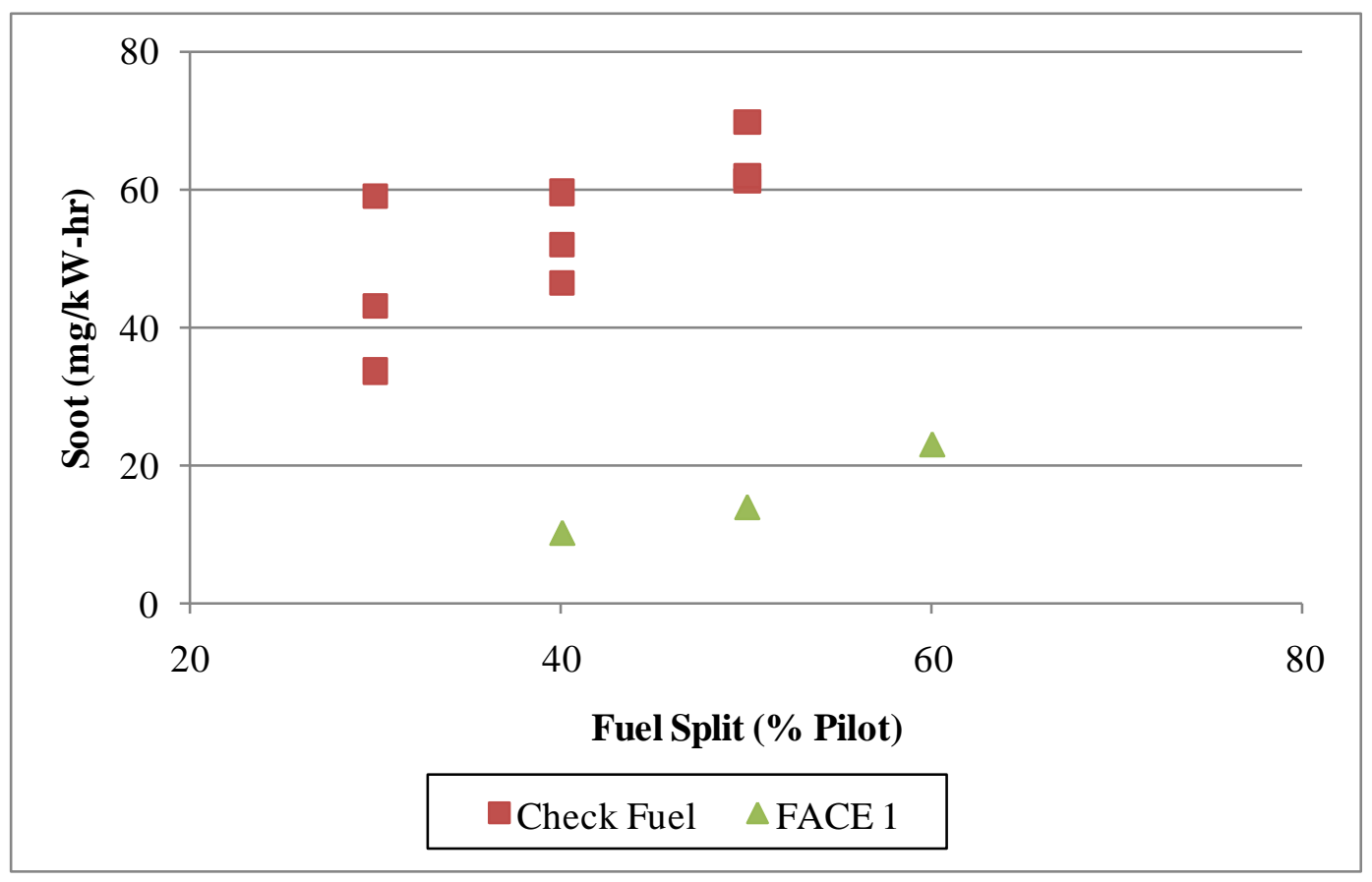

Figure 91: Soot Emissions during Fuel Split Sweeps

As a stronger percentage of the total fuel injected is shifted to the pilot injection, both gravimetric based PM emissions and photo acoustic based soot emissions increase as displayed in Figure 90 and Figure 91 respectively. While the increase in PM emissions could be contributed to greater SOF from unspent fuel, the increase of soot emissions directly conflicts the reasoning for decreasing $\mathrm{CO}$ emissions presented in Figure 88. It would be expected that lower local equivalence ratios would reduce soot emissions, yet raw fuel from wall wetting could form soot after peak combustion has occurred. 


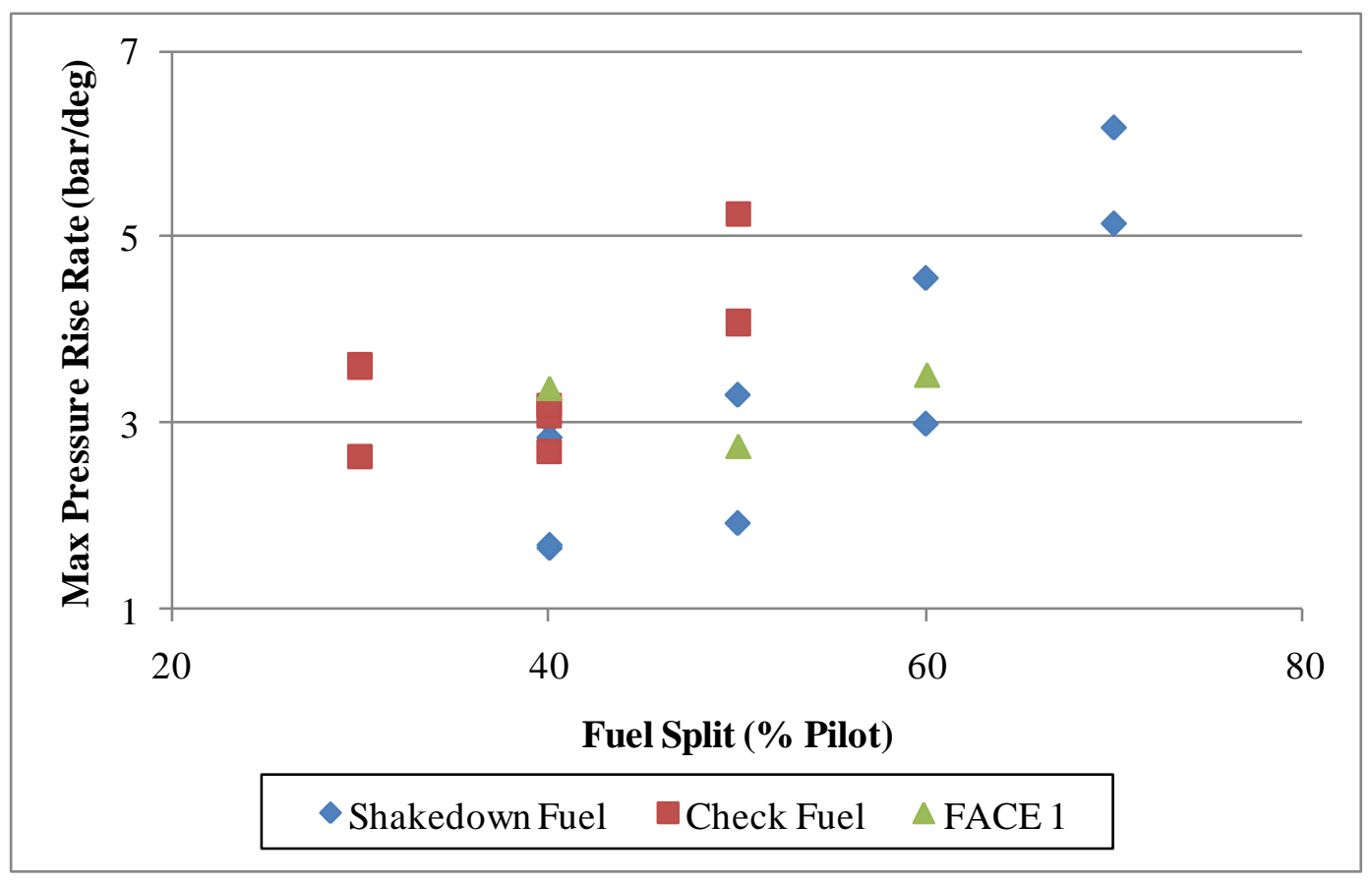

Figure 92: Max Pressure Rise Rate during Fuel Split Sweeps

Brake specific fuel consumption and $\mathrm{CO}_{2}$ measurements display no observable trends to which a conclusion of the effects of fuel split sweeps can be drawn. Maximum pressure rise rate data plotted in Figure 92 demonstrate that the highest PRR is found during the tests with the greatest percentage of fuel injected during the pilot injection for all fuels. This follows suit with the notion, that advancing an injection event past TDC will increase the PRR, as shown when more emphasis is placed on the pilot injection. 


\section{Conclusions and Recommendations}

Increasingly strict emissions regulations and future fuel consumption standards for commercial and private transportation vehicles have fueled research of advanced combustion strategies throughout the last two decades. The primary focus of much of this research is to decrease $\mathrm{NO}_{\mathrm{x}}$ and $\mathrm{PM}$ emissions to strict regulatory standards while retaining or even increasing efficiency. Some engine manufacturers and other organizations alike view advanced combustion as a less intrusive solution over large, bulky after treatment packages. Commercial implementation of advanced combustion poses several issues though. A primary drawback lies in the nature of the combustion itself; to achieve the desired results, a low temperature, well mixed lean charge is necessary. These circumstances are often very close to a threshold of misfire and erratic combustion. In addition to the difficulty associated with combustion control, low in-cylinder temperatures and early injections (to promote better mixing) equate to severe $\mathrm{HC}$ and $\mathrm{CO}$ emissions. Also as a result of low combustion temperature requirements, advanced combustion at high loads and high speeds has proved to be erratic and unachievable.

\subsection{Conclusions}

The research presented herein sought to explore a global focus on the influences of injection strategies with different fuels on advanced combustion. Three secondary objectives defined in Section 1.2 were developed to aid in this exploration. Characterization of emissions, performance, and combustion characteristics of various injections was achieved through the implementation of two general injection strategies; a single injection and split injection.

Achievement $\mathrm{NO}_{\mathrm{x}}$ emissions as low as $.05 \mathrm{~g} / \mathrm{kW}-\mathrm{hr}$, PRR below $10 \mathrm{bar} / \mathrm{deg}$, and BSFC less than $250 \mathrm{~g} / \mathrm{kW}$-hr were observed at EGR levels greater than 75 percent. These results were a direct effect of the combustion event being phased closer to TDC (optimal combustion phasing) due to the significant EGR levels present. Trends of increasing HC, CO and PM emissions were demonstrated as SOI timing was advanced from $40^{\circ}$ to $50^{\circ} \mathrm{BTDC}$. These trends were assumed to be an effect of increased wall wetting. Formidable PM emissions were hypothesized to be directly related to substantial SOF primarily composed of unburnt fuel. This was confirmed by near zero soot measurements during operation of FACE 1 with a single injection strategy. 
Implementation of a split injection strategy reduced PRR below $3.5 \mathrm{bar} / \mathrm{deg}$, cut $\mathrm{HC}$ and $\mathrm{CO}$ measurements by approximately 50 percent (in comparison to the single injection strategy), while achieving $\mathrm{NO}_{\mathrm{x}}$ emissions as low as $.1 \mathrm{~g} / \mathrm{kW}$-hr. At the base configuration the shakedown fuel demonstrated a BSFC as low as $250 \mathrm{~g} / \mathrm{kW}$-hr, while other fuels exhibited a BSFC closer to $300 \mathrm{~g} / \mathrm{kW}$-hr. Advancing the pilot SOI timing from $25^{\circ}$ to $60^{\circ}$ BTDC resulted in trends of increasing $\mathrm{HC}, \mathrm{CO}$, and PM emissions, yet soot emissions trends remained relatively constant. This phenomenon was attributed to increased fuel impingement on the cylinder walls as SOI timing was advanced. $\mathrm{NO}_{\mathrm{x}}$ emissions decreased as the pilot injection was performed earlier. Elevated rail pressure demonstrated an increasing trend of $\mathrm{HC}$ emissions, yet $\mathrm{CO}$ emissions began to decline at rail pressures greater than 1200 bar. PM emissions trended downward slightly, alluding to less soot emissions at elevated rail pressures, but greater SOF measurements.

Trends related to specific fuel properties for given injection strategies proved to be somewhat difficult to decipher due to the variability inherent with the technology employed on the test engine. The most dominant fuel property was found to be cetane number. In a comparison of FACE 1 (low cetane) and FACE 6 (high cetane) combustion was retarded by approximately $10^{\circ}$ with the operation of FACE 1 . Additionally cetane number played a significant roll the limits of SOI timing and EGR levels. High cetane fuels required an earlier injection timing to achieve comparable mixing to that of a low cetane fuel. Allowable EGR fraction was limited by the appearance of misfire especially for low cetane fuels. FACE 1 could not sustain an EGR fraction greater than 50 percent during the base configuration split injection strategy, while higher cetane fuels were able to operate close to 65 percent EGR fraction.

\subsection{Recommendations}

Experiments performed during this study were based around the overall goal of achieving advanced combustion for a funded research project. Due to the necessity of meeting project deliverables, concurrent experiments could not be performed for every fuel presented in this document. This issue stands out as the most significant cause for recommended future actions; each injection strategy, as well as parameter variations, should be performed for each fuel in such a way that they can be accurately compared and contrasted. Additionally, repeat tests without differing variables should be performed to establish confidence in the emissions and performance results. Stricter methods of EGR and fuel injection control should be explored and implemented to achieve tests with repeatable results. 
Soot sensor data was not available for many tests. Re-running these configurations and obtaining soot emissions measurements would provide further insight to form conclusions about the combustion occurring. Continuity among equipment utilized and correct calibrations for this equipment would significantly benefit the quality of the results. Presentation of these results in such a way that clear trends can be observed and a decisive plan can be formed to achieve desired results is very important. A prime example is the use of the combustion parameter CA10-50. Only focusing on the duration of 10 percent to 50 percent mass fraction burned exposed shortfalls when operating under the split injection strategy. CA10-90 would be a much better parameter to analyze combustion duration for this research.

Further optimization of injection strategies for specific fuels is recommended. Emissions data were used primarily in the optimization of these injection strategies, but after scrutinizing combustion data it was found that many of these strategies phased combustion to un-optimal locations. This was especially apparent for high cetane fuels in which combustion began to take place well before TDC. Unfortunately, to phase combustion closer to TDC where it would likely be more efficient may require modification of engine hardware such as lowering the compression ratio or increasing swirl. Injector spray angle is another hardware modification that has the capability of greatly reducing the effects of wall wetting and improving efficiencies. 


\section{Bibliography}

1. “Gas GuzzlerTax." US Environmental Protection Agency. Web. 17 Sep. 2010. <http://www.epa.gov/fueleconomy/guzzler/>.

2. "Heavy-Duty Regulations." Regulations \& Standards $\mid$ Transportation and Climate $\mid$ US EPA. US Environmental Protection Agency. Web. 17 Nov. 2010. <http://www.epa.gov/oms/climate/regulations.htm\#1-2>.

3. "DOT, EPA Propose the Nation's First Greenhouse Gas and Fuel Efficiency Standards for Trucks and Buses A Win for the Environment, Economy and Energy Efficiency." Environmental Protection Agency. Ed. Cathy Milbourn. 25 Oct. 2010. Web. 17 Nov. 2010.<http://yosemite.epa.gov/opa/admpress.nsf/d0cf6618525a9efb85257359003fb69d/9 b3706622f4ac560852577c7005ea140!OpenDocument>.

4. Neely, G., Sasaki, S., Huang, Y., Leet, J., and Steward, D., "New Diesel Emission Control Strategy to Meet US Tier 2 Emissions Regulations," SAE Technical Paper 200501-1091.

5. Ballauf, Jörg. The 9th Annual Automobile and Engine Technology Colloquium in Aachen An Overview. PDF.

6. Simescu, S., Ryan, T. W., Neely, G. D., Matheaus, A. C., and Surampudi, B., "Partial Pre-Mixed Combustion with Cooled and Uncooled EGR in a Heavy-Duty Diesel Engine," SAE Technical Paper 2002-01-0963.

7. Eppring, K., Aceves, S., Bechtold, R., and Dec, J., "The Potential of HCCI Combustion for High Efficiency and Low Emissions," SAE Technical Paper 2002-01-1923.

8. Kawano, D., Suzuki, H., Ishii, H., Goto, Y., and Matsuo, O., "Ignition and Combustion Control of Diesel HCCI," SAE Technical Paper 2005-01-2132, Tokyo, Japan, 2005.

9. Park, Su H., Seung H. Yoon, and Chang S. Lee. "Effects of Multiple-injection Strategies on Overall Spray Behavior, Combustion and Emissions Reduction Characteristics of Biodiesel Fuel." Applied Energy 88.1 (2010): 88-98. Print.

10. Hasegawa, R., and Yanagihara, H., "HCCI Combustion in DI diesel Engine," SAE Technical Paper 2003-01-0745.

11. Gan, Suyin, Hoon K. Ng, and Kar M. Pang. "Homogeneous Charge Compression Ignition (HCCI) Combsition: Implementation and Effects on Pollutants in Direct Injectin Diesel Engines." Applied Energy 88.3 (2010): 559-67. Print.

12. Weall, A., and Collings, N., "Highly Homogenous Compression Ignition in a Direct Injection Diesel Engine Fuelled with Diesel and Biodiesel," SAE Technical Paper 200701-2020.

13. Wagner, U., Anca, R., Velji, A., and Spicher, U., “An Experimental Study of Homogeneous Charge Compression Ignition (HCCI) with Various Compression Ratios, Intake Air Temperatures and Fuels with Port and Direct Fuel Injection," SAE Technical Paper 2003-01-2293.

14. Nevin, R. M., Sun, Y., Gonzalez D., M. A., and Reitz, R. D., "PCCI Investigation Using Variable Intake Valve Closing in a Heavy Duty Diesel Engine," SAE Technical Paper 2007-01-0903.

15. Benajes, J., Molina, S., Novella, R., and Arthozoul, S., "Advanced Injection Strategies to Attain Partially Premixed Combustion Process in a Heavy Duty Diesel Engine," SAE Technical Paper 2008-01-0642. 
16. Kulkarni, Anup M., Karla C. Stricker, Angeline Blum, and Gregory M. Shaver. "PCCI Control Authority of a Modern Diesel Engine Outfitted With Flexible Intake Valve Actuation." Journal of Dynamic Systems, Measurement, and Control 132.5 (2010): 9-1051009-0510015. Print.

17. Buchwald, R., Brauer, M., Blechstein, A., Sommer, A., and Kahrstedt, J., “Adaption of Injection System Parameters to Homogeneous Diesel Combustion," SAE Technical Paper 2004-01-0936.

18. Vanegas, A., Won, H., and Peters, N., "Influence of the Nozzle Spray Angle on Pollutant Formation and Combustion Efficiency for a PCCI Diesel Engine," SAE Technical Paper 2009-01-1445.

19. Gallant, T., Franz, J., Alnajjar, M., Storey, J., Lewis, S., Sluder, S., Cannella, W., Fairbridge, C., Hager, D., Dettman, H., Luecke, J., Ratcliff, M., and Zigler, B., "Fuels for Advanced Combustion Engines Research Diesel Fuels: Analysis of Physical and Chemical Properties," SAE Technical Paper 2009-01-2769.

20. Kawano, D., Naito, H., Suzuki, H., Ishii, H., Hori, S., Goto, Y., and Odaka, M., Effects of Fuel Properties on Combustion and Exhaust Emissions of Homogeneous Charge Compression Ignition (HCCI) Engine," SAE Technical Paper 2004-01-1966.

21. Pulkrabek, Willard W. Engineering Fundamentals of the Internal Combustion Engine. 2nd ed. Upper Saddle River, NJ: Pearson Prentice Hall, 2004. Print.

22. Cho, K., Han, M., Sluder, C., Wagner, R., and Lilik, G., "Experimental Investigation of the Effects of Fuel Characteristics on High Efficiency Clean Combustion in a Light Duty Diesel Engine," SAE Technical Paper 2009-01-2669.

23. Bunting, B., Crawford, R., Wolf, L., and Xu, Y., "The Relationships of Diesel Fuel Properties, Chemistry, and HCCI Engine Performance as Determined by Principal Components Analysis," SAE Technical Paper 2007-01-4059.

24. Gibble, John C. Comparison of Heavy-Duty Diesel Engine Emissions Between an OnRoad Route. Thesis. West Virginia University, 2003. Web. 9 Nov. 2010. $<$ http://thesis.wvu.edu/>.

25. Mead, John S. Vauxhall/Opel Vectra Owners Workshop Manual. Somerset: Haynes, 2008. Print.

26. "Robert Bosch GmbH - Common Rail System." Robert Bosch GmbH - Bosch Automotive Technology. Web. 06 Oct. 2010. <http://www.boschautomotivetechnology.com/en/antriebssysteme/dieselcommonrailsystem/kraftstoffeinspri tzung_6/commonraileinspritzung.asp>.

27. "Common Rail System: Injectors." Robert Bosch GmbH. Web. 06 Oct. 2010. <http://rbkwin.bosch.com/us/en/powerconsumptionemissions/dieselsysteme/dieselsystem/passenge r-car/technology/injection_systems/commonrailsystem/injectors.html>.

28. "Diesel Injector Driver Module Kit." Drivven. Web. 12 Oct. 2010. <http://www.drivven.com/DieselInjectorDriverModuleKit.htm>.

29. "RTD Elements and RTD Probes - Resistance Temperature Detection Sensors(RTDS)." Sensors, Thermocouple, PLC, Operator Interface, Data Acquisition, RTD. Omega. Web. 13 Oct. 2010. <http://www.omega.com/prodinfo/rtd.html>.

30. "GE General Eastern Dew-10 Dewpoint Transmitter - Instrumart.com." Instrumart Industrial Instruments Superstore. Web. 13 Oct. 2010. <http://www.instrumart.com/Product.aspx?ProductID=19774>.

31. Horiba, Ltd. PDF. Kyoto: Horiba, Ltd., July 2004. THC Analyzer FIA-725A. 
32. Horiba Ltd. NO/NOx Analyzer CLA-720MA. Kyoto: Horiba Ltd., July 2004. PDF.

33. Horiba Ltd. CO/CO2 (HC,NO,N2O,SO2) Analyzer AIA-72X Series Instruction Manual. Kyoto: Horiba Ltd., Sept. 2005. PDF.

34. Metrotec. "Measurement Principle, Oxygen Measurement Unit, Zirconium Oxide Sensor." Oxygen Measuring Instruments. Web. 21 Oct. 2010.

<http://www.metrotec.de/measurementprinciple.html>.

35. Emerson Process Management. Paramagnetic Oxygen Analyzer. Orrville: Rosemount Analytical Inc., Sept. 1999. PDF.

36. AVL. AVL Micro Soot Sensor with AVL Exhaust Conditioning Unit. Graz: AVL, May 2008. htm.

37. ASTM. Standard Specification for Diesel Fuel Oils. West Conshohocken: ASTM International, 2010. PDF. 


\section{Appendices}

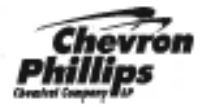

CoA Date: 07/15/2009

Repeat printout

\section{Certificate of Analysis}

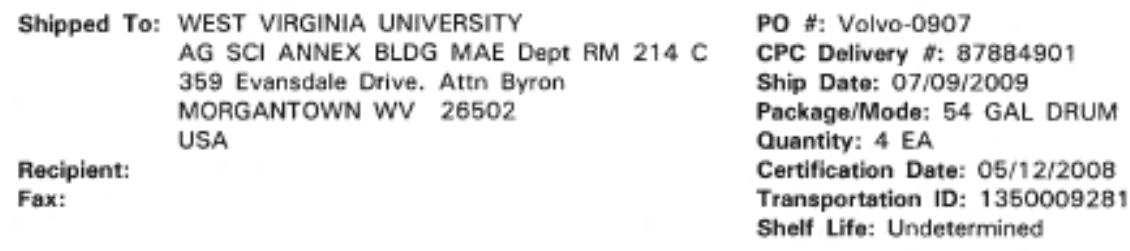

Product: DIESEL 2007 ULS FUEL, 54 GAL DRUM

Material Code:1069147

Lot Number: 8EPUL701

\begin{tabular}{|c|c|c|c|c|}
\hline Property & Test Method & Specification & Value & Unit \\
\hline Specific Gravity $60 / 60$ & ASTM D-4052 & $0.8400-0.8550$ & 0.8496 & \\
\hline API Gravity & ASTM D-4052 & $36.0 \cdot 37.0$ & 35.0 & \\
\hline Particulate Matter & ASTM D.6217 & $\leqslant 15.0$ & 0.9 & $m g / 1$ \\
\hline Cloud Point & ASTM D-2500 & & 30 & FAH \\
\hline Flash Point, PM & ASTM D-93 & $>=130$ & 158 & FAH \\
\hline Pour Point & ASTM D-97 & & -20 & FAH \\
\hline sulfur & ASTM 0-5453 & $7.0 \cdot 15.0$ & 8.4 & ppre \\
\hline Viscosity a $40 \mathrm{C}$ & ASTM $0=645$ & $2.0-3.0$ & 2.5 & cst \\
\hline Fydrogen & ASTM D-3343 & & 13.1 & UTX \\
\hline Carbon & Calculated & & 86.9 & WTI \\
\hline Polynuclear Aronatics & ASTM D-5186 & & 13.2 & WTE \\
\hline sfe Aronaties & ASTM D-5186 & & 36.7 & WTZ \\
\hline Net Heat of Contustion & ASTM 0-3338 & & 18425 & BTU/LB \\
\hline Cetane Number & ASTM 0.613 & $43 \cdot 47$ & 46 & \\
\hline Cetane Index & ASTM D-976 & $42.0 \cdot 48.0$ & 63.9 & \\
\hline HFRe Lubricity & ASTM D-6079 & $c=0.4$ & 0.6 & $m$ \\
\hline Distillation - IBP & ASTM D-BG & $360 \cdot 400$ & 356 & FAH \\
\hline Distillation - $5 \mathrm{~S}$ & ASTM 0-86 & & 386 & FAH \\
\hline Distillation = 100 & ASTM 0-86 & $400=460$ & 408 & FAH \\
\hline Distillation - $20 x$ & ASTM 0-86 & & 436 & FAM \\
\hline Distitlation - yok & ASTM D-BS & & 655 & FAH \\
\hline Distillation - 40 s & ASTM D-B6 & & 471 & FAH \\
\hline Distillation = $50 x$ & ASTM 0.86 & $470=540$ & 486 & FAH \\
\hline Distillation - $60 x$ & AsTM 0-86 & & so1 & FAH \\
\hline Distillation - $70 \mathrm{~s}$ & ASTM D-86 & & 520 & FAM \\
\hline Distitlation - sox & ASTM D-BG & & 565 & FAH \\
\hline
\end{tabular}



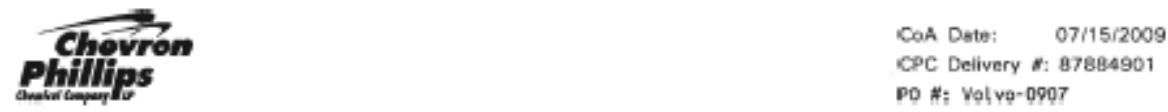

\section{Certificate of Ánalysis}

Product: DIESEL 2007 ULS FUEL. 54 GAL DRUM

Material Codẹ: 1069147

\begin{tabular}{|c|c|c|c|c|c|}
\hline Distillation = 9, & 90: & ASTN 0.86 & $560 \cdot 630$ & 582 & FAH \\
\hline Distillation - S & $95 x$ & ASTM D-BS & & 619 & FAH \\
\hline Distitlation - E & EP & ASTN D-BS & $610=690$ & 652 & FAH \\
\hline 01stritation - L & $\cos$ & Astim 0.00 & & 0.8 & mL \\
\hline Distillation - R & Residue & ASTM 0.86 & & 1.0 & ML \\
\hline Aromatics & & ASTM 0.1319 & $28.0-32.0$ & 28.8 & Lvz \\
\hline oletins & & ASTM D-1319 & & 6.7 & Lvs \\
\hline Saturates & & ASTM D. 1319 & & 66.5 & $\operatorname{tv} x$ \\
\hline
\end{tabular}

The following tests, HFRR Lubricity, Polynuclear Aromatics, and SFC Aromatics, are conducted after initial release. If the results do not appear on your Certificate of Analysis and you would like to receive them, please e-mail cpcrashippingclerks@cpchem.com

The data set forth herein have been carefully compiled by Chevron Phillips Chemical Company LP. However, there is no warranty of any kind, either expressed or implied, applicable to its use, and the user assumes all risk and liability in connection therewith.

\section{$k \ldots x$}

Ken Inkrott

Quality, Applications and Technical Service Manager

For COA questions contact Kim Lindley at $80 \mathrm{~b}-2 / \mathrm{b}-5 \mathrm{~b} / /$

Figure 93: CP CHEM 2007 ULSD Certification Fuel Certificate of Analysis 


\section{ERGON WEST VIRGINIA, INC \\ P.D. BOX 356 \\ Newell, WV 26050}

\section{ULTRA LOW SULFUR DIESEL TANK CERTIFICATE OF ANALYSIS}

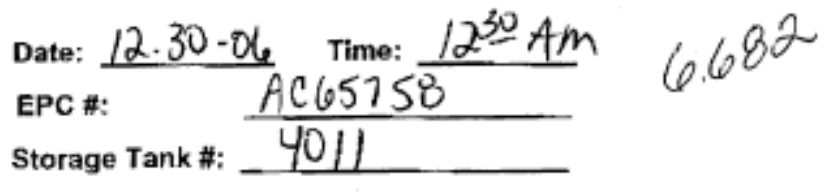

\begin{tabular}{|c|c|c|}
\hline Test Description & Test Method & Result \\
\hline API Gravity, $60^{\circ} \mathrm{F}$ & ASTM D 287 & 44.8 \\
\hline Viscosity. cSt. 100'F & ASTM D 445 & 2.10 \\
\hline$\sqrt{i s c o s i t y}$ SUS, $100^{\circ} \mathrm{F}$ & ASTM D 445 & \\
\hline Sulfur.ppm & ASTM D 2622 & 11 \\
\hline Fash Pont, PMCC. " F & ASTM D 93 & 138.0 \\
\hline Cclo: ASTM & ASTM D 6045 & 0.1 \\
\hline Cioud Point. "F & ASTM D 5772 & 0 \\
\hline Pour Point, " $\mathrm{F}$ & ASTM D 5949 & \\
\hline Distillation. IBP, ${ }^{\circ} \mathrm{F}$ & ASTM D 86 & \\
\hline Distllation, $5 \%,{ }^{\circ} \mathrm{F}$ & ASTM D 86 & \\
\hline Distillation. $10 \%, " \mathrm{~F}$ & ASTM D 86 & \\
\hline Distillation, $20 \%,{ }^{\circ} \mathrm{F}$ & ASTM D 86 & \\
\hline Distillation, $30 \%$, ${ }^{\circ} \mathrm{F}$ & ASTM D 86 & 404 \\
\hline Distilation, $40 \%,{ }^{\circ} \mathrm{F}$ & ASTM D 86 & \\
\hline Distillation, $\overline{50 \%,{ }^{\circ} \mathrm{F}}$ & ASTM D $\overline{86}$ & \\
\hline Distalation, $60 \%,{ }^{\circ} \mathrm{F}$ & ASTM D 86 & 488 \\
\hline Distillation, $70 \%,{ }^{\circ} \mathrm{F}$ & ASTM D 86 & 523 \\
\hline Distillation, $80 \%,{ }^{\circ} \mathrm{F}$ & ASTM D 86 & 560 \\
\hline Distillation, $90 \%,{ }^{\circ} \mathrm{F}$ & ASTM D 86 & \\
\hline Distillation, $95 \%,{ }^{4} \mathrm{~F}$ & ASTM D86 & 611 \\
\hline Distillation. EP, ${ }^{\circ} \mathrm{F}$ & ASTM D 86 & 626 \\
\hline Cetane Number & ASTTM D 976 & 56.66 \\
\hline
\end{tabular}

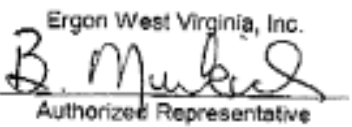

Figure 94: Guttman ULSD Certificate of Analysis 12/30/06 


\begin{tabular}{|c|c|c|c|}
\hline \multicolumn{4}{|c|}{\begin{tabular}{|c} 
Data Summary for West Virginia University \\
ULSD Guttman Fuel 500 Gallon Tank \\
SWRI Work Order \# 39412
\end{tabular}} \\
\hline & & & \\
\hline & SmpiCode & & WVU 1099 \\
\hline$\overline{D 240 G}$ & Combust & BTU/lb & 19904 \\
\hline D240N & Cumbust & BTU/Ib & 18626.7 \\
\hline D2500 & Cloud Pt & Deg C & -16 \\
\hline \multirow[t]{3}{*}{ D4052s } & API@60F & & 44.7 \\
\hline & SPGri60F & & 0.8032 \\
\hline & Dens@15C & grams/L & 802.8 \\
\hline D445 40c & Viscosty & $\mathrm{cSt}$ & 2.091 \\
\hline D4629 & Nitrogen & ppm & 5.6 \\
\hline D4737A & Cetanind & & 58.7 \\
\hline \multirow[t]{3}{*}{ D5186 } & Tt|Arom & Mass\% & 9.3 \\
\hline & MonoArom & Mass\% & 8.8 \\
\hline & PolyArom & Mass\% & 0.6 \\
\hline \multirow[t]{2}{*}{ D5291 } & Carbon & $w t \%$ & 85.35 \\
\hline & Hydrogen & $w t \%$ & 14 \\
\hline D5453 & Sulfur & ppm & 13.9 \\
\hline D613 & CetaneNo & & 58.3 \\
\hline \multirow[t]{17}{*}{ D86 } & IBP & $\operatorname{deg} F$ & 321.7 \\
\hline & Evap_5 & $\operatorname{deg} F$ & 352.1 \\
\hline & Evap 10 & degF & 365.8 \\
\hline & Evap 15 & $\operatorname{deg} \bar{F}$ & 374.9 \\
\hline & Evap 20 & degF & 385.9 \\
\hline & Evap 30 & $\operatorname{deg} \mathrm{F}$ & 408.7 \\
\hline & Evap_40 & degF & 434.2 \\
\hline & Evap 50 & $\operatorname{deg} F$ & 464.5 \\
\hline & Evap 60 & $\operatorname{deg} F$ & 498.8 \\
\hline & Evap 70 & degF & 536 \\
\hline & Evap 80 & $\operatorname{deg} F$ & 570.7 \\
\hline & Evap_90 & $\operatorname{deg} F$ & 600.1 \\
\hline & Evap 95 & $\operatorname{deg} F$ & 616.6 \\
\hline & FBP & degF & 631.8 \\
\hline & Recoverd & $\mathrm{mL}$ & 98.3 \\
\hline & Residue & $\mathrm{mL}$ & -7 \\
\hline & Loss & $\mathrm{mL}$ & 0.7 \\
\hline \multirow[t]{2}{*}{ D93 } & Flash & degF & 127 \\
\hline & FlashP-C & $\operatorname{deg} C$ & 52.8 \\
\hline D976 & Cetanind & & 57.9 \\
\hline
\end{tabular}

Figure 95: Guttman ULSD Certificate of Analysis 8/8/07 
Table 5: ASTM Method of Fuel Property Measurement

\begin{tabular}{|c|c|c|c|c|c|c|c|}
\hline Fuel & $\begin{array}{c}\text { Cetane } \\
\text { Number }\end{array}$ & $\begin{array}{c}\text { Aromatics } \\
(\text { Volume \% })\end{array}$ & $\begin{array}{c}\text { T 90 } \\
\text { Distillation } \\
\text { Temperature } \\
\left({ }^{\circ} \mathrm{C}\right)\end{array}$ & $\begin{array}{c}\text { Specific } \\
\text { Gravity }\end{array}$ & $\begin{array}{c}\text { Flash Point } \\
\left({ }^{\circ} \mathrm{C}\right)\end{array}$ & $\begin{array}{c}\text { Sulfur } \\
(\mathrm{ppm})\end{array}$ & $\begin{array}{c}\text { Net Heat of } \\
\text { Combustion } \\
(\mathrm{BTU} / \mathrm{Lb})\end{array}$ \\
\hline Shakedown & D613 & D1319 & D86 & Lab & D93 & D5453 & D240N \\
\hline Check & D613 & D1319 & D86 & D4052 & D93 & D5453 & D3338 \\
\hline FACE 1 & D613 & D1319 & D86 & D4052 & D93 & D5453 & D240 \\
\hline FACE 6 & D613 & D1319 & D86 & D4052 & D93 & D5453 & D240 \\
\hline
\end{tabular}

\section{EGR Fraction Calculation}

$$
\text { EGR Fraction }=\frac{\left[\mathrm{CO}_{2}\right]_{\text {Intake }}}{\left[\mathrm{CO}_{2}\right]_{\text {Exhaust }}}
$$

